Portland State University

PDXScholar

$2-25-2020$

\title{
Migrant Health Policies in the European Union: a Comparative Policy Analysis
}

Jessica Joanne Currier

Portland State University

Follow this and additional works at: https://pdxscholar.library.pdx.edu/open_access_etds

Part of the Health Services Administration Commons

Let us know how access to this document benefits you.

\section{Recommended Citation}

Currier, Jessica Joanne, "Migrant Health Policies in the European Union: a Comparative Policy Analysis" (2020). Dissertations and Theses. Paper 5419.

https://doi.org/10.15760/etd.7292

This Dissertation is brought to you for free and open access. It has been accepted for inclusion in Dissertations and Theses by an authorized administrator of PDXScholar. Please contact us if we can make this document more accessible: pdxscholar@pdx.edu. 
Migrant Health Policies in the European Union:

A Comparative Policy Analysis

by

Jessica Joanne Currier

A dissertation submitted in partial fulfillment of the requirements for the degree of

\author{
Doctor of Philosophy \\ in \\ Health Systems and Policy
}

\author{
Dissertation Committee: \\ Neal Wallace, Chair \\ Jill Rissi \\ Billie Sandberg \\ Birol Yesilada
}

Portland State University

2020 
(C) 2020 Jessica Joanne Currier 


\begin{abstract}
There is an undeniable relationship between migration and health (Nagy, 2011). Despite the fact that the concept of health as a fundamental human right has been enshrined in numerous international and supranational policy instruments, health disparities between migrants and host nation populations persist. Inequities in health are perpetuated by several factors that include, but are not limited to, immigration status, lack of knowledge of health system access points, appropriateness of health care services, language barriers, and unique health profiles of migrants. The literature firmly positions migrants as a vulnerable population due to their collective risk of poor health outcomes in multiple areas.
\end{abstract}

Between 1998 and 2007, 10 European Union (EU) member states, plus Switzerland in a special partnership with the EU through the European Economic Area, adopted a migrant health policy to improve the health of migrants through targeted strategies (Mladovsky, et al., 2012). These national level migrant health policies go beyond statutory requirements outlined in international and supranational charters and treaties to protect the health migrants (Mladovsky et al, 2012) and address factors that contribute to health inequity between migrants and European host nation populations. Listed in alphabetical order, European nations with migrant health policies include: Austria, England, France, Germany, Ireland, Italy, the Netherlands, Portugal, Spain, Sweden, and Switzerland (Mladovsky, et al., 2012; Nurse, 2008). 
While barriers encountered by migrants in accessing health care services in host nations and inequities in health between migrants and host nation populations have been well-documented in the literature, scholarly research on comparative analysis of the content of European-based migrant health policies is relatively limited and migrant health policy process or outcome analyses are virtually non-existent.

Comparative analysis of eleven migrant health policies that broadly share the same objective to improve the health status of migrant populations provides insight into how a group of nations responded to addressing the health of migrant populations through a policy instrument. This study identified how the policies are similar and different through a two-phased analytic process that included content analysis followed by typological analysis. The coding scheme that emerged from content analysis was mapped onto a typology matrix. The result was the emergence of four themes that are a "type" of orientation toward the health of migrant populations. The theme-based typology goes beyond description and classification of the policy cases by offering a higher level of understanding of variation across the themes and cases. This is a new framework from which to compare concepts, explore dimensionality, and identify hierarchical relationships at macro and micro levels. The macro level occurs across and within emergent themes, while the micro level is the policy case. This study aims to inform future policy making processes concerning all areas of immigration and provide context for future migrant health policy process and outcomes research. 


\section{Dedication}

To Phil, thank you for being my partner in life. And to Madeleine and Olivier, thank you for supporting me and being a part of this journey. This dissertation and the future that it brings is for our family. 


\section{Acknowledgements}

In 2012 I read a book (Mountains Beyond Mountains by Tracy Kidder) that inspired me to cross-off an important bucket list item, attend graduate school. One term into my Masters of Public Health program at Oregon state, I realized that I wanted to know more. A doctoral program in health systems and policy was my ultimate trajectory.

This dissertation is the culmination of a research goal that has been influenced by several important mentors, teachers, friends, and family. Neal Wallace, my dissertation committee chair, has had the biggest and most important role in shaping me as a social scientist. This research is a reflection of his invaluable mentorship. I also wish to recognize members of my dissertation committee that include Jill Rissi, Billie Sandberg, and Birol Yesilada. Thank you for your sharing your knowledge, insights, perspectives, and time. I am proud of this research because of your influence throughout the process.

Several other important people in my life are due my gratitude. Sherril Gelmon, thank you for pushing me, encouraging me to take chances, celebrating my successes, listening to me through my tears, and holding me to a standard of excellence. I will endeavor throughout my career to make you proud.

$\mathrm{PhD}$ school is tough, long, and, at times, very lonely. Thank you to my friends, both in and outside of the health systems and policy program, who listened, related to me, supported me, agreed with me, challenged me, led me to insights about this dissertation (that's you Shauna Petchel), and kept me from quitting on myself.

Big accomplishments don't happen on their own. The person achieving the big accomplishment generally has a group of amazing people supporting them. This is the case with me. Teachers, mentors, friends, and especially my husband and children, are the tall shoulders with which I stand upon with this dissertation. Thank you. I love you all. 


\section{Table of Contents}

$\begin{array}{lr}\text { Abstract } & \text { ii } \\ \text { Dedication } & \text { iv } \\ \text { Acknowledgements } & \text { vii } \\ \text { List of Tables } & \text { x }\end{array}$

\section{Chapter I - Background}

Issue Background $\quad 1$

Problem Statement $\quad 8$

Research Question $\quad 10$

Theoretical Frame 10

Methods Overview 13

Research Design \& Rationale $\quad 13$

Analytic Process $\quad 15$

$\begin{array}{ll}\text { Purpose and Significance of Study } & 18\end{array}$

Chapter II - Review of Related Literature

Migrant health outcomes in destination countries $\quad 21$

Migration and communicable disease transmission 26

Who is a migrant? $\quad 29$

Migration and migrant perceptions 32

Migration and health as a human right 35

Supranational European Union Policies and the Right to Health 37

Why migrant health policies at all? $\quad 41$

European Union-based migrant health policies 43

Comparative policy analyses \& extant comparative migrant health policy analyses $\quad 45$

Migrant Health Policy Case Variation 55

Analytic frame $\quad 57$

Typologies $\quad 59$

$\begin{array}{ll}\text { Chapter Conclusion } & 61\end{array}$

\section{Chapter III - Methodology and Methods \\ Introduction $\quad 65$ \\ Research Question $\quad 65$ \\ Core Concepts $\quad 66$ \\ Comparative Policy Analysis Methodology and Analytic Frame 67}


Research Design and Rationale

$\begin{array}{ll}\text { Analytic Methods } & 77\end{array}$

$\begin{array}{ll}\text { Type of Analysis } & 79\end{array}$

$\begin{array}{ll}\text { Analytic Process } & 87\end{array}$

Validity and Reliability of Analysis $\quad 97$

Assumptions $\quad 97$

Role of the Researcher $\quad 100$

Limitations $\quad 102$

Translation of Documents 103

Human Subjects Research 104

$\begin{array}{ll}\text { Chapter Conclusion } & 104\end{array}$

\section{Chapter IV - Presentation and Analysis of Data}

Data Organization and Categorization 106

Policy Case Comparisons by Major Category 141

Policy Typology and Theme Development 158

Migrant Health Policy Orientation Toward Migrant Health Typology 160

Matrix Development

$\begin{array}{ll}\text { Theme Identification } & 197\end{array}$

Migrant Health Policy Orientation Toward Migrant Health Typology Presentation 202

Chapter Conclusion 206

\section{Chapter V - Discussion and Conclusion}

Discussion $\quad 211$

Synthesis of Content Analysis of the Policy Cases $\quad 212$

Existing Migrant Health Policy Research Comparisons 218

Synthesis of Policy Typology Analysis $\quad 227$

Major Category Interrelationships with Themes 229

Theme Description Summary 238

Migrant Health Policy Case Theme Alignment $\quad 245$

Extant Migrant Health Policy Comparative Analysis Research 256

Migrant Health Policy Case Continuum 262

Conclusion $\quad 264$

Assumptions and Limitations $\quad 271$

Implications for Policy and Practice $\quad 274$

Implications for Future Research 276 
References

284

Appendix A: Human Subjects Research Review Committee (HSRRC) Application

295 
List of Tables

1.2 Policy Case List 15

$2.1 \quad$ Migrant Definitions 31

2.2 EU and EEA nations that have adopted a national migrant health policy 45

3.1 Definition of Core Concepts of Research Question 66

$\begin{array}{lll}3.2 & \text { Policy Document Information } & 79\end{array}$

4.1 Policy Objective Major Category Units of Text Sample 109

4.2 Coding Scheme for Policy Objective Major Category 114

4.3 Policy Strategy Category Assigned Codes to Units of Text Sample 117

4.4 Policy Strategy Major Category Coding Scheme 121

4.5 Health Services Major Category Assigned Code to Units of Text Sample 125

4.6 Coding Scheme for the Health Service Major Category with Code Count 129

4.7 Target Population Units of Text and Assigned Code Example 132

4.8 Target Population Major Category Coding Scheme 134

$\begin{array}{lll}4.9 & \text { Policy Code Abbreviation Key } & 161\end{array}$

4.10 Policy Strategy Major Category 161

4.11 Category Access to Care and Quality of Care Range 163

4.12 Policy Objective Major Category Policy Association 166

4.13 Policy Objective Major Category Abbreviations 167

4.14 Policy Case Association with Subcategories in the Health Services 169 Major Category

4.15 Policy Case Association with the Primary Prevention Category 171

4.16 Policy Case Association with the Secondary Prevention Category 172

4.17 Policy Case Association with the Tertiary Prevention Category 172

4.18 Health Services Category Abbreviations 174

4.19 Policy Case Association with Target Population Major Category 175

4.20 Target Population Major Category Abbreviations 176

4.21 Subcategories in the Access to Care Category Abbreviation Key 182 
4.22 Subcategories in the Quality of Care Category Abbreviation Key

4.23 Policy Strategy Subcategory Abbreviations 185

4.24 Primary Prevention Category Abbreviations 190

4.25 Secondary Prevention Category Abbreviations 191

4.26 Abbreviation Key for Figure 4.17 and $4.18 \quad 206$

5.1 Abbreviation Key for Figure 5.3 231

5.2 Abbreviation Key for Figure 5.4

5.3 Abbreviation Key for Figure 5.5 234

$\begin{array}{lll}5.4 & \text { Abbreviation key for Figure } 5.6 & 237\end{array}$ 


\section{List of Figures}

1.1 Application of H. Laswell's frame to data organization 12

$\begin{array}{lll}1.2 & \text { Typology Matrix Framework } & 18\end{array}$

2.1 Number of international migrants by major area of destination, 2000-2015 33

2.2 Health structure and value system of differences 53

3.1 Typology Matrix $\quad 85$

3.2 Structure of Policy Strategy Major Category Mapped onto Typology Matrix 94

4.1. Policy Case Distribution Across Categories in the Policy Objective 143 Major Category

4.2 Policy Case Distribution Across the Policy Strategy Major Category 144

4.3 Policy Case Distribution Across Subcategories in the Access to 146 Care Category

4.4 Policy Case Distribution Across Subcategories in the Quality of 148 Care Category

4.5a Policy Case Distribution Across Categories in the Health Service 149 Major Category

4.5b Policy Case Distribution Across Subcategories in the Primary 150 Prevention Category

4.5c Policy Case Distribution Across Subcategories in the Secondary 151 Prevention Category

4.6 Policy Case Distribution Across Subcategories in the Tertiary 153 Prevention Category

4.7 Policy Case Distribution in the Target Population Major Category 155

4.8 Initial Policy Strategy Theme Typology Matrix 164

4.9 Policy Objective Major Category Typology Matrix Presentation 167

4.10 Health Services Major Category Typology Matrix Presentation 173

4.11 Target Population Major Category Matrix Presentation 176

4.12 Policy Strategy Major Category Subcategories in the Access to 182

Care Category Mapping on the Access to Care Dimension 
4.13 Policy Strategy Subcategories in the Access to Care Category Along the Quality of Care Matrix Dimension

4.14 Subcategories in the Policy Strategy Major Category Typology Matrix Presentation

4.15 Primary Prevention Subcategory Typology Matrix Presentation

4.16 Subcategories within the Health Services Secondary Prevention 191 Category Matrix Presentation

4.17 Migrant Health Policy Orientation Pertaining to Migrant Health 204 Typology Matrix

4.18 Theme Alignment with Subcategories in the Policy Strategy and 205 Health Services Major Categories

5.1. Application of Laswell's Frame to Data Organization

5.2 Migrant Health Policy Orientation Pertaining to Migrant Health Typology Matrix

5.3 Migrant Health Policy Orientation Pertaining to Migrant Health Typology Matrix Theme Association with the Primary, Secondary \& Tertiary Prevention Categories

5.4 Migrant Health Policy Orientation Pertaining to Migrant Health Typology Matrix Theme Association with Target Population Categories

5.5 Migrant Health Policy Orientation Pertaining to Migrant Health Typology Matrix Theme \& Policy Strategy Subcategory Apparent Relationships

5.6 Migrant Health Policy Orientation Pertaining to Migrant Health Typology Matrix Theme Association with Health Services Subcategories

5.7 Policy Case Positioning on the Migrant Health Policy Orientation Toward Migrant Health Policy Typology Matrix

5.8 Health Structure and Value System of Differences Typology Matrix 


\section{Chapter I - Background}

\section{Issue Background}

According to the Alma Ata Declaration, "health is defined as a state of complete physical, mental and social wellbeing, and not merely the absence of disease or infirmity, is a fundamental human right and that the attainment of the highest possible level of health is a most important world-wide social goal whose realization requires the action of many other social and economic sectors in addition to the health sector" (World Health Organization, 1978). Within the broad definition of health lies the concepts of health promotion and health protection. The World Health Organization (2016a) defines health promotion as "the process of enabling people to increase control over, and to improve, their health. This definition moves beyond a focus on individual behavior towards a wide range of social and environmental interventions." Health protection, as defined by the National Health Service (2015), "encompasses a set of activities within public health that include: 1) ensuring the safety and quality of food, water, air and the general environment; 2) preventing the transmission of communicable diseases; and 3) managing outbreaks and the other incidents which threaten the public health" (para. 1).

While a state's role in promoting and protecting health continues to be debated among policy makers, at the core of this debate is the question of responsibility for health promotion and health protection. Specifically, what is the extent of the state's responsibilities in promoting and protecting health of its citizens and how should it respond to fulfill them? In an era of increasing globalization and immigration, this raises 
a second important question: to what extent is the state responsible for the health of resident non-citizens and how should it respond, if at all? This second question related to migrant health and health policy has been particularly salient among European Union and affiliated nations over the last decade as they have responded to an increased flow of migrants both to and within Europe.

A spate of recent national migrant health policies implemented in ten European Union member states and one nation in the European Economic Area provide an opportunity to explore variation in nations' responses to migrant health issues, how these policies relate to the "problem" as constructed within their respective policy processes, and ultimately how policy content relates to migrant health outcomes. Better understanding of the European migrant health policy experience has the potential to broadly inform the emerging field of migrant health comparative policy analysis in an increasingly globalized and mobile world.

Immigration is not new in Europe. However, the past few decades have marked an increase in the flow of migrants both to and within Europe. According to EURO Stat, the statistical office of the European Union, on 1 January 2015, the number of people living in the current 28 European Union (EU) member states who were citizens of nonmember countries was 19.8 million, and the number of people living in the EU who were born outside of the 28 member states totaled 34.3 million (Eurostat, 2017). Countries in Europe are experiencing pressure to organize and respond to resettling large numbers 
of migrants. Health, social service, housing, transportation, and education systems are responding to growing and diversifying populations.

Migrant workers comprise 4\% of Europe's workforce in 2009 (Mladovsky, Ingleby, McKee, \& Rechel, 2012), and make up a large proportion of the workforce in low-skilled job sectors. Low-skilled migrant workers often occupy jobs that indigenous populations shun and have easy entry points such as manual labor, agriculture, construction, and the hospitality industry (Salt, 2007). Low-skilled jobs attract migrants because little or no prior work experience is required. As such, migrants often take jobs that are physically demanding, require longer working hours, and have dangerous working conditions (Boden \& Rees, 2009). Additionally, falling birthrates and ageing populations in many European countries have led to a dependence on migrant workers in assuming a vital role in Europe's economy. According to Doyle, McKee, Rechel \& Grundy (2009), "Europe needs migrants to fill labor shortages arising from falling birth rates and ageing populations, especially among those who care for the growing number of older people" (p. 893).

One aspect in the conversation on immigration in Europe is the issue of health of both migrant populations and health protection of the host nation population from communicable disease transmission. The connection between migration and health has been documented in migrant health outcome literature (Nagy, 2011). Determinants of health for migrant populations is influenced by several factors that include age, occupational health hazards and accidents, infectious disease, living situations and 
crowding, the process of migration, lifestyle, and unique health profiles that reference a migrant's country of origin (Nagy, 2011). In order for migrant populations in Europe to obtain a state of "health" the policy environment (i.e., supranational, international, and national policies protecting the right to health or health promotion) must be considered.

The right to health has been enshrined in numerous policy instruments developed by international and supranational organizations that include, among others, the United Nations (UN), World Health Organization (WHO), World Health Assembly (WHA), and European Union (EU). Additionally, all EU member states recognize the right of everyone to obtain the "highest attainable standard of physical and mental health" (International Covenant on Economic, Social and Cultural Rights, 1966: 12). In this regard, the right to health encompasses both the right to health care and the right to the preconditions to health (Pace, 2011).

Migrants who have obtained permission to live and work in an EU member state have, in theory, access to the same health care services as EU nationals. However, access to health care services for undocumented migrants (i.e., migrants who do not have permission to enter or remain in an EU member state) are limited to emergency medical services (Nagy, 2011). While all of the 28 current EU member states recognize the right of everyone to achieve the "highest attainable standard of physical and mental health," integration of migrant health needs into national health care systems has not been fully realized (Nagy, 2011). The European Commission, through the Programme of Community Action in the Field of Health 2008-2013, called for member states to 
integrate migrant health into health systems in order to facilitate access to health care for migrant populations (Nagy, 2011). Several EU member states resisted the Commission's recommendations on fostering migrant health, specifically in the area of providing health care services to undocumented migrants who have not obtained permission to live or work in the nation (Nagy, 2011).

Perhaps the impetus for member states to resist adopting the Programme of Community Action in the Field of Health 2008-2013 is that health and health system services are primarily a national level matter for EU member states (Pace, 2011). This is based in the relationship member states have with the EU. While member states join the EU and benefit from collective strength and influence as a union, they remain sovereign, independent nations. As such, EU actions are subject to the subsidiarity principle that posits EU action is necessary only when it will be more effective at a supranational level than at a national level (Directorate-General for Communication European Commission, 2014). In relation to issues concerning health, the subsidiarity principle ensures that "all decisions are taken as close as possible to citizens, and that constant checks are made as to whether action at the community level is justified in light of the possibilities available at the national, regional or local levels" (Hämäläinen et al., 2004, p. 6). As a result, health system organization and access to health care services are a national matter that is handled in accordance to national priorities of each member state. 
The literature suggests that inequities in health between migrants and host nation populations are widening (Peiro and Benedict, 2009). The drivers of health inequities between migrants and non-migrants are multi-layered and complex. They range from legal barriers that affect entitlement to receiving health care services, accessibility of health care services, a migrant's knowledge of rights and protections, harmful living conditions, occupational health hazards, to a migrants' self-perception of health (Rechel et al. 2013; Padilla and Miguel, 2009; Mladovsky et al., 2012).

According to Peiro and Benedict (2009) "Migrants are at risk of not receiving the same level of health care in diagnosis, treatment, and preventative services, that the average populations receives in host communities" (p. 7). Furthermore, migrants have more health risk factors when compared to the host nation population in the destination country (Mladovsky, 2007; McKay et al., 2003). Rechel, Mladovsky, Ingleby, Mackenbach \& McKee (2013), state that "Available data suggests that migrants are vulnerable to certain communicable diseases, occupational health hazards, and injuries, and poor mental health" (p. 1,238). These barriers perpetuate inequity in health between migrants and host nation populations and can lead to more costly care for migrants due to delays in receiving healthcare (World Health Organization, 2010).

Even though some may argue that Europe's economy depends on migrant workers, European countries demonstrate various levels of responsibility and support of the health of migrants. Of the current $28 \mathrm{EU}$ member states, 10 countries plus Switzerland in a special partnership with the EU through the European Economic Area 
(EEA) have implemented national policies that specifically address the health of their migrant population. These second-level policies go beyond statutory and legal entitlements outlined in international and supranational policy instruments (Mladovsky, Rechel, Ingleby, \& McKee, 2012). National level migrant health policies reflect the national context in which they were adopted. Consequently, as reflected in the content, scope, and intent of each policy, motivations to adopt a migrant health policy vary across the group of 11 nations. Between 1998 and 2007, migrant health policies were implemented in: Austria, England, France, Germany, Ireland, Italy, the Netherlands, Portugal, Spain, Sweden, and Switzerland. The lack of consensus at an international and supranational level on the definition of the term "migrant" confounds the topic, especially in the area of designating eligibility for resources and legal entitlement to services. For example, there is significant variation of legal boundaries that designate who is and is not entitled to health care services among EU nations and Switzerland, an EEA nation. Broadly, the term "migrant" refers to a person who is foreign-born and residing in a host nation. It is also a term that describes subpopulations that include asylum seekers, displaced persons, economic migrant, irregular or undocumented migrant, refugees, and students (Mladovsky, 2009).

For the purpose of the study, a broad definition of "migrant" will be followed in order to ensure all sub-categories of the term that are included as the target population in a policy are fully considered in the analysis (e.g., asylum seekers, economic migrants, ethnic minorities, irregular migrants, regular migrants, unaccompanied minor, victims of 
trafficking, etc.). The migrant definition applied in this study is "a person who has left their home country to live in a foreign country, either legally or illegally; migration may be the result of various factors (e.g., natural disaster, civil war, persecution, job opportunities), and can be either long-term or short-term (United Nations High Commission on Refugees, 2017).

\section{Problem Statement}

To date, scholarly research on migrant health has mainly focused on inequities in health between migrants and host nation populations, barriers migrants encounter accessing health care, and health risks associated with the process of migration (Buja et al., 2013; Gushulak, Pace, and Weekers, 2010; Kiss \& Hossain, 2011; Malmusi, Borrell and Benach, 2010; Mladovsky et al., 2012; Rechel et al., 2013; Zimmerman, 2011). The field of comparative migrant health policy analysis research is relatively young. According to Vasquez et al. (2010), "The scientific literature has barely tackled the issue of analyzing health and health care policies developed for immigrant populations" (p. 71). The majority of existing published comparative migrant health policy analyses have been based on the group of eleven EU-based migrant health policies (Chimenti, 2007; Mladovsky, 2009; Mladovsky et al., 2012; Vásquez, et al., 2011). These include comparative content analyses of subsets of the eleven EU-based policies and initial conceptions of frameworks with which to base these policy content comparisons.

Further research to dimensionalize these existing polices within a basic comparative conceptual framework would provide a stronger foundation for answering 
the basic question of how and to what extent nations view their responsibility for migrant health, whether within the EU, or within and across other supranational, international, or national jurisdictions. Existing policy content research on a subset of the eleven EU-based migrant health policies have engendered potential policy types or definitions derived from external frames through an a priori research process.

Definitions include "protectionist", "migrants need saving", "migrants need special services", "difference-blind/republican", or "difference-sensitive/communitarian". Difference-sensitive policies recognize the unique health needs of migrants as separate from the host nation's population, whereas policies that follow a difference-blind approach do not single out a specific population (e.g., migrants and ethnic minorities) from the general population as a whole (Chimienti, 2007).

Within this issue of protecting health of non-state residents, the state's policy objectives, inclusive of both socio-cultural and economic objectives, toward migrants must be considered. The state's policy objectives for protecting the health of the migrant population may likely include one or more of the following: 1) responsibility to protect the health of the indigenous population; 2) the need for a healthy, productive, and inexpensive workforce to foster or sustain economic growth; or 3) a belief that health is a basic human right and it is the state's moral responsibility to protect the health of everyone within its borders. 


\section{Research Question}

The study was guided by the research question:

What are the similarities and differences in policy content that can be found among the eleven European Union- based migrant health policies and to what extent can they be grouped or classified?

The study has three aims:

1. Categorize policy content of the eleven EU-based policy cases in order to identify broad structural elements and specific similarities and differences among the policy cases within and across these structural elements.

2. Construct a migrant health policy typology that seeks to depict policy orientation toward migrant health based on the policy content categorization developed in Aim 1.

3. Assess the constructed policy typology generally, and in regard to the position of each of the eleven policy cases within it, for the extent and consistency to which it contributes to the understanding of policy structure and orientation regarding migrant health and implications for policy, policy-making processes, migrant health advocacy, and future migrant health outcomes research.

\section{Theoretical Frame}

Comparing similarities and differences across multiple policies has a long-

standing position in comparative policy analysis literature. Findings and insights derived from this area of inquiry elicit important information about "how" and "why" policies are different by identifying patterns across policy cases (Gupta, 2012; deLeon and Resnick-Terry, 1998). Moreover, comparative policy analysis has gained traction in the last two decades as a method to study policy cases in different countries that address the same public problem or concern in order to generate rich insights on characteristics 
of public policy (Geva-May, Hoffman, Muhleisen, 2017; Cyr and deLeon, 1975). This research is on focused on the content of the policy cases as the sole basis of evaluation and does not investigate the policy processes associated with the policy cases. As such, "how" the policy cases are similar and different will be fully explored. "Why" they are similar and different per policy making processes is a subject for future research.

Comparative policy analysis is useful in identifying policy patterns and contrasts through inductive comparisons of similar policy issues in different national contexts (deLeon and Resnick-Terry, 1998). Based in this orientation, this comparative case study examines how a group of nations with similar and interconnected political institutional structures and share the distinction of migration receiving nations responded to the issue of the health of migrant populations through a designated policy.

Comparative policy analysis research has a history of drawing on theoretical frameworks from various disciples. According to Gupta (2012), "Even though this type of research is indispensable, it does not explicitly utilize (or seek to build upon) theories of the policy process when explaining divergent policy outcomes. Rather, these scholars employ broad theoretical frameworks borrowed from various strands of literature like risk analysis, cultural theory, economic theory, and path dependence" (pg. 15)

In keeping the tradition of borrowing broad theoretical frameworks to explain variation in the policy cases, this study borrows from Harold Laswell's seminal definition 
of politics and policy, "Who gets what, when, and how?" as a broad theoretical frame to categorize data at the highest level of organization (i.e., legislative documents associated with a policy case) that were analyzed in phase one (Laswell, 1936). Laswell's frame was utilized to identify and categorize structural elements of the policy documents, creating a comprehensive organizational scheme for the data analyzed. This distinctive organizing frame was used to derive meaningful comparisons and understanding of variation across the policy cases based solely on content analysis of the language of a policy document. Figure 1.1 depicts the study's application of Laswell's frame as an organizing structure for that data analyzed, coded, and grouped in phase one.

Figure 1.1. Application of Laswell's frame to data organization.

\section{Harold Laswell: "Who, gets what, when, and how?"}

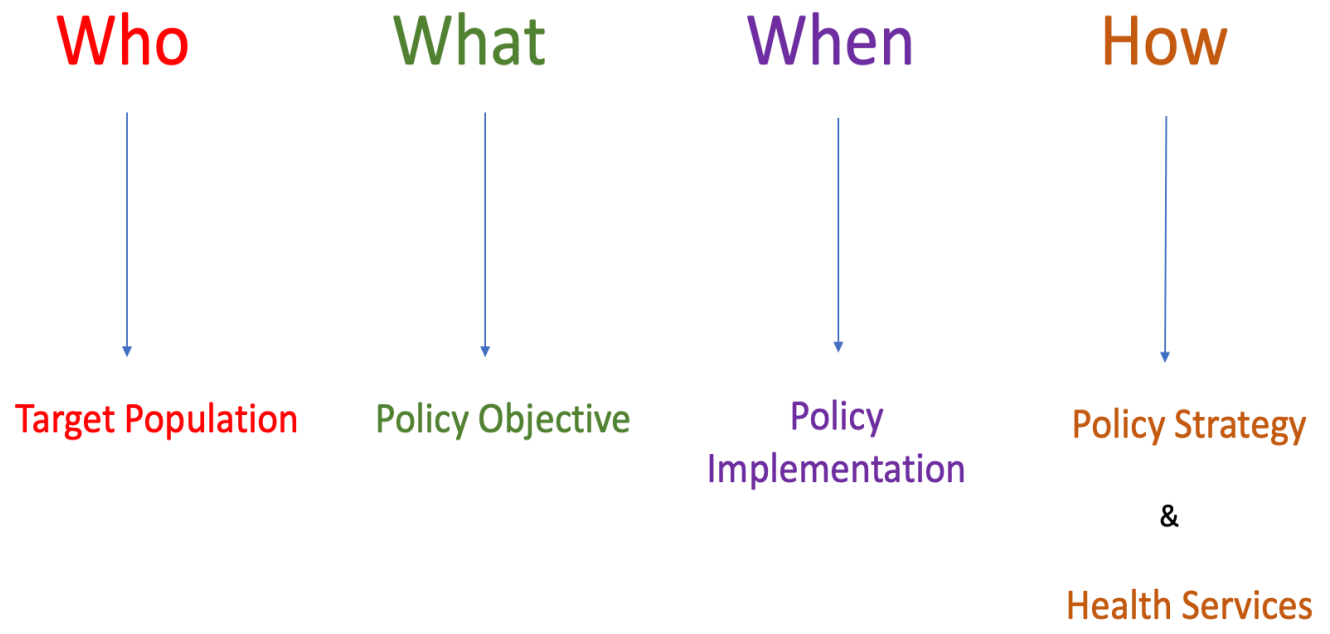




\section{Methods Overview}

\section{Research Design and Rationale}

The research design is a cross-case study using two qualitative methods that are content analysis and typological analysis. The design enabled the researcher to fully explore the research question and three aims that this study sought to answer (Glaser and Strauss, 1967, 1970). Case study research is useful in answering "how" and "why" questions that pertain to a specific real-life event or phenomenon. According to Yin (1989), "Case study research is when a "how" or "why" question is being asked about a contemporary set of events, over which the investigator has little or no control" (pg. 20). Furthermore, the case study approach is useful when analyzing data from multiple sources that reference a particular situation (Yin, 2009). In this study, the key question is how the policies are similar and different?

This study defines a policy case as the language of the policy statement, report, or scheme that directly pertains to the health of migrant populations. Implementation of a policy statement, report, or scheme prescribed a "course of action (and inaction)" that affect the delivery of health care services to migrant population (Shiffman, Schneider, Murray, Bruga, and Gilson, 2008). The policy statement, report, or scheme generally prescribes a context in which migrant populations are entitled to health care services. For example, this context could be immigration status of a migrant, (e.g., documented or asylum seeker), or place where services are received (e.g., migrant friendly hospital). Documents associated with a policy case (i.e., policy statement, report, or scheme) are the data collected and analyzed in this study. 
The primary factor that determined inclusion of a policy case was its presence in extant research on migrant health policy content published in peer-reviewed journals. Existing and related research on migrant health policies cover a window of activity that is EU-based in a certain time period, (i.e., 1998-2007). These cases reflect shared common experiences as migration receiving nations and have been studied previously. While the cases are all democratic nations, each one has a unique history and democratic structure of its own. As a result, differences across the policy cases are likely due to variation in specific factors such as political structures, ideology, perceptions towards migrants, and/or a nation's economy. Table 1.2 presents the cases included in this study, the year the policy instrument was adopted, the length of the policy document, report, or scheme, and whether or not the policy document was available in English. Policy documents associated with a case that were written in a foreign language were translated into English by a certified translator.

Table 1.2. Policy Case List.

\begin{tabular}{|c|c|c|c|c|}
\hline Country & Policy/Scheme/Report & $\begin{array}{c}\text { Year } \\
\text { Adopted }\end{array}$ & $\begin{array}{l}\text { Number } \\
\text { of pages }\end{array}$ & $\begin{array}{c}\text { English } \\
\text { Translation } \\
\text { Available }\end{array}$ \\
\hline Austria & $\begin{array}{l}\text { The National Social Report adopted in } \\
2005 \text { and updated in } 2014\end{array}$ & 2005 & 31 & Yes \\
\hline England & Race and Equality Scheme 2005-2008 & 2006 & 118 & Yes \\
\hline France & $\begin{array}{l}\text { Contract d'accueil et d'intégration } \\
\text { (Integration and Welcome Contract) }\end{array}$ & 2006 & 2 & Yes \\
\hline Germany & National Integration Plan & 2007 & 4 & Yes \\
\hline Ireland & $\begin{array}{l}\text { National Intercultural Health Strategy } \\
2007-2012\end{array}$ & 2007 & 116 & Yes \\
\hline
\end{tabular}




\begin{tabular}{|c|c|c|c|c|}
\hline Country & Policy/Scheme/Report & $\begin{array}{c}\text { Year } \\
\text { Adopted }\end{array}$ & $\begin{array}{l}\text { Number } \\
\text { of pages }\end{array}$ & $\begin{array}{l}\text { English } \\
\text { Translation } \\
\text { Available }\end{array}$ \\
\hline Italy & $\begin{array}{l}\text { The National Health Care Plan 2006- } \\
2008\end{array}$ & $\begin{array}{l}\text { 1998; } \\
\text { updated } \\
\text { in } 2006\end{array}$ & 100 & Yes \\
\hline $\begin{array}{l}\text { The } \\
\text { Netherlands }\end{array}$ & $\begin{array}{l}\text { The Amsterdam Declaration: Towards } \\
\text { Migrant Friendly Hospitals in an Ethno- } \\
\text { Culturally Diverse Europe }\end{array}$ & 2000 & 8 & Yes \\
\hline Portugal & $\begin{array}{l}\text { Plan for the Integration of Immigrants } \\
2007-2009\end{array}$ & 2007 & 40 & Yes \\
\hline Spain & $\begin{array}{l}\text { The National Strategic Plan on } \\
\text { Citizenship and Integration 2007-2010 }\end{array}$ & 2007 & 100 & Yes \\
\hline Sweden & $\begin{array}{l}\text { The National Agreement on Health and } \\
\text { the First Years in Sweden }\end{array}$ & 2004 & 27 & No \\
\hline Switzerland & $\begin{array}{l}\text { The Migration and Public Health } \\
\text { Strategy 2002-2006 }\end{array}$ & 2002 & 18 & Yes \\
\hline
\end{tabular}

\section{Analytic Process}

Two qualitative analytic methods were applied to identify and fully explore similarities and differences across the eleven policy cases and the extent to which they could be grouped or classified. Content analysis was used to organize policy content and assess similarities and differences across the policy set. Typological analysis was used to identify apparent policy groups or types.

\section{Content Analysis}

Content analysis was utilized to identify and systematically code relevant units of policy text, as well as determine the frequency of specific words or phrases across the policy cases. Application of this method fostered a reliable and valid process with which to identify similarities and differences in the content of policy statements, reports, or schemes across the policy cases. Harold Laswell's seminal definition of politics and 
policy, "Who gets what, when, and how?" was utilized as a guide to inform categorization of policy content at the highest level of organization (Laswell, 1936).

Content analysis is an empirically grounded research technique used to make reliable, replicable, and valid inferences from texts pertaining to the contexts of their use (Krippendorf, 2004). A distinguishing feature of the method's reliability and validity is the systematic application of the coding scheme to all data in textual form (Ethridge, 2002). According to Krippendorf (2004), because "the coding technique is expected to be reliable and replicable, the rules governing coding must be explicitly stated and applied equally to all units of analysis" (p. 19).

\section{Typological Analysis}

Collier et al. (2012) define typologies as "an organized system of types" (p. 217). Organized by categorization rather than a hierarchal arrangement, scholars create typologies in order to form concepts, refine measurement, explore dimensionality, and organize claims (Given, 2008; Collier et al., 2012). Given (2008) states, “Typological analysis is a strategy for descriptive qualitative (or quantitative) data analysis whose goal is the development of a set of related but distinct categories within a phenomenon that discriminate across the phenomenon" (p. 2). In a typological analysis, the researcher first identifies areas of commonality and variation in the data set, then investigates patterns of similarity and difference (Given, 2008).

A typology matrix developed by Collier et al. (2012) was applied as an organizing framework to identify and examine apparent relationships, tendencies, and patterns within and across the data structure that emerged from content analysis that occurred 
in phase one. The typology matrix measures an overarching concept, (e.g., migrant health policy orientation toward migrant health in this case). The overarching concept is disaggregated into dimensions that represent differentiating characteristics of the phenomenon under study. The intersection of the matrices dimensions identify categorical variables that are concepts located in the matrix's cells. They describe attributes of the overarching concept that is measured by the typology (Collier, Laporte \& Seawright, 2008; Collier et al., 2012). The categorical variable for each cell communicates a substantive meaningful label that corresponds with a "type" or group within the overall phenomenon. In this research, the dimensions of the matrix will be developed from the policy content identified in the first phase of the research. Emergent policy types reflect the relationships among and between the dimensions and the structure of policy content using Laswell as an organizing frame. The typology matrix framework developed by Collier et al. (2012) is presented again in Figure 1.2. 
Figure 1.2. Typology Matrix Framework.

Typology Title: Overarching Concept Measured by the Typology Matrix

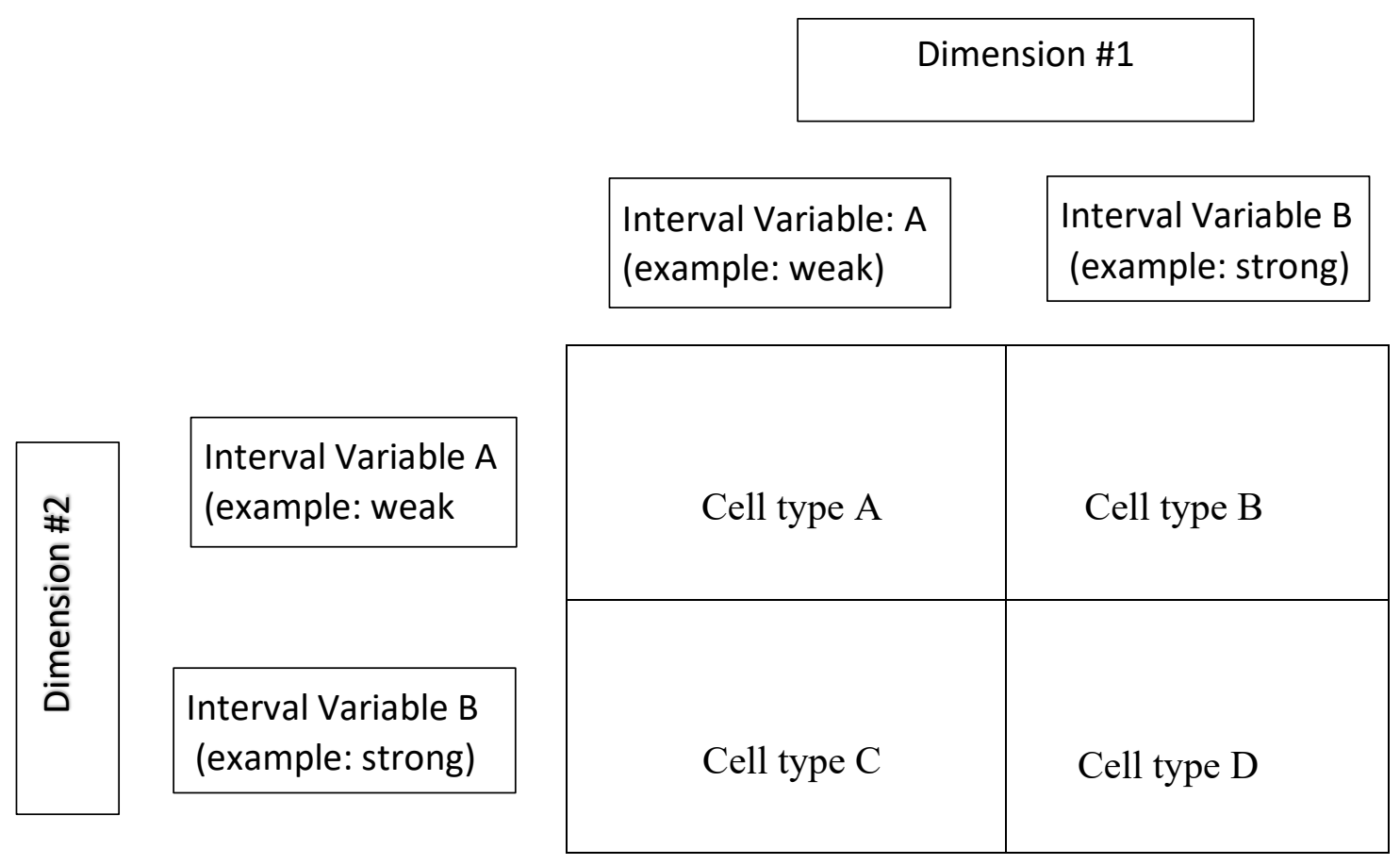

source: Collier et al. (2012)

\section{Purpose and Significance of the Study}

Europe offers a unique opportunity for comparative migrant health policy

research. Of the current 28 European Union (EU) member states and EEA nations,

eleven countries have implemented national policies that share a common objective of

addressing the health of migrant populations. While the policies all have the same

overarching objective, each one reflects a unique national context and societal values

pertaining to migrant health. As such, eleven policy cases vary in content, scope, and

objective. Comparative analysis of policies that broadly share the same objective

enables insight into how a group of nations conceptualized, defined, operationalized, 
and responded to the health of migrant populations.

While barriers encountered by migrants in accessing health care services in host nations and inequities in health between migrants and host nation populations have been well-documented in the literature, comparative analysis of the migrant health policies is relatively limited. A limited amount of existing research examined similarities and differences among the eleven policy cases included in this research. Only one other study by Chimenti et al. (2007) classified migrant health policies by type with a prior process deriving structural elements of the typology from sources external to the policies included in her study.

The study's two-phased analytic process is relevant to existing research on the eleven policy cases. It also has potential for broader implication for any field of comparative policy analysis research that seeks to categorize a set of policies that broadly share the same objective or goal. This research offers future comparative policy analysis research an analytic process that is transparent, comprehensive, and can be replicated. Application of Laswell's "Who gets what, when, and how?" is a relevant frame to organize policy content at the highest level of organization (Laswell, 1936). An organized coding scheme of the data derived from content analysis of the cases enabled comparisons across the eleven policies. The coding scheme was mapped onto the typology matrix developed by Collier et al. (2012) in phase two of the study.

Findings from this research have the potential to confirm existing comparative analysis research on the policy cases in terms of the organization and presentation of 
data or validating results. This study also offers migrant health policy evaluation research context with which to position findings, more thoroughly understand policy performance, identify best practices, and recognize areas for policy refinement. Results of this research also create a frame for migrant health outcomes researchers to develop hypotheses based upon the theme-based typology that depicts policy orientation toward migrant health. Given that people have been and always will migrate, it is highly probable that more nations will engage in migrant health policy-making processes. Policy process research among the eleven cases has the potential to explain variation among the policy cases that was identified in this study. In other words, "why" are these eleven cases are different. Furthermore, policy makers and migrant health policy advocates engaged in migrant health policy making processes can reference results of this study and gain insight into the structural policy elements necessary to have a specific "type" of migrant health policy. 


\section{Chapter II - Review of Related Literature}

This chapter reviews the relevant literature and policy areas in order to orient the reader to the topics of migrant health, migrant health policy, and comparative policy analysis research that supports the goals of this study. Synthesis of relevant migrant health policy literature positions the study within the broader scope of migrant health policy and comparative policy analysis research and creates the context for the relevancy of the study's research question and aims. The chapter is organized by the following sections: migrant health outcomes in destination countries, migration and communicable disease transmission, who is a migrant, migration and migrant perceptions, migration and health as a human right, why migrant policies at all, European Union-based migrant health policies, comparative policy analysis, extant comparative migrant health policy analysis research, analytic frame, typologies, and conclusion.

\section{Migrant Health Outcomes in Destination Countries}

While the act of migrating, when viewed as an isolated act of moving from one country to another, is generally not considered to be a risk factor to health, the process of migration can trigger mental and physical health problems for the migrant (Pace, 2011). The process of migration is organized into four phases: pre-migration, movement, arrival, and integration (Gushulak et al., 2010) and each phase can influence a migrant's health profile and health status.

Migrants have unique health profiles that are a reference to: 1) their country of origin; 2) living and working conditions in the destination country; and 3) distinctive 
health needs regarding the acceptability and accessibility of health care services (Gushulak, et al., 2010). Within these three areas, a migrant's health is also influenced by many factors that range from age, gender, ethnic identity, genetic characteristics, country of origin, country of destination, time of residency in a host nation, occupational health hazards, socioeconomic status, social determinants of health, access to health care services, and potential exposure to communicable diseases (Rechel et al., 2011; Ingleby et al., 2009). As a result, migrants present unique challenges to health care systems in destination countries (Nagy, 2011).

Factors that influence health are magnified or diminished depending on the living and working conditions in which the migrant finds him/herself, their ability to access health care services in the host nation, and the acceptability of health care services (Nagy, 2011). Acceptability is defined from the migrant's perspective and refers to health care services that are respectful of, and responsive to, the cultural and ethnic diversity of service users (Centers for Disease Control, 2017).

The literature suggest that, while migrants are relatively healthy when compared to the host nation population upon arrival in the destination country (a phenomenon known as the "healthy migrant effect"), migrants have more health risk factors over time when compared to the indigenous population (Mladovsky, 2007; McKay et al., 2003; Rechel et al., 2011). According to Peiro and Benedict (2009) “Migrants are at risk of not receiving the same level of health care in diagnosis, treatment, and preventative services than the average population receives in host communities" (p. 7). 
Migrant women and children

encounter a higher rate of maternal and child health problems then non-migrant women and children in the destination country. According to Rechel et al. (2011), migrant women "have differences in perinatal outcomes persisting between migrants and non-migrants, and evidence that both utilization and quality of antenatal care is lower among migrant women" (p. 5). A 2009 systemic literature review on the topic of stillbirth, neonatal mortality and infant mortality among migrants in Europe, found that over half of the 55 studies reviewed reported worse mortality outcomes for migrants compared to the respective non-migrant population (Gissler et al., 2009).

Additionally, the literature suggests that migrants are at higher risk for poor mental health when compared to host nation populations. While a large body of literature suggests that people migrate to improve their life chances and that of their children, the process of migration involves stress and can result in potentially negative impacts on mental health (Bhuga and Jones, 2001). Research measuring the ratio of mental disorders in migrants against the indigenous populations in six European countries found that migrants are 2.5 times more likely to develop mental health disorders when compared to the indigenous population (Health \& Consumer Directorate General, 2004).

Migrants have a disproportionate burden of adverse health outcomes when compared to host nation populations in receiving country (Rechel et al, 2011; Gushalulak et al., 2010; Nagy, 2011). A study of the prevalence of diabetes across 
Europe found that, although both migrants and lower socioeconomic groups have an increased risk of diabetes, the excess risk seems larger for migrants than disadvantaged groups of the host nation population (Espelt et al., 2008). Adverse health outcomes are influenced by several factors that include, but are not limited to, a migrant's country of origin, their individual health profile, and their living and working situation in the destination country.

In terms of occupational health hazards, the literature suggests that migrants are at greater risk than the host nation population due to over-representation in low-skilled, entry level jobs that have higher rates of risk and injury (Agudelo-Suárez, Ronda-Pérez \& Benavides, 2011). Entry-level jobs, also known as 3-D category jobs that are dirty, dangerous, and degrading work, have a higher incidence of occupational accidents and disease compared to other job sectors (Gushulak et al., 2010; Bollini and Siem, 1995).

The literature also addresses inequities in mortality rates between migrants and host nation populations. Migrants have worse mortality outcomes when compared to host nation, non-migrant populations. In a systemic literature review in 2009 on the topic of stillbirth, neonatal mortality and infant mortality among migrants in Europe, over half of the 55 studies reviewed reported worse mortality outcomes for migrants compared to the respective non-migrant population (Gissler et al., 2009).

Factors that contribute to health inequity between migrants and the host nation population are well-documented in the literature. They range from a lack of knowledge among migrants of health system access points, language barriers, limited health 
literacy, and restrictive work schedules, and lack of acceptability of health care services (Rowlands et al., 2015; Aronsson \& Gustafson, 2005; Gushulak et al., 2010). Examination of these factors has heightened awareness that migrants face numerous obstacles in accessing health services that extend beyond removal of legal barriers to health system entry (Madovsky, 2011).

Language barriers undermine both the accessibility of health services for migrants as well as the quality of service (Rechel et al., 2013). A migrant's inability to communicate their health needs and adhere to follow-up care is a significant barrier to seeking and receiving health care services in a host nation (Euranet, 2010; Rechel, Mladovsky, \& Devillé, 2012). Health literacy is the level of knowledge, personal skills and confidence to take action to improve personal and community health by improving people access to health information and their capacity to use it effectively (Centers for Disease Control, 2017). The literature suggests that health literacy is often poor among migrants and there is a need to inform migrants, in their native languages, about health and accessing health services in their host nation (Rechel et al., 2013; Mladovsky et al., 2012). Additionally, limited knowledge of rights and protections can result in migrants delaying seeking care when they need it (Rechel et al., 2013). Restrictive work schedules also contribute to health inequity as migrant workers are more inclined to attend work while ill. A study in Denmark found that absenteeism was lower for migrant workers than non-migrant workers, despite a worse state of health (Carneiro et al., 2010.) 


\section{Migration and Communicable Disease Transmission}

The literature offers evidence that the process of migration is a driver of communicable disease transmission in western and northern European nations (Wörmann and Krämer, 2011). Migrants coming from countries with a high burden of communicable disease can be vectors of transmission to the host nation's population. According to Odone et al. (2014), "The pathways through which migrants are at higher risk for both transmissions of TB infection and development of disease might include coming from high TB burden countries" (p. 506). National surveillance data indicates higher incidences of tuberculosis (TB), human immunodeficiency virus (HIV), and hepatitis among migrants residing in receiving countries (Wörmann and Krämer, 2011).

The literature also offers evidence affirming higher incidence of TB among migrants when compared to the indigenous, or native born, population in destination/receiving countries (Borgdorff et al., 2010; Barniol, et al., 2009; Baker et al., 2009). Researchers found that this was a trend in the majority of European Union and European Economic Area countries. For example, 2009 national surveillance data from France revealed that the incidence of TB was 9 times higher in migrants than the indigenous population (Odone et al., 2014). Diagnosed cases of TB in 2010 in the United Kingdom were nearly twice as high among foreign-born migrants than UK-born nationals, 54\% compared to 31\% (Health Protection Agency, 2011). Data collected between 1993 and 2001 in the Netherlands provided evidence that foreign-born, nonDutch nationals were more likely to have extra-pulmonary TB (te Beek, et al., 2006). 
The association between migration and HIV/AIDS transmission has also been documented in the literature, specifically in HIV tranmission (Wörmann and Krämer, 2011). Among diagnosed cases of heterosexually transmitted HIV infections reported in western Europe in 2006, 43\% occurred among migrants originating from highprevalence countries (EuroHIV, 2007). Migrants from sub-Saharan Africa were overwhelmingly represented in new HIV cases reported in Iceland (36.4\%), Ireland (32.2\%), Norway (39.5\%), and Sweden (35.3\%) (EuroHIV, 2007). Also, a 2007 study in Italy found that the estimated rate of HIV infections among migrants was 11 times higher than the indigenous population (Pezzoli et al., 2009).

The link between migration and preventable communicable diseases has also been addressed in the literature. While the incidence of measles, mumps, rubella, and polio is very low in developed countries, outbreaks have been linked to migrants originating from countries with lower immunization rates among children. A study in Italy linked a 2006 and 2007 measles outbreak to people originating from Romania (Curtale et al., 2010). Furthermore, a German study found that measles, mumps, and rubella immunization rates were lower among children of non-native German parents (Markuzzi et al., 1997).

\section{Section Summary}

There is an undeniable relationship between migration and health (Nagy, 2011). Research on migrant health outcomes tells us that migrants are vulnerable to occupational health hazards, injuries, poor mental health, diabetes, and poor maternal and child health outcomes (Rechel et al., 2011). Inequality in health is perpetuated by 
several factors that include, but are not limited to, immigration status, lack of knowledge of health system access points, appropriateness of health care services, language barriers, and unique health profiles of migrants. The abundance of evidence in the literature firmly positions migrants as a vulnerable population as this group has a greater risk of poor health outcomes in multiple areas when compared to the host nation populations in receiving countries.

The literature also documents an undeniable association between migration and the transmission of communicable diseases. Transmission pathways most often originate with migrants who come from countries where certain communicable diseases remain highly endemic. Numerous studies document higher incidence rates among migrants across several communicable diseases when compared to the host nation population. Research also tells us that migration can also influence the evolution of infectious diseases, such as multidrug-resistant TB, which has been linked to migrants who do not complete TB treatment (Gushulak, Pace, and Weekers (2010).

Migrants are a heterogeneous group in that they come from numerous different cultural and ethnic backgrounds (Hoffman et al., 2009). As such, this population represents challenges to receiving nations. Migrants, though often referred to as a group, presents a myriad of unique health profiles that are a reference to their country of origin as well as ethnic and cultural background. Moreover, migrants are vulnerable to adverse health outcomes including occupational health hazards and poor mental health. Finally, migrants originating from countries with unsuccessful TB control may 
present a public health challenge for receiving nations as they themselves may be communicable disease vectors.

\section{Who is a Migrant?}

The definition of the term "migrant" is not straightforward (Mladovsky, 2009). While the United Nations defines "migrant" as "a person who moves to a country other than that of his or her personal residence for a period of at least one year," not all countries follow this definition (United Nations Department of Economic and Social Affairs, 1998: 18; Rechel et al., 2011). Furthermore, who constitutes a migrant varies from country to country (Rechel et al., 2011). The term "migrant" can describe a specific group of people who were born abroad and are living in a host nation (Mladovsky, 2009), or follow a legal orientation that is defined by entry to a host nation, the right to work, and length of stay allowed. To date, there is no recognized definition for the term "migrant" that has broad supranational and/or international consensus.

Flexible in its application, the term "migrant" can represent a specific subgroup population or be used as an umbrella term that broadly references multiple subgroups such as asylum seeker, displaced person and returnee, regular and irregular migrant, refugee, student, and victim of human trafficking (Mladovsky, 2009; Gushulak, Pace and Weekers, 2010). The literature suggests that there is considerable variation among nations on subgroups (e.g., asylum seeker, internally displaced person, irregular migrant, refugee, and student) that are and are not included under the term "migrant" (Mladovsky, 2009). To compound matters, there is a lack of consensus in the literature on the length of time a foreign-born person residing in a host nation is considered to be 
a migrant (Mladovsky, 2009). Finally, while "migrant" is generally associated with foreign-born persons who are recent arrivals to a host nation, consideration is needed for long-term migrants who have resided in the host nation for one or more years. Mladovsky et al., (2012) state, “In general, the term 'migrant' tends to be associated with recent arrivals, while migrants who have been in the UK for more than a few years, as well as descendants of migrants, are usually described as belonging to 'ethnic minorities'” (p.250). While there is no consensus on the definition of who constitutes a migrant, nor the duration of a foreign-born person's migrant status in a host nation, nations have used migrant length of time in the host country, legal or illegal entry and immigration status, and circumstances of entry (e.g., economic opportunities, fleeing violence or discrimination, natural disaster) as parameters to classify a person's migrant status.

The majority of the eleven EU-based migrant health policies use the general term "migrant" to define the target population. However, given the scope of the term, it is not always clear who is and is not covered (e.g., asylum seekers, refugees, irregular or undocumented migrants, and students). For example, Ireland's policy applied the broadest scope the term. In addition to migrant, the policy also includes travelers, ethnic minorities, and children of migrants who were born in the country (Mladovsky et al., 2012). Migrant health policies adopted in Italy, Portugal, Spain, and Switzerland use the general term "migrant" to define the target population, but do not specify subgroups that are or are not included (Mladovsky et al., 2012). Conversely, the term 
"migrant" excludes asylum seekers and undocumented migrants in Austria and Germany's migrant health policies (Mladovsky et al., 2012). The one sub-group that is covered by all policies is documented, or regular, migrants who have received permission to live and work in the receiving nation/host country. As a point of reference, migrant classifications developed by the United Nations High Commissioner for Refugees are presented in Table 2.1.

Table 2.1. Migrant Definitions.

\begin{tabular}{|l|l|}
\hline Term & Definition \\
\hline Immigrant & $\begin{array}{l}\text { A person who comes to live permanently in a foreign } \\
\text { country }\end{array}$ \\
\hline Regular Migrant & $\begin{array}{l}\text { A person who has permission to live and work in a foreign } \\
\text { country }\end{array}$ \\
\hline Irregular Migrant & $\begin{array}{l}\text { A person who has not been granted permission to enter or } \\
\text { stay in a foreign country }\end{array}$ \\
\hline Refugee & $\begin{array}{l}\text { A person who has fled home country due to conflict or } \\
\text { natural disaster, but does not necessarily fear persecution }\end{array}$ \\
\hline Asylum Seeker & $\begin{array}{l}\text { A person whom has applied for asylum seeking international } \\
\text { protection }\end{array}$ \\
\hline Internally Displaced Person & $\begin{array}{l}\text { A person who has not crossed a boarder to find safety and is } \\
\text { seeking safety in other parts of their own country }\end{array}$ \\
\hline
\end{tabular}

Source: United Nations High Commissioner for Refugees, 2017.

For the purpose of the study, a broad definition of "migrant" will be followed in order to ensure all sub-categories of the term that are included as the target population in the eleven policies included in this analysis (e.g., asylum seekers, economic migrants, ethnic minorities, irregular migrants, regular migrants, and victims of trafficking). The migrant definition that will be used is "a person who has left their home country to live in a foreign country, either legally or illegally; migration may be the result of various 
factors (e.g., natural disaster, civil war, persecution, job opportunities), and can be either long-term or short-term" (United Nations High Commission on Refugees, 2017).

\section{Migration and Migrant Perceptions Global Migration Statistics}

The United Nations Population Division has been tracking international migration since 1990 (United Nations, Department of Economic and Social Affairs, 2016). Globally, 244 million people migrated in 2015 (United Nations, Department of Economic and Social Affairs, 2016). International migration has been steadily increasing over the last three decades, with 152.5 million migrants in 1990, 173 million in 2000, and 222 million in 2010 (United Nations, Department of Economic and Social Affairs, 2016). The number of international migrants increased by more than 91 million people over a 30-year period, between 1990 and 2015 (United Nations, Department of Economic and Social Affairs, 2016).

In 2015, the largest group of migrants (i.e., $25,758,970$ ) were between the ages of 30-34, originating from the African continent (United Nations, Department of Economic and Social Affairs, 2016). The median age of international migrants worldwide in 2015 was 39 years (United Nations, Department of Economic and Social Affairs, 2016). The top three destination regions receiving immigrants in 2015 were Europe (more than 49 million people), Asia (more than 48 million people), and North America (more than 27.6 million people) (United Nations, Department of Economic and Social Affairs, 2016). Correspondingly, Europe, Asia, and North America have the largest populations of international migrants, with 76 million migrants living in Europe, 75 
million in Asia, and 54 million in North America (United Nations, Department of Economic and Social Affairs, 2016). The number of international migrants by destination region is presented in Figure 2.1.

Figure 2.1. Number of international migrants by major area of destination, 2000-2015. Number of international migrants by major area of destination, 2000 and 2015

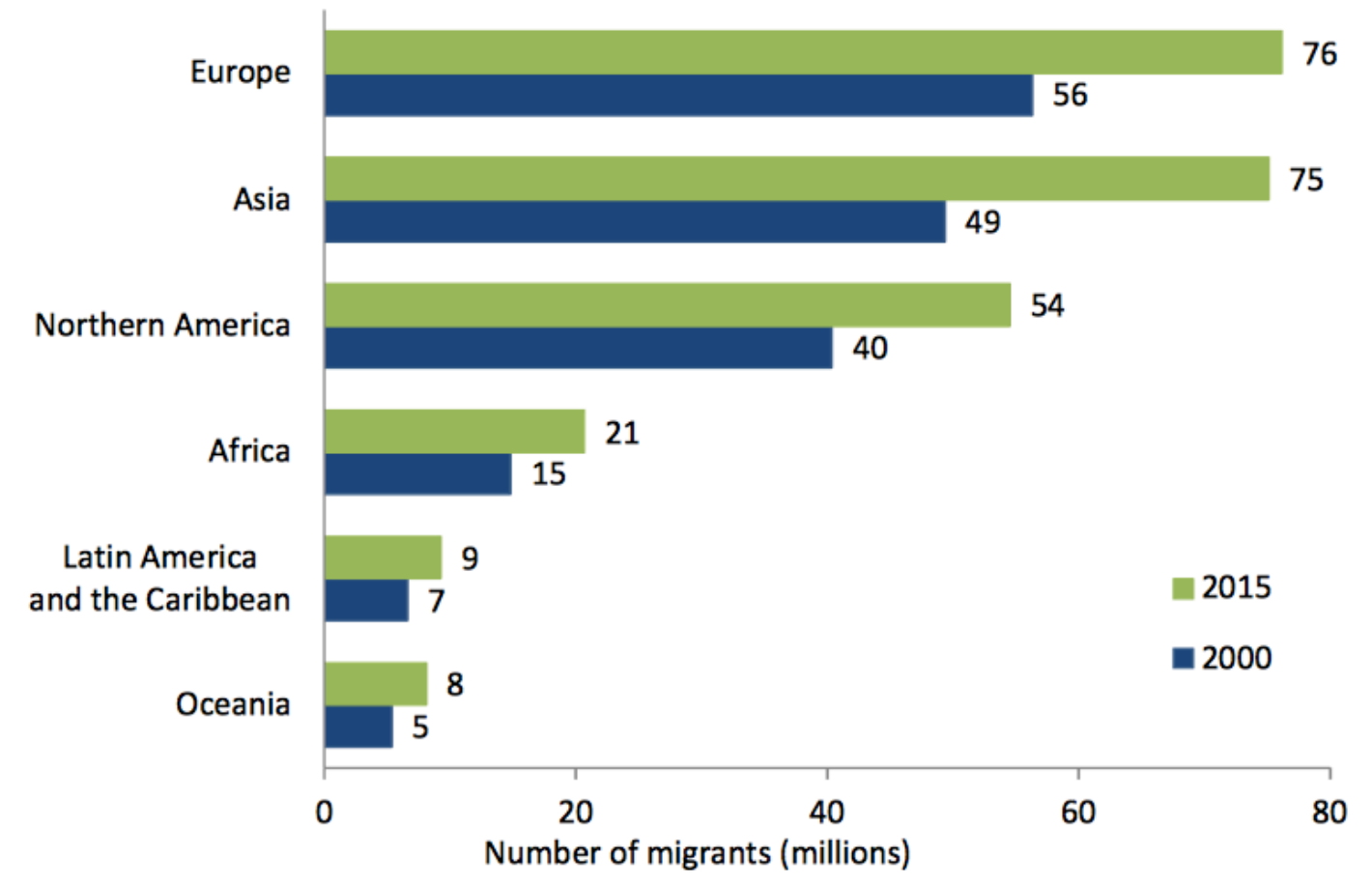

source: United Nations, Department of Economic and Social Affairs, 2016

Drivers of migration are both voluntary and involuntary. Economic migration is generally considered voluntary, as those who elect to migrant do so in search of economic opportunity in a foreign country. As of the end of 2015 , there were an estimated 250 million economic migrants globally (The World Bank, 2017). Involuntary, or forced, migration occurs when people are forced to leave their homeland due to natural disaster, conflict, violence, famine, or fear of persecution (Zimmerman, Kiss \& 
Hossain, 2011; UNHCR, 2017). In 2016, an estimated 66 million people globally were involuntary displaced as a result of natural disaster and conflict (The World Bank, 2017).

\section{Perceptions of Migrants in Host Nations}

Migration is a contentious social, political, and economic issue. The issue often sparks reactions among governmental and non-governmental actors in receiving countries regarding the value or risk migrant populations present to the host nation. Scholars speculate that divergent perceptions on the value of migrants stems from a receiving country's uncertainty about migrants coming into the country and its ability to control migration (Boswell, Geddes, \& Scholten, 2011). For example, answers to the following questions are unknown for the receiving country: 1) Will migrants contribute to a nation's economic growth? 2) Will there be higher unemployment? 3) Will migrants be a drain on social services? 3) Will crime increase? 4) How will migrants help a nation realize social and economic goals? 5) Where are migrants coming from? 6) To what extent will migrants integrate into main-stream society, as demonstrated through language acquisition and knowledge of customs and traditions? Answers to these questions are influenced by multiple factors in the receiving nation and can shift as economic, political, and social situations change over time.

Migrants are often perceived by host nation populations through narratives that are constructed by policy makers, elected officials, special interest groups, constituents, and scholars. Narratives are disseminated through print, broadcast, and social media outlets. Migrant narratives are influenced by the national context of the receiving 
country and can include the state of the economy, national values and interests, and views concerning the appropriation of social services (Boswell et al., 2010). Policy actors artfully select and use narratives pertaining to migrants that advance their interests and agendas (Boswell et al., 2010).

\section{Section Summary}

Perceptions of migrants in host nations are influenced by many factors that reflect the national context of the receiving country and include national interests, national values, uncertainty, and economic prosperity among other factors. Perceptions of migrants are not static and oscillate. Societal values are often reflected in policy, including policies pertaining to health of migrant population.

\section{Migration and Health as a Human Right International Policy Instruments and the Right to Health}

The concept of health as a fundamental human right has been enshrined in

numerous international policy instruments developed by international and supranational organizations that include, among others, the United Nations (UN), World Health Organization (WHO), World Health Assembly (WHA), and the European Union (EU). Human rights are "rights which are inherent in our nature and without which we cannot live as a human being" (United Nations, 1948). Access to health care as a human right is an important aspect of numerous UN declarations and policy instruments. Adopted by the general assembly in 1948, the UN's Universal Declaration of Human Rights declares that access to health care is a fundamental human right for everyone. The declaration states, "everyone has the right to a standard of living adequate for the 
health and well-being of himself and of his family, including food, clothing, housing and medical care...." (United Nations, 1948).

In 1990, The United Nations General Assembly adopted the International Convention on the Protection of the Rights of All Migrant Workers and Members of Their Families (United Nations, 1990). The policy instrument guarantees the right to necessary medical emergency treatment to migrant workers regardless of their legal status (United Nations, 1990). Article 28 states,

"Migrant workers and members of their families shall have the right to receive any medical care that is urgently required for the preservation of their life or the avoidance of irreparable harm to their health on the basis of equality of treatment with nationals of the State concerned. Such emergency medical care shall not be refused them by reason of any irregularity with regard to stay or employment" (United Nations, 1990: 28).

To date, however, none of the EU's largest and wealthiest member states have ratified International Convention on the Protection of the Rights of All Migrant Workers and Members of Their Families. Reluctance among European nations to ratify the International Convention on the Protection of the Rights of All Migrant Workers could be because all EU member states are also members of the United Nations. As such, they have consented to the United Nation's human rights treaties. The most notable treaty being the International Covenant of Economic, Social and Cultural Rights (ICESCR), Article 12 , which affirms the right of everyone to enjoy the highest attainable standard 
of physical and mental health irrespective of nationality (United Nations, 1966).

EU member states are also members of the World Health Organization (WHO). Similar to membership in the United Nations, EU member states observe the Constitution of the World Health Organization that addresses the right to health (WHO, 1946). Additionally, a handful of EU member states have adopted the 2008 World Health Assembly's Health of Migrants Resolution (World Health Assembly, 2008).

Other international binding treaties incorporating the right to health include the International Convention of the Rights of the Child (CRC), the International Convention on the Elimination of All Forms of Racial Discrimination (ICERD), the Declaration of Alma-Ata enacted in September 1978, the Ottawa Charter for Health Promotion, the 2007 Brataslava Declaration on Health, Human Rights and Migration, and the Bangkok Charter for Health Promotion on a Globalized World (Cuadra, 2011; Mladovsky et al, 2012; Peiru \& Benedict, 2010). These international treaties are intended to protect the health of all people including documented and undocumented migrants, refugees, and asylum seeks by securing the right to receive emergency care and essential treatment of illness.

\section{Supranational European Union Policies and the Right to Health}

All EU member states recognize the right of all residents, regardless of

citizenship, to obtain "highest attainable standard of physical and mental health" (International Covenant on Economic, Social and Cultural Rights, 1966: 12). The right to health encompasses both the right to health care and the right to the preconditions to 
health (Pace, 2011).

Respect for human rights and well-being is articulated in the EU's Lisbon Treaty that was adopted in 2009 (EU, 2010). The Lisbon Treaty reaffirms the values on which the EU was founded in 1950 (EU, 2010). In the treaty, well-being is closely associated with health as defined in the WHO 1946 Constitution as "a state of complete physical, mental, and social well-being" (WHO, 1946: 2).

A call for cooperation across EU member states concerning health and public health matters can be found in Article 152 of the Treaty to Establish the European Community States,

"Community action, which shall complement national policies, shall be directed towards improving public health, preventing human illness and diseases, and obviating sources of danger to human health. Such action shall cover the fight against the major health scourges by promoting research into their causes, their transmission and their prevention, as well as health information and education" (EC, 1958: 152).

Additionally, Article 168 of the Consolidated Versions of the Treaty on European Union strengthened cooperation and coordination of health services among EU member states (EU, 2010: 168). According to Pace (2011), “Most importantly, the Treaty also gives legally binding force to the Charter of Fundamental Rights of the European Union. The Charter sets out the right of everyone to access preventative health care and to benefit from medical treatment" (p. 63). While this right is firmly positioned "under the 
conditions established by national laws and practices" (EU, 2000: 16), it does heighten the importance of human health protection in EU policy instruments (EU, 2000: 16). EU member states also agreed to respect fundamental human rights as outlined in the European Convention for the Protection of Human Rights and Fundamental Freedoms (Padilla \& Miguel, 2009). Health is specifically identified as a human right in this policy instrument.

Specific to migrant populations accessing health care services in EU receiving nations, migrants who have obtained permission to live and work in an EU member state have, in theory, access to the same health care services as EU nationals (Nagy, 2011). However, access to health care services for undocumented migrants (i.e., illegal entry or stay in a EU member state) are limited to emergency health services (Nagy, 2011). While all of the current $28 \mathrm{EU}$ member states recognize the right of everyone to achieve the "highest attainable standard of physical and mental health", integration of migrant health needs into national health care systems has not been fully realized (Nagy, 2011). The European Commission through the Programme of Community Action in the Field of Health 2008-2013 called for member states to integrated migrant health into health systems in order to facilitate access to health care among migrant populations (Nagy, 2011). Several EU member states resisted the Commission's recommendations on fostering migrant health, specifically in the area of providing health care services to undocumented migrants who have not obtained permission to live or work in the nation (Nagy, 2011). 
Despite the growing direct influence of the EU, health and health system services are primarily a national level matter (Pace, 2011). The reason for this is the subsidiarity principle which, in relation to issues concerning health, ensures that "all decisions are taken as close as possible to citizens and that constant checks are made as to whether action at the community level is justified in light of the possibilities available at the national, regional, or local levels" (Hämäläinen et al, 2004, p. 6). As a result, health system organization and access to health care services are a national matter that is handled in accordance to national priorities in each of the current $28 \mathrm{EU}$ member states.

\section{Section Summary}

While the right to health is firmly established in the aforementioned international and supranational policy instruments, there is significant variation across EU member states and one EEA nation in their adherence and support of them. The literature presents a few viable reasons for this. First, funding for migrant health initiatives declined by EU member states between 2007 and 2010 as a result of the global economic recession (Peiro and Benedict, 2010). Second, the international charters, declarations, and treaties declaring health as a human right generally lack enforcement mechanisms, leaving EU member states and EEA nations to determine the extent to which they will fulfill the obligations and benefits enumerated in the policy instruments. Per Rechel et al. (2013), "Yet even those rights enshrined in international conventions all too often remain confined to paper, because commitment to implementation is weak" (p. 1241). Lastly, within the European Union, the principle of 
subsidiarity positions the EU to act only where action will be more effective at the EU level as opposed to the national level (European Union, 2014). Health and health systems are considered a national level matter.

\section{Why Migrant Health Policies at All?}

The literature suggests that inequities in health between migrants and host nation populations in the EU and EEA are widening (Peiro and Benedict, 2009). While health inequities and access to health care services vary considerable across Europe, numerous studies detail how the general health status of persons involved in migration are worse than that of the native population (Pace, 2007). Rechel et al. (2011) states, "Migrants seem to be more vulnerable to diabetes, certain communicable diseases, maternal and child health problems, occupational health hazards, injuries, and poor mental health" (p. 1235).

Inequities in health between migrants and host nation populations is perpetuated by a complex weave of legal entitlements to health care, immigration status, accessibility of health care services, appropriateness of health care services, language barriers, and unique health profiles of migrants. The impetus for a migrant health policy may be recognition that migrants are a vulnerable population that encounter barriers in accessing health care services and need help. For example, Mladovsky (2011) states, "There is a growing recognition that migrants face specific obstacles in accessing health care services that go beyond legal restrictions, such as lack of information, cultural and linguistic barriers, and socioeconomic deprivation" (p. 185). 
Additionally, scholars hypothesize that barriers migrants encounter when accessing health care services are often the reason for delays in seeking health care when they need it (Mladovsky, 2012). From this perspective, migrants may be perceived as needing extra support navigating the health system in the host nation. Migrant health policies are a tool for mitigating inequities in health by addressing obstacles migrants may encounter in accessing the health system.

Nations that perceive migrants as deserving of support may elect to engage in a migrant health policy process as their duty to support and foster the health of migrant populations. Converseley, migrant populations are sometimes framed as valued members of society for their contributions for productivity and economic growth (Boswell et al., 2014). The motivation to develop a migrant health policy could be keeping the migrant labor workforce healthy. Other literature references the value of migrants for their contribution to society (Peiro and Benedict, 2010). National values that prioritize interculturalism, social cohesion, and social inclusion can also be impetus for a migrant health policy. Lastly, the association between migration and the spread of communicable diseases is well documented in the literature (Mladovsky, 2007; Odone et al., 2014; Wörman and Krämer, 2011). When migrants are perceived as the source of communicable disease transmission and a public health threat, the impetus for a migrant health policy may follow a protectionist philosophy. Through this particular lens, the nation's motivation in focusing on the health of the migrant is derived from a population health perspective aimed at protecting the health of the indigenous 
population from diseases introduced by migrant populations.

\section{Section Summary}

A migrant health policy specifically addresses the health of migrant populations in receiving countries. While the objective of a migrant health policy is to improve the health of migrants, and thereby work toward mitigating inequities in health between migrants and the indigenous population, motivations for supporting this objective vary from nation to nation. A nation's motivation for developing and implementing a migrant health policy is influenced by many factors that may range from protecting the host nation population from communicable diseases introduced by immigrants, to the need for a healthy and productive workforce, to adherence to the belief that health is a human right and mitigating inequities in health between immigrants and the host nation population is the right thing to do.

\section{European Union-based Migrant Health Policies}

In 2007, the Portuguese President of the European Commission, José Manuel Barroso, elevated the issue of migrant health to national policy agendas in EU member states by making migrant health a principle issue of his tenure (Mladovsky, 2007). President Barroso championed "a shared vision on migration and health based on common EU values and principles" (Padilla and Miguel, 2009). To advance this vision, President Barroso hosted an EU member state conference, "Health and Migration in the EU: Better health for all in an inclusive society" that took place on September 27 and 28, 
2007. That year, four EU member states adopted migrant health policies: Germany, Ireland, Portugal, and Spain.

National level migrant health policies, adopted by $10 \mathrm{EU}$ member states and one EEA nation between 1998 and 2007, go beyond that statutory requirements outlined in the aforementioned international and supranational charters and treaties to protect the health of migrants (Mladovsky et al, 2012) and address factors that contribute to health inequity between migrants and European host nation populations. The policies operationalize entitlement to health care services for migrants, define the migrant group who is entitled to access health care services, and, in some cases, adapt health systems to meet the cultural and health needs of migrants (Mladovsky et al., 2012). Finally, national level migrant health policies are a response to the recognition of evidence that health inequities between migrants and the host nation population exist and that migrants are at higher risk for illness.

To date, ten of the current $28 \mathrm{EU}$ member states and one EEA nation have implemented national level migrant health policies, also known as second-level policies which seek to improve the health of migrants through targeted strategies (Mladovsky et al., 2012). First-level policies are international and supranational instruments. Secondlevel policies have been adopted at the national or country level. Each migrant health policy is a reflection of the nation's priorities pertaining to the health of the migrant population. While some countries prioritize equitable access to health services for migrants, other nations prioritize public health through communicable diseases 
transmission control. As such, the objective of addressing the health of migrants is a

first-order strategy to protect the health of the indigenous population. Listed in

alphabetical order, European nations with migrant health policies include: Austria,

England, France, Germany, Ireland, Italy, the Netherlands, Portugal, Spain, Sweden, and

Switzerland (Mladovsky, et al., 2012; Nurse, 2008). A list of European nations with

national migrant health policies is presented in Table 2.2.

Table 2.2- EU and EEA nations that have adopted a national migrant health policy.

\begin{tabular}{|l|l|c|}
\hline Country & The National Social Report & Year Adopted \\
\hline Austria & Race and Equality Scheme 2005-2008 & updated in 2014 \\
\hline England & $\begin{array}{l}\text { Contract d'accueil et d'intégration } \\
\text { (Integration and Welcome Contract) }\end{array}$ & 2006 \\
\hline France & National Integration Plan & 2006 \\
\hline Germany & National Intercultural Health Strategy 2007-2012 & 2007 \\
\hline Ireland & $\begin{array}{l}\text { The National Health Care Plan 1998-2000 } \\
\text { (Amended in the 2001-2003, 2004-2005 \& 2006-2008) }\end{array}$ & 2007 \\
\hline Italy & $\begin{array}{l}\text { The Amsterdam Declaration: Towards Migrant Friendly } \\
\text { Hospitals in an ethno-culturally diverse Europe }\end{array}$ \\
\hline The Netherlands & $\begin{array}{l}\text { Plan for the Integration of Immigrants 2007-2009 } \\
\text { The National Strategic Plan on Citizenship and Integration } \\
\text { 2007-2010 }\end{array}$ & 2007 \\
\hline Portugal & $\begin{array}{l}\text { The National Agreement on Health and the First Years in } \\
\text { Sweden }\end{array}$ & 2007 \\
\hline Spain & The Migration and Public Health Strategy 2002-2006 & 2004 \\
\hline Sweden & Switzerland & 2002 \\
\hline
\end{tabular}

source: Mladovsky et al., 2012; Nurse 2017

\section{Comparative Policy Analyses \& Extant Comparative Migrant Health Policy Analysis Research}

\section{Comparative Policy Analysis}

Comparative policy analysis has gained traction in the last two decades as a

method to study policy cases in different countries that address the same public 
problem or concern in order to generate rich insights on characteristics of public policy (Geva-May, Hoffman, Muhleisen, 2017; Cyr and deLeon, 1975). Comparing similarities and differences across multiple policies has a long-standing position in comparative policy analysis literature. Findings and insights derived from this area of inquiry elicit important information about "how" and "why" policies are different by identifying patterns across policy cases (Gupta, 2012; deLeon and Resnick-Terry, 1998). Moreover, comparative policy analysis has gained traction in the last two decades as a method to study policy cases in different country contexts that address the same public problem or concern in order to generate rich insights on characteristics of public policy (Geva-May, Hoffman, Muhleisen, 2017; Cyr and deLeon, 1975).

Comparative policy analysis is useful in identifying policy patterns and contrasts through inductive comparisons of similar policy issues in different national contexts (deLeon and Resnick-Terry, 1998). Based in this orientation, this comparative case study examines how a group of nations with similar and interconnected political institutional structures and share the distinction of migration receiving nations responded to the issue of the health of migrant populations through a designated policy. This study's analysis of a set of eleven migrant health policies adopted by EU member states and nations in the EEA determined whether and to what extent the policies are similar or different and can be classified in a typology. A significant body of comparative policy analysis literature positions cross-national comparative policy analysis in political, 
economic, social, and cultural policy process characteristics that likely influenced the substance of the policies analyzed (Cyr and deLeon, 1975).

\section{Extant EU-based Migrant Health Comparative Policy Analysis}

The vast majority of scholarly research on migrant health focuses on health

inequities between migrants and host nation populations, barriers migrants encounter accessing care, policy strategies aimed at enhancing migrants' access to care, and mitigating the spread of communicable diseases introduced by migrant populations (Mladovsky et al, 2012; Barniol et al.; 2009; Baker et al., 2009; Bollini and Siem, 1995; Borde, 2008; Curtale et al. 2010; Healy and McKee, 2004; Nagy, 2011; Pezzoli et al., 2009). Despite the fact that the first migrant health policy of the eleven cases in this research was adopted in Italy in 1998, comparative analysis of the eleven migrant health policies adopted by EU member states and one EEA nation is still relatively limited. Scholarly research on the topic of migrant health has mainly focused on health inequities between migrants and host nation populations, barriers migrants encounter accessing care, policy strategies aimed at enhancing migrants' access to care, and mitigating the spread of communicable diseases introduced by migrant populations (Mladovsky et al, 2012).

While relatively small, a group of studies have compared the eleven migrant health policies adopted between 1998 and 2007 by nations in Europe. Generally, studies generally selected a subset of policies to analyze, ranging from one to seven with the mean number of policies analyzed being 3. Only one study included the full group of 
eleven migrant health policies in its analysis. The policy inclusion strategy varied by study. One researcher used health system organization to determine which policies to include in the analysis. Other researchers used similar size of migrant population, history of a host nation as an migrant receiving nation, geographic location of nations with migrant health policies, alignment between the language of the migrant health policy and native language of the researcher to identify policies to include in their analyses (Mladovsky, 2009; Mladovsky et al., 2012; Vázquez, Terraza-Núñez, Vargas, Rodriquez and Lizana, 2011; Cattacin, Chimenti and Cuadra, 2006; Vasquez et al., 2011). For example, a study of migrant health policies adopted in England, Italy, and Spain selected these three nations because they all have a national health system that provides universal coverage that includes documented migrants (Vázquez et al., 2011).

Scholars followed different approaches to identify and explain variation among the European-based migrant health policies in their analysis. For example, in their study of the content of three policies (i.e., England, Italy, and Spain), Vasquez et al. (2011) grouped relevant units of policy text into three categories that include policy objective, "actions aimed at improving access to health services," "actions aimed at improving quality of care," and health services (pg. 74-75). Vázquez et al. (2011) found that the overall objective across the three policies was "to improve the health status of migrants" (pg. 72). The researchers found that, while the three nations in their study all have national health systems that guarantee access to health care for the entire population, a specialized policy modifying health care service delivery is necessary for 
certain populations to ensure that the right to health care is guaranteed (Vasquez et al., 2011). Fostering access to health care services and improving the quality of service delivery are the mechanisms through which these three nations protect the right to health among migrant populations. The researchers found that identification of access and quality as mechanisms to improve health among migrants was a response to difficulties or barriers identified within migrant populations (Vasquez et al., 2011).

Another study by Philipa Mladovsky published in 2009 presented a framework to compare and contrast four migrant health policies adopted in England, Italy, the Netherlands, and Sweden. Mladovsky's framework organized by five categories that include data collection, population groups targeted, health issues targeted, part of the health system targeted (i.e., supply-side versus demand-side), and implementation (Mladovsky, 2009). The objective of Mladovsky's research was to explore how governments responded to policy issues (i.e., data collection, population groups targeted, health issues targeted, part of health system targeted, and policy implementation) within different national contexts through a systematic comparison (Mladovsky, 2009). Organized by policy issue, Mladovsky positioned the conceptual framework as a guidepost for policy makers in that it offered a series of policy options from four different national contexts (Mladovsky, 2009).

This research has the potential to benefit other nations engaged in a migrant health policy development processes just as Mladovsky's framework offered examples of policy issues and options across four different nations. She noted in her 2009 study 
there is a need for more analysis that extends the boundaries of her conceptual framework as well as the need to include more nations with a migrant health policy (Mladovsky, 2009). In that regard, this study is an extension of Mladovsky's research as its scope includes eleven migrant health policies, including the four in her 2009 study (i.e., England, Italy, the Netherlands, and Sweden).

Philipa Mladovsky is a subject matter expert on migrant health policies adopted in European nations. In addition to her 2009 study, she is co-author on several research projects involving this group of migrant health policies. Notable among this work was a comparative analysis of the full group of eleven policies published in 2012 by Mladovsky, Rechel, and McKee. The researchers organized their analysis by topic area that included population group targeted, health issues addressed, and whether the policy targeted patients (demand) or providers (supply) (Mladovsky et al., 2012). The authors compare and contrast the eleven policies and offer general conclusions about the possible strengths and limitations of the 11 policies' approach to migrant health (Mladovsky et al., 2012). They found significant variation across the eleven policies in terms of population group targeted, health services addressed, and whether the policies were oriented toward health system supply or demand. In their study, these three researchers identified some areas of disconnect between health services identified in a policy and the health needs of migrant populations served by that policy (Mladovsky et al., 2012). 
Migrant health policy initiatives or strategies that change health care seeking behavior among migrants target the demand-side of the health system, while strategies that target the workforce or supply of health services fall on the supply-side of migrant health policy health system implications. Health system initiatives that target providers include translated material, interpretation, translation, and intercultural competence and racial equality training for the health system's workforce (International Organization for Migration, 2007; Mladovsky et al., 2012). Fulfilling a request from a migrant to receive care from a practitioner based upon their gender is an example of a demandside health system level intervention (International Organization for Migration, 2007). Other examples of demand-side health system provisions or initiatives include translated material provided by the health system to migrant populations, health information provided to migrants, improving communication between patient and provider, the use of health mediators, and health education programs to improve health literacy among the migrant population (Mladovsky et al., 2012).

All eleven migrant health policies adopted in Europe share a common policy content element in that they include communicable disease control (Mlasovsky et al., 2012). In their study, Rechel et al. (2013) speculated that the majority of policies are a response to the potential spread of communicable diseases introduced by migrants. The reason for uniformity across the policy group is likely a result of the body of literature documenting migration as a pathway for communicable disease transmission and the higher incidence of communicable diseases among migrant populations compared to 
host nation indigenous populations (Borgdorff et al., 2010; Barniol, et al., 2009; Baker et al., 2009; Odone et al., 2014).

Milena Chimienti (2007) explored variation among seven policies (i.e., Austria, France, Germany, the Netherlands, Sweden, Switzerland, and the United Kingdom) through a conceptual typology framework that she developed. Her typology framework classified policies by the financing mechanism of the health system that was either taxbased financing or individualized insurance schemes. Chimienti posited that, while further distinctions could be made within these two primary categorizations, "policy answers regarding migration and health are related to the logic of the health system" (Chimienti, 2007, p. 83). She then linked health system financing structure to societal values embedded within the health system financing structure. Societal values were either difference-sensitive or difference -blind regarding the health of migrant populations. She posited that societal values are based on communitarian or republican approach to diversity and are embedded within a health system's organizational structure (Chimenti, 2007). Communitarian/difference-sensitive social values are sensitive to difference, whereas republican/difference-blind values do not recognize differences or diversity. Chimienti theorized that categorizing migrant health policies first according to health system financing structures and then by the health systems values (i.e., sensitivity or lack of sensitivity toward migrant populations) explained the substantial variation across the group of seven migrant health policies (Chimienti, 2007). Chimienti typology framework of health system structure and values system of 
differences is presented in Figure 2.2.

Figure 2.2- Health structure and value system of differences.

\begin{tabular}{|c|c|c|}
\hline $\begin{array}{l}\text { Health structure } \\
\text { value system of } \\
\text { differences }\end{array}$ & $\begin{array}{l}\text { Universalistic approach* } \\
\text { (Tax based) }\end{array}$ & $\begin{array}{l}\text { Categorical } \\
\text { approach** } \\
\text { (Insurance) }\end{array}$ \\
\hline $\begin{array}{l}\text { Difference sensitive } \\
\text { (Communitarian) }\end{array}$ & UK & $\begin{array}{l}\text { Netherlands } \\
\text { Switzerland }\end{array}$ \\
\hline $\begin{array}{l}\text { Difference "blindness" } \\
\text { (Republican) }\end{array}$ & Sweden & $\begin{array}{l}\text { Austria } \\
\text { France } \\
\text { Germany }\end{array}$ \\
\hline \multicolumn{3}{|c|}{$\begin{array}{l}\text { * Often also called "Beveridgian System" } \\
\text { ** Often also called "Bismarckian System" } \\
\text { Table } 1 \text { permits already an initial analysis concerning migration and health. In fact, the UK is funda- } \\
\text { mentally the best-prepared nation to include }\end{array}$} \\
\hline
\end{tabular}

source: Chimienti, M. (2007). Migration and Health: National Policies Compared.

Difference-sensitive, also known as "difference-based" policies are more likely to incorporate migrant-friendly strategies (Cattacin et al., 2006). Within this construct, the health system adapts to the health and cultural needs of the migrant population. The most common pathway for health system adaption is through parallel health services for migrants. Translation, interpretation, cultural competency training for the health system workforce, and health literacy education for migrants are examples of parallel health services (Chimienti, 2007; Rechel et al., 2013; Mladovsky et al., 2012). Cultural competency is the ability to interact effectively with people of different cultures (Substance Abuse and Mental Health Services Administration, 2017). Cultural 
competency strategies include workforce training in cultural competency, addressing language barriers, improving health literacy among migrants, creating safe and welcoming environments within a health system, engaging patients in care, and disseminating resources for staff (Borde, 2008).

The literature suggests that nations with a long history of immigration tend to fall into the difference-sensitive category. The United Kingdom and Ireland are examples of difference-sensitive migrant health policies (Chimienti, 2007). Chimienti (2007) states, "The United Kingdom is fundamentally the best prepared nation to include migrants in the health system because of its openness and its structural sensitivity to difference" ( $p$. 83). Moreover, "migrant friendly" health system services tend to predominate in nations that have a long history with high rates of immigration, such as the United Kingdom (Fortier, 2010).

At the opposite end of the spectrum, the difference-blind policy considers all citizens in the host nation equal and equally deserving of equal treatment. Within this context, there is no recognition minority groups, including migrants, for the potential of doing so could invite discrimination (Cattacin et al., 2006). Difference-blind health systems do not take into account the difference in health profiles and health needs of the migrant population. France, Germany, and Austria's migrant health policies follow a difference-blind health system orientation (Chimienti, 2007). Specific to France, the motivation behind this perspective is a strategy to foster cultural inclusion (Chimienti, 2007). Migrants adapt to difference-blind health systems in that no special or parallel 
health services for migrants are offered. Health systems that don't offer parallel services operate with the assumption that migrants will assimilate and that parallel or special services are not necessary (Chimenti, 2007). Migrant health policies adopted in Austria, Germany, and France do not call for parallel health services for migrants (Chimenti, 2007).

When synthesized as a group, comparative policy analysis research gives the reader an understanding of a country's national priorities specified in the migrant health policy. For example, the target population in Ireland's migrant health policy, the National Intercultural Health Strategy 2007-2012, targets ethnic minorities, including migrants, undocumented migrants, asylum seekers, and refugees (Health Service Executive, 2008). The policy focuses on anti-discrimination, social inclusion, developing cultural competence resources for health care providers, and measuring outcomes (Mladovsky, 2011). Based on the content of Ireland's policy, one can determine that the policy prioritizes interculturalism, equity of access to the health system, and maps a pathway through the health system responding with sensitivity to migrant populations from diverse cultures and ethnicities (Mladovsky, 2011).

\section{Migrant Health Policy Case Variation}

Reinforcing the notion that the policies reflect the national priorities of the nations in which they were implemented, nearly all of the migrant health policy comparative research in the literature noted substantial variation across the group of eleven migrant health policies. For example, England, Spain, and the Netherlands' 
policies prioritize improving mental health care for migrants, while Italy and Switzerland's policies focus on sexual and reproductive health, and Germany's policy identifies improving the situation of women and girls and fostering gender equity (Mladovsky, 2011; German Federal Government, 2007). The only area where there is alignment across the full group of eleven policies is communicable diseases transmission control (Rechel et al., 2012; Mladovsky et al., 2012). Below is a summary of organizational elements of policy content identified in the existing literature pertaining the some or all of the eleven European-based migrant health policies.

Health issues addressed in a policy:

- Alcohol and addiction services

- Maternal and child health

- Mental health

- Diabetes

- Sexual and reproductive health

- Family planning

- Translation services

- Interpretation services

- Communicable disease targeted through the policy

Targeted migrant populations addressed in a policy:

- Documented migrant

- Undocumented migrant

- Asylum seeker

- Refugee

Health System Policy Implications: 
- Multiculturism versus interculturalism

- Demand-side (patient) versus supply-side (provider) health system initiatives

- Policies with parallel health care services for migrants versus no parallel health services

- Difference-sensitive health systems to the health needs of migrants/communitarian

- Difference-blind health systems to the health needs of migrants/protectionist

- Tax-based financing

- Individualized insurance schemes

\section{Section Summary}

While barriers encountered by migrants in accessing health care services in host nations and inequities in health between migrants and host nation populations have been well-documented in the literature, comparative analysis of the migrant health policies is relatively limited. A few studies have published research that examined similarities and differences across some or all of the eleven policy cases included in this research. Only one other study by Chimenti et al. (2007) classified migrant health policies by type with an a priori process deriving typology structural elements from sources external to the policies included in her study. The two phased analytic structure of this study contributes to existing research on some or all of the policy cases and gives scholars a more complete picture of policy content and variation across the eleven EUbased migrant health policies.

\section{Analytic Frame}

Comparing similarities and differences across multiple policies has a longstanding position in comparative policy analysis literature. Findings and insights derived 
from this area of inquiry elicit important information about "how" and "why" policies are different by identifying patterns across policy cases (Gupta, 2012; deLeon and Resnick-Terry, 1998). Moreover, comparative policy analysis has gained traction in the last two decades as a method to study policy cases in different countries that address the same public problem or concern in order to generate rich insights on characteristics of public policy (Geva-May, Hoffman, Muhleisen, 2017; Cyr and deLeon, 1975).

Comparative policy analysis is useful in identifying policy patterns and contrasts through inductive comparisons of similar policy issues in different national contexts (deLeon and Resnick-Terry, 1998). Based in this orientation, this comparative case study examines how a group of nations with similar and interconnected political institutional structures and share the distinction of migration receiving nations responded to the issue of the health of migrant populations through a designated policy. This study's analysis of a set of eleven migrant health policies adopted by EU member states and one EEA nation determined whether and to what extent the policies were similar or different and could be classified in a typology.

Comparative policy analysis research has a history of drawing on theoretical frameworks from various disciples. According to Gupta (2012),

"Even though this type of research is indispensable, it does not explicitly utilize (or seek to build upon) theories of the policy process when explaining divergent policy outcomes. Rather, these scholars employ broad theoretical frameworks 
borrowed from various strands of literature like risk analysis, cultural theory, economic theory, and path dependence" (pg. 15)

In keeping the tradition of borrowing broad theoretical frameworks to explain variation in the policy cases, this study borrows from Harold Laswell's seminal definition of politics and policy, "Who gets what, when, and how?" as a broad theoretical frame to categorize data at the highest level of organization (i.e., legislative documents associated with a policy case) (Laswell, 1936). This frame was utilized to identify and categorize structural elements of the policy documents, creating a comprehensive organizational scheme for the data analyzed. Applied in this research, Laswell's frame was a transparent frame from which to draw comparisons, derive meaningful comparisons and understanding of variation across the policy cases (Laswell, 1936).

\section{Typologies}

Typologies are an analytic tool applied in social science research to form concepts, refine measurement, explore dimensionality, and organize claims (Given, 2008; Collier et al., 2012). Defined as an "an organized system of types" (Collier et al., 2012, pg. 217), typologies are organized by categorization rather than a hierarchal arrangement. Given (2008) states,

"Typological analysis is a strategy for descriptive qualitative (or quantitative) data analysis whose goal is the development of a set of related but distinct 
categories within a phenomenon that discriminate across the phenomenon" (pg. 2).

In a typological analysis, the researcher first identifies areas of commonality and variation in the data set, then investigates patterns of similarity and difference (Given, 2008).

This analytic tool is often applied in comparative policy analysis research. Social science research where typologies were utilized as an analytic tool in structuring comparisons span numerous topic areas such as political regimes, state and statesociety relations, international relations, public policy, public laws, American politics, organizational theory, political economy, gender politics, social relations, political parties, elections, and political participation (Collier, Laporte, and Seawright, 2008). Theodore Lowi's well-known policy typology categorized policies by type (i.e., regulatory, distributive, redistributive, and constituency) (Lowi, 1964). He argued that the policy processes vary significantly depending on policy type (Lowi, 1964). The typology developed by Lowi is about understanding policy process and politics through classifying policy by type. Lowi's typology has been the impetus for research in political theory, public policy formation, and comparative policy analysis.

Categorizing policies by type furthers understanding of variation and patterns. In this regard, conceptual typologies function as a building block in mapping variation in the outcomes that are being explained (Collier et al., 2012). For example, Dahl (1971) developed a typology that explains how different types of political regimes defined 
different paths in the transition toward polyarchy. In 2001, Mazur presented a typology explaining the interactions between women's participation in social movements and the state's acceptance of their involvement in the policy process. Numerous examples of typologies can be referenced to explain variation, form concepts, and organize explanatory claims.

Existing literature pertaining to the eleven migrant health policy cases includes one typology developed by Chimenti in 2007. As previously noted, her typology is organized by health system organization and societal values (i.e., difference-sensitive and difference-blind). The structural elements of Chimenti's 2007 typology were a priori and derived from sources external to the policy cases. The typological analysis in this study applied an ordered two dimension matrix framework developed by Collier et al. in 2012. The typology was constructed from content analysis of the eleven policy cases that occurred in phase one. A typology derived from the content of the policy cases is currently missing from the existing comparative policy analysis research on these migrant health policy cases. In this regard, this research addressed a gap in the literature and contributed to furthering knowledge on the similarities and differences of the policy group.

\section{Chapter Conclusion}

The aim of this chapter was twofold: 1) to fully acquaint the reader with the topics of migrant health and migrant health policy comparative analysis research; and 2) to position the study within the scope of migrant health and migrant health policy 
comparative analysis research. This chapter presented a synthesis of literature on migrant health outcomes in destination countries, complexities in defining the term "migrant," global migration statistics, perceptions of migrants among receiving countries, the concept of health as a fundamental human right codified in international and supranational policy instruments, national-level migrant health policies adopted by $10 \mathrm{EU}$ member states and one EEA nation, extant EU-based migrant health policy content analyses, EU-based policy process analyses, and three theoretical frameworks that supported the study's methodological approach.

The literature suggests European nations are reliant on migrant labor to fill an important need in their economy resulting from aging populations and falling birthrates. Migrants assume low-wage, entry level jobs shunned by some European nationals. There is also a body of literature that suggests migration and health are intertwined and that health inequities persist between European host nation populations and their respective migrant populations (Mladovsky et al, 2012; Rechel et al., 2011).

While the concept of health as a fundamental human right for everyone is enshrined in numerous international and supranational charters, treaties, and declarations, a lack of enforcement protocols within these policy instruments gives way to substantial variation among nations pertaining to implementation and adherence. The adoption of eleven national level migrant health policies by eleven of the current 28 EU member states and one EEA nation is evidence that the health of migrant 
populations is gaining priority on agendas across Europe. A migrant health policy is a glimpse into a nation's ideology regarding the health of the migrant population. The EUbased nations that adopted a migrant health policy offered an opportunity to explore variation across the policy group on how the problem of migrant health was perceived by policy makers.

The field of migrant health policy comparative research is relatively young, despite the fact that the first migrant health policy was adopted in 1998 (Mladovsky et al., 2012). With the exception of two studies, published EU-based migrant health policies comparative analysis research does not include development and presentation of a framework with which to compare and contrast policy content. The study aims to address a current gap in the field of migrant health policy research. Through content and typological analysis of the full group of the eleven EU-based migrant health policies, the study identified variation across the policies.

The study is timely given that Europe is experiencing a migrant crisis. The literature affirms that global migration, both voluntary and involuntary, has been increasing over the last three decades. Globally, there is an estimated 244 million voluntary migrants and more than 64 million involuntary refugees, and asylum seekers (United Nations, Department of Economic and Social Affairs, 2016). Europe is receiving more migrants than any other place in the world. As such, the health of the migrant population in receiving countries is, and will likely continue, receiving attention on policy agendas. Multiple policy responses targeting migrants are expected. Policy 
responses will likely range from transportation, housing, workforce, education, and especially health. Results of this research create a frame for future migrant health policy process research that explores "why" the policy are similar and different. This study also provided context for future migrant health outcomes research whereas health outcomes can be linked to policy type or the content of a specific policy case included in this research. Furthermore, policy makers and migrant health policy advocates engaged in migrant health policy making processes can reference results of this study and gain insight into the structural policy elements necessary to have a specific "type" of migrant health policy. To achieve these aims, the study seeks to answer the following research question:

What are the similarities and differences in policy content that can be found among the eleven European Union- based migrant health policies and to what extent can they be grouped or classified? 


\section{Chapter III - Methodology and Methods}

\section{Introduction}

Guided by three objectives, this chapter outlines the methodology and methods used to conduct this research in order to fully explore and answer the study's research question and its three aims. The first objective is to provide a comprehensive description of the theoretical and conceptual frameworks in which this research is grounded. This section begins with a restatement of the study's research question and identification of core concepts that underpin the study context and design. The second objective is to present the methodology and methods followed in this research and provide an explanation and justification for the application of specific methods. The chapter's third objective is to discuss the assumptions and limitations of this research stemming from the study's design, analytic process, and the data corpus that was analyzed.

\section{Research Question}

The study was guided by the research question:

What are the similarities and differences in policy content that can be found among the eleven European Union- based migrant health policies and to what extent can they be grouped or classified?

The study had three aims:

1. Categorize policy content of the eleven EU-based policy cases in order to identify broad structural elements and specific similarities and differences among the policy cases within and across these structural elements.

2. Construct a policy typology that seeks to depict policy orientation toward migrant health based on the policy content categorization developed in Aim 1. 
3. Assess the constructed policy typology generally, and in regard to the position of each of the eleven policy cases within it, for the extent and consistency to which it contributes to the understanding of policy structure and orientation regarding migrant health and implications for policy, advocacy, and future research.

\section{Core Concepts}

The core concepts of interest in the study reflect the study's research question

and its three aims. Core concepts pertaining to the study's research question are presented in Table 3.1.

Table 3.1- Definitions of Core Concepts of Research Question.

\begin{tabular}{|c|c|c|}
\hline Concept & Definition & Source \\
\hline Policy & $\begin{array}{l}\text { An intentional action that "sets forth problems } \\
\text { to be solved or goals to be achieved and } \\
\text { identifies the people whose behavior is linked } \\
\text { to the achievement of desired ends" (p. 335). }\end{array}$ & $\begin{array}{l}\text { Schneider, Ingram, } \\
1993 .\end{array}$ \\
\hline $\begin{array}{l}\text { Comparative Policy } \\
\text { Analysis }\end{array}$ & $\begin{array}{l}\text { "Comparing cases across systems in order to } \\
\text { establish general empirical connections } \\
\text { between the characteristics of a system and } \\
\text { the phenomenon under investigation." }\end{array}$ & Gupta, 2012, p. 12 \\
\hline Policy Content & $\begin{array}{l}\text { The text of a policy statement or legislative } \\
\text { language that is inclusive of context, discourse, } \\
\text { and purpose. }\end{array}$ & $\begin{array}{l}\text { Krippendorff, 2004; } \\
\text { Theodoulou and Cahn, } \\
2013\end{array}$ \\
\hline Content Analysis & $\begin{array}{l}\text { Content analysis is an empirically grounded } \\
\text { research method used to determine the } \\
\text { presence of words in qualitative data. The } \\
\text { method enables researchers to quantify and } \\
\text { analyze meanings, patterns, and relationships } \\
\text { among selected words. As a result, the } \\
\text { qualitative method is used to make reliable, } \\
\text { replicable, and valid inferences from texts } \\
\text { pertaining to relationships. }\end{array}$ & $\begin{array}{l}\text { Hsieh and Shannon, } \\
\text { 2005; Krippendorf, } \\
2004\end{array}$ \\
\hline
\end{tabular}




\begin{tabular}{|c|c|c|}
\hline Concept & Definition & Source \\
\hline $\begin{array}{l}\text { Policy Typology } \\
\text { Group }\end{array}$ & $\begin{array}{l}\text { A set of public policies that are classified } \\
\text { together based upon alignment such as topic } \\
\text { matter or structure, (e.g., distributive or } \\
\text { redistributive orientation). }\end{array}$ & Smith, 2002. \\
\hline Typology & $\begin{array}{l}\text { "An organized system of types." Typologies are } \\
\text { applied in research to form concepts, refine } \\
\text { measurement, explore dimensionality, and } \\
\text { organize claims." }\end{array}$ & $\begin{array}{l}\text { Collier et al. (2012) } \\
\text { p. } 217\end{array}$ \\
\hline $\begin{array}{l}\text { Conceptual } \\
\text { Framework }\end{array}$ & $\begin{array}{l}\text { An analytic tool used to identify research } \\
\text { variables, clarify the relationship among } \\
\text { variables, and organize ideas. }\end{array}$ & $\begin{array}{l}\text { McGaghie, Bordage, } \\
\text { and Shea, } 2001\end{array}$ \\
\hline
\end{tabular}

\section{Comparative Policy Analysis Methodology and Analytic Frame}

Comparing similarities and differences across multiple policies has a longstanding position in comparative policy analysis literature. Findings and insights derived from this area of inquiry elicit important information about "how" and "why" policies are different by identifying patterns across policy cases (Gupta, 2012; deLeon and Resnick-Terry, 1998). Moreover, comparative policy analysis has gained traction in the last two decades as a method to study policy cases in different countries that address the same public problem or concern in order to generate rich insights on characteristics of public policy (Geva-May, Hoffman, Muhleisen, 2017; Cyr and deLeon, 1975).

Comparative policy analysis is useful in identifying policy patterns and contrasts through inductive comparisons of similar policy issues in different national contexts (deLeon and Resnick-Terry, 1998). Based in this orientation, this comparative case study 
examines how a group of nations with similar and interconnected political institutional structures and share the distinction of migration receiving nations responded to the issue of the health of migrant populations through a designated policy. This study's analysis of a set of eleven migrant health policies adopted by eleven EU member states and one nation in the EEA nation determined whether and to what extent the policies are similar or different and can be classified in a typology.

A significant body of comparative policy analysis literature positions crossnational comparative policy analysis in political, economic, social, and cultural policy process characteristics that likely influenced the substance of the policies analyzed (Cyr and deLeon, 1975). This research, however, intentionally focused on the content of the policy cases as the sole basis of evaluation and did not investigate the policy processes associated with the policy cases (i.e., "how" the policy cases are similar and different, rather than "why" they are similar and different per policy making processes). Rather, this research sought to classify the policy cases into a typology based on their similarities and differences. This research is an important first step to future research on this set of policies, as well as other migrant health policy-making processes as it offers an important organizing frame, (i.e., migrant health policy typology) from which to explore policy processes and connect health outcomes to a policy's orientation toward migrant health.

The vast majority of scholarly research on migrant health focuses on health inequities between migrants and host nation populations, barriers migrants encounter 
accessing care, policy strategies aimed at enhancing migrants' access to care, and mitigating the spread of communicable diseases introduced by migrant populations (Mladovsky et al, 2012; Barniol et al.; 2009; Baker et al., 2009; Bollini and Siem, 1995; Borde, 2008; Curtale et al. 2010; Healy and McKee, 2004; Nagy, 2011; Pezzoli et al., 2009). Despite the fact that the first EU-based migrant health policy was adopted in Italy in 1998, comparative analysis of these or other migrant health policies is still relatively limited. Generally, extant literature examined a subset of policy cases in this study, ranging from one to seven with the mean number of policies analyzed being three. Only one study included the full group of eleven migrant health policies in its analysis. Existing research in the literature pertaining to the eleven cases analyzed in this study followed one of two paths. Some researchers analyzed the content of the policies and then developed an analytic framework (Vasquez et al. 2011; Mladovsky 2009; Mladovsky et al., 2012). Other research categorized the policies by type (Chimenti, 2011).

Vasquez et al. (2011) analyzed the content of three of the policy cases included in this analysis (i.e., England, Italy, and Spain). Their analysis identified policy objectives, strategies, and types of health issues addressed. Vasquez et al. (2011) identified "improving the health status of migrants" as the main objective across the three policies in their analysis (p. 72). From an overarching objective across the policy set, the researchers then moved to identifying objectives associated with each of the policy cases as a way to highlight similarities and differences across the policies. Vasquez et al. 
(2011) identified and categorized strategies as "types of actions aimed at improving access or improving immigrant population health" (Vasquez. Et al., 2011, pg. 74-75). Research by Vasquez et al. (2011) was relevant to this study because policy objectives and strategies were two potential categories of policy content to consider. Furthermore, the categorization of policy strategies as "types of actions" offered an approach to organizing policy strategies to consider.

Research published by Mladovsky et al. in 2012 compared and contrasted the eleven policy cases in this study. The researchers organized their analysis by population group targeted, health issues addressed, and if the policy targeted patients or providers, (i.e., supply-side referencing providers or demand-side referencing patients) (Mladovsky et al., 2012). The authors offered general conclusions about the possible strengths and limitations of the eleven policies' approach to migrant health (Mladovsky et al, 2012). Another study by Mladovsky examined four of the eleven policy cases in this study. In her 2009 research, Mladovsky presented a framework to compare and contrast four policies adopted in England, Italy, the Netherlands, and Sweden. The framework has five categories that are data collection, population groups targeted, health issues targeted, part of the health system targeted (i.e., supply-side versus demand-side), and implementation (Mladovsky, 2009).

Mladovsky (2009) and Mladovsky et al.'s (2012) research is significant in that the organization of data such as population group targeted, health issues targeted, and part of health system targeted are potential policy content categories to consider. Extant 
literature does not provide a clear direction as to how analytic decisions were made such as how Mladovsky (2009) and Mladovsky et al. (2012) determined the organizing structure of their data in a framework or the process Vasquez et al. (2011) used to assign policy strategies as a "field of action" as organizing elements in her content analysis of three policy cases in this study. For example, policy objectives and policy strategies are content categories identified in Vasquez et al. (2011) research, but are not present in Mladovsky (2009) and Mladovsky et al.'s (2012).

This study differs from Mladovsky (2009) and Mladovsky et al.'s (2012) in the policy documents are the data analyzed and all relevant content was identified and categorized in a transparent process. Mladovsky (2009) collected information on census data, health surveys, living standard surveys, and health care utilization data. Mladovsky et al.'s (2012) surveyed policy makers from 19 European Union countries. Moreover, while Laswell's seminal definition of policy and politics informed how data was organized at the highest structural level, the process of identifying and categorizing relevant units of text was inductive, not a priori. This study contributes to existing migrant health policy comparative analysis extant literature with a comprehensive organizational structure of the content of the eleven policy cases derived solely from policy documents associated with the cases and void of a priori assumptions of content area priorities. This study along with extant literature on some or all of the policy cases give scholars a complete picture of policy content and variation across the eleven migrant health policies. 
A body of existing research organized the policies by type.

External frames such as health system financing, difference-blind versus difference sensitive, or part of the health system targeted (i.e., supply-side versus demand-side) were applies as an organizing structure to group policies by type (Chimenti, 2007; Mladovsky, 2009; Mladovsky et al.'s 2012). These studies are largely descriptive and broadly characterize policy types. For example, Mladovsky et al.'s (2012) developed a framework that among other categories includes types of initiatives proposed and whether they target patients or providers (i.e., supply-side versus demand-side) based on comparative analysis of seven of the policy cases that are included in this research. Milena Chimienti's (2007) comparative analysis research on seven policy cases, that are also a part of this study, assessed health system organizational structure crossed with value systems of differences (i.e., difference-blind versus difference sensitive) to categorize the policies by type. Policy cases were categorized based on the policy case's health system's financing mechanism, single-payer/tax-based financing and individualized insurance schemes, and the societal values of being difference-blind or difference sensitive to the health of migrant populations. Chimenti's research suggests that single-payer/tax-based or insurance-based health systems can be difference-blind or difference-sensitive to the health of migrant populations. What is important, however, is that policy answers pertaining to the health of migrant populations are the result of the "logic" of a health system which is a combination of financing organizational structure and societal values (Chimenti, 2007). 
A central difference between this study and Chimenti's (2007) typology framework is that her typology was constructed from sources external to the migrant health policy (i.e., health system organization and societal values). She did not analyze the policies in order to construct the typology. The typology developed in this study materialized from the coding scheme that was the product of content analysis of the eleven policy cases that occurred in phase one. In this regard, this study is additive to scholarly knowledge on migrant health policy types as the typology matrix framework is derived from policy content. While Chimenti's (2007) typology is an important source of information, her work did not inform the development of the migrant health policy typology framework that is the product of this study. Chimenti's research and this study differ considerably on the source of data and information used to construct the respective typology frameworks. However, Chimenti's research published in 2007 was referenced following the completion of the typological analysis that occurred in phase two in order to determine if this study's results align Chimenti's typology framework and, if so, in what ways.

A comprehensive approach and consistent frame from which to analyze the content of all eleven policies and identify policy types is missing from existing migrant health policy comparative analysis literature. This study intentionally addresses this gap in the literature. It advances existing comparative research pertaining to the policy cases by applying a two-phased transparent, comprehensive, and structured analytic process to explore variation in migrant health policy content and identify policy types. 
This research drew upon Harold Laswell's definition of politics and policy, "Who gets what, when, and how?" as an organizing frame for the data (Laswell, 1936). Laswell's frame was utilized to identify and categorize structural elements of the policy documents, creating a comprehensive organizational scheme for the data analyzed. This distinctive organizing frame was the basis to derive meaningful comparisons and understanding of variation across the policy cases based solely on content analysis of the language of a policy document.

Regardless of the scope and comprehensiveness of existing comparative analysis on the migrant health policies, the identification and organization of content appears to be somewhat arbitrary. The reason for this could be that the field of comparative policy analysis generally lacks macro-level theories and frameworks with which to reference and position research. Given the absence of a macro-level theory to reference, such as the Multiple Stream Framework that is often used in policy process research, the study applied Laswell's frame "Who gets what, when, and how" (1936). Laswell's frame provided an external, transparent, and grounded structure to organize data at the highest level, which led to identifying variation across the policy cases. Moreover, the frame can be referenced and replicated by other scholars seeking to identify patterns and contrasts through inductive comparisons of cases included in this research (deleon and Resnick-Terry, 1998). Application of Laswell as an organizing frame offers the field of comparative policy analysis research a more comprehensive frame to approach the categorization of relevant units of policy content text in that it is a grounded structure 
that is replicable.

As noted above, this analysis does not investigate, nor explain, policy-making processes that influenced the content of the migrant health policies. Why the policies converged or diverged in content is an important topic for future research. Analysis of policy content characteristics associated with the eleven policy cases provides a framework for understanding the outcome of the underlying policy processes. The migrant health policy typology that is one of the results of this research can be combined with future policy process research, such as answering the three key questions posed by Harold Laswell (1968), " 1 . Who are the participants in the policy process?; 2) Whose value demands and expectations are realized?; 3) Which values have priority?" (p. 8) to understand how power and resources were distributed through a migrant health policy and why content of the policy documents converged or diverged.

\section{Section Summary}

This comparative analysis of eleven policy cases that broadly share the same objective, (i.e., address the health of migrant populations) provides insight into how a group of nations responded to the health of migrant populations through a policy instrument. Harold Laswell's question "Who get what, when, and how" was referenced as organizing frame to analyze continuity, variation, and identify patterns across the policy cases (1936). Comparative analysis of similar cases enabled insight into how a group of nations conceptualized, defined, operationalized, and responded to the health 
of migrant populations. Findings from this research have the potential to confirm extant research on the policy cases in regards to the organization and presentation of data or validating results. This study also has the potential to inform future migrant health policy making processes and policy refinement processes among the cases included in this research as well as link migrant health outcomes to policy types that emerged from typological analysis that occurred in phase two.

\section{Research Design and Rationale}

The research design is a cross-case study using qualitative methods. The design enabled the researcher to fully explore the research question and three aims that this study sought to answer (Glaser and Strauss, 1967, 1970). Case study research is useful in answering "how" and "why" questions that pertain to a specific real-life event or phenomenon. According to Yin (1989), "Case study research is when a "how" or "why" question is being asked about a contemporary set of events, over which the investigator has little or no control" (pg. 20). Furthermore, the case study approach is useful when analyzing data from multiple sources that reference a particular situation (Yin, 2009). In-depth investigation of a particular case and cross examination of more than one case are benefits of case study research. Results from the small sample of cases in this research are intended to inform understanding of "how" migrant health policies that share the same broad goal differ in content and scope. According to Gerring (2007), "A case study may be understood as the intensive study of a single case where the purpose of that study is- at least in part- to shed light on a larger class of cases" (p. 20). 
The cross-case analysis design used in this study enabled exploration of policy structure, and policy types based on that structure. The purpose is the generalize findings from a small set of cases in order understand this specific policy area better.

"How" the content of the policy cases do or do not differ was the central focus of this study. Stemming from development of a coding structure, the cross-case analysis design offered this research multiple areas to compare and contrast content across the policy cases (Miles and Huberman, 1994). The analysis investigated the specific similarities and differences among the policy cases and then transitioned to investigating whether and to what extent these policies could be grouped into policy types. This process illuminated "how" content of the policy cases was divergent or convergent and then whether overarching patterns in the specific divergences and convergences exist, which is the purpose and point of a (policy) typology.

\section{Analytic Methods}

\section{Policy Case Selection}

This study defines a policy case as the language of the policy statement, report, or scheme that directly pertains to the health of migrant populations. Implementation of the policy statement, report, or scheme was the impetus for health system level changes in the delivery and health care services to migrant populations designated in the policy. Additionally, the policy statement, report, or scheme prescribed a context in which migrant populations are entitled to health care services. For example, this context could be immigration status of a migrant (e.g., documented or asylum seeker). 
The primary factor that determined inclusion of a policy case was its presence in extant research on migrant health policy content published in peer-reviewed journals. Extant and related research on migrant health policies cover a window of activity that is EU-based in a certain time period (i.e., 1998-2007). These cases reflect shared common experiences as migration receiving nations and have been studied previously. While the cases are all democratic nations, each one has a unique history and democratic structure of its own. As a result differences across the policy cases are likely due to variation in specific factors such as political structures, ideology, perceptions towards migrants, and/or a nation's economy.

The researcher did not look beyond the EU as the eleven migrant health policies formed a "case set" related to a similar time period, geographic region with similar political structures, and shared experienced as migration receiving nations. As a result, eleven policy cases adopted between 1998 and 2007 were included in the study. The eleven policy statements, reports, or schemes ranged in length from two to 118 pages.

Ten policy documents were available in English. One policy document was published in Swedish and required translation into English. Translation of the policy document followed the translation protocol outlined later in this chapter. Table 3.1 presents the policy document title, country where the policy was adopted, year adopted, the length of the policy document in pages, and if the policy was translated from its language of origin into English. The policy cases included in this research are presented in Table 3.2. 
Table 3.2. Policy Document Information.

\begin{tabular}{|c|c|c|c|c|}
\hline Country & Policy/Scheme/Report & $\begin{array}{c}\text { Year } \\
\text { Adopted }\end{array}$ & $\begin{array}{l}\text { Number } \\
\text { of pages }\end{array}$ & $\begin{array}{l}\text { English } \\
\text { Translation } \\
\text { Available }\end{array}$ \\
\hline Austria & $\begin{array}{l}\text { The National Social Report adopted in } \\
2005 \text { and updated in } 2014\end{array}$ & 2005 & 31 & Yes \\
\hline England & Race and Equality Scheme 2005-2008 & 2006 & 118 & Yes \\
\hline France & $\begin{array}{l}\text { Contract d'accueil et d'intégration } \\
\text { (Integration and Welcome Contract) }\end{array}$ & 2006 & 2 & Yes \\
\hline Germany & National Integration Plan & 2007 & 4 & Yes \\
\hline Ireland & $\begin{array}{l}\text { National Intercultural Health Strategy } \\
2007-2012\end{array}$ & 2007 & 116 & Yes \\
\hline Italy & $\begin{array}{l}\text { The National Health Care Plan 2006- } \\
2008\end{array}$ & $\begin{array}{l}\text { 1998; } \\
\text { updated } \\
\text { in } 2006\end{array}$ & 100 & Yes \\
\hline $\begin{array}{l}\text { The } \\
\text { Netherlands }\end{array}$ & $\begin{array}{l}\text { The Amsterdam Declaration: Towards } \\
\text { Migrant Friendly Hospitals in an Ethno- } \\
\text { Culturally Diverse Europe }\end{array}$ & 2000 & 8 & Yes \\
\hline Portugal & $\begin{array}{l}\text { Plan for the Integration of Immigrants } \\
2007-2009\end{array}$ & 2007 & 40 & Yes \\
\hline Spain & $\begin{array}{l}\text { The National Strategic Plan on } \\
\text { Citizenship and Integration 2007-2010 }\end{array}$ & 2007 & 100 & Yes \\
\hline Sweden & $\begin{array}{l}\text { The National Agreement on Health and } \\
\text { the First Years in Sweden }\end{array}$ & 2004 & 27 & No \\
\hline Switzerland & $\begin{array}{l}\text { The Migration and Public Health } \\
\text { Strategy 2002-2006 }\end{array}$ & 2002 & 18 & Yes \\
\hline
\end{tabular}

\section{Type of Analysis}

Two qualitative analytic methods were applied to identify and fully explore similarities and differences across the eleven policy cases. Types of analysis include qualitative content analysis and typological analysis.

\section{Content Analysis}

Content analysis was utilized to identify salient pieces of policy content, systematically code relevant units of policy text, and determine the frequency of specific words or phrases across the policy cases. Application of this method fostered a reliable 
and valid process with which to identify similarities and differences in the content of policy statements, reports, or schemes across the policy cases.

Content analysis is an empirically grounded research technique used to make reliable, replicable and valid inferences from texts pertaining to the contexts of their use (Krippendorf, 2004). A distinguishing feature of the method's reliability and validity is the systematic application of the coding scheme to all data in textual form (Ethridge, 2002). According to Krippendorf (2004), because "the coding technique is expected to be reliable and replicable, the rules governing coding must be explicitly stated and applied equally to all units of analysis" (p. 19).

Lasswell's assertion of what policymaking is,( i.e., "Who gets what, when, and how?"), was used as foundational framework for categorizing policy content (Laswell, 1936). Following the identification of relevant units of text which are basic content elements and the assignment of a descriptive code to each unit of text, codes were organized into "major" categories reflecting "who", what", "when" and "how. The "who" was identified as the target groups or populations designated in the policy. "What" are the policy objectives listed in a policy document. "How" spanned two content areas: strategies for achieving policy objectives (e.g., increase access to services) and specific health services specified in the policy. "When" was not explored as this information was not included in policy documents analyzed in this study.

Utilization of Laswell's definition of politics and policy as an organizing frame enabled broad categorization of policy content grounded in theoretical framework. 
Once this high-level structure was established, sub-structure within the "major" categories of policy content were identified, and patterns, tendencies, and relationships within and across these categories were then explored. This comparative assessment of similarities and differences across the data enabled the discovery of rich, contextual information about the eleven policy cases and provided a structured foundation for the subsequent typology analysis.

Application of content analysis generally, and Laswell's policy content frame specifically, in the systematic analysis of the policy cases was both an intentional and appropriate method. The transparent development and systematic application of the coding scheme to the textual data (i.e., migrant health policy legislative documents which are the unit of analysis) enabled comprehensive and structured comparisons across the policy cases.

\section{Typological Analysis}

Collier et al. (2012) define typologies as "an organized system of types" (p. 217). Organized by categorization rather than a hierarchal arrangement, scholars create typologies in order to form concepts, refine measurement, explore dimensionality, and organize claims (Given, 2008; Collier et al., 2012). Given (2008) states, "Typological analysis is a strategy for descriptive qualitative (or quantitative) data analysis whose goal is the development of a set of related but distinct categories within a phenomenon that discriminate across the phenomenon" (p. 2). In a typological analysis, the researcher first identifies areas of commonality and variation in the data set, then 
investigates patterns of similarity and difference (Given, 2008). The two-part analytic process is reflected in the two phases of the study. Phase one identified areas of commonality and variation through: 1) organization and categorization of the data; and 2) comparative assessment of similarities and differences across the cases. Phase two applied the typology matrix framework developed by Collier et al (2012) as an organizing framework to identify and examine apparent relationships, tendencies, and patterns within and across the data structure that emerged from phase one.

The typology matrix measures an overarching concept, (i.e., migrant health policy orientation toward migrant health in this case). The overarching concept is disaggregated into two dimensions that are access to care and quality of care. Access to care is the row variable and quality of care is the column variable. Access to care is defined as a migrant's opportunity to seek and receive health care. Quality of care is defined as "the degree to which health care services for individuals and populations increase the likelihood of desired health outcomes and are consistent with current professional knowledge (Institute of Medicine, 2018). The row and column variables are cross-tabulated to form a matrix. The two dimensions in the typology developed in this study are ordered in the sense that they have weak, medium, and strong levels, yielding a $3 \times 3$ matrix that is the result of cross-tabulation of the two dimensions.

The categorical variables are concepts located in the matrix's cells. They describe attributes of the overarching concept that is measured by the typology (Collier, Laporte \& Seawright, 2008; Collier et al., 2012). The categorical variable for each cell 
communicates a substantive meaningful label that corresponds with its position in the matrix in relation to the access to care (i.e., the row variable) and quality of care (i.e., column variable). Mutually exclusive, positioning of the categorical variables in the matrix's cells was determined using an equivalent criterion developed by the researcher. An interval scale was applied to the major categories and the row and column variables based on rules determined and outlined by the researcher. Scaling the data created dimensions among the data (i.e., weak, medium, or strong) that was then mapped onto the typology matrix. The researcher's application of an equivalent criteria to construct a multidimensional conceptual typology was based upon equal scope of comparison of the major categories governed by a set of measurement rules.

Application of nominal, partial order, ordinal, and ratio scale types in the formation of a multidimensional typology has been documented in the literature. For example, in their typology on democratization, O'Donnell and Schmitter applied an interval scale to differentiate levels in the row and column variables (O'Donnell and Schmitter, 1986). An interval scale was applied in this study to the row and column variables in order to differentiate levels of access to care and quality of care across the major categories.

While no a priori theory exists pertaining to mapping data onto the typology matrix framework, Collier et al. (2012) posit that identification of a scope of comparison, measurement, and level of aggregation should be best suited to the analytic goals of the study. Constructing the multidimensional typology developed as a result of this research 
began with referencing a template developed by Collier, Laporte \& Seawright in 2008 . First, the overarching concept measured by the typology was identified (i.e., migrant health policy orientation toward migrant health). Next, the overarching concept was disaggregated into two dimensions, the row variable of access to care and the column variable of quality of care. A matrix was then developed by cross-tabulation of the access to care and quality of care dimensions. Categorical variables, which are the cell types in the matrix that are "a kind of" relation to migrant health policy orientation toward migrant health which is the overarching concept measured by the typology, were then identified as a result of mapping in a sequential and layered process the major categories on the typology matrix. As recommended in the literature, development of the typology involved multiple cycles of analysis in order to better organize the typology, tighten its coherence, and examine relationships among different components (Collier et al., 2012).

While a template for constructing a typology is present in the literature, the process of identifying its component parts is absent. What is notable from scholarly articles published by David Collier is that construction of the typology should suit the analytic goals of the study (Collier et al., 2012). To that end, implementation of a set of rules using an interval scale were developed by the researcher to ensure an equivalent criterion were followed in identifying the categorical variables and their location in the matrix. The typology matrix framework developed by Collier et al. (2012) is presented again in Figure 3.1. 
Figure 3.1. Typology Matrix.

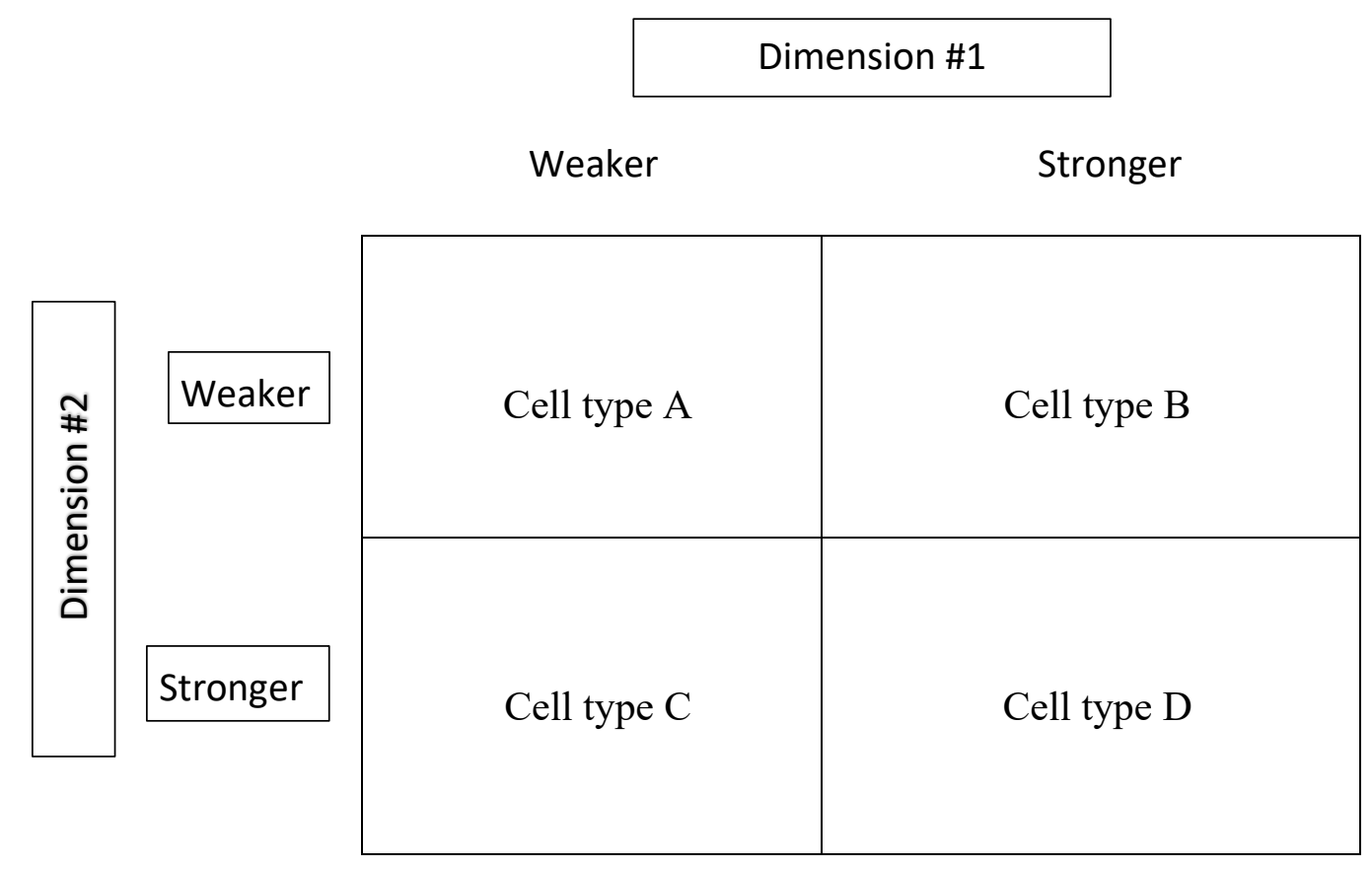

Breadth versus Depth

The organization of the data has a structure that builds from individual descriptive codes into the highest level of groupings. The data's structure (i.e., coding scheme) has layers that include categories and subcategories. The presence or absence of policy content across the highest level of categorization of the data guided the process of mapping the coding scheme onto the typology matrix. The presence or absence of content is a policy's breadth. In other words, breadth is a policy's scope in a particular content area. Depth is a policy's concentration within a specific content area. Interval scales were applied using a policy's breadth and depth at the highest level of 
organization of the coding scheme in order to apply equivalent criteria to mapping data onto the typology matrix. Mapping data onto the matrix is not an exact empirical process. Rather, it is intended to provide context for assessing both the presence of general relationships between the data and to assure that the scaling used to develop the typology matrix does not drive or bias the general conclusions drawn from it.

\section{Section Summary}

The analytic process occurred in two distinct phases. Phase one involved content analysis of the policy documents, reports, or schemes associated with each of the eleven cases. Content analysis was utilized to identify salient pieces of policy content, systematically code relevant units of policy text, and determine the frequency of specific words or phrases across the policy cases. Utilization of Harold Laswell's 1936 seminal definition of politics and policy, (i.e., "Who get what, when, and how?") applied as an organizing frame enabled the broad categorization of policy content grounded in a theoretical framework. Phase two applied the typology matrix framework developed by Collier et al. (2012) as an organizing framework to identify and examine apparent relationships, tendencies, and patterns within and across the data structure that emerged from phase one. The themes/concepts that emerged from typological analysis were inductively derived from the data and are intentionally reflected in the typology framework. As related, yet distinct categories, the themes/concepts are a "type" of orientation toward the health of migrant populations. 


\section{Analytic Process}

The analytic process was iterative, reflective, and took place in two phases. The first phase involved identifying relevant units of text in the data, developing rules governing the application of the coding scheme, assigning descriptive codes to the data, and organizing grouped codes into categories and subcategories. Similarities and differences among policy cases were identified based on the frequency of occurrence of codes, subcategories or categories. Phase two involved identifying patterns and relationships by sequentially mapping major categories onto the typology matrix framework developed by Collier et al. (2012). Themes emerged as a result of this process. In addition to identification of themes, application of the typology matrix informed a theme's defining structure, how themes interrelate with one another, and how they interact with the matrix's two dimensions that are access to care and quality of care. At the highest level of synthesis across categories, themes/concepts emerged and informed the structure of a typology matrix framework (i.e., the categorical variables and their location). While multiple cycles of analysis occurred within both phases, the exact number of cycles was not known nor determined prior to the analytic process commencing.

\section{Phase One: Content Analysis}

The analytic process started with the researcher reading and re-reading the policy documents in order to familiarize herself with the data, gain an understanding of the structure and content of the corpus of data. After gaining an understanding of the policies, the development of the coding scheme took place over multiple cycles of 
coding. The first cycle of analysis commenced with identification of relevant units of text and assignment of codes to words, phrases, sentences, or whole paragraphs of text in the policy document as labels that assigned meaning to the data (Miles and Huberman, 1994). Codes were not predetermined, but followed a reflective, flexible, and iterative process which took place over several coding cycles. Content analysis of the policy cases concluded when no new information emerged from the policy documents and the organization of descriptive codes in categories was complete. Categories are defined as codes classified together based upon alignment of themes, pattern, and apparent relationships.

Initial coding, also referred to as open coding, took place during the first cycle. These initial codes were provisional and tentative. The purpose of the initial coding process was twofold. First, initial coding divided the corpus of data into discrete and manageable parts (Saldana, 2013). Second, initial codes enabled the researcher to remain open to every possibility and all potential directions stemming from her reading and interpretation of the data (Saldana, 2013).

Initial codes assigned to the policy documents during the first cycle were a starting point in the cross-case comparative analysis of the policy cases included in this research. For instance, some initial codes applied to units of text were equal opportunities for migrants, value migrants, accept host nation values, and adapt to the host nation. Cycle two built upon cycle one and involved review of the initial codes assigned to relevant units of text and revisions of some initial codes. For example, the 
code migrant threat to host nation was revised to protect the health of the host nation population in order to situate the code within the context of population health. Review of initial codes assigned in cycle one revealed that the coding schema was descriptive, meaning that an assigned code summarized the researcher's interpretation of a segment of qualitative data (Miles and Huberman, 1994; Saldana, 2013). A descriptive code communicates the meaning of a specific segment of qualitative data which, for the purpose of this research, are segments of the policy documents (Saldana, 2013). All assigned codes in this research are descriptive.

The third cycle of coding involved further refinement of assigned descriptive codes to the data corpus and a review of all coded textual data to ensure that the coding scheme was systematically applied. Thus, the coding scheme was developed and refined through a flexible, reflective, and iterative process. Systematic application of the coding scheme to textual data is a defining characteristic of content analysis (Ethridge, 2002).

Identification of major categories occurred during the fourth cycle. Codes were clustered or grouped into major categories based upon alignment of themes, patterns, and apparent relationships. Referencing Laswell's frame of "Who gets what, when, and how" (1936), codes describing a specific population were grouped into the "who" category. Codes describing health services or health service delivery or actions to achieve the goals of a policy were grouped into the "how" category. Codes describing the intention of a policy and what it wants to achieve were grouped into the "what" 
category. These became major categories of data. Subsequent cycles of coding imposed a structure within each of the major categories.

The fifth cycle involved identifying structure of the descriptive codes within the major categories. Descriptive codes were grouped into categories based on their relationship to each other through content or context (Erlingsson and Brysiewicz, 2017). Depending on the composition of codes in a major category, categories and/or subcategories were developed. Codes were grouped at the "lowest" common level first and then these groupings were assessed for further higher-level categorization. Either one or two levels of categorization were identified in each major category, with the higher level defined as a category and the lower (if present) defined as a sub-category. While primarily inductive, development of the coding scheme did reference existing research on a subset of the eleven policy cases. This research was reviewed during the grouping or clustering of descriptive codes into categories within the major categories. Specifically, research conducted by Vasquez et al. (2011) was referenced. In their comparative policy analysis study of three cases that are also included in this research (i.e., England, Italy, and Spain). Vasquez et al. (2011) organized policy strategies as "types of actions aimed at improving access to care or actions aimed at improving immigrant population health" (pg. 74 \& 75). This study referenced Vasquez et al. (2011) categorization of policy strategies as types of actions that either foster access to care and address the quality of care provided to migrant populations. Access to care and quality of care were identified as relevant category titles in the policy strategy major 
category. Subcategories within the policy strategies major category could be grouped into one of these two categories based upon being an action that fostered access to health care services or an action that sought to augment quality of health care delivery to immigrant populations.

The sixth cycle involved documenting code frequency. The cycle commenced with a general count of the frequency of each code. However, the emphasis transitioned to documenting the number of policies associated with a particular code, category and subcategory. The process of determining policy case association with a particular code, category, and subcategory was the first step in identifying patterns in the data and variation across the policy cases.

The sixth cycle concluded with drawing general conclusions about the organization of the data. By examining the organization of codes in major categories, categories and subcategories, the shape and structure of the data emerged.

Documenting policy case association with codes, subcategories, and categories revealed patterns among the cases that included two content areas of universal convergence and two areas of near universal divergence. The analysis then transitioned to phase two, typological analysis, using the major categories and their structure as the building blocks to identify higher-level concepts and themes (Richards and Morse, 2007).

\section{Phase Two: Typological Analysis}

Phase two involved typological analysis. The purpose of this analytic method following content analysis which occurred in phase one was to determine if there was a 
defining structure across the eleven policy cases that could lead to a theme/conceptbased typology. That structure was identified by mapping the four major categories individually in a sequential process onto a typology matrix developed by Collier et al. (2012). This allowed for examination and identification of interrelationships among the data determined by patterns, tendencies, and relationships within and across major categories that include policy objective, policy strategy, health services, and target population. Apparent relationships between the major categories and the matrix's two dimensions, access to care and quality of care, were also examined. The result was the emergence of four themes/concepts that are a "type" of orientation toward the health of migrant populations.

Typological analysis of the data occurred in cycles. Cycle one involved determining if the organization and structure of the data could fit with Collier et al. (2012) typology matrix's framework. No a priori theory exists pertaining to mapping data onto the typology matrix framework developed by Collier et al. as it is a generalized analytic method. Furthermore, the literature pertaining to typological analysis does not document specific processes regarding the transition from data to identification of categorical variables in a typological matrix. As this study was generally exploratory in a nature, the data structure from phase one was assessed to identify major categories (or combination of major categories) that could be a functional starting point to apply the typology matrix approach. The internal structure of the policy strategy major category was identified as a strong candidate to initially assess relationships among the policies 
using the matrix framework. Its structure included two categories that corresponded with the typology framework's two dimensions (access to care and quality of care) that are frequently referenced in health services research as distinct but interrelated concepts. As noted above, these categories of policy content were previously identified as relevant constructs within a subset of the migrant health policies included in the study by Vasquez et al. (2012). Policies were distinguished within these categories by the extent to which they referenced the subcategories that made up each category within the major category.

The mapping of the policy strategy major category onto the typology matrix framework was a test to determine whether or not an apparent relationship within that major category existed that differentiated the policies through their relationship with the initial matrix's two dimensions. A general example of the mapping of a major into the typology matrix framework as applied in the case of the policy strategy major category is presented in Figure 3.2. Categories A and B are dimensions one and two. The boxes in the matrix are defined as majority or minority of the subcategories associated with each category. 
Figure 3.2. Structure of Policy Strategy Major Category Mapped onto Typology Matrix Framework.

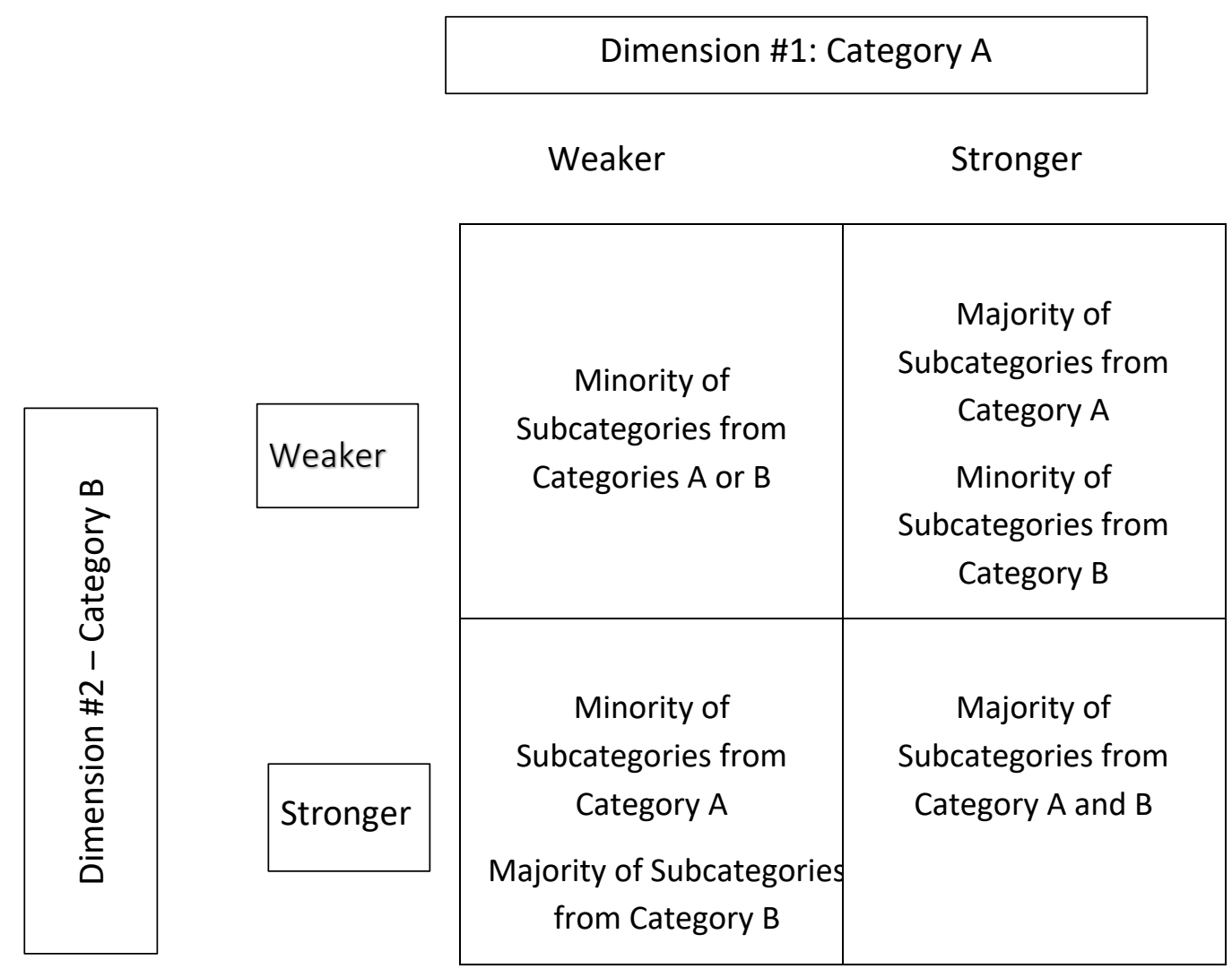

source: Collier et al., (2012)

Mapping the policy strategy major category onto the typology matrix framework revealed that the policy strategy major category showed a structure on the matrix. Policy cases associated with the category that were mapped onto the matrix spread along a diagonal moving from weak to strong with both dimensions. As a result, the typology matrix framework was determined to be an appropriate tool generally. This process also established the policy strategy major category mapping as an initial frame to explore its relationship with the other major categories and their structure. 
Cycles two through four involved layering the three remaining major categories sequentially onto the initial matrix framework in order to examine and identify apparent relationships and patterns of these major categories' interaction with the initial strategy-based matrix and its dimensions. Cycle two involved mapping the policy objective major category onto the matrix. Cycle three entailed mapping the target population major category onto the matrix. The health services major category was mapped onto the matrix in cycle four. The purpose of this analysis was to determine if the other major categories had any defining characteristics, such as an apparent stronger association with one dimension of the initial strategy-based matrix. This process enabled investigation of if and how major categories interrelate.

Cycles five and six involved mapping subcategories in the policy strategy and health services major categories onto the matrix framework. These major categories' structure included subcategories grouped into a category. The process of mapping subcategories grouped by category on the matrix framework illuminated more nuanced identification of apparent patterns, tendencies, and relationships across subcategories within a major category in relation to the initial strategy-based matrix. This level of analysis supported the identification of mutually distinct themes.

Cycle seven involved synthesis of the results from previous cycles of analysis. Identification of themes emerged during this final cycle of typological analysis. Cycle seven also involved exploration of how the themes interrelate and their apparent 
association with the typology matrix framework two dimensions. The cycle concluded with placement of the themes as categorical variables in the typology matrix.

The analytic process intentionally followed a layered process that began with exploring tendencies, patterns, and relationships within a major category, then across major categories, to the identification of higher-level constructs (i.e., themes). This intentionally layered analytic process of mapping each major category's structure onto the typology matrix explored whether or not a typology that categorized the policy cases in an organized system of types, based upon similarities and differences in policy content, existed.

\section{Section Summary}

The analytic process which occurred in two distinct phases was intentionally iterative and reflective. Identification and organization of data into and within major categories was the result of multiple cycles of coding that was the result of content analysis that occurred in phase one. Areas of commonality and variation emerged across the policy cases. Typological analysis followed the content analysis and took place in phase two. Typological analysis involved investigating patterns of commonality and variation across the major categories that emerged in phase one. Collier et al.'s (2012) typology matrix framework was utilized to determine if the policy cases formed an organized system of types based upon identification of patterns and relationships across the data that occurred over multiple cycles of analysis. Themes were identified as a result of this process as well as the structure of the typology matrix that is a result of this research. 


\section{Validity and Reliability of Analysis}

Validity pertains to the integrity and application of the research methods utilized in the study and the accuracy of the findings reflecting the data (Long and Johnson, 2000). In order to foster validity in the research process, the researcher followed standard procedures documented in the literature to reduce bias and increase the validity of the study's results. For example, the researcher solicited input from researchers external to this research throughout the analytic process. Second, the researcher acknowledged personal biases that may have been present during data collection by writing thoughts and reactions to the data in a journal (Sandelowski, 1993). Lastly, the researcher kept a journal to document decision processes and interpretations of the data. The purpose of the journal was to provide the researcher with a written record of analytic decisions and interpretations of data in order to ensure the analysis of the data was consistent, transparent, and replicable (Sandelowski, 1993; Long and Johnson, 2000).

\section{Assumptions}

\section{Exploratory and Confirmatory Orientation}

This study is primarily exploratory with some confirmatory aspects. The cases

analyzed in this research have been studied by several scholars whose work is documented in the literature. Scholars have compared and contrasted the policies based upon content and developed framework to group some or all of the policies included in this research by type. The confirmatory orientation of this research lies in referencing existing literature on the policy cases. Existing literature on a subset of the 
eleven policy cases was referenced in order to determine if results from phase one, content analysis, aligned with other scholars who sought to categorize the policy cases by content. Specifically, the organization and presentation of data in categories and identification of higher-level themes that were the outcome of the coding was compared with previously published comparative analysis research on the eleven EUbased migrant health policies (Saldana, 2013).

The organization of data into and within major categories was compared with research published by two scholars was particularly relevant. Mladovsky et al. (2012) compared content of the eleven policy cases and organized results by content areas that include name of the policy, year adopted, population groups targeted, and main diseases or conditions treated. Vasquez et al. (2011) applied content analysis to three policy cases that include England, Italy, and Spain. Their research categorized relevant units of text (i.e., policy content units) as strategies into a "type of action aimed at improving access to care for the immigrant population or an action aimed at improving immigrant population's health care" (Vasquez. Et al., 2011, pg. 74-75). While referencing existing migrant health policy literature confirmed the study's coding scheme, content analysis which occurred in phase one was generally exploratory in that no a priori presumptions governed the process of identifying relevant units of text, assigning descriptive codes to text, and grouping codes into categories and subcategories based on thematic relationship. 
The study is also intentionally exploratory. The process of determining if there was a defining structure across the eleven policy cases that could lead to a theme-based typology is exploratory. A theme-based typology depicting orientation toward migrant health that was derived solely from the content of the policy cases does not currently exist in the literature.

An important component of this research was determining how findings from the study, specifically the organization of the data corpus and identification of themes, aligned with existing research on the eleven policy cases. Existing research on all or a subset of the eleven policy cases was reviewed particularly during the grouping or clustering of descriptive codes into categories. Specifically, the study applied category titles (i.e., access to care and quality of care) referenced in the scholarly research comparing and contrasting three of the policy cases also included in this study (Vasquez et al., 2010) as organizing elements in one of the major categories.

Another assumption of this research is that the eleven policy cases selected for analysis are good candidates for comparative analysis. While the case selection process was governed by selection criteria reflecting prior identification of these policies for comparative analysis in the literature as discussed earlier in this chapter, there are several potential specific assumptions that underlie the broader assumption of their suitability as policy "set". These include assumptions that the political climate, the economy, competing policy issues, presence of a political scandal, democratic election processes or other national conditions do not limit the suitability of comparative 
analysis of the eleven policy cases. Moreover, it is assumed that variation in time of policy adoption (i.e., 1998 to 2007) is an insignificant variable in the analysis.

The final assumption of this research was that the eleven policy cases are important, relevant sources of data and, through cross-case analysis, have the potential to contribute salient new information to the field of migrant health policy research globally. In other words, this study assumes that these policy cases are relevant in that as a group they represent something bigger than themselves.

\section{Role of the Researcher}

Classification of policy typology groups rests on the assumption that the researcher is using a valid and reliable system to objectively assign policies into categories (Smith, 2002). In order to ensure the researcher maintained objectivity in identifying, coding, and organizing salient units of policy text and the identification of theme from the data corpus the study adopted the following protocol:

1. This research intentionally applied an analytic method that is reliable and replicable as a means of increasing its validity. Content analysis is an empirically grounded method and results should be replicable (Krippendorf, 2004).

2. Sections of the coding scheme that emerged from content analysis of the eleven policy cases are included in chapter four. Transparency in the inductive coding process followed in this research explains how the researcher derived her judgements in identifying relevant units of text from the data corpus, assigned 
descriptive codes, and grouped codes into categories and, if necessary, subcategories. By being transparent in the analysis of the data, the research can show how themes were the outcomes of coding, categorization, and analytic reflection (Saldana, 2013). The researcher kept a journal documenting decisionmaking processes regarding imposing a structure on the data by grouping codes into major categories, categories, and sometimes subcategories.

3. A researcher external to this research was invited to review the coding schema and discuss judgements made by the researcher in grouping codes into categories and deriving themes from the application of a typology matrix. The intentional involvement of an external researcher provides external validity and helped determine whether or not the results from this research are justified, grounded in a valid empirical process, and could be replicated.

4. While previous migrant health policy comparative policy analysis is a valid confirmatory source, the study was also exploratory. Despite the fact that existing scholarly research on all or a subset of the eleven policy cases served as a guideline to code data and to compare results, the study was intentionally open to finding new themes that emerge from the data corpus and analytic process. As such, the researcher did not approach this research with preconceived ideas of themes or in what ways they relate. 


\section{Limitations}

One of the assumptions is that these policies represent a cogent, comprehensive set. However, it is possible that other documents, such as administrative rules and regulations, exist and may have mediating effects on the related migrant health policy legislation. While the researcher did work to identify additional and supplemental policy documents and none were found, a limitation of this study is a possible incompleteness of policy documentation.

Another limitation is that this study is a comparative cross-case analysis of eleven policies that were implemented in a particular place and timeframe, (i.e., Europe between 1998-2007). While the results of this study are internally valid, they may not be externally valid and generalizable to a broader policy context.

Next, the potential for bias was present throughout this research due to the fact that it was conducted by a single researcher. To mitigate the potential for bias, including confirmatory bias, researchers external to this study were invited throughout the analytic process to review and provided input on the researcher's analysis.

This research was also subject to numerous threats to validity that included errors of omission, errors of frequency, and errors in description. These threats were particularly present during the first phase of this research that involved identification of salient units of text and the assignment of descriptive codes. Future research on the same set of policy cases utilizing the same empirical methods might reach difference conclusions by focusing on different units of text or electing to apply a different framework than the typology matrix developed by Collier et al. in 2012. While the 
researcher was transparent in her analytic process and regularly invited other investigators who were external to this study to review her analytic process and results, the judgements, synthesis of data, and presentation of results were her own and reflect her personal perspective. It is feasible that other research on the same set of policy cases could come up with difference conclusions.

A final limitation of the study concerned the translation of the migrant health policy documents from the language of origin into English. As the analysis was conducted in the researcher's native language, English, policy documents not readily available in English required translation. The translation of policy documents could compromise the quality and integrity of the data analyzed in this study, should there be a lack of integrity of the translated document. To mitigate this issue, the translation protocol outlined in the following section of this chapter was followed in order to ensure integrity of transcribed policy documents.

\section{Translation of Documents}

While the researcher's primary language is English, the study was not limited to policy documents readily available in English. Policy documents selected for inclusion in the study and written in a foreign language were translated into English by a certified translator. The authenticity of the translated documented was verified by a second certified translator. Translator service providers were paid for their service and were employed by a translation service company with an EN 15038 certification through the European Committee for Standardization. Implemented in 2006, EN 15038 is a European 
Quality standard for translation services. Included within the standards are a basic set of basic requirements and processes used in the provision of translation services (European Quality Standard for Translation Service Providers, 2006). Across the European Union, EN 15038 is widely accepted as the benchmark for translation services (European Quality Standard for Translation Service Providers. 2006).

The study contracted with translator service providers with EN 15038 certification for one policy document that required translation from Swedish into English.

\section{Human Subjects Research}

Prior to collecting data, the researcher obtained permission for human subjects' research through Portland State University's Institutional Review Board (IRB).

Application to the IRB included a comprehensive list of secondary data sources analyzed in the study. The IRB's determination for the study protocol \# 174457 is appended.

\section{Chapter Conclusion}

Comparative analysis of the policy cases utilizing qualitative content analysis followed by typological analysis facilitated understanding of areas convergence and divergence (i.e., "how" the policy cases are similar and different) across the policy cases. The two-phased analytic process informed construction of typology that characterized the set of policies by orientation toward migrant health. By thoroughly understanding "how" the policy cases differ, this research sets the stage to meaningfully ask policy process questions exploring "why" the policy cases differ. Future research investigating 
"why" the policy cases differ can build on this study with application of the MSA framework and the SCF to explore the policy processes across eleven different political and social contexts that produced these policies.

The iterative, reflective, and flexible orientation of this analysis generally followed an inductive logic. The methodology and methods (i.e., content analysis in phase one and typological analysis in phase two) presented in this chapter outlined a primarily exploratory research process. Some potential confirmatory aspects of the research are associated with phase one as well as reflection on existing literature pertaining to the eleven policy cases. The purpose of this two-phased analytic process was to fully explore the study's research question and determine whether or not a typology that categorized the policy cases in a system of types, based upon their similarities and differences in policy content, existed. Patterns and relationships emerged from the data corpus that built-up from the identification of relevant units of text, to the assignment of descriptive codes, to grouping codes into categories, to layering categories onto a typology matrix in order to identify themes and determine if there was a structure across the eleven cases that could lead to a theme-based typology. Utilization of Laswell's frame of "Who gets what, when, and how" and Collier et al.'a typology matrix provided a research framework to organize data and identify similarities and differences across the policy cases. Results of the analysis are presented in the next chapter (Laswell, 1936; Collier et al., 2012). 


\section{Chapter IV - Presentation and Analysis of Data}

\section{Chapter Organization}

This chapter presents the qualitative research study results following the methods discussed in chapter three. The chapter begins with an explanation of the process that was followed in phase one of the study. Phase one involved the identification of relevant units of text, assignment of initial codes that are descriptive, the refinement of assigned codes, grouping of descriptive codes, identification of major categories, and the organization of descriptive codes within these major categories inclusive of categories and subcategories as necessary, and finally assessment of the similarities and differences across the 11 policy cases within each major category. Phase one analysis is presented in two parts: 1) organization and categorization of the data and 2) comparative assessment of the similarities and differences across and within major categories and across the eleven policy cases. The second half of the chapter describes the analytic process followed in phase two, application of the typological analysis. Phase two applies the typology matrix framework developed by Collier et al. in 2012 that was introduced in chapter three. The matrix is an organizing framework that was used to identify and examine apparent relationships, tendencies, and patterns both within and across major categories identified in phase one. The chapter concludes with the emergence of four themes from the typology analysis that are further explored in chapter five. 


\section{Data Organization and Categorization}

Major Category Identification

Subsequent to the initial refinement of codes derived from the policy text, the first step in data organization and categorization was to identify sets of codes that represent common categories across all policies. Laswell's frame, (i.e., who, what, when and how) was applied in determining these common categories. Four major categories of data emerged from content analysis of the eleven policy cases and include policy objective ("what"), policy strategy ("how"), health services ("how"), and target population ("who"). A policy objective was an articulation of a goal the policy aims to achieve. A policy strategy was an articulation of a specific action designed to achieve the policy goal. The health services category includes areas of health care delivery that were prioritized in a policy as part of achieving the policy goal or strategy. Lastly, target population was an articulation of specific migrant populations identified to receive benefits enumerated in a policy document.

The major categories are important for a number of reasons. First, they emerged across all eleven policy cases, creating a basis for comparison across the policies within the common major categories. Second, the major categories communicate important information about the policy cases. Specifically, what were policy's goals (policy objective)? How were the goals operationalized (policy strategy and health services)? And specific groups identified in the policy (target population)? These questions reference the organizing frame applied in this research that was developed by Harold Laswell in 1936, "Who gets what, when, and how." (Laswell, 1936). 


\section{Data Organization within Major Categories}

Codes within major categories were iteratively organized to the highest level of categorization evident. In some cases, this involved identifying initial (sub-) categories that were subsequently organized into categories. Thus, codes within each major category were organized into categories representing the highest level of aggregation, with two major categories (strategies and health services) organized by categories through sub-categories. Detail of this categorization of codes within the four major categories is described below.

\section{Code, Subcategory and Category Frequencies}

The number of policies associated with a code, subcategory, and category within each major category was counted. The purpose of counting the number of policies associated with a code was to examine the frequency of an idea, as articulated by at least one instance of an assigned descriptive code, across the eleven cases included in this analysis. This count offers insight into the level to which a specific idea was or was not present across the policy cases. The more policy cases associated with a code, subcategory, or category within a major category (defined as 6-11 policy cases), indicates an idea that was generally more present, whereas a lower number (1-5 policy cases ), is indicative of an idea that was present in a minority of the cases. For each major category, the number of policy cases associated with a category and subcategory was also referenced in typological analysis which occurred in phase two. 


\section{Policy Objective Major Category}

The analysis found units of text that articulated an intent or a goal to be achieved as a result of the policy. When analyzing the policy cases, words or phrases that emerged when policies articulated objectives included "equal opportunities for migrant" (National Agreement on Health and the First Years in Sweden, pg. 8), "adapt to host nation" (Integration and Welcome Contract, France, pg. 2), "whole system approach to the provision of health services to a culturally and ethnically diverse population" (National Intercultural Health Strategy 2007-2012, Ireland, pg. 71), "immigrants make important contributions" (National Strategic Plan on Citizenship and Integration 2007-2010, Spain, pg. 2), and "improve migrant health outcomes" (Race and Equality Scheme 2005-2008, England, pg. 25). These units of text are important because they communicate goals, objectives, or policy purpose, and are an indication of outcomes a policy hopes to achieve regarding the health of migrant populations residing in the host nation. Table 4.1 presents a sample of units of text and the assigned descriptive code that communicates the meaning of the text.

Table 4.1. Policy Objective Major Category Units of Text Sample.

\begin{tabular}{|l|l|}
\hline Code & Coded Text Example \\
\hline $\begin{array}{l}\text { Pluralistic and } \\
\text { heterogeneous population }\end{array}$ & $\begin{array}{l}\text { "Institutions should in future plan and be oriented towards the } \\
\text { entire population" (Migration and Public Health Strategy, } \\
\text { Switzerland, pg. 8). }\end{array}$ \\
\hline Inclusive Care of Migrants & $\begin{array}{l}\text { Promote understanding for concerns that are specific to } \\
\text { migration and gender, as a basis for implementing measures } \\
\text { (Migration and Public Health Strategy, Switzerland, pg. 10). }\end{array}$ \\
\hline
\end{tabular}




\begin{tabular}{|c|c|}
\hline Code & Coded Text Example \\
\hline $\begin{array}{l}\text { Service Adaptation; } \\
\text { Equality of Opportunity }\end{array}$ & $\begin{array}{l}\text { "The orienting values are equality of opportunity and adaptation } \\
\text { of the service to the specific needs of the migrant population" } \\
\text { (Race and Equality Scheme 2005-2008, England, pg. 13). }\end{array}$ \\
\hline $\begin{array}{l}\text { Migrant Health Care } \\
\text { Experience }\end{array}$ & $\begin{array}{l}\text { "Improve health care seeking experiences and outcomes among } \\
\text { migrants through integrated health services" (Race and Equality } \\
\text { Scheme 2005-2008, England, pg. 25). }\end{array}$ \\
\hline Health Care Experience & $\begin{array}{l}\text { "Improve migrant health seeking and user experience" (Race and } \\
\text { Equality Scheme 2005-2008, England, pg. 25). }\end{array}$ \\
\hline Health Care Experience & $\begin{array}{l}\text { "Improve migrant mental health seeking and user experience" } \\
\text { (Race and Equality Scheme 2005-2008, England, pg. 13) }\end{array}$ \\
\hline Service Adaptation & $\begin{array}{l}\text { "A whole system approach to the provision of health services to a } \\
\text { culturally and ethnically diverse population demands the } \\
\text { elements of mainstreaming and targeted approaches be } \\
\text { considered for the health service to ensure equality of access, } \\
\text { participation and outcomes" (National Intercultural Health } \\
\text { Strategy 2007-2012, Ireland, pg. 71). }\end{array}$ \\
\hline Value Migrant & $\begin{array}{l}\text { "Immigrants make important contributions in different orders } \\
\text { and produce new opportunities for themselves and their families } \\
\text { as well as for the whole of Spanish society" (National Strategic } \\
\text { Plan on Citizenship and Integration 2007-2010, Spain, pg. 2). }\end{array}$ \\
\hline Social Inclusion & $\begin{array}{l}\text { "Social inclusion implies being in a position to enjoy full } \\
\text { participation in all aspects of society" (National Intercultural } \\
\text { Health Strategy 2007-2012, Ireland, pg. 34). }\end{array}$ \\
\hline Social Inclusion & $\begin{array}{l}\text { "We will work to protect, promote and improve the health and } \\
\text { well-being of the population, based on identified need and with } \\
\text { particular focus on measured to address social exclusion" } \\
\text { (National Intercultural Health Strategy 2007-2012, Ireland, pg. } \\
\text { 33). }\end{array}$ \\
\hline Gender Equality & $\begin{array}{l}\text { "The gender segregation of the labour market often gives } \\
\text { migrant women the lowest status in the hierarchy of } \\
\text { income, qualification and professional status. The } \\
\text { consequences of this situation are increased health risks } \\
\text { and a limited perception of their own interests. } \\
\text { Recognizing the vulnerability of female immigrants" } \\
\text { (Migration and Public Health Strategy, Switzerland, pg. 6). }\end{array}$ \\
\hline
\end{tabular}




\begin{tabular}{|l|l|}
\hline Code & Coded Text Example \\
\hline $\begin{array}{l}\text { Equal Opportunities for } \\
\text { Migrants }\end{array}$ & $\begin{array}{l}\text { "Realization of integration policy goals - equal rights, obligations } \\
\text { and opportunities for all regardless of ethnic and cultural } \\
\text { background - also encompasses areas of health and social policy" } \\
\text { (National Agreement on Health and the First Years in Sweden, } \\
\text { Sweden, pg. 3). }\end{array}$ \\
\hline $\begin{array}{l}\text { Equal Opportunities for } \\
\text { Migrants }\end{array}$ & $\begin{array}{l}\text { "It (the policy) pursues a holistic approach and is committed to } \\
\text { the principle of equal opportunities" (Migration and Public } \\
\text { Health Strategy, Switzerland, pg. 8). }\end{array}$ \\
\hline $\begin{array}{l}\text { Equal Opportunities for } \\
\text { Migrants }\end{array}$ & $\begin{array}{l}\text { "All people must be given access to social conditions necessary } \\
\text { for good health on equal terms for the entire population } \\
\text { (National Agreement on Health and the First Years in Sweden, } \\
\text { pg. 8) }\end{array}$ \\
\hline $\begin{array}{l}\text { Equal Opportunities for } \\
\text { Migrants }\end{array}$ & $\begin{array}{l}\text { "The objective of achieving full equality for all services users in } \\
\text { accessing and using health services lies at the heart of this } \\
\text { strategy" (National Intercultural Health Strategy 2007-2012, } \\
\text { Ireland, pg. 71). }\end{array}$ \\
\hline Accept Host Nation Values & $\begin{array}{l}\text { "Migrants must have the willingness to adapt to society" } \\
\text { (Integration and Welcome Contract, France, pg. 2). }\end{array}$ \\
\hline Welcome Contract, France, pg. 2). \\
\hline Adapt to Host Nation & $\begin{array}{l}\text { "Assimilation of migrants into host nation's national identity" } \\
\text { (Integration and Welcome Contract, France, pg. 2). }\end{array}$ \\
\hline "Action
\end{tabular}

Codes and categories were refined through multiple cycles of coding. Descriptive codes were grouped into one major category that was subdivided into four categories. The organization of codes thematically grouped in the policy objective major category is presented below.

\section{Major Category: Policy Objective}

Category 1: Health System Adapts to Migrants

Code: Pluralistic and heterogeneous population

Code: Inclusive Care of Migrants 
Code: Service Adaptation

Code: Equal Opportunities for Migrants

Code: Migrant Health Care Experience

Code: Service Adaptation

Category 2: Integration/social cohesion

Code: Social cohesion

Code: Value migrant population

Code: Feeling of belonging

Code: Recognize migrant contributions to host nation

Code: Respect for diversity

Code: Holistic approach to integration

Category 3: Health Equity

Code: Equal opportunities for migrants

Code: Equality between host nation and immigrant population

Code: Reduce health inequities

Code: Right to health care

Code: Gender equality

Category 4: Assimiliation

Code: Accept host nation values

Code: Adapt to host nation society

Code: Assimilate to host nation identity

Code: Protect health of the host nation population

Four categories emerged through the process of coding, recoding, and refining the policy objective major category based on determining thematic alignment, patterns, and apparent relationships among sets of codes. Category titles for a group of codes intentionally articulate the topic and patterns of codes clustered within the category. For example, topics that emerged among the codes in the health equity category were equal opportunities for migrants in the host nations and addressing inequities in health 
between migrants and the host nation population. We see a pattern of the topics "equality" and "equal access" emerge from these codes. Based on these topics and patterns, the category for this group of codes was labeled "health equity". Other patterns that emerged among a group of codes included changing delivery of health care services to meet the needs of a racially and ethnically diverse population and the health care seeking and receiving needs of migrant populations, and expectations of a migrant's behavior in the host nation.

Codes organized into categories or subcategories within a major category were grouped based on thematic alignment. For example, codes in the health system adapts to migrants category were grouped together because they are share a common theme of health system level measures that target the health care seeking and receiving needs of migrant populations. The category title, health system adaptation, articulates the meaning of the codes grouped within it. Codes in the integration/social cohesion category were grouped together because they share a common theme of inclusivity of immigrant populations. Again, the title of the integration/social cohesion category reflects the meaning of the grouped codes within it. In the health equity category, codes were grouped together based on shared commonality of equality and health. The assimilation category contains a set of codes that were grouped together because they share the common characteristics of protection of the host population and the assimilation of migrants into the host nation society. As with the other categories in the policy objective major category, the title of the category assimilation articulates the 
meaning of codes that were grouped within it. The coding scheme for the policy objective major category and the number of policies associated with a code is presented in Table 4.2.

Table 4.2. Coding Scheme for Policy Objective Major Category.

\begin{tabular}{|c|c|c|}
\hline Category & Code & $\begin{array}{l}\text { Number of } \\
\text { policies } \\
\text { associated } \\
\text { with code }\end{array}$ \\
\hline \multicolumn{3}{|l|}{$\begin{array}{l}\text { Category 1: } \\
\text { Health System Adapts } \\
\text { to Migrants }\end{array}$} \\
\hline & $\begin{array}{l}\text { Orient health care to pluralistic and } \\
\text { heterogeneous population }\end{array}$ & 5 \\
\hline & Service adaptation & 5 \\
\hline & Intercultural competence of the health system & 4 \\
\hline & Inclusive care of migrants & 3 \\
\hline & Migrant health care experience & 3 \\
\hline & Health Care Experience & 2 \\
\hline \multicolumn{3}{|l|}{$\begin{array}{l}\text { Category 2: } \\
\text { Integration/Social } \\
\text { Cohesion }\end{array}$} \\
\hline & Social inclusion & 9 \\
\hline & Feeling of belonging & 4 \\
\hline & Value migrant population & 4 \\
\hline & Recognize migrant contributions to host nation & 4 \\
\hline & Respect for diversity & 2 \\
\hline & Holistic approach to integration & 1 \\
\hline & Social cohesion & 1 \\
\hline $\begin{array}{l}\text { Category 3: } \\
\text { Health Equity }\end{array}$ & & \\
\hline
\end{tabular}




\begin{tabular}{|l|l|c|}
\hline Category & Code & $\begin{array}{c}\text { Number of } \\
\text { policies } \\
\text { associated } \\
\text { with code }\end{array}$ \\
\hline & Equal opportunities for migrants & 6 \\
\hline & Equality between host nation and immigrant & 4 \\
\hline & Reduce health inequities & 3 \\
\hline & Right to health care & 3 \\
\hline & Quality of life & 1 \\
\hline Category 4: & Gender equality & 1 \\
\hline & & Accept host nation values \\
\hline & Adapt to host nation society & 1 \\
\hline & Assimilate to host nation identity & 1 \\
\hline & Protect health of the host nation population & 1 \\
\hline
\end{tabular}

(*Bold font denotes majority of policy cases associated with code, more than six of the 11 policy cases included in the study.)

Looking across the four categories in the policy objective major category, a few key findings are worth noting. First, the assimilation category is associated with the fewest policy cases. The four codes grouped in this category are associated with one case. This suggests that the expectation of migrants to fully assimilate into the host nation society is not a viewpoint shared among the majority of the cases included in this study. Another take away is the prevalence of the code, social inclusion, in the integration/social cohesion category. Six policy cases are associated with this code, signifying that social inclusion is a common idea with a majority of the cases. Majority is defined as more than $50 \%$ of the eleven policy cases, (i.e., $>$ than 6 cases). Codes in the 
health system adapts to migrants and health equity categories are associated with between one and five policy cases. The orient health care to pluralistic and heterogeneous population and service adaptation codes were associated with four cases, the highest in the health system adapts to migrants category. In the health equity category, the code equality between host nation and immigrant population was associated with four policy cases.

\section{Policy Strategy Major Category}

The analysis identified units of text that communicate specific actions that relate to objectives or goals articulated in the policy cases. In other words, these units of text describe strategies related to how objectives enumerated in the policy cases will be accomplished. Example units of text described above include: "specific needs of a heterogeneous clientele in a pluralistic society" (Migration and Public Health Strategy, Switzerland, pg. 8), "provision of culturally competent and anti-racist services" (National Intercultural Health Strategy 2007-2012, Ireland, pg. 79), "patients with particular spiritual or religious needs" (National Intercultural Health Strategy 2007-2012, Ireland, pg. 79), "migrant-friendly hospital" (The Amsterdam Declaration, the Netherlands, pg. 2), "cultural mediation has a role in promoting interculturalism in the health service" (National Intercultural Health Strategy 2007-2012, Ireland, pg. 20), and “using Cultural Mediators at community level" (National Intercultural Health Strategy 2007-2012, Ireland, pg. 20). Table 4.3 presents a sample of units of text in the policy strategy major category and the assigned descriptive code communicating the meaning of the text. 
Table 4.3. Policy Strategy Category Assigned Codes to Units of Text Sample.

\begin{tabular}{|c|c|}
\hline Code & Coded Text Example \\
\hline $\begin{array}{l}\text { Cultural Competence } \\
\text { Training }\end{array}$ & $\begin{array}{l}\text { "For example, the understanding and professional handling of the } \\
\text { specific needs of a heterogeneous clientele in a pluralistic society should } \\
\text { be encouraged during both basic and advanced training of medical } \\
\text { personnel" (Migration and Public Health Strategy, Switzerland, pg. 8). }\end{array}$ \\
\hline $\begin{array}{l}\text { Cultural Competence } \\
\text { Training }\end{array}$ & $\begin{array}{l}\text { "Training and associated initiatives currently under way around the } \\
\text { provision of culturally competent and anti-racist services will be } \\
\text { mainstreamed across a range of community and hospital settings" } \\
\text { (National Intercultural Health Strategy 2007-2012, Ireland, pg. 79). }\end{array}$ \\
\hline $\begin{array}{l}\text { Health System } \\
\text { Workforce Training }\end{array}$ & $\begin{array}{l}\text { "Regular advanced and continuing education courses in "Migration and } \\
\text { Public Health" should be provided for all healthcare professions, } \\
\text { reinforcing the expertise of specialists in the care and treatment of } \\
\text { migrants" (Migration and Public Health Strategy, Switzerland, pg. 10). }\end{array}$ \\
\hline Migrant Friendly Hospital & $\begin{array}{l}\text { "Developing a migrant-friendly hospital is an investment in more } \\
\text { individualized and more person-oriented services for all patients and } \\
\text { clients as well as their families" (The Amsterdam Declaration, the } \\
\text { Netherlands, pg. 2). }\end{array}$ \\
\hline Interpretation & $\begin{array}{l}\text { "The Confederation's main goal in the educational sector over the next } \\
\text { five years is to establish professional basic and advanced training and } \\
\text { recognized certification for interpreting and intercultural mediation (in } \\
\text { the healthcare and, if possible, the social sector)" (Migration and Public } \\
\text { Health Strategy, Switzerland, pg. 9). }\end{array}$ \\
\hline $\begin{array}{l}\text { Health System } \\
\text { Workforce Diversity }\end{array}$ & $\begin{array}{l}\text { "Promote diversity in the health system workforce" (Race and Equality } \\
\text { Scheme 2005-2008, England, pg. 54). }\end{array}$ \\
\hline $\begin{array}{l}\text { Health Care Delivery } \\
\text { Adaptation }\end{array}$ & $\begin{array}{l}\text { "Adapt clinical practice, preventative services and schemes for } \\
\text { promoting health to migrants" (National Intercultural Health Strategy } \\
\text { 2007-2012, Ireland, pg. 20). }\end{array}$ \\
\hline $\begin{array}{l}\text { Health Care Delivery } \\
\text { Adaptation }\end{array}$ & $\begin{array}{l}\text { "Deliver health care that meets the particular needs of migrants" (Race } \\
\text { and Equality Scheme 2005-2008, England, pg. 34). }\end{array}$ \\
\hline $\begin{array}{l}\text { Culturally Competent } \\
\text { Service Delivery }\end{array}$ & $\begin{array}{l}\text { "Provision for patients with particular spiritual or religious needs to } \\
\text { perform appropriate ablutions, to have access to facilities for worship, } \\
\text { meditation and religious counselling, and to offer a diet in accordance } \\
\text { with religious beliefs is fundamental to culturally competent service } \\
\text { delivery" (National Intercultural Health Strategy 2007-2012, Ireland, pg. } \\
\text { 81). }\end{array}$ \\
\hline $\begin{array}{l}\text { Improve understanding } \\
\text { of migrant health needs }\end{array}$ & $\begin{array}{l}\text { "The key service providers in Switzerland will also be sensitized to the } \\
\text { subject of migration and health" (Migration and Public Health Strategy, } \\
\text { Switzerland, pg. 8). }\end{array}$ \\
\hline
\end{tabular}




\begin{tabular}{|l|l|}
\hline Code & Coded Text Example \\
\hline $\begin{array}{l}\text { Migrant Health } \\
\text { Disparities Awareness }\end{array}$ & $\begin{array}{l}\text { "Increased awareness will be needed of migrant population experiences } \\
\text { and existing health disparities and inequities, including those that are } \\
\text { gender-related, leading to changes in communication, organizational } \\
\text { routines and resource allocations" (The Amsterdam Declaration, the } \\
\text { Netherlands, pg. 2). }\end{array}$ \\
\hline $\begin{array}{l}\text { Research to inform } \\
\text { health services for } \\
\text { migrants }\end{array}$ & $\begin{array}{l}\text { "Research will be undertaken around aspects of prevalence and } \\
\text { management of specific conditions disproportionately affecting minority } \\
\text { ethnic communities" (National Intercultural Health Strategy 2007-2012, } \\
\text { Ireland, pg. 81). }\end{array}$ \\
\hline Cultural Mediators & $\begin{array}{l}\text { "Cultural mediation has a role in promoting interculturalism in the } \\
\text { health service. Pending evaluation of existing projects in this area, } \\
\text { consideration should be given to ways of optimally using Cultural } \\
\text { Mediators at community level" (National Intercultural Health Strategy } \\
\text { 2007-2012, Ireland, pg. 20). }\end{array}$ \\
\hline Remove Access Barriers & $\begin{array}{l}\text { "Information will be adapted, aimed at ensuring all services users be } \\
\text { supported in being informed of their entitlements to a medical card and } \\
\text { utilization of general practitioner services" (National Intercultural Health } \\
\text { Strategy 2007-2012, Ireland, pg. 79). }\end{array}$ \\
\hline Extended Clinic Hours; \\
Traveller; Migrant & $\begin{array}{l}\text { Develop flexible mechanisms to facilitate those social excluded people, } \\
\text { such as Travellers or migrants who have a more mobile lifestyle, in } \\
\text { accessing services. Examples include the use of hand-held health records } \\
\text { and the extension of hours outside the usual core hours to } \\
\text { accommodate the needs of these communities. (National Intercultural } \\
\text { Health Strategy 2007-2012, Ireland, pg. 19). }\end{array}$ \\
\hline
\end{tabular}

Development of the coding scheme for the policy strategy major category built-

up from identification of units of text that articulated a strategy to achieve one or more policy objectives to the assignment and refinement of descriptive codes through multiple cycles of coding. Codes were then grouped into one major category. The process of organizing and refining descriptive codes based on a higher level of commonality across codes in this major category resulted in the emergence of eight subcategories. The subcategories were then organized based on thematic alignment. This process resulted in the emergence of two categories that include access to care and 
quality of care. The access to care category has five subcategories and the quality of care category has three subcategories.

The categorization subcategories into the categories was based on orientation toward either fostering access to health care services or addressing the quality of health care services delivered to migrants. Access to health care services is defined as a migrant's opportunity to seek and receive health care. Broadly, subcategories in the access to health care category seek to increase opportunities among migrant populations to seek and receive care. Quality of health care delivery is defined as the "the degree to which health care services for individuals and populations increase the likelihood of desired health outcomes and are consistent with current professional knowledge" (Institute of Medicine, 2018). Subcategories grouped in the quality of health care category aim to improve health outcomes through health system level changes that meet the cultural and health care seeking and receiving needs of migrant populations, such as such adaptation of health care service delivery.

The category titles, access to care and quality of care, intentionally reference published comparative policy analysis research on three of the migrant health policies analyzed in this research, that include England, Italy, and France. Maria-Luisa Vazquez et al.'s research categorized policy elements as strategies in relation to a field of action that were directed at improving access to services or improving quality of care (Vasquez et al., 2011). This is one area where the development of the coding scheme was more deductive than inductive as research conducted by Vasquez et al. (2011) was 
intentionally referenced. The coding scheme for the policy strategy major category is presented below.

\section{Major Category: Policy Strategy}

Category 1: Access to Care

Subcategory 1: Health Information

Code: Disseminate health information to migrants

Code: Migrant right to health care

Code: Translated information

Code: Health education

Code: Health literacy

Code: Provider information on migrant rights to health care

Code: Access health system translated Information

Code: Health education for migrant children

Code: Health information campaigns

Code: Translated health information on migrant risk of disease

Subcategory 2: Communication

Code: Interpretation

Code: Translation

Subcategory 3: Facilitate Access to Health Care Services

Code: Remove access barriers

Code: Right to health care

Code: Mental health care access

Code: Improve access to health care for migrants through partnerships

Code: Social determinants of health

Code: Migrant self-sufficient for health

Code: Medically vulnerable population

Code: State responsible for health care costs

Code: Migrant enrollment in insurance/national health insurance

Subcategory 4: Care Coordination

Code: Cultural Mediator

Code: Coordinate Health Care Services for Migrants

Subcategory 5: Increase Supply of Services

Code: Migrant Friendly Hospitals

Code: Mobile Health Units 
Code: Extended Clinic Hours

Code: 24-hour Safety-net Clinic

Code: Migrant Choice of Provider

Category 2: Quality of Care

Subcategory 1: Health System Workforce Professional Development

Code: Cultural competence/cultural diversity training

Code: Occupational safety and workplace health

Code: Migrant population health profile training

Code: Health determinants of migrant populations training

Subcategory 2: Migrant Health Needs Assessment

Code: Research and evaluation

Code: Monitor health of migrant populations

Code: Improve understanding of migrant health needs

Code: Migrant health disparities awareness

Subcategory 3: Adaptation of Services

Code: Adapt Clinical Practice

Code: Culturally Competent Service Delivery

Code: Examples of good health care delivery practices for migrants

Code: Health system workforce diversity

Code: Health system meets migrant patients' spiritual and faith needs

Table 4.4 presents the coding scheme for the policy strategy major category.

Table 4.4. Policy Strategy Major Category Coding Scheme.

\begin{tabular}{|l|l|l|c|}
\hline Category & Subcategory & Code & $\begin{array}{c}\text { Number of policies } \\
\text { associated with code }\end{array}$ \\
\hline Access to care & $\begin{array}{l}\text { Subcategory 1: } \\
\text { Health Information }\end{array}$ & & \\
\hline & & $\begin{array}{l}\text { Disseminating Translated Health } \\
\text { Information }\end{array}$ & 6 \\
\hline & & Health Education & 4 \\
\hline & Health Literacy & 3 \\
\hline & & Migrant Right to Health Care & 3 \\
\hline
\end{tabular}




\begin{tabular}{|c|c|c|c|}
\hline Category & Subcategory & Code & $\begin{array}{l}\text { Number of policies } \\
\text { associated with code }\end{array}$ \\
\hline & & Provider Information on Migrant & 1 \\
\hline & & Access Health System Translated & 1 \\
\hline & & Health Education for Migrant & 1 \\
\hline & & Health Information Campaigns & 1 \\
\hline & & Translated Health Information on & 1 \\
\hline \multicolumn{4}{|l|}{ Access to care } \\
\hline & $\begin{array}{l}\text { Subcategory 2: } \\
\text { Communication }\end{array}$ & & \\
\hline & & Interpretation & 7 \\
\hline & & Translation & 6 \\
\hline \multicolumn{4}{|l|}{ Access to care } \\
\hline & $\begin{array}{l}\text { Subcategory 3: } \\
\text { Facilitate Access to Health } \\
\text { Care Services for Migrants }\end{array}$ & & \\
\hline & & Remove Access Barriers & 5 \\
\hline & & Right to health care & 3 \\
\hline & & Mental Health Care Access & 3 \\
\hline & & $\begin{array}{l}\text { Improve Access to Health Care } \\
\text { for Migrants Through } \\
\text { Partnerships }\end{array}$ & 3 \\
\hline & & Social Determinants of Health & 2 \\
\hline & & Migrant Self-sufficient for Health & 2 \\
\hline & & Medically Vulnerable Population & 1 \\
\hline & & State Responsible for Health & 1 \\
\hline & & Migrant Enrollment in & 1 \\
\hline \multicolumn{4}{|l|}{ Access to care } \\
\hline & $\begin{array}{l}\text { Subcategory 4: } \\
\text { Care Coordination }\end{array}$ & & \\
\hline & & Cultural Mediators & 6 \\
\hline
\end{tabular}




\begin{tabular}{|c|c|c|c|}
\hline Category & Subcategory & Code & $\begin{array}{l}\text { Number of policies } \\
\text { associated with code }\end{array}$ \\
\hline \multicolumn{4}{|l|}{ Access to care } \\
\hline & $\begin{array}{l}\text { Subcategory 4: } \\
\text { Care Coordination }\end{array}$ & & \\
\hline & & $\begin{array}{l}\text { Coordinate Health Care Services } \\
\text { for Migrants }\end{array}$ & 2 \\
\hline \multicolumn{4}{|l|}{ Access to care } \\
\hline & $\begin{array}{l}\text { Subcategory 5: } \\
\text { Increase Supply of }\end{array}$ & & \\
\hline & & Migrant Friendly Hospital & 6 \\
\hline & & Mobile Health Units & 1 \\
\hline & & Extended Clinic Hours & 1 \\
\hline & & 24-hour Safety-net Clinic & 1 \\
\hline & & Migrant Choice of Provider & 1 \\
\hline \multirow[t]{5}{*}{ Quality of Care } & $\begin{array}{l}\text { Subcategory 1: } \\
\text { Health System Workforce } \\
\text { Professional Development }\end{array}$ & & \\
\hline & & $\begin{array}{l}\text { Cultural Competence/Cultural } \\
\text { Diversity Training }\end{array}$ & 8 \\
\hline & & Occupational Safety and & 2 \\
\hline & & $\begin{array}{l}\text { Migrant Population Health } \\
\text { Profile Training }\end{array}$ & 1 \\
\hline & & $\begin{array}{l}\text { Health Determinants of Migrant } \\
\text { Populations Training }\end{array}$ & 1 \\
\hline \multirow[t]{4}{*}{ Quality of Care } & $\begin{array}{l}\text { Subcategory 2: } \\
\text { Migrant Health Needs } \\
\text { Assessment }\end{array}$ & & \\
\hline & & Research and Evaluation & 6 \\
\hline & & $\begin{array}{l}\text { Monitor Health of Migrant } \\
\text { Populations }\end{array}$ & 1 \\
\hline & & $\begin{array}{l}\text { Improve Understanding of } \\
\text { Migrant Health Needs }\end{array}$ & 1 \\
\hline
\end{tabular}




\begin{tabular}{|l|l|l|c|}
\hline Category & Subcategory & Code & $\begin{array}{c}\text { Number of policies } \\
\text { associated with code }\end{array}$ \\
\hline & Migrant Health Disparities & 1 \\
\hline Quality of Care & Subcategory 3: \\
& Adaptation of Services & Adapt Clinical Practice & \\
\hline & & Culturally Competent Service & \\
\hline & Examples of Good Health Care \\
& Delivery Practices for Migrants & \\
\hline & $\begin{array}{l}\text { Health System Workforce } \\
\text { Diversity }\end{array}$ \\
\hline
\end{tabular}

(*Bold font denotes majority of policy cases associated with code, more than six of the 11 policy cases included in the study.)

\section{Major Category: Health Services}

Several descriptive codes were assigned to units of text that articulated specific

forms of health care delivery services for migrant populations residing in host nations that are among the eleven cases included in this study. When analyzing the policy cases, a sample of the words or phrases that emerged when policies articulated different forms of health service delivery include "mental health care should be provided in a culturally sensitive manner" (National Intercultural Health Strategy 2007-2012, Ireland, pg. 18), "care and support needs of older persons" (National Intercultural Health Strategy 2007-2012, Ireland, pg. 18), “information and training for procreative choices" (National Health Care Plan 2006-2008, Italy, pg. 79), and "strengthen prevention activities for adolescents and young foreign adults" (National Health Care Plan 2006- 
2008 , Italy, pg. 78). As with the other major categories of data previously discussed in

this chapter, each unit of text was assigned a code that reflected its meaning. Table 4.5

presents a sample of assigned descriptive codes to units of text in the health services

major category.

Table 4.5. Health Services Major Category Assigned Code to Units of Text Sample.

\begin{tabular}{|c|c|}
\hline Code & Coded Text Example \\
\hline Mental Health Care & $\begin{array}{l}\text { "Mental health care should be provided in a culturally sensitive manner" } \\
\text { (National Intercultural Health Strategy 2007-2012, Ireland, pg. 18). }\end{array}$ \\
\hline $\begin{array}{l}\text { Mental Health Care; } \\
\text { Asylum Seeker }\end{array}$ & $\begin{array}{l}\text { "Therapy for traumatized asylum seekers" (Migration and Public Health } \\
\text { Strategy, Switzerland, pg. 8). }\end{array}$ \\
\hline $\begin{array}{l}\text { Primary Care; Pediatric } \\
\text { Care; Migrant Children }\end{array}$ & $\begin{array}{l}\text { "Mechanisms will be instituted around collaboration with relevant } \\
\text { personnel within the children and family sector towards supporting the care } \\
\text { needs of children and families of diverse ethnicities and cultures" (National } \\
\text { Intercultural Health Strategy 2007-2012, Ireland, pg. 18). }\end{array}$ \\
\hline Primary Care & $\begin{array}{l}\text { "The rollout of the Primary Care Strategy will be supported in line with the } \\
\text { principles of needs assessments" (National Intercultural Health Strategy } \\
\text { 2007-2012, Ireland, pg. 19). }\end{array}$ \\
\hline Geriatric Care & $\begin{array}{l}\text { "Research and associated action will be undertaken around the care and } \\
\text { support needs of older persons, with a special focus on identifying existing } \\
\text { issues and planning for future needs" (National Intercultural Health Strategy } \\
\text { 2007-2012, Ireland, pg. 18). }\end{array}$ \\
\hline $\begin{array}{l}\text { Required Medical } \\
\text { Screening }\end{array}$ & $\begin{array}{l}\text { "The State undertakes the following provision: a medical examination } \\
\text { allowing the delivery of temporary residence documents" (Integration and } \\
\text { Welcome Contract, France, pg. 2). }\end{array}$ \\
\hline $\begin{array}{l}\text { Health Promotion and } \\
\text { Disease Prevention }\end{array}$ & $\begin{array}{l}\text { "Strengthen prevention activities for adolescents and young foreign adults } \\
\text { through a trans-cultural and multidisciplinary approach" (National Health } \\
\text { Care Plan 2006-2008, Italy, pg. 78). }\end{array}$ \\
\hline $\begin{array}{l}\text { Family Planning (not } \\
\text { abortion) }\end{array}$ & $\begin{array}{l}\text { "As regards the maternal and child sector, the high number of abortions } \\
\text { must be countered by voluntary pregnancy among immigrant women. } \\
\text { Necessary interventions, aimed at promoting responsible parenting, include } \\
\text { information and training for procreative choices" (National Health Care Plan } \\
\text { 2006-2008, Italy, pg. 79). }\end{array}$ \\
\hline
\end{tabular}




\begin{tabular}{|l|l|}
\hline Code & Coded Text Example \\
\hline $\begin{array}{l}\text { Communicable Disease } \\
\text { Treatment }\end{array}$ & $\begin{array}{l}\text { "Inequality in access to vaccination prevention that raises the need for an } \\
\text { appropriate supply of vaccinations, both mandatory and recommended, to } \\
\text { all population groups provided for by the national vaccine plan, regardless } \\
\text { of socioeconomic status, with the specific problem of vaccination coverage, } \\
\text { including for mandatory vaccinations in immigrant populations from non-EU } \\
\text { countries and Roma populations" (National Health Care Plan 2006-2008, } \\
\text { Italy, pg. 81). }\end{array}$ \\
\hline Maternal Health & $\begin{array}{l}\text { "Actions around addressing the maternal care and support needs of women } \\
\text { from diverse ethnicities and cultures will be addressed through the } \\
\text { Maternity Action Plan" (National Intercultural Health Strategy 2007-2012, } \\
\text { Ireland, pg. 17). }\end{array}$ \\
\hline $\begin{array}{l}\text { Pediatric Care; Primary } \\
\text { Care (Family Medicine) }\end{array}$ & $\begin{array}{l}\text { "Mechanisms will be institutes around collaboration with relevant personnel } \\
\text { within the children and family sector towards supporting care needs of } \\
\text { children and families of diverse ethnicities and cultures" (National } \\
\text { Intercultural Health Strategy 2007-2012, Ireland, pg. 18). }\end{array}$ \\
\hline $\begin{array}{l}\text { Sexual and Reproductive } \\
\text { Health }\end{array}$ & $\begin{array}{l}\text { "Aspects of sexual health delivery for service users from minority ethnic } \\
\text { groups will be addressed within the context of the development and } \\
\text { implementation of the National Sexual Health Strategy" (National } \\
\text { Intercultural Health Strategy 2007-2012, Ireland, pg. 19). }\end{array}$ \\
\hline Primary Care & $\begin{array}{l}\text { "The Health Service Executive will address relevant aspects of addiction } \\
\text { within the remit of the current National Drug Strategy" (National } \\
\text { Intercultural Health Strategy 2007-2012, Ireland, pg. 19). }\end{array}$ \\
\hline $\begin{array}{l}\text { "The rollout of the Primary Care Strategy will be supported in line with the } \\
\text { principles of needs assessments. Participation of minority ethnic } \\
\text { communities in this process will be actively promoted" (National } \\
\text { Intercultural Health Strategy 2007-2012, Ireland, pg. 19). }\end{array}$ \\
\hline and
\end{tabular}

In the health services major category, the coding scheme is a highly structured order of codes. Codes grouped in the health services major category were reviewed and categorized into subcategories based on relationships or patterns on the type of health service delivery. A total of ten subcategories emerged from the process of grouping 
codes by thematic association. The classification of codes within a subcategory was determined based on relationships and patterns of similarly coded data. Subcategory titles intentionally articulate meanings of the group of codes categorized within. For example, meanings among the group of codes in the communicable disease control subcategory were equal access to vaccinations, treatment of immigrants with communicable diseases, and preventing the spread of communicable disease introduced by immigrants who originate from areas of the world where communicable disease are highly endemic.

Subcategories were then reviewed and grouped into categories based on stages of disease detection and development. This process resulted in the emergence of three categories that include primary, secondary, and tertiary prevention. Primary prevention is concerned with avoiding development of a disease, secondary prevention are health services that are focused on early disease detection and mitigating or preventing the progression of a disease, while tertiary prevention aims to reduce the impact of an already established disease through the reduction of disease-related complications (Shi and Singh, 2008). Refined through multiple cycles of coding, the coding scheme that resulted from this inductive process is presented below.

\section{Major Category: Health Services}

Category 1: Primary Prevention

Subcategory 1: Communicable Disease Control

Code: Communicable Disease Screening and Treatment

Code: Communicable Disease Focus: Tuberculosis

Code: Communicable Disease Focus: HIV/AIDS 
Subcategory 2: Health Promotion

Code: Health Promotion

Code: Disease Prevention

Subcategory 3: Communicable Disease Prevention

Code: HIV Prevention

Code: Medical Screening Required

Code: General Medical Exam

Code: Communicable Disease Prevention

Category 2: Secondary Prevention

Subcategory 1: Mental health

Code: Mental health care

Subcategory 2: Sexual and reproductive health

Code: Sexual and reproductive health

Code: Obstetric care

Code: Family planning (not abortion)

Code: Pregnancy care

Subcategory 3: Health Services for Target Populations

Code: Pediatric care

Code: Women's health/Gynecology

Code: Geriatric care

Subcategory 4: General Health Care

Code: Primary care (Family Medicine)

Code: Dental care

Subcategory 5: Substance Abuse

Code: Drug and alcohol addiction treatment

Code: Drug and alcohol addiction screening

Subcategory 6: Emergency Care

Code: Emergency care only

Category 3: Tertiary Prevention

Subcategory 1: Disease Treatment

Code: Long-term care and treatment of disease

Code: Chronic disease management

Code: Infectious disease treatment 
The coding scheme for the health services major category with the frequency of each code across the eleven policy cases included in this study and the number of policies associated with a particular code is shown in table 4.6.

Table 4.6. Coding Scheme for the Health Service Major Category with Code Count.

\begin{tabular}{|c|c|c|c|}
\hline Category & Subcategory & Code & $\begin{array}{l}\text { Number of } \\
\text { policies } \\
\text { associated with } \\
\text { code }\end{array}$ \\
\hline \multicolumn{4}{|l|}{$\begin{array}{l}\text { Primary } \\
\text { Prevention }\end{array}$} \\
\hline & $\begin{array}{l}\text { Subcategory \#1: } \\
\text { Communicable Disease } \\
\text { Control }\end{array}$ & & \\
\hline & & $\begin{array}{l}\text { Communicable Disease Screening and } \\
\text { Treatment }\end{array}$ & 11 \\
\hline & & Communicable Disease Focus: & 1 \\
\hline & & Communicable Disease Focus: & 1 \\
\hline & $\begin{array}{l}\text { Subcategory \#2: } \\
\text { Health Promotion }\end{array}$ & & \\
\hline & & Health Promotion and Disease & 5 \\
\hline & $\begin{array}{l}\text { Subcategory \#3: } \\
\text { Communicable Disease } \\
\text { Prevention }\end{array}$ & & \\
\hline & & HIV Prevention & 5 \\
\hline & & Medical Screening Required & 2 \\
\hline & & General Medical Exam & 1 \\
\hline & & Communicable Disease Prevention & 1 \\
\hline \multicolumn{4}{|l|}{$\begin{array}{l}\text { Secondary } \\
\text { Prevention }\end{array}$} \\
\hline & $\begin{array}{l}\text { Subcategory \#1: } \\
\text { Mental Health }\end{array}$ & & \\
\hline & & Mental Health Care & 8 \\
\hline
\end{tabular}




\begin{tabular}{|c|c|c|c|}
\hline Category & Subcategory & Code & $\begin{array}{l}\text { Number of } \\
\text { policies } \\
\text { associated with } \\
\text { code }\end{array}$ \\
\hline \multicolumn{4}{|l|}{$\begin{array}{l}\text { Secondary } \\
\text { Prevention }\end{array}$} \\
\hline & $\begin{array}{l}\text { Subcategory \#2: } \\
\text { Sexual and } \\
\text { Reproductive Health }\end{array}$ & & \\
\hline & & Sexual and Reproductive Health & 4 \\
\hline & & Obstetric Care & 1 \\
\hline & & Family Planning (not abortion) & 1 \\
\hline & & Pregnancy Care & 1 \\
\hline \multicolumn{4}{|l|}{$\begin{array}{l}\text { Secondary } \\
\text { Prevention }\end{array}$} \\
\hline & $\begin{array}{l}\text { Subcategory \#3: } \\
\text { Health Services for } \\
\text { Target Populations }\end{array}$ & & \\
\hline & & Pediatric Care & 4 \\
\hline & & Women's Health/Gynecology & 5 \\
\hline & & Geriatric Care & 2 \\
\hline \multicolumn{4}{|l|}{$\begin{array}{l}\text { Secondary } \\
\text { Prevention }\end{array}$} \\
\hline & $\begin{array}{l}\text { Subcategory \#4: } \\
\text { General Health Care }\end{array}$ & & \\
\hline & & Primary Care & 3 \\
\hline & & Dental Care & 1 \\
\hline \multirow[t]{4}{*}{$\begin{array}{l}\text { Secondary } \\
\text { Prevention }\end{array}$} & & & 3 \\
\hline & $\begin{array}{l}\text { Subcategory \#5: } \\
\text { Substance Abuse }\end{array}$ & & \\
\hline & & Drug and Alcohol Addiction Treatment & 3 \\
\hline & & Drug and Alcohol Addiction Screening & 2 \\
\hline
\end{tabular}




\begin{tabular}{|c|c|c|c|}
\hline Category & Subcategory & Code & $\begin{array}{l}\text { Number of } \\
\text { policies } \\
\text { associated with } \\
\text { code }\end{array}$ \\
\hline \multicolumn{4}{|l|}{$\begin{array}{l}\text { Secondary } \\
\text { Prevention }\end{array}$} \\
\hline & $\begin{array}{l}\text { Subcategory \#6: } \\
\text { Emergency Care }\end{array}$ & & \\
\hline & & Emergency Care Only & 1 \\
\hline \multicolumn{4}{|l|}{$\begin{array}{l}\text { Tertiary } \\
\text { Prevention }\end{array}$} \\
\hline & $\begin{array}{l}\text { Subcategory \#1: } \\
\text { Disease Treatment }\end{array}$ & & \\
\hline & & Long-term care and treatment of & 2 \\
\hline & & Chronic disease management & 1 \\
\hline & & Infectious disease treatment & 1 \\
\hline
\end{tabular}

( ${ }^{*}$ Bold font denotes majority of policy cases associated with code, more than six of the 11 policy cases included in the study.)

Target Population Major Category

One or more target populations were identified in all eleven policy cases. Target populations were designated to receive benefits enumerated in the policy document. Words or phrases that emerged when policies articulated a target population included people of migrant origin, ethnic minorities, migrants, black and ethnic minorities, migrant women, asylum seekers, the stay of foreigners, "Roma" (National Health Care Plan 2006-2008, Italy, pg. 78), "Irish Traveller" (National Intercultural Health Strategy 2007-2012, Ireland, pg. 46), "program refugee”, "asylum seeker" (The Migration and Public Health Strategy 2002-2006, Switzerland, pg. 6), “Residents in a regular situation” (The National Strategic Plan on Citizenship and Integration 2007-2010, Spain, pg. 8), and 
"people of Black and minority ethnic communities" (Race and Equality Scheme 2005-

2008, England, pg. 42). Table 4.7 presents a sample of units of text that articulate a

specific population and the assigned descriptive code.

Table 4.7. Target Population Units of Text and Assigned Code Example.

\begin{tabular}{|c|c|}
\hline Code & Coded Text Example \\
\hline Travellers & $\begin{array}{l}\text { "Irish Travellers are a small indigenous minority group with a unique shared } \\
\text { history, culture, customs, and language. Their distinctive lifestyle and } \\
\text { culture, based on a nomadic tradition, makes them an identifiable group, } \\
\text { both to themselves and to others" (National Intercultural Health Strategy } \\
\text { 2007-2012, Ireland, pg. 46). }\end{array}$ \\
\hline Roma & $\begin{array}{l}\text { "A population presenting specific problems is represented by the Roma. A } \\
\text { high number of Roma live in hygienic-housing conditions that have been } \\
\text { universally recognized as being among the main health determinants and } \\
\text { their improvement is a priority" (National Health Care Plan 2006-2008, Italy, } \\
\text { pg. 78). }\end{array}$ \\
\hline Black and Ethnic Minority & $\begin{array}{l}\text { "People of Black and minority ethnic communities in this country are among } \\
\text { the most disadvantaged groups in our society" (Race and Equality Scheme } \\
2005-2008 \text {, England, pg. 42). }\end{array}$ \\
\hline $\begin{array}{l}\text { Asylum Seekers; } \\
\text { Undocumented Migrant }\end{array}$ & $\begin{array}{l}\text { "The uncertainty of residence status is a key factor in the increased health } \\
\text { risk among asylum seekers and sometimes also of people with a limited } \\
\text { right of residence" (The Migration and Public Health Strategy 2002-2006, } \\
\text { Switzerland, pg. 6). }\end{array}$ \\
\hline Refugee & $\begin{array}{l}\text { "A refugee is a person who, owing to a well-founded fear of being } \\
\text { persecuted for reasons of race, religion, nationality, membership of a social } \\
\text { group or political opinion, is outside the country of his nationality and is } \\
\text { unable or, owing to such fear unwilling to avail himself of the protection of } \\
\text { that society" (National Intercultural Health Strategy 2007-2012, Ireland, pg. } \\
\text { 38). }\end{array}$ \\
\hline $\begin{array}{l}\text { Child of Migrant Born in } \\
\text { Host County }\end{array}$ & $\begin{array}{l}\text { "New procedure were announced regarding the consideration of claims for } \\
\text { permission to remain in the State from the non-national parents of Irish- } \\
\text { born children" (National Intercultural Health Strategy 2007-2012, Ireland, } \\
\text { pg. 50). }\end{array}$ \\
\hline
\end{tabular}




\begin{tabular}{|l|l|}
\hline Code & Coded Text Example \\
\hline Undocumented Migrant & $\begin{array}{l}\text { People who have entered the country legally but are working without a legal } \\
\text { right to do so and persons who have entered the country illegally. (National } \\
\text { Intercultural Health Strategy 2007-2012, Ireland, pg. 39). }\end{array}$ \\
\hline New Migrant & $\begin{array}{l}\text { The first time in Sweden refers to the individual's establishment period, i.e. } \\
\text { the time you may need to support before you can live and live in Sweden on } \\
\text { your own, usually 2-5 years. (The National Agreement on Health and the } \\
\text { First Years in Sweden, Sweden, pg. 1). }\end{array}$ \\
\hline Documented Migrant & $\begin{array}{l}\text { "Residents in a regular situation" (The National Strategic Plan on Citizenship } \\
\text { and Integration 2007-2010, Spain, pg. 8). }\end{array}$ \\
\hline Undocumented Migrant & $\begin{array}{l}\text { "People residing illegally" (National Intercultural Health Strategy 2007-2012, } \\
\text { Ireland, pg. 50). }\end{array}$ \\
\hline
\end{tabular}

Development of the categories in the target population major category was a reflective process in that grouped coded data was organized into categories and reorganized and refined into different and sometimes new categories. The result of this process was the emergence of five categories of grouped codes that were related. For example, the refugee, programme refugee, and asylum seeker codes were grouped together because there is alignment among these three codes on conditions of entry to a host nation (i.e., based on fear of persecution). Other codes were grouped together based on legal status of entry, legal status to work, age, and length of time in the host county. The coding scheme that resulted from this inductive process is presented below.

\section{Major Category: Target Population}

Category 1: Documented migrant

Code: Documented migrant

Code: Black or ethnic minority

Category 2: Special Populations

Code: Asylum Seeker 
Code: Refugee

Code: Programme Refugee

Category 3: Newly Arrived Migrant

Code: Documented Migrant First 5 Years in Host Nation

Code: Newly Arrived Migrant

Category 4: Migrant Child

Code: Child of Migrant Born in Host County

Code: Child of Migrant Born Outside Hose Nation

Code: Unaccompanied Minor (<18 years of age)

Category 5: Undocumented Migrant

Code: Undocumented migrant

Code: Roma/Traveller/Gypsy

Code: Undocumented Migrant Registered with Local Council/Municipality

The coding scheme for the target population super category and the number of policy cases associated with each code in the Target Population Major Category is shown in table 4.8.

Table 4.8. Target Population Major Category Coding Scheme.

\begin{tabular}{|c|l|l|}
\hline \multicolumn{1}{|c|}{ Category } & \multicolumn{1}{|c|}{ Code } & $\begin{array}{l}\text { Number of } \\
\text { policies } \\
\text { associated } \\
\text { with code }\end{array}$ \\
\hline Documented Migrant & & \\
\hline & Documented Migrant & 9 \\
\hline Category & Black or Ethnic Minorities & $\begin{array}{l}\text { Number of } \\
\text { policies } \\
\text { associated } \\
\text { with code }\end{array}$ \\
\hline Special Populations & & 2 \\
\hline & Asylum Seeker & 7 \\
\hline & Refugee & 2 \\
\hline
\end{tabular}




\begin{tabular}{|c|c|c|}
\hline Category & Code & $\begin{array}{l}\text { Number of } \\
\text { policies } \\
\text { associated } \\
\text { with code }\end{array}$ \\
\hline & Programme Refugee & 2 \\
\hline \multicolumn{3}{|l|}{ Newly Arrived Migrant } \\
\hline & Documented Migrant First 5 Years in Host Nation & 3 \\
\hline & Newly Arrived Migrant & 1 \\
\hline \multicolumn{3}{|l|}{ Migrant Child } \\
\hline & Child of Migrant Born in Host County & 3 \\
\hline & Child of Migrant Born Outside Hose Nation & 1 \\
\hline & $\begin{array}{l}\text { Unaccompanied Minor } \\
\text { (<18 years of age) }\end{array}$ & 1 \\
\hline \multicolumn{3}{|l|}{ Undocumented Migrant } \\
\hline & Undocumented Migrant & 5 \\
\hline & Roma/Traveller/Gypsy & 3 \\
\hline & $\begin{array}{l}\text { Undocumented Migrant Registered with Local } \\
\text { Council or Municipality }\end{array}$ & 2 \\
\hline
\end{tabular}

( *Bold font denotes majority of policy cases associated with code, more than six of the 11 policy cases included in the study.)

\section{Target Population Categories Defined}

The terms, documented migrant and black and ethnic minorities, refer to the same population, migrants who have obtained residency permission from the host nation. England and Ireland use the term "black and ethnic minorities", while the other policies use the term "documented migrant" or simply "migrant". England and Ireland's migrant health policies are integrated into a broad scope of policies that encompass ethnic minorities (Rechel, Mladovsky, Deville et al., 2011). For this reason, the two countries use the term "black and ethnic minorities" in keeping with the language used 
in other policies that address the broader population group of ethnic minorities. While some polices use the term "migrant" generally and do not specify documented migrant per se, it is apparent that this is the target population as specific alternative migrant groups, such as undocumented migrant or asylum seeker, are specifically noted in the policy documents.

Codes in the documented migrant category share one common trait, the legal right to live and work in the host nation. A migrant's legal status is determined by legal entry to a host nation country and obtaining the necessary permission from the government to remain in the county.

The three codes in the special populations category, which include asylum seeker, refugee, and program refugee, are related in that residency status has not yet been determined as applications for permanent residency are under review. These codes also share a common link of a traumatic event that instigated migration to the host country. Asylum seekers seek refuge in a new country for fear of persecution upon returning to their homeland (World Health Organization, 2019). Refugees, on the other hand, either elect or are forced to leave their homeland due to economic hardship, conflict, or natural disaster. Returning home for a refugee does not coincide with persecution (World Health Organization, 2019).

The newly arrived migrant category includes codes that are related by the length of time in the host country. Codes grouped in this category include migrants who are documented and have been in the host nation for less than five years. Policy cases 
where the new migrants code appeared also specified documented migrants as a target population. Documented migrants do not have a timeframe associated with their immigration status, however, it is assumed that residence in the host nation is longterm, or more than five years. Policy cases where we see the new migrant code emphasize the health and well-being of newly arrived migrant populations for two primary reasons. First, this population is seen as especially vulnerable during formative years in a host nation. Second, the opportunity to achieve integration into the host nation's society among this population is perceived to be the highest during a migrant's formative years in a new country (Swedish Integration Board, 2004).

The migrant child category has three codes that include child of a migrant who was born in the host country, child of a migrant who was born outside of the host country, and unaccompanied minor. An unaccompanied minor is under age 18 who entered the host nation without a parent or guardian. Codes that were grouped together in the migrant child category are not bound by legal residency in the host nation. The code, migrant child born in host country, was assigned to units of text that communicated children who are documented residents of the host nation due to the circumstances of their birth. The code was also assigned to text that communicated children who were born in the host nation but were not registered in the host country at the time of their birth. The reason for this choice is that many Roma children are stateless as they were not registered with the host nation at the time of their birth. Documentation status with the host nation also varies with the migrant child born 
outside the host nation. The code was intentionally assigned to units of text that communicated children of Roma/Travelers/Gypsy who are undocumented and children of asylum seekers who are in a temporary status while their asylum application is under review.

The undocumented migrant category includes three codes that are related in terms of not having residency permission, (e.g., documentation from the host nation). The term undocumented is often used interchangeably with the term "irregular" and both refer to residency status. An undocumented migrant who is registered with local councils or municipalities does not possess residency permission from the host nation, but has taken the step to make their presence known to local municipalities. Roma/Traveler/Gypsy are generally nomadic and stateless, meaning that many do not have citizenship in the host nations in which they reside.

\section{Data Organization Section Summary}

Relevant units of text were identified across the eleven policy cases. Descriptive codes were assigned, reviewed, and refined over multiple coding cycles. Following the process of identifying and coding relevant units of text, four distinct major categories of codes emerged as a result of the process of reviewing all assigned codes. Major category titles describe the codes grouped within. Next, the analysis organized and categorized codes grouped in each of the four major categories in order to add structure. The process of clustering codes into categories and, if needed, subcategories within a major category was refined over multiple cycles. The end result was a coding scheme for each of the four major categories. 
Codes grouped in the policy objective major category's coding scheme were organized into four categories that include assimilation, integration and social cohesion, health equity, and health system adapts to migrants. We see significant variation in the code counts across the four categories. For example, the assimilation category is associated with one policy case, the lowest of the four categories within the policy objective major category. At the other end of the spectrum, the code social inclusion in the integration and social cohesion category was associated with six policy cases, signifying that social inclusion is a generally agreed upon objective in more than half of the eleven cases.

The policy strategy major category has a layered structure. Codes were first organized eight subcategories that were then categorized into two categories, access to care and quality of care. The access to care category is comprised of five subcategories and the quality of care category is comprised of three subcategories.

The health services major category has a similar structure to the policy strategy major category in that has both categories and subcategories. The three categories are primary, secondary, and tertiary prevention. Codes clustered in each category were organized into subcategories based on patterns and relationships among coded data. The primary prevention category has three subcategories, the secondary prevention category has five subcategories, and the tertiary prevention category has one subcategory. The number of policies associated with a code in a subcategory varied considerably across the three categories. For example, the primary prevention category 
includes a code, communicable disease control, that is associated with all eleven cases. At the other end of the spectrum, the tertiary prevention category is comprised of three codes. Two codes in this category, chronic disease management and infectious disease treatment, are associated with one case. The code long-term care and treatment of disease is associated with two cases.

Target populations is the fourth major category. The coding scheme for the major category has five categories that include documented migrant, special populations, undocumented migrant, migrant child, and new migrant. Codes were grouped into the categories based on legal status, conditions of entry to the host nation, age, and duration in the host nation. As we have seen in the three other major categories, there is considerable variation across the five categories regarding the number of policies associated with a code. For example, the code documented migrant is associated with all eleven cases, while the code refugee is associated with two cases. The number of policy cases associated with codes in the five categories in the target population major category tells us important information about the priorities and orientation of the cases in relation to specific migrant population groups that were prioritized in a policy.

Content analysis of the eleven policy cases resulted in the emergence of four major categories and their structure. As a result, we understand the highest and lowest level of grouped codes that are thematically related. The structure of the four major 
categories enabled the second phase of this analysis which involved policy case comparisons by major category.

\section{Policy Case Comparisons by Major Category}

Following the identification and organization of units of text into and within major categories, the analysis moved onto investigating apparent similarities and

differences across the major categories. The number of policy cases associated with codes categorized in a major category was used to determine content areas of convergence and divergence within each the major categories. The unit of analysis is the policy case, meaning that a policy case was counted once if it was associated with a category or subcategory. Policy case association with a category or subcategory was measured by one or more codes in a category or subcategory identified in the content analysis of a policy case.

Organized by major category, this section presents information on policy content areas where there is universal consensus across the policy cases, areas of convergence as measured by policy association greater than or equal to six categories or subcategories in a major category. Areas of significant convergence were defined as policy association with greater than or equal to nine categories or subcategories in a major category. Areas of divergence were measured by policy association less than or equal to six categories or subcategories in a major category. Finally, significant divergence was measured by policy association of less than or equal to two categories or subcategories in a major category. 


\section{Policy Objective Major Category}

Categories within the policy objective major category depict an orientation

toward migrant health. For example, the assimilation category is oriented toward protecting the health of the host nation's population and preservation of the host nation's national identity. As such, the onus is on the migrant to assimilate into the health system. The health equity category has a strong orientation toward equality, equal opportunities for migrants, anti-discrimination, and equality across the entire population. The health system adapts to migrants category is a collection of health system level objectives aimed at meeting the particular health care seeking and receiving needs of migrant populations. Lastly, the integration/social cohesion category is centered on valuing and respecting cultural diversity and bridging cultural differences to build cohesion across cultures and ethnicities.

The health equity, health system adapts to migrant populations, and integration/social cohesion categories are areas of convergence across the eleven policy cases. The health equity and health system adapts to migrant populations categories were associated with seven of the eleven policy cases/ Approximately six cases were associated with the integration/social cohesion category. The assimilation category is an area of significant divergence. A single policy case was associated with the major category. Figure 4.1 is a visual representation of the number of policies associated with the four categories. 
Figure 4.1. Policy Case Distribution Across the Policy Objective Major Category.

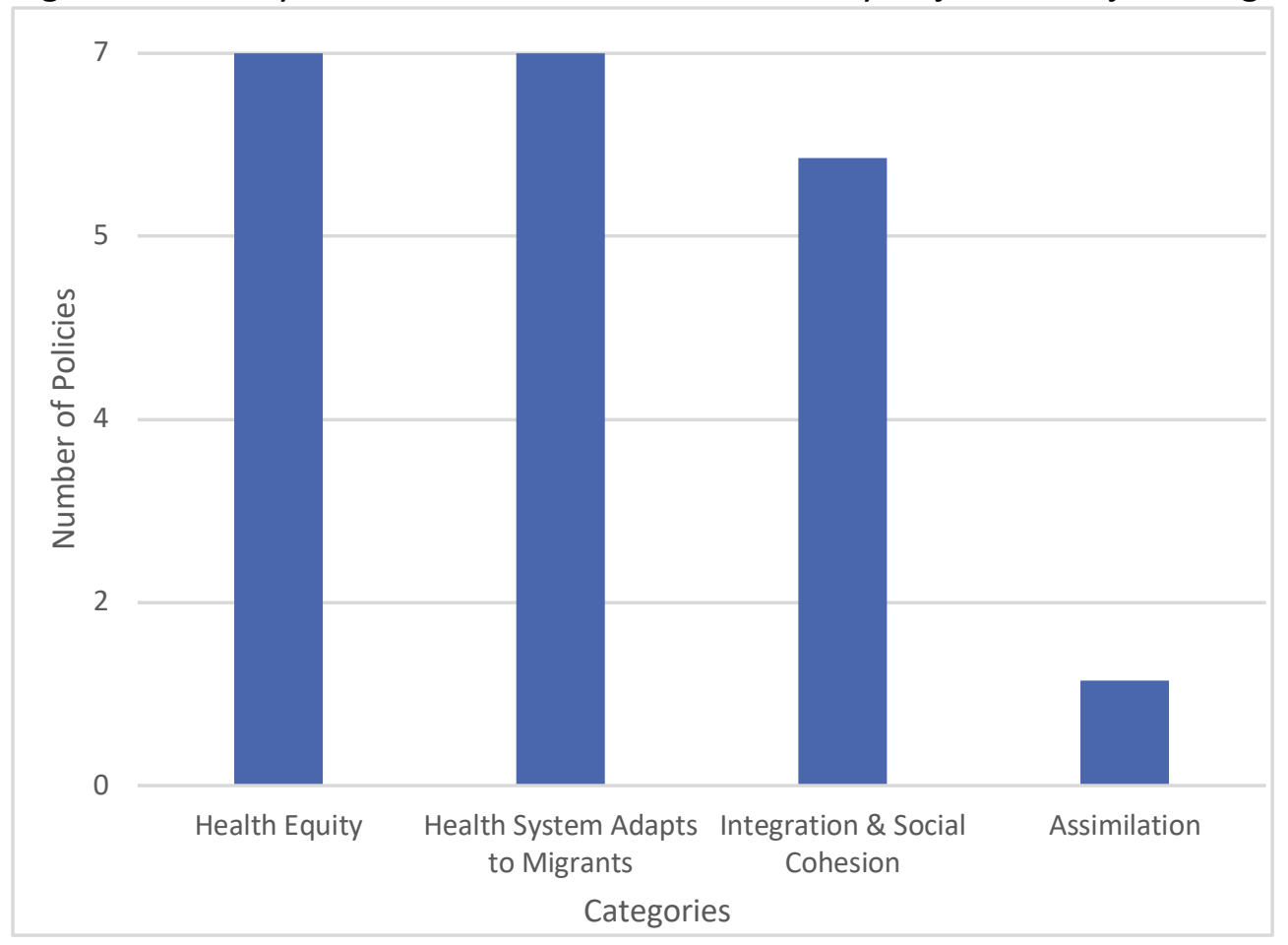

The policy objective major category ranges from category association with one to seven cases. As previously stated, the health equity, health system adapts to migrants, and integration/social cohesion categories are areas of convergence across the policy cases. Seven cases are associated with the health equity and health system adapts to migrants categories and six policy cases are linked to integration/social cohesion category. This suggests that a majority of the policies (i.e., more than half) are oriented toward meeting the health care seeking and receiving needs of heterogeneous migrant populations. The assimilation category is a content area of significant divergence as one policy case is associated with the category. The implication from this 
area of divergence is that a minority of the policy cases do not consider migrants a unique or medically vulnerable population.

\section{Policy Strategy Major Category}

The policy strategy major category's organizational structure includes the categorization of coded data into two categories and eight sub categories. The access to care category has five subcategories and the quality of care category has three subcategories. Data is presented at the category and subcategory level to demonstrate areas of convergence and divergence across the policy cases. Figure 4.2 present distribution of the number of policies associated with subcategories in both categories.

Figure 4.2. Policy Case Distribution Across the Policy Strategy Major Category
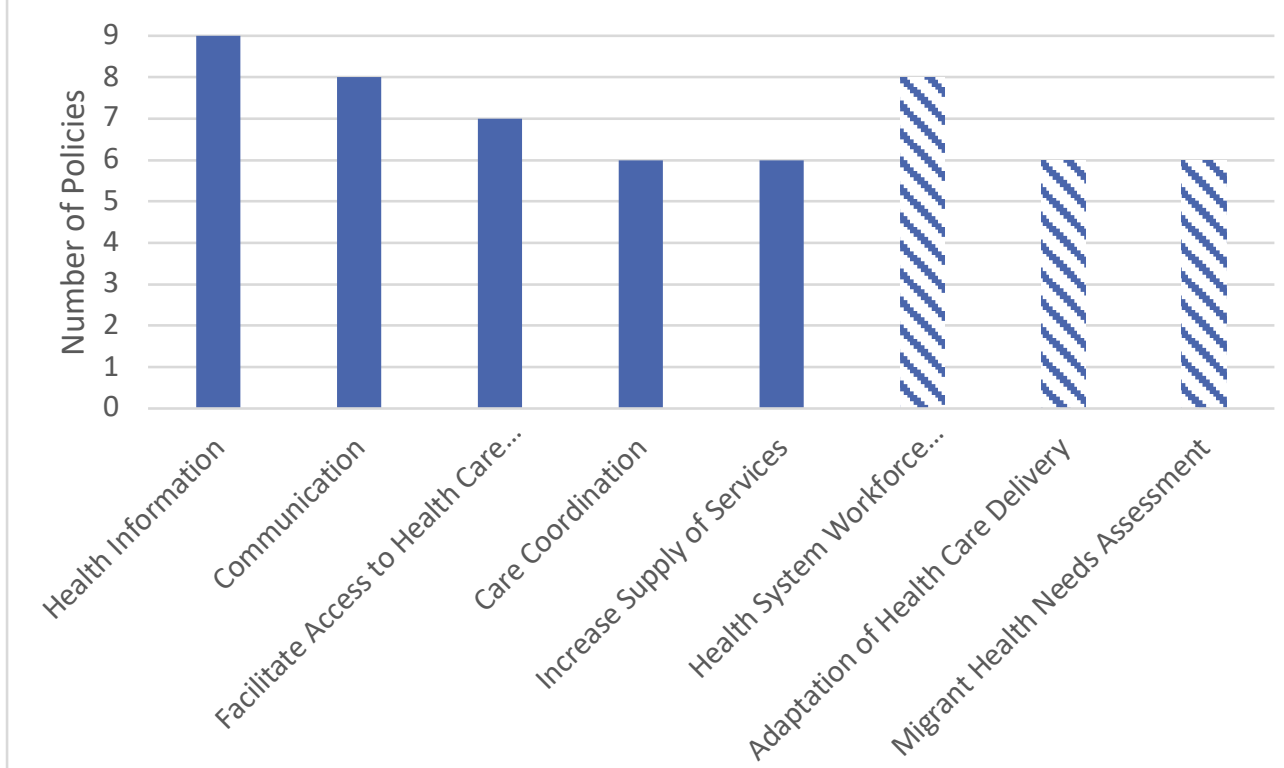

Subcategories

Legend

Access to care sub-domains $=\square$ Quality of care sub-domains $=1 / / / /$, 


\section{Access to Care Category}

Listed in order of frequency, the five subcategories in the access to care category include health information, communication, facilitate access to health care services for migrants, care coordination, and increase supply of services. The subcategory health information focuses on dissemination of health information to migrants and providers. Health information topics range from fostering health literacy to informing migrants of their rights to access health care services. The subcategory communication has two codes, translation and interpretation. This subcategory is concerned with improving communication between patient and provider through an intermediary when language barriers exist. Codes in the facilitate access to health care services for migrants subcategory are connected in that they speak to increasing access to health care services by removing barriers that prevent migrants from receiving health care services. Within this subcategory are codes that articulate fostering access to health care such as support for migrants to enroll in health insurance schemes, the state assuming financial responsibility for health care services provided to migrants, and public and private partnerships to promote migrant access to health care. The care coordination subcategory is also focused on improving access to health care service delivery for migrants by helping migrant populations navigate a health system through the support of cultural mediators, community navigators, or ethnic health educators. Lastly, the increase supply of services subcategory includes a set of codes that are aimed at increasing access to care for migrant populations through health system level changes such as resource allocation (e.g., mobile health units, 24-hour clinics, or the option to 
request care from a provider of a specific gender). Figure 4.3 shows distribution of the policy cases across the five subcategories in the access to care category.

Figure 4.3. Policy Case Distribution Across Subcategories in the Access to Care Category.

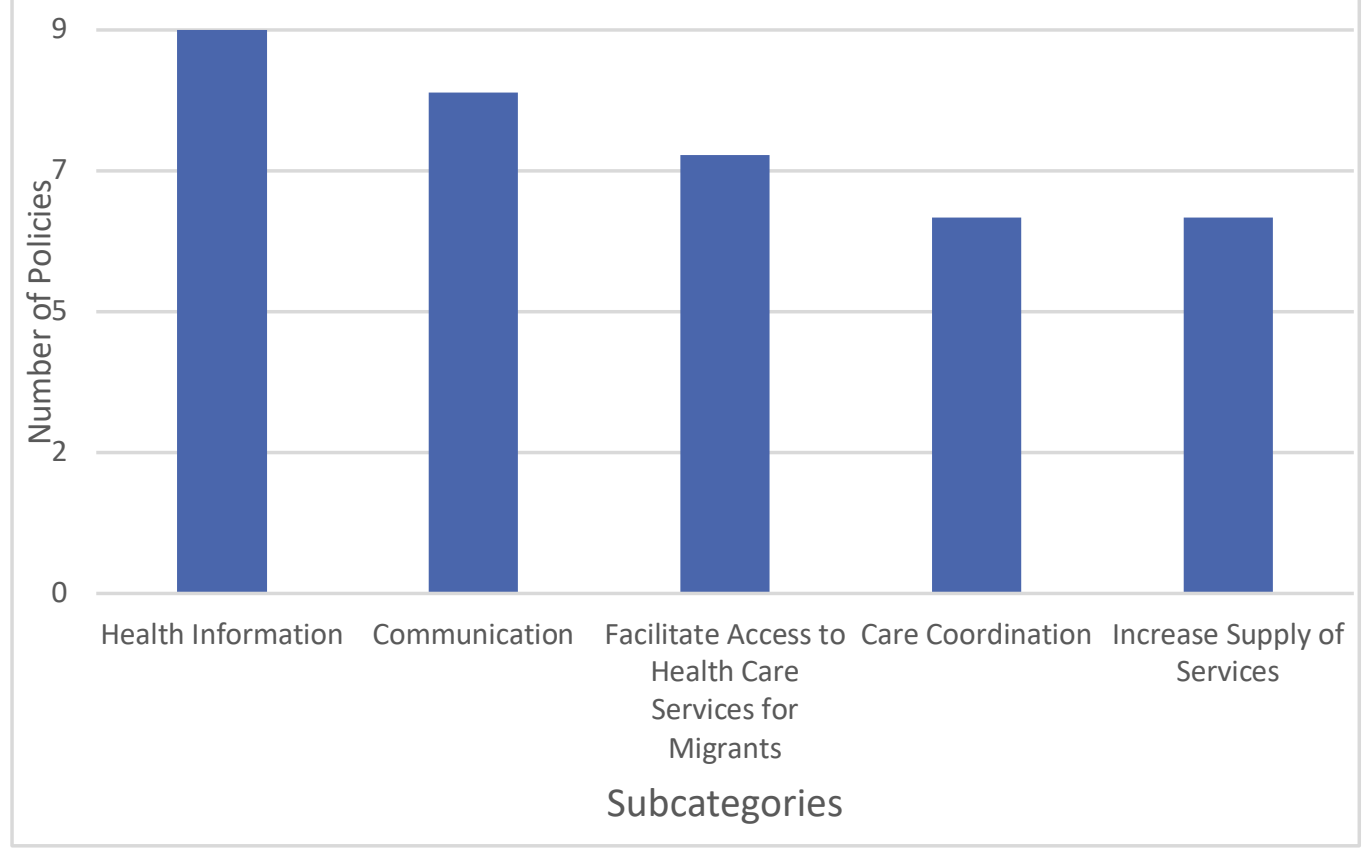

The number of policy cases associated with a subcategory ranged from nine, health information, to six, care coordination and increase supply of services. The majority of policy cases, six or more, are associated with all five subcategories in the access to care category. This suggests that the five subcategories are all common pathways to foster access to health services for migrant populations residing in host nations.

\section{Quality of Care Category}

Listed in order of frequency, the three subcategories in the quality of care category include health system workforce professional development, migrant health 
needs assessment, and adaptation of health care delivery. Eight policy cases are associated with codes in the health system workforce professional development subcategory and six cases are associated with both the migrant health needs assessment and adaptation of health care delivery subcategories.

Codes in the health system workforce professional development subcategory are related in that there is a thematic alignment of professional development and training among the health system workforce to provide culturally competent health care to ethnically diverse populations and understand the medical history and demographics of ethnically diverse populations. The subcategory, while generally focused on the health system workforce, also includes training on safety in the workforce and occupational health. Codes within the migrant health needs assessment subcategory are connected in that these codes all focus on learning about migrant health needs and health profiles through research, evaluation, and monitoring the health of migrant populations. Information from these activities informs health service delivery for migrants and determines adequate service levels as a crosswalk to healthcare improvement targeted toward migrant populations residing in host nations. Lastly, the adaptation of health care delivery subcategory is comprised of a set of codes that are related at the health system level. Codes in the subcategory articulate a change or adaptation of health care delivery to meet the particular health seeking and receiving needs of migrant populations. Figure 4.4 is a visual representation of the distribution of policy cases associated with the three subcategories in the quality of care category. 
Figure 4.4. Policy Case Distribution Across the Quality of Care Category.

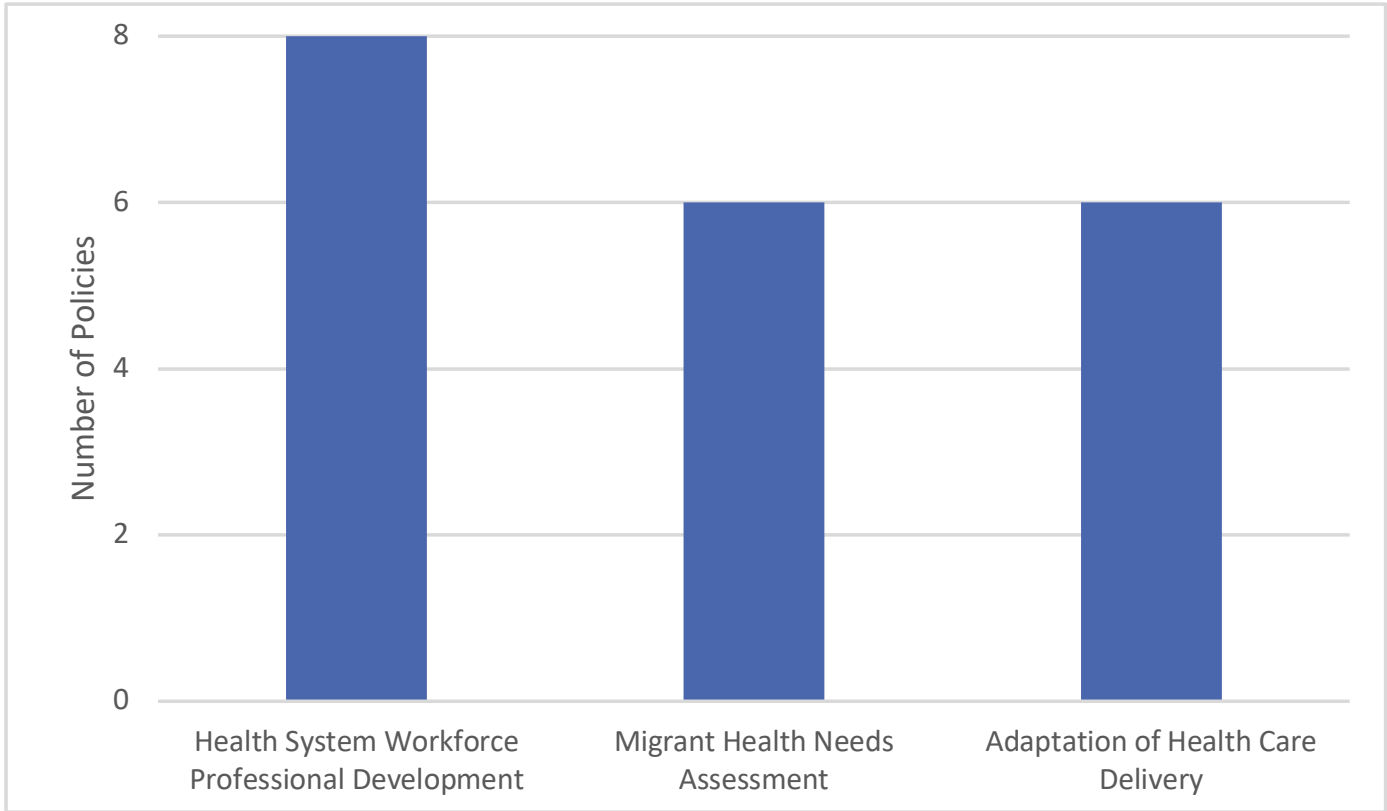

The health system workforce professional development subcategory was associated with eight of the eleven policy cases. This suggests that health system workforce professional development training in cultural competence or cultural diversity is an area of convergence across the policy cases. Both the migrant health needs assessment and adaptation of health care delivery subcategories are associated with six of the eleven cases. The three subcategories are associated with the majority of policy cases and all areas of convergence. No areas of divergence were identified in the quality of care category.

\section{Health Services Major Category}

The health services major category is organized into three categories that include primary, secondary, and tertiary prevention. Each category has between one and six subcategories. Data will be presented at the category level in this section to 
facilitate investigation of areas of convergence and divergence across the policy cases.

Figure 4.5a is a visual presentation of the distribution of policy cases associated with the primary, secondary, and tertiary prevention categories.

Figure 4.5a. Policy Case Distribution Across Categories in the Health Service Major Category.

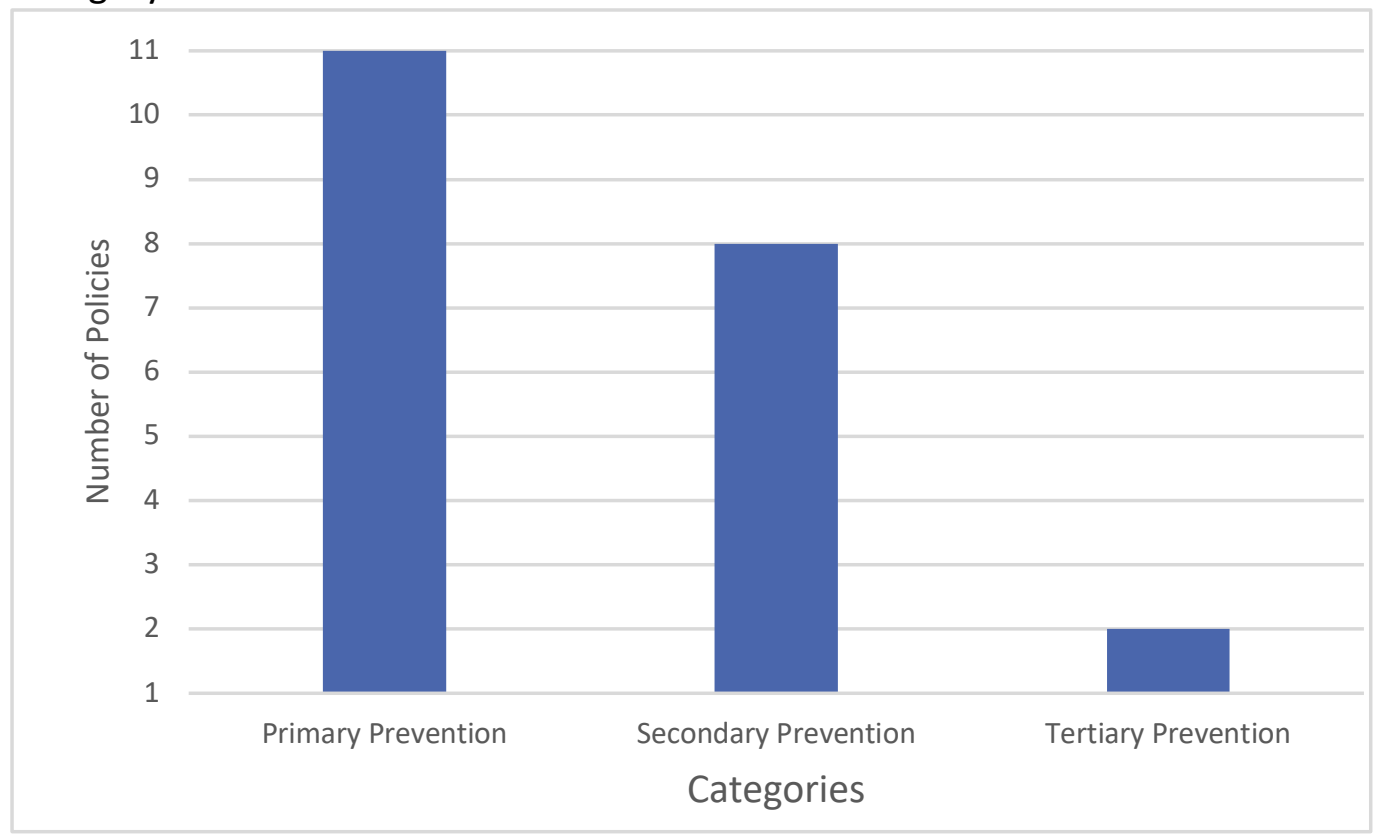

All eleven policy cases are associated with the primary prevention category. This category has three subcategories that include communicable disease control, communicable disease prevention, and health promotion. The secondary prevention category, the largest of the three categories with six subcategories, was associated with eight policy cases. The tertiary prevention category was associated with the fewest policy cases, two cases total. Tertiary prevention is the smallest of the subcategories, with one subcategory entitled disease treatment. Examination of the primary, secondary, and tertiary prevention categories individually identified more detailed 
information pertaining to areas of convergence and divergence across the eleven policy cases.

\section{Primary Prevention Category}

The primary prevention category with one subcategory, communicable disease control, was associated with all eleven policy cases. Within the health services major category, this was the only subcategory that was an area of universal convergence of policy content across the eleven cases. The focus on mitigating the spread of communicable disease transmission is not surprising, given that the literature offers ample evidence that the process of migration is a driver of communicable disease transmission in western and northern European nations (Wörmann and Krämer, 2011).

Figure $4.5 \mathrm{~b}$ is a visual presentation of the distribution of policy cases that were associated with subcategories in the primary prevention category.

Figure 4.5b. Policy Case Distribution Across Subcategories in the Primary Prevention Category.

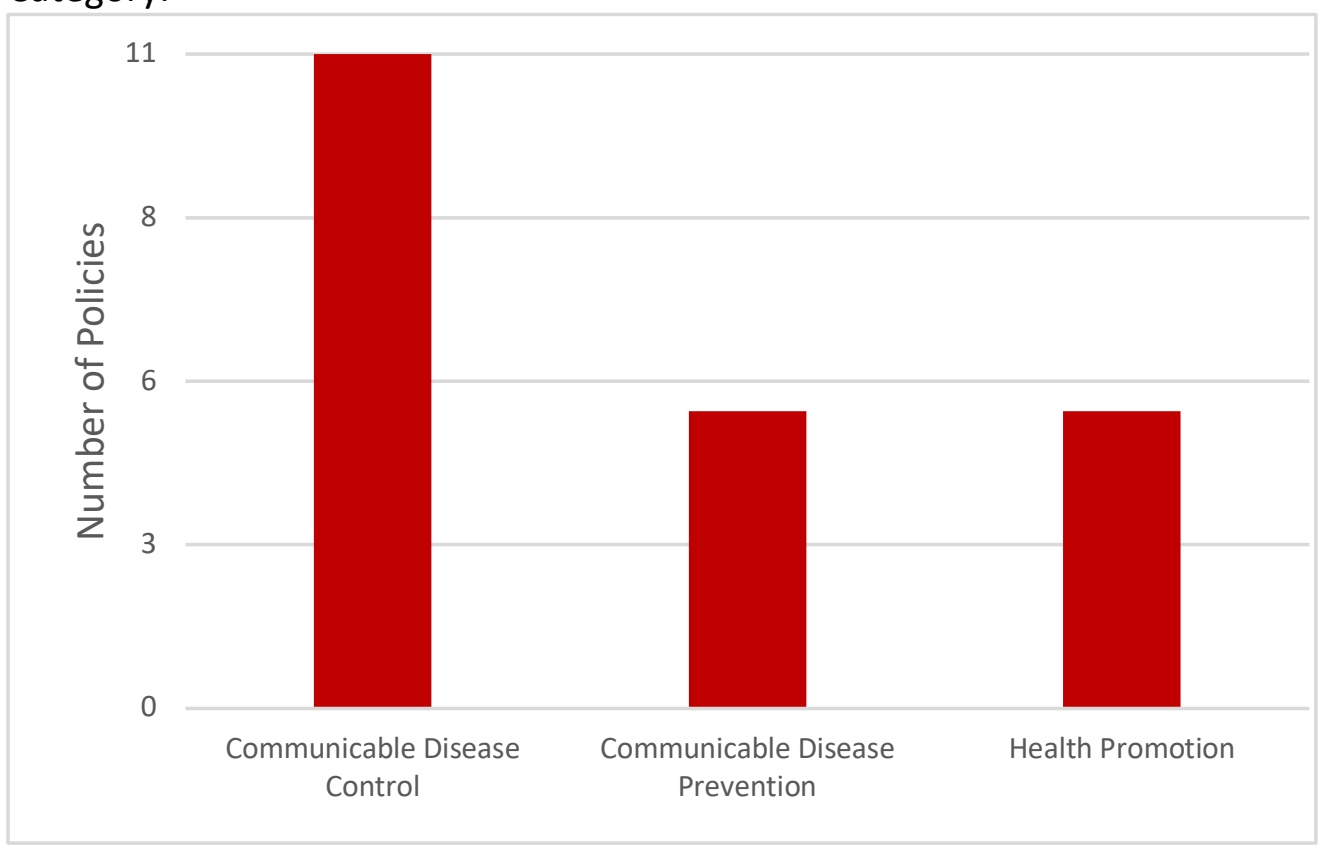


As previously noted, the communicable disease control subcategory was associated with all eleven policy cases. Two subcategories, communicable disease prevention and health promotion, were both associated with five cases.

\section{Subcategory Secondary Prevention}

The secondary prevention category has six subcategories. In order of frequency they include metal health, sexual and reproductive health, health services for target populations, general health care, substance abuse, and emergency care. The subcategories generally focus on early disease detection and the mitigation or prevention of disease progression (Shi and Singh, 2008). Figure $4.5 \mathrm{c}$ is a visual presentation of the distribution of the number of policies that are associated with codes in one or more of the six subcategories in the secondary prevention category.

Figure 4.5c. Policy Case Distribution Across the Secondary Prevention Category.

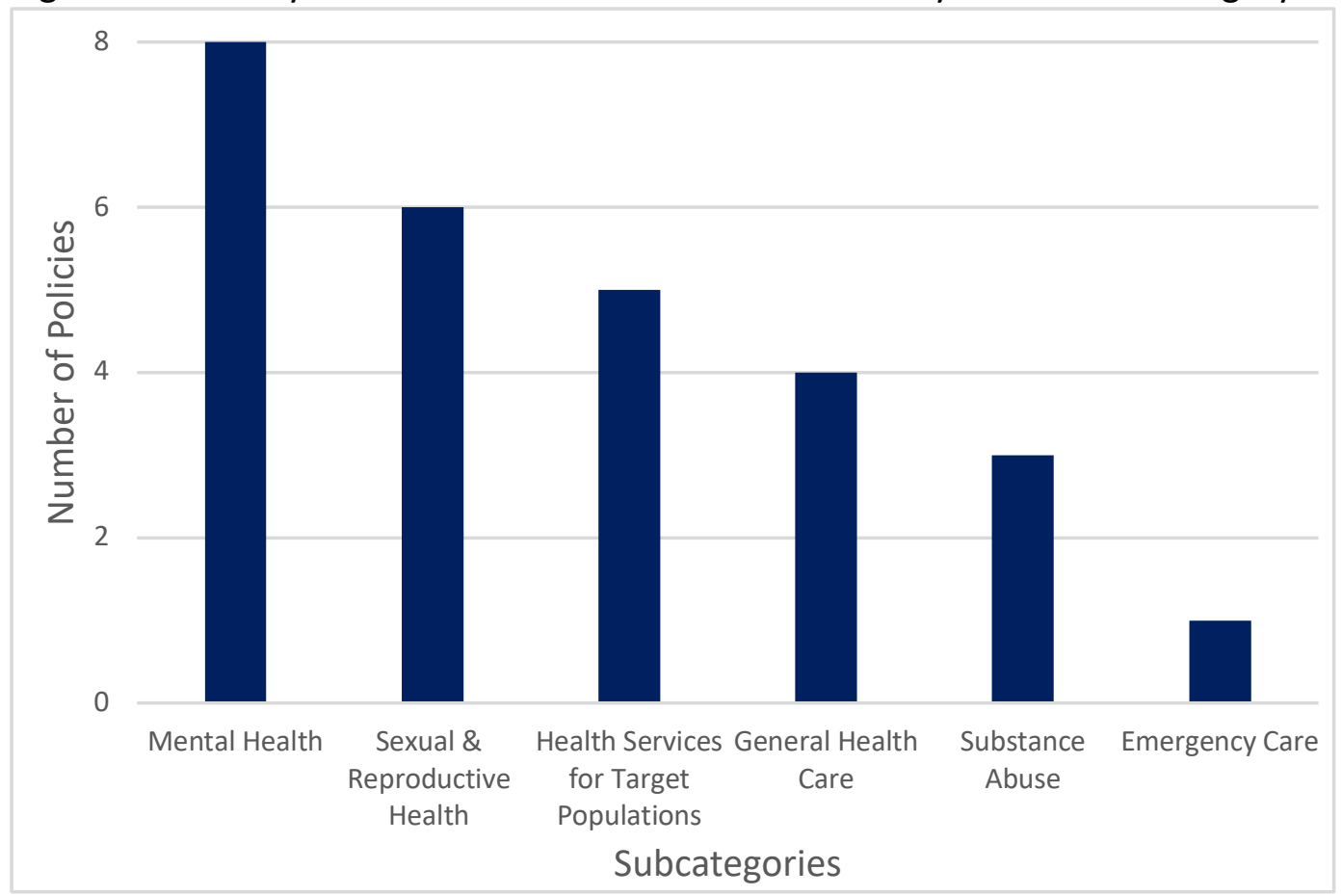


The number of policy cases associated with subcategories in the secondary prevention category ranged from eight for mental health, to one for emergency care. The mental health subcategory is one of two health services that are associated with the majority of policy cases. Policy case alignment with this subcategory is likely a response to the trauma a migrant may have experienced during the pre-flight, flight, or resettlement phases of migration. Trauma experienced by refugees and migrants during the pre-flight, flight, and resettlement phases of migration is well-documented in the literature (Rechel et al., 2013; Rechel et al., 2011; Nagy 2011; Zimmerman, Kiss \& Hossain, 2011). The subcategory, sexual and reproductive health, was also associated with a majority of cases, six in all. The health care for targeted populations subcategory includes a group of codes describing health services for children, women, and the elderly. The subcategory was associated with five policies. A total of three policies were associated the substance abuse subcategory. The emergency care subcategory was the most divergent policy content area in the secondary prevention category, with its association with a single policy case.

Within the secondary prevention category there were areas of convergence and divergence across the policy cases. Areas of policy content convergence (i.e., six or more policy cases) were identified in the mental health and sexual and reproductive health subcategories. Divergent policy content areas (i.e., five or less) were found in four of the six subcategories that include health services for target populations, general health care, substance abuse, and emergency care. The emergency care subcategory is a significant 
area of policy content divergence, with a single policy case associated with the subcategory.

\section{Tertiary Prevention Category}

The tertiary prevention category has one subcategory entitled disease treatment. Tertiary prevention aims to reduce the impact of an already established disease through the reduction of disease-related complications (Shi and Singh, 2008). The disease treatment subcategory has three codes that are long-term care and treatment of disease, chronic disease management, and infectious disease treatment.

The tertiary prevention category is another area of significant divergence across the policy cases. Two cases were associated with the category's single subcategory, disease treatment. Figure 4.6 presents the tertiary prevention category at the code level. The reasons for presenting data at the code level is to show the distribution of the number of policies associated with the one subcategory in the tertiary prevention category.

Figure 4.6. Policy Case Distribution Across Subcategories in the Tertiary Prevention Category.

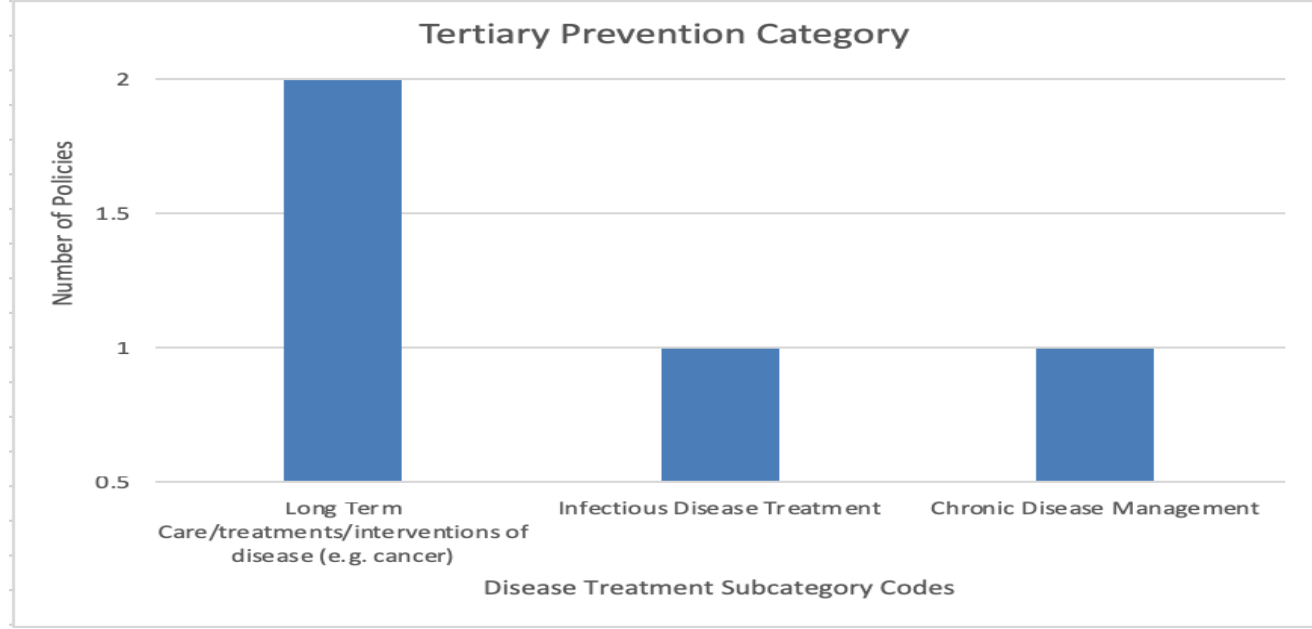




\section{Health Services Major Category Section Summary}

Areas of policy case convergence and divergence in the health services major category indicate health system priorities regarding the provision of specific health services to migrant populations. The primary prevention category, which includes the subcategory communicable disease control, has universal convergence across the policy cases. Policy case association decreases in the secondary prevention category which has six subcategories. The range of policy cases associated with the six subcategories ranged from eight in the mental health subcategory to one in the emergency care subcategory. The most significant area of divergence across the policy group is in the tertiary prevention category. We see the fewest policies, two in all, associated with the category. These findings suggest that within the primary prevention category, communicable disease control, is a priority of all eleven policy cases. The secondary prevention category has both areas of convergence and divergence, with most convergence of the cases associated with the mental health subcategory. The area of the most divergence among the cases was the emergency care subcategory. At the category level, tertiary prevention, represented the most significant area of divergence. Codes in the category's single subcategory, disease treatment, were associated with two of the eleven policy cases.

\section{Target Population Major Category}

The target population major category is organized into five categories that include documented migrant, newly arrived migrant, special populations, undocumented migrant, and migrant child. Figure 4.7 is a visual presentation of the 
number of policies associated with one or more category in the target population major category.

Figure 4.7. Policy Case Distribution in the Target Population Major Category.

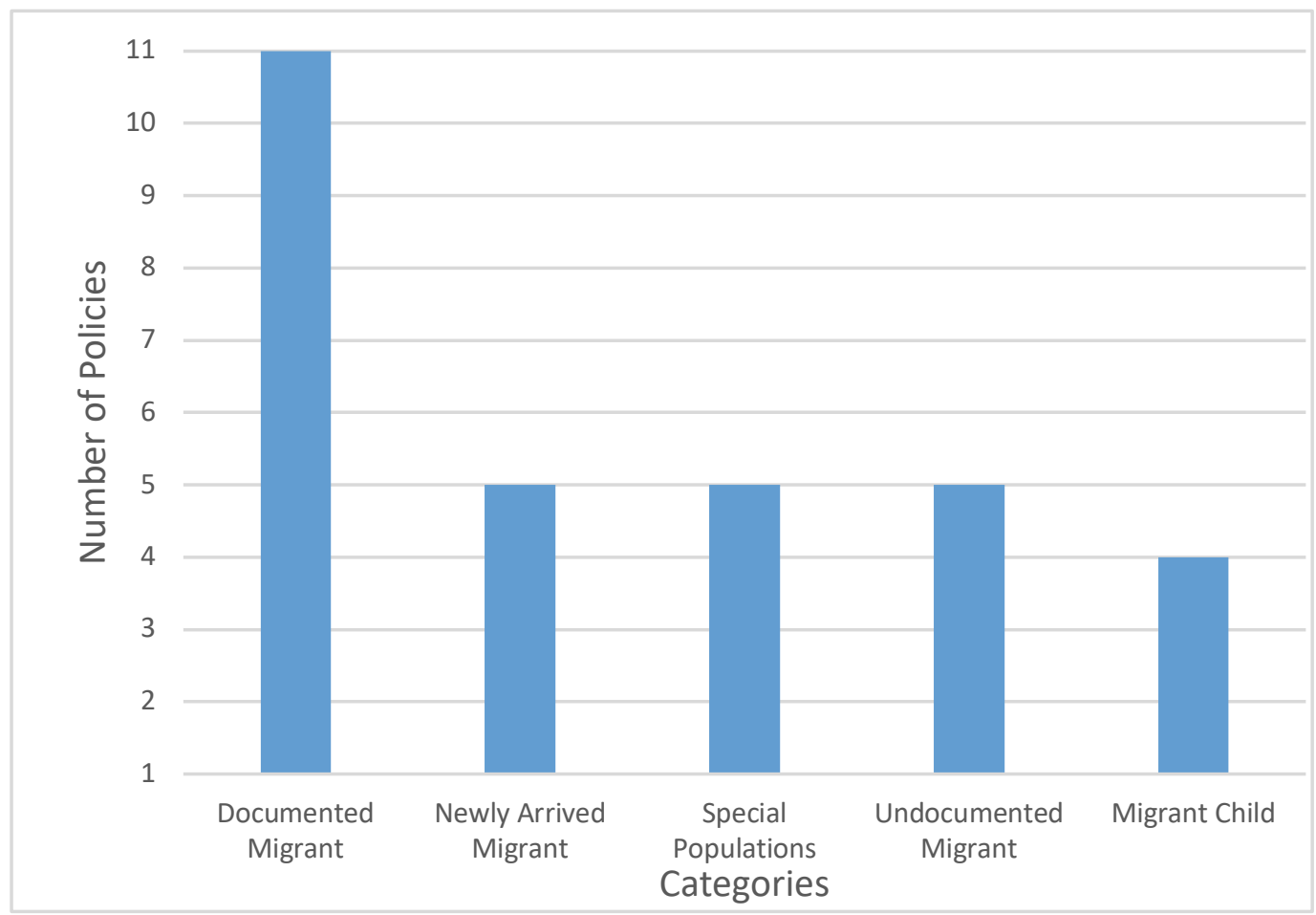

The number of policy cases associated with the five categories ranged from four to eleven. The documented migrant category is the only category in the target population major category with universal convergence across the cases. There is a significant decrease in policies associated with the other target population categories. Five policies were associated with the newly arrived, special population, and undocumented migrant categories. Four policies were associated with the migrant child category. 


\section{Policy Case Comparisons within Major Categories Section Summary}

Identifying areas of convergence and divergence across the four major

categories was the first step to understand variation among the policy cases included in this study. Identifying areas where the majority of policy converge or diverge tells us important information about policy case priorities and perspectives and migrant health.

The number of policy cases associated with categories in the policy objective major category ranged from two to seven. The health equity, health system adapts to migrants categories and integration/social cohesion categories are all areas of convergence across the policy cases suggesting that a majority of the policies are oriented toward responding to the health needs of heterogeneous migrant populations. The assimilation category is a significant area of divergence as it is associated with a single policy case. This suggests that a minority of the policy cases place the onus on migrant populations to assimilate and adapt to the health care system.

The policy strategy major category is comprised of eight subcategories that are organized into two categories, access to care and quality of care. Five subcategories are categorized in the access to care category and three are in the quality of care category. All subcategories are areas of convergence across the eleven policy cases. The number of policy cases associated with subcategories in the access to care category range from six to nine. The health information subcategory in the access to care category is a content area of significant convergence across the cases. Nine of the eleven cases were associated with the subcategory. Between six and eight cases are associated with the 
three categories in the quality of care category. No areas of divergence were identified in the policy strategy major category.

The health services major category has three categories that include the primary, secondary, and tertiary prevention. The primary prevention category, which includes the subcategory communicable disease control, was an area of universal content convergence across the policy cases. The secondary prevention category, with its six subcategories, has the broadest spectrum of policy case association ranging from eight cases linked with the mental health subcategory, to one case connected to the emergency care subcategory. The tertiary prevention category is an area of significant divergence. A total of two cases were associated with the category.

Four of the five categories that comprise the target population major category are areas of policy case divergence. Five or fewer policy cases were associated with the newly arrived migrant, special populations, undocumented migrant, and migrant child categories. The documented migrant category is the only category in the target population major category that is a content area of universal convergence across the eleven cases. Moreover, documented migrant shares this distinction with only one other policy content area which is communicable disease control subcategory in the primary prevention category within the health services major category.

The structure of the four major categories enabled investigation of areas of convergence and divergence across the policy cases. Areas of convergence and divergence in policy content tells us which policy content ideas are generally agreed 
upon and which ones are held by a minority of cases included in this analysis. As a result, we have a better idea "how" the policy cases are similar and different by content area.

Typological analysis which occurred in phase two of the analysis expands upon our understanding of policy variation by identifying patterns, tendencies, and relationships within and across the major categories.

\section{Policy Typology and Theme Development}

\section{Introduction}

Phase two of the analysis commenced with application of typological analysis described in chapter three. This analytic method was utilized to identify patterns, tendencies, and relationships within and across the major categories. Typological analysis is useful in determining whether and how the structure of the policies' content were interrelated and in what ways. Identification of relationships within and across major categories was utilized to identify themes that describe relationships.

As an exploratory analysis without prior guidance on how or whether the policies' content may or may not interrelate, the analysis began with identifying a major category most suitable to the typology matrix approach. The policy strategy major category was selected as the initial candidate to apply the typology matrix framework because it had only two categories, access to care and quality of care that could be used to provide dimensionality to the framework and were constructs that have been previously established as relevant to the content of this set of migrant health policies 
(Vasquez et al., 2011). Furthermore, access to care and quality of care are recognized generally in the health services literature as distinct and interrelated measures of health system performance (Agency for Healthcare Research and Quality, 2018; lacobuţă, 2012; Koustev, 2017). Following the determination that the typology matrix framework was a useful tool to identify relationships across the policies within that major category, the resulting matrix was used as frame to assess whether and how the other three major categories, (i.e., policy objective, health services, and target populations) interrelate with the initial strategy based matrix. This was accomplished by placing a policy's categories from the other major categories in the initial matrix based on a policy's position determined by mapping the policy strategy major category onto the matrix. In addition, subcategories for the strategy and health services major categories were mapped onto the initial matrix to identify further detail in patterns, relationships, and tendencies among the major categories.

Findings from the analytic process of mapping the major categories on the initial strategy based matrix were then used to create a robust typology depicting the policy cases' orientation toward migrant health. The development of the migrant health policy typology is presented in the next section of this chapter. The sequential analytic process followed in phase two resulted in identification of similarities and differences across the eleven policy cases that were clearly articulated through higher thematic organization. 


\section{Migrant Health Policy Orientation Toward Migrant Health Typology Matrix Development}

\section{Policy Strategy Major Category and the Typology Matrix Framework}

As noted previously, the policy strategy major category was selected as a good

candidate for initial mapping onto the matrix framework because it is comprised of two categories that have a two-dimensional structure, access to care and quality of care. The policy objectives, health services, and target population major categories were then mapped over the policy strategy major category based matrix to assess whether or not there was a relational association among the major categories, assess the distribution of access to care and quality of care in relation to the major categories, identify themes from the major categories, and ultimately determine if a summary typology depicting orientation toward migrant health could be developed from these findings.

Initial mapping of the policy strategy major category onto the matrix started by re-configuring the results from phase one to identify the structure of each policy in regard to the policy strategy major category. Table 4.9 presents the policy strategy major category's organizing structure by policy case with summary the number of codes per subcategory that were associated with each of the eleven policy cases. For each of the two categories - access to care and quality of quality - summary counts of the number of subcategories and number of codes present are tabulated (i.e., breadth and depth, respectively, as defined in chapter 3). Country code abbreviations used in Tables 4.10, 4.11, 4.12 and 4.13 are shown below in Table 4.9. 
Table 4.9. Country Code Abbreviation Key.

\begin{tabular}{|l|c|c|c|}
\hline Country & Abbreviation & \multicolumn{1}{l|}{ Country } & Abbreviation \\
\hline Austria & AUS & Portugal & PRT \\
\hline England & ENG & The Netherlands & NL \\
\hline Germany & DEU & Sweden & SWE \\
\hline France & FRA & Switzerland & CHE \\
\hline Italy & ITA & Spain & ESP \\
\hline Ireland & IRL & & \\
\hline
\end{tabular}

Table 4.10. Policy Strategy Major Category

\begin{tabular}{|c|c|c|c|c|c|c|c|c|c|c|c|}
\hline & AUT & ENG & DEU & FRA & ITA & IRL & PRT & NL & SWE & CHE & ESP \\
\hline \multicolumn{12}{|c|}{ CATEGORY: ACCESS TO CARE } \\
\hline \multicolumn{12}{|l|}{ Subcategory } \\
\hline $\begin{array}{l}\text { Facilitate } \\
\text { Access to } \\
\text { Health Care } \\
\text { Services }\end{array}$ & 0 & 4 & 0 & 0 & 1 & 0 & 5 & 0 & 2 & 2 & 4 \\
\hline Communication & 1 & 2 & 0 & 0 & 0 & 2 & 2 & 2 & 1 & 2 & 1 \\
\hline $\begin{array}{l}\text { Care } \\
\text { Coordination }\end{array}$ & 0 & 1 & 0 & 0 & 0 & 0 & 1 & 1 & 1 & 2 & 1 \\
\hline $\begin{array}{l}\text { Health } \\
\text { Information }\end{array}$ & 0 & 3 & 3 & 2 & 4 & 0 & 3 & 2 & 1 & 1 & 2 \\
\hline $\begin{array}{l}\text { Increase Supply } \\
\text { of Services }\end{array}$ & 0 & 2 & 0 & 0 & 0 & 1 & 0 & 0 & 0 & 0 & 0 \\
\hline $\begin{array}{l}\text { Number of } \\
\text { subcategories } \\
\text { associated with } \\
\text { a policy } \\
\text { (Breadth) }\end{array}$ & 1 & 5 & 1 & 1 & 2 & 2 & 4 & 3 & 4 & 4 & 4 \\
\hline $\begin{array}{l}\text { Number of } \\
\text { subcategory } \\
\text { codes } \\
\text { associated with } \\
\text { a policy (Depth) }\end{array}$ & 1 & 12 & 3 & 2 & 5 & 3 & 11 & 5 & 5 & 7 & 8 \\
\hline
\end{tabular}




\begin{tabular}{|c|c|c|c|c|c|c|c|c|c|c|c|}
\hline & AUT & ENG & DEU & FRA & ITA & IRL & PRT & NL & SWE & CHE & ESP \\
\hline \multicolumn{12}{|c|}{ CATEGORY: QUALITY OF CARE } \\
\hline $\begin{array}{l}\text { Needs } \\
\text { Assessment }\end{array}$ & 0 & 1 & 0 & 0 & 1 & 1 & 0 & 0 & 1 & 2 & 1 \\
\hline $\begin{array}{l}\text { Adaptation of } \\
\text { Services }\end{array}$ & 1 & 5 & 0 & 0 & 0 & 2 & 2 & 2 & 1 & 2 & 0 \\
\hline $\begin{array}{l}\text { Professional } \\
\text { Development }\end{array}$ & 1 & 1 & 0 & 0 & 0 & 2 & 2 & 1 & 1 & 3 & 2 \\
\hline $\begin{array}{l}\text { Number of } \\
\text { subcategories } \\
\text { associated with } \\
\text { a policy } \\
\text { (Breadth) }\end{array}$ & 2 & 3 & 0 & 0 & 1 & 3 & 2 & 2 & 3 & 3 & 2 \\
\hline $\begin{array}{l}\text { Number of } \\
\text { subcategory } \\
\text { codes } \\
\text { associated with } \\
\text { a policy (Depth) }\end{array}$ & 2 & 7 & 0 & 0 & 1 & 5 & 4 & 3 & 3 & 7 & 3 \\
\hline
\end{tabular}

Within the policy strategy major category, placement of the policy cases in the initial typology matrix was determined by the number subcategories identified by a policy case in the access to care and quality of care categories (i.e., "depth"). Policies were identified as low, medium or high in terms of "depth" in each category (access and quality). The number of subcategories identified across the policy cases in the access to care category ranged from one to five. Policy cases that identified zero to one subcategory were categorized as weak, two to three subcategories were medium, and four or five subcategories were categorized as strong. Regarding the quality of care dimension of the matrix, policy cases were associated with between zero and three subcategories. Policy cases that were associated with zero and one subcategory were categorized as weak, two subcategories were classified as medium, and three 
subcategories were categorized as strong. This ranking system was selected because it divided the access to care and quality of care dimensions equally into three segments, providing relative simplicity of presentation without inadvertently "over categorizing" the data. Table 4.10 presents the rules governing classification of policy cases along the access to care and quality of care dimensions.

Table 4.11. Category Access to Care and Quality of Care Range.

\begin{tabular}{|l|c|c|c|c|}
\hline $\begin{array}{l}\text { Matrix } \\
\text { Dimension }\end{array}$ & Range & Weak & Medium & Strong \\
\hline Access to Care & $\begin{array}{c}1-5 \\
\text { subcategories }\end{array}$ & $\begin{array}{c}0-1 \\
\text { subcategory }\end{array}$ & $\begin{array}{c}2-3 \\
\text { subcategories }\end{array}$ & $\begin{array}{c}4-5 \\
\text { subcategories }\end{array}$ \\
\hline Quality of Care & $\begin{array}{c}0-3 \\
\text { subcategories }\end{array}$ & $\begin{array}{c}0-1 \\
\text { subcategory }\end{array}$ & $\begin{array}{c}2 \\
\text { subcategories }\end{array}$ & $\begin{array}{c}3 \\
\text { subcategories }\end{array}$ \\
\hline
\end{tabular}

The initial policy strategy typology matrix is presented in Figure 4.9. As previously stated, policy cases were positioned in the matrix based on the number of subcategories associated with each policy case in the access to care and quality of care categories. The shaded areas of the matrix form a diagonal from weak-weak to strongstrong along the access to care and quality of care dimensions. The diagonal is a visual reference to differentiate the area in the matrix where the levels of access and quality are relatively equal (i.e., the shaded diagonal area), the area where the level of access is greater than the level of quality (i.e., the area above the diagonal), and the area in the matrix where the level of quality is greater than the level of access (i.e., the area below the diagonal). Referencing Figure 4.8, policy cases that are located in the shaded areas have similar levels of access to care and quality of care. Cases that are located above the 
diagonal have more breadth in access than quality. Policy cases located below the diagonal have more breadth in quality of care than access to care.

Figure 4.8. Initial Policy Strategy Theme Typology Matrix.

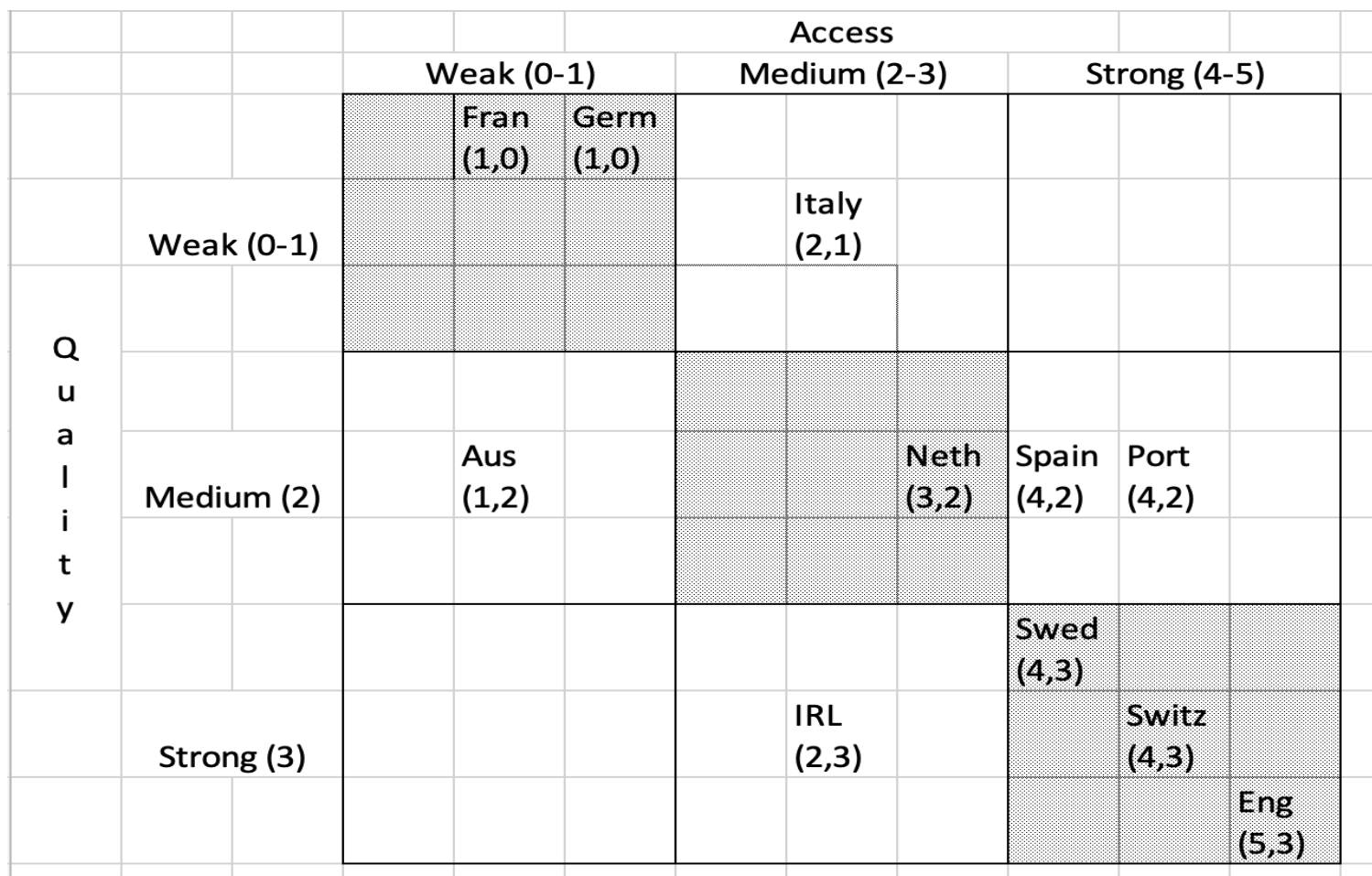

The parentheses below each country name are a count of the number of subcategories associated with the policy case. The number on the left is the number of subcategories categorized in the access to care category. On the right, is the number of subcategories in the quality of care category. Should two policy cases be associated with the same number of subcategories in the access to care or quality of care categories, the number of codes associated with a policy (i.e., depth) was referenced to determine placement in the matrix. A policy case with a higher code count in the access to care category is positioned to the right of a case with the same number of subcategories in 
the access to care category. A policy case with a higher number of codes in the quality of care category is positioned below a case associated with the same number of subcategories in the category. This process is not an exact empirical coordinate mapping but is intended to provide context for assessing both the presence of general relationships between the eleven cases and the access to care and quality of care dimensions as well as to assure that the scaling used to develop the matrix does not drive or bias the general conclusions drawn from it.

Based solely upon the initial typology matrix presented in Figure 4.9, the policy cases appear to be spread along a diagonal as we move from weak to strong along both the access to care and quality of care dimensions. None of the cases are located in extreme corners of the matrix that are strong along the access to care dimension and weak in the quality of care dimension or vice versa.

Policy Objective Major Category and the Typology Matrix Framework Mapping the policy objective major category was the next step in the analytic process followed in phase two. As previously stated, the policy objective major category was organized into four categories that include assimilation, health equity, health system adapts to migrants, and integration/social cohesion. Table 4.12 presents the policy objective major category and the number of categories and codes in a category that is associated with each of the eleven policy cases. 
Table 4.12. Policy Objective Major Category Policy Association.

\begin{tabular}{|c|c|c|c|c|c|c|c|c|c|c|c|}
\hline & AUS & ENG & GER & FRA & ITA & IRL & PRT & $\mathrm{NL}$ & SWE & CHE & ESP \\
\hline \multicolumn{12}{|l|}{ Category } \\
\hline Assimilation & 0 & 0 & 0 & 2 & 0 & 0 & 0 & 0 & 0 & 0 & 0 \\
\hline $\begin{array}{l}\text { Integration \& } \\
\text { Social Cohesion }\end{array}$ & 0 & 1 & 1 & 0 & 0 & 1 & 2 & 0 & 2 & 0 & 1 \\
\hline Health Equity & 0 & 5 & 0 & 0 & 2 & 2 & 3 & 0 & 2 & 3 & 2 \\
\hline $\begin{array}{l}\text { Health System } \\
\text { Adapts to } \\
\text { Migrants }\end{array}$ & 1 & 4 & 1 & 0 & 0 & 4 & 3 & 2 & 0 & 1 & 0 \\
\hline $\begin{array}{l}\text { Number of } \\
\text { categories } \\
\text { associated with } \\
\text { a policy } \\
\text { (Breadth) }\end{array}$ & 1 & 3 & 2 & 1 & 1 & 3 & 3 & 1 & 2 & 2 & 2 \\
\hline $\begin{array}{l}\text { Number of } \\
\text { codes in a } \\
\text { category } \\
\text { associated with } \\
\text { a policy } \\
\text { (Depth) }\end{array}$ & 1 & 10 & 2 & 2 & 2 & 7 & 8 & 2 & 4 & 4 & 3 \\
\hline
\end{tabular}

Figure 4.9 presents policy placement in the typology matrix framework once again with the four categories in the policy objective major category associated with each policy used in place of the policy case name, (i.e., country name) that was shown in the policy strategy-based typology, Figure 4.8. Table 4.13 is a key for abbreviations and color coding used in Figure 4.9. The parentheses below each country name are a count of the number of categories associated with a policy case (breadth) and the number of codes associated with a policy case (depth) in the major category. The number on the 
left is a policy's breadth and the number on the right is its depth within the major category.

Figure 4.9. Policy Objective Major Category Typology Matrix Presentation.

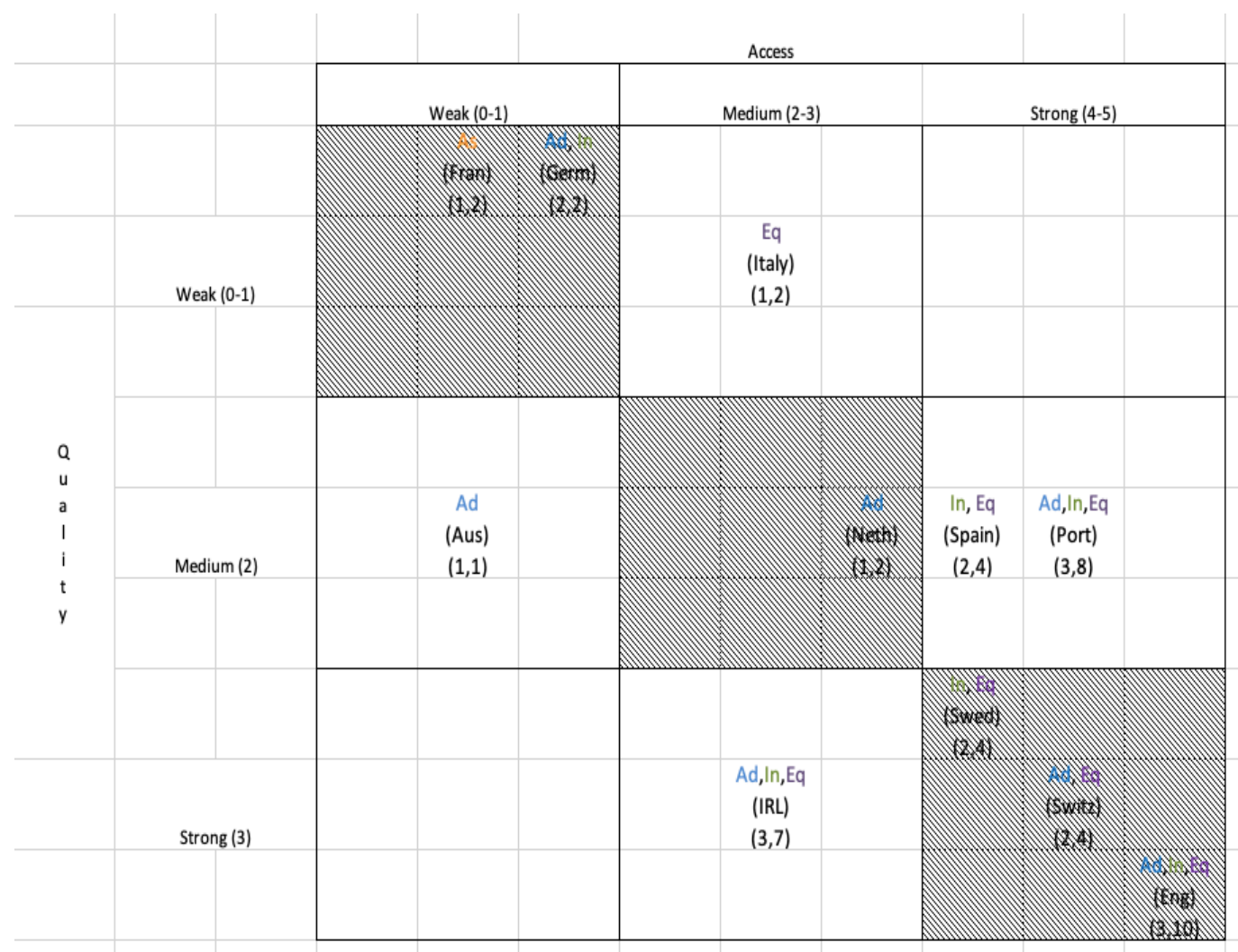

Table 4.13. Policy Objective Major Category Abbreviations.

\begin{tabular}{|l|c|}
\hline Objective Category & Abbreviation \& Color \\
\hline Assimilation & As \\
\hline Adaptation & Ad \\
\hline Health Equity & Eq \\
\hline Integration & In \\
\hline
\end{tabular}


The matrix presentation in Figure 4.9 was useful in examining apparent relationships between the policy strategy major category structure and that of the policy objective major category. Apparent relationships were examined by layering policy objective categories associated with each policy case over the policy's placement in the policy strategy-based typology matrix presented in Figure 4.8 on page 164.

The assimilation category is the only category that is weak in both the access to care and quality of care dimensions of the matrix. The integration/social cohesion category appears on and above the diagonal and has an apparent alignment with access to care. The health system adapts to migrants category generally appears on or below the shaded diagonal and has a tendency to relate more to quality of care than access to care. The category appears to increase in prevalence along the quality of care dimension, while remaining relatively constant along the access to care dimension. The health equity category appears in with matrix along with the integration/social cohesion category, the health system adapts to migrants category, or both categories. Health equity also increases in prevalence along both the quality of care and access to care and is most prevalent in the area of the matrix that is strong in both dimensions.

\section{Policy Objective Major Category Matrix Summary}

Looking across the typology matrix, it appears that the assimilation and health equity categories appear to be at opposite ends of a diagonal. The assimilation category is weak in access and quality, while the health equity category is strong in both 
dimensions. The health system adapts to migrants and integration/social cohesion

categories appear to follow the access and quality dimensions of the typology matrix independently.

\section{Health Services Major Category}

The health services major category was organized into three categories that

include primary, secondary, and tertiary prevention. Each of the categories has between one and six subcategories. Organized by the primary, secondary, and tertiary prevention categories, table 4.14 presents the number of subcategories and codes associated with each of the eleven cases.

Table 4.14. Policy Case Association w/Subcategories in Health Services Major Category.

\begin{tabular}{|c|c|c|c|c|c|c|c|c|c|c|c|}
\hline & AUS & ENG & GER & FRA & ITA & IRL & PRT & NL & SWE & CHE & ESP \\
\hline \multicolumn{12}{|c|}{ Primary Prevention Category } \\
\hline $\begin{array}{l}\text { Number of } \\
\text { subcategories }\end{array}$ & 1 & 1 & 1 & 2 & 3 & 2 & 1 & 2 & 3 & 3 & 2 \\
\hline $\begin{array}{l}\text { Number of } \\
\text { codes }\end{array}$ & 1 & 1 & 1 & 3 & 3 & 2 & 1 & 2 & 4 & 4 & 2 \\
\hline \multicolumn{12}{|c|}{ Secondary Prevention Category } \\
\hline $\begin{array}{l}\text { Number of } \\
\text { subcategories }\end{array}$ & 3 & 5 & 1 & 1 & 2 & 5 & 2 & 1 & 3 & 2 & 3 \\
\hline $\begin{array}{l}\text { Number of } \\
\text { codes }\end{array}$ & 4 & 7 & 1 & 1 & 2 & 7 & 2 & 1 & 3 & 2 & 4 \\
\hline \multicolumn{12}{|c|}{ Tertiary Prevention Category } \\
\hline $\begin{array}{l}\text { Number of } \\
\text { subcategories }\end{array}$ & 0 & 1 & 0 & 0 & 0 & 0 & 0 & 0 & 1 & 0 & 0 \\
\hline $\begin{array}{l}\text { Number of } \\
\text { codes }\end{array}$ & 0 & 3 & 0 & 0 & 0 & 0 & 0 & 0 & 1 & 0 & 0 \\
\hline $\begin{array}{l}\text { Total \# of } \\
\text { categories } \\
\text { associated w/a } \\
\text { case }\end{array}$ & 2 & 3 & 2 & 2 & 2 & 2 & 2 & 2 & 3 & 2 & 2 \\
\hline
\end{tabular}


The number of subcategories associated with the eleven policies ranged from two, Germany, to seven, England, Ireland, and Sweden. Three policy cases that include Italy, Sweden, and Switzerland are associated with three subcategories in the primary prevention category. Four cases, (e.g., Austria, England, Germany, and Portugal) are associated one subcategory in the primary prevention category. In the category secondary prevention category, the number of subcategories associated with policy cases ranged from one to five. Germany, France, and the Netherlands are associated with one subcategory, while England and Ireland are associated with five subcategories. The tertiary prevention category has one subcategory that is associated with two policies, England and Sweden. Worth noting is that England and Sweden are the only two policy cases associated with the primary, secondary, and tertiary prevention categories.

Due to the structure of the health services major category, investigation of its three categories independently reveals important information about policy case association, relationships, patterns, and tendencies. Table 4.15 presents policy cases associated with the primary prevention category. Policy cases associated with the secondary preventions category are shown in Table 4.16 and Table 4.17 depicts policy case association with the tertiary prevention category. 
Table 4.15. Policy Case Association with Primary Prevention Category.

\begin{tabular}{|c|c|c|c|c|c|c|c|c|c|c|c|}
\hline & AUS & ENG & GER & FRA & ITA & IRL & PRT & NL & SWE & CHE & ESP \\
\hline \multicolumn{12}{|l|}{ Subcategory } \\
\hline $\begin{array}{l}\text { Communicable } \\
\text { Disease Control }\end{array}$ & 1 & 1 & 1 & 2 & 1 & 1 & 1 & 1 & 2 & 2 & 1 \\
\hline $\begin{array}{l}\text { Communicable } \\
\text { Disease } \\
\text { Prevention }\end{array}$ & 0 & 0 & 0 & 1 & 1 & 1 & 0 & 0 & 1 & 1 & 0 \\
\hline $\begin{array}{l}\text { Health } \\
\text { Promotion }\end{array}$ & 0 & 0 & 0 & 0 & 1 & 0 & 0 & 1 & 1 & 1 & 1 \\
\hline $\begin{array}{l}\text { Number of } \\
\text { subcategories } \\
\text { associated with } \\
\text { a policy }\end{array}$ & 1 & 1 & 1 & 2 & 3 & 2 & 1 & 2 & 3 & 3 & 2 \\
\hline $\begin{array}{l}\text { Number of } \\
\text { codes associated } \\
\text { with a policy }\end{array}$ & 1 & 1 & 1 & 3 & 3 & 2 & 1 & 2 & 4 & 4 & 2 \\
\hline
\end{tabular}


Table 4.16. Policy Case Association with Secondary Prevention Category.

\begin{tabular}{|c|c|c|c|c|c|c|c|c|c|c|c|}
\hline & AUS & ENG & GER & FRA & ITA & IRL & PRT & NL & SWE & CHE & ESP \\
\hline \multicolumn{12}{|l|}{ Subcategory } \\
\hline Mental Health & 1 & 1 & 0 & 0 & 0 & 1 & 1 & 1 & 1 & 1 & 1 \\
\hline $\begin{array}{l}\text { Substance } \\
\text { Abuse }\end{array}$ & 0 & 2 & 0 & 0 & 0 & 2 & 0 & 0 & 0 & 1 & 0 \\
\hline $\begin{array}{l}\text { General } \\
\text { Health Care }\end{array}$ & 0 & 1 & 0 & 0 & 1 & 0 & 1 & 0 & 1 & 0 & 0 \\
\hline $\begin{array}{l}\text { Health Care for } \\
\text { Target } \\
\text { Populations }\end{array}$ & 2 & 2 & 0 & 0 & 0 & 3 & 0 & 0 & 1 & 0 & 1 \\
\hline $\begin{array}{l}\text { Sexual \& } \\
\text { Reproductive } \\
\text { Health }\end{array}$ & 1 & 1 & 1 & 0 & 1 & 1 & 0 & 0 & 0 & 0 & 2 \\
\hline $\begin{array}{l}\text { Emergency } \\
\text { Care Only }\end{array}$ & 0 & 0 & 0 & 1 & 0 & 0 & 0 & 0 & 0 & 0 & 0 \\
\hline $\begin{array}{l}\text { Number of } \\
\text { subcategories }\end{array}$ & 3 & 5 & 1 & 1 & 2 & 4 & 2 & 1 & 3 & 2 & 3 \\
\hline $\begin{array}{l}\text { Number of codes } \\
\text { associated with } \\
\text { a policy case }\end{array}$ & 4 & 7 & 1 & 1 & 2 & 7 & 2 & 1 & 3 & 2 & 4 \\
\hline
\end{tabular}

Table 4.17. Policy Case Association with Tertiary Prevention Category.

\begin{tabular}{|c|c|c|c|c|c|c|c|c|c|c|c|}
\hline & AUS & ENG & GER & FRA & ITA & IRL & PRT & NL & SWE & CHE & ESP \\
\hline \multicolumn{12}{|l|}{ Subcategory } \\
\hline $\begin{array}{l}\text { Disease } \\
\text { Treatment }\end{array}$ & $\underline{0}$ & $\underline{3}$ & $\underline{0}$ & $\underline{0}$ & $\underline{0}$ & $\underline{0}$ & $\underline{0}$ & $\underline{0}$ & $\underline{1}$ & $\underline{0}$ & $\underline{0}$ \\
\hline $\begin{array}{l}\text { Number of } \\
\text { subcategories }\end{array}$ & 0 & 1 & 0 & 0 & 0 & 0 & 0 & 0 & 1 & 0 & 0 \\
\hline $\begin{array}{l}\text { Number of } \\
\text { codes } \\
\text { associated } \\
\text { with a policy } \\
\text { case }\end{array}$ & 0 & 3 & 0 & 0 & 0 & 0 & 0 & 0 & 1 & 0 & 0 \\
\hline
\end{tabular}


Categories in the health services major category are mapped onto the typology matrix in Figure 4.10. The categories are mapped over a policy case's placement in the initial policy strategy-based major category typology matrix presented in Figure 4.8 on page 164. Table 4.18 is a list of abbreviations used in Figure 4.10. The parentheses below each country name are a count of the number of categories associated with associated with a policy case (breadth) and the number of codes associated with a policy case (depth) in the major category. The number on the left is a policy's breadth and the number on the right is its depth within the major category.

Figure 4.10. Health Services Major Category Typology Matrix Presentation.

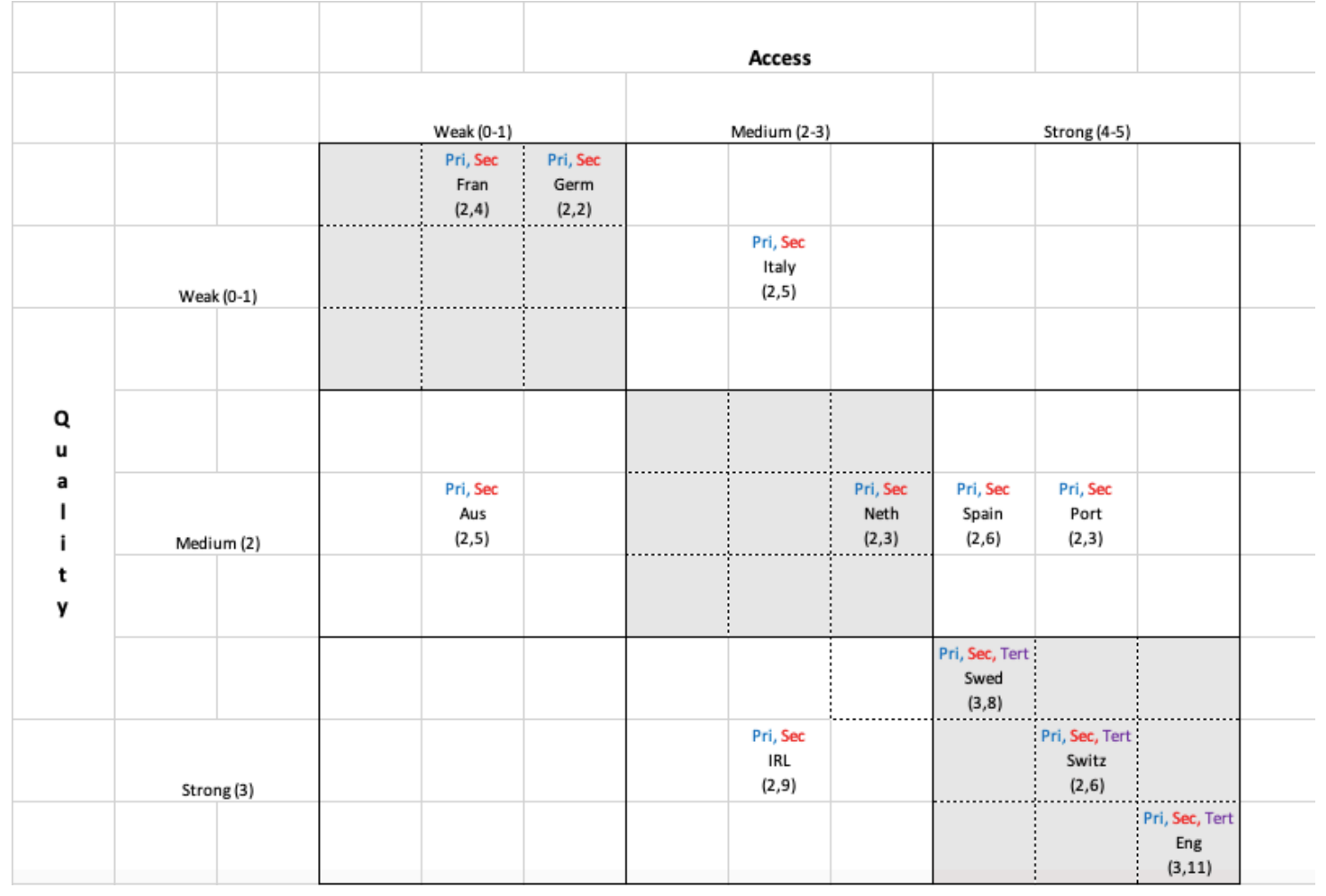


Table 4.18. Health Services Category Abbreviations.

\begin{tabular}{|l|c|}
\hline Theme & Abbreviation \& Color \\
\hline Primary Prevention & Pri \\
\hline Secondary Prevention & Sec \\
\hline Tertiary Prevention & Tert \\
\hline
\end{tabular}

The primary and secondary prevention categories are present in the typology matrix from weak to strong along both the access to care and quality of care dimensions. The tertiary prevention category is only present in the area of the matrix that is strong in both access and quality. Using the shaded area of the matrix as a reference, both the primary and secondary categories do not appear to have a tendency to align more with access to care or quality of care. Rather, we see both categories relatively evenly distributed in the access to care and quality of care areas of the matrix. The tertiary prevention category, however, appears to be evenly associated with strong access to care and quality of care.

\section{Target Population Major Category Matrix Presentation}

The target population major category's structure has five categories that include documented migrant, migrant child, newly arrived migrant, undocumented migrant, and special populations. The number of categories and codes in each of the categories that are associated with the eleven policy cases are shown in Table 4.19. 
Table 4.19. Policy Case Association with Target Population Major Category.

\begin{tabular}{|c|c|c|c|c|c|c|c|c|c|c|c|}
\hline & AUS & ENG & GER & FRA & ITA & IRL & PRT & NL & SWE & CHE & ESP \\
\hline \multicolumn{12}{|l|}{ Category } \\
\hline $\begin{array}{l}\text { Documented } \\
\text { Migrant }\end{array}$ & 1 & 1 & 1 & 1 & 1 & 1 & 1 & 1 & 1 & 1 & 1 \\
\hline $\begin{array}{l}\text { Newly Arrived } \\
\text { Migrant }\end{array}$ & 0 & 0 & 0 & 1 & 1 & 1 & 1 & 0 & 1 & 0 & 0 \\
\hline Migrant Child & 1 & 0 & 0 & 0 & 0 & 1 & 0 & 1 & 1 & 0 & 0 \\
\hline $\begin{array}{l}\text { Undocumented } \\
\text { Migrant }\end{array}$ & 0 & 0 & 0 & 1 & 1 & 2 & 1 & 0 & 0 & 0 & 2 \\
\hline $\begin{array}{l}\text { Special } \\
\text { Populations }\end{array}$ & 1 & 0 & 0 & 0 & 0 & 2 & 0 & 0 & 1 & 1 & 2 \\
\hline $\begin{array}{l}\text { Number of } \\
\text { categories } \\
\text { associated with a } \\
\text { policy case } \\
\text { (Breadth) }\end{array}$ & 3 & 1 & 1 & 3 & 3 & 5 & 3 & 2 & 4 & 2 & 3 \\
\hline $\begin{array}{l}\text { Number of codes } \\
\text { associated with a } \\
\text { policy case } \\
\text { (Depth) }\end{array}$ & 3 & 1 & 1 & 3 & 3 & 7 & 3 & 2 & 4 & 2 & 5 \\
\hline
\end{tabular}

The five categories in the target population major category were mapped onto

the typology matrix and are presented in Figure 4.12. Categories associated with each policy case were mapped over a case's placement in the initial policy strategy-based typology matrix presented in Figure 4.9. The parentheses below each country name are a count of the number of categories associated with a policy case (breadth) and the number of codes associated with a policy case (depth). The number on the left is a policy's breadth in the major category. The number on the right is its depth within the 
major category. Table 4.20 is a key for abbreviations and color coding used in Figure

\subsection{1 .}

Figure 4.11. Target Population Major Category Matrix Presentation.

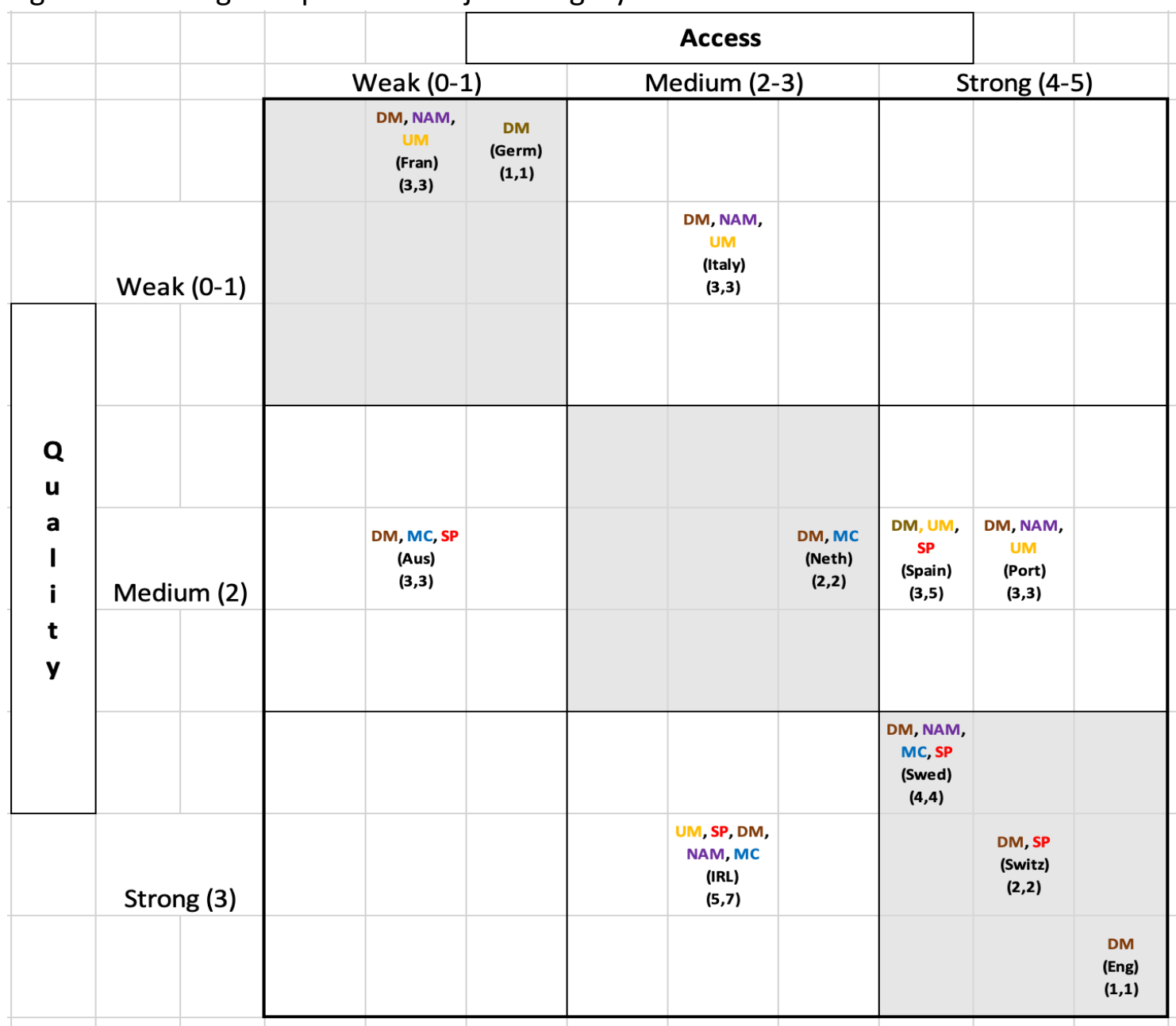

Table 4.20. Target Population Major Category Abbreviations.

\begin{tabular}{|l|c|}
\hline Category & Abbreviation \& Color \\
\hline Documented Migrant & DM \\
\hline Migrant Child & MC \\
\hline Newly Arrived Migrant & NAM \\
\hline Undocumented Migrant & UM \\
\hline Special Populations & SP \\
\hline
\end{tabular}


The documented migrant category is present throughout the entire matrix as all eleven cases are associated with one or more codes in the category. As a result, the documented migrant category does not vary. The special populations and migrant child categories appear on the shaded area of the matrix as well as below the diagonal. As a result, the special populations and migrant child categories appear to be more related to the quality of care dimension. The newly arrived migrant and undocumented migrant categories appear on and above the shaded diagonal. As such, these two categories have a tendency to be more aligned with access to care.

While the prevalence of the special populations category seems to increase as we move from weak to strong along the access to care dimension, it appears to be more related to quality of care as the category is most prevalent in the area of the matrix that is strong along the quality of care dimension. The newly arrived migrant category has a tendency to increase slightly in prevalence as we move from weak to medium along the access to care dimension of the matrix. While the category appears all along the quality of care dimension, it does not seem to increase in prevalence moving from weak to strong. The migrant child category has a tendency to cluster in the medium and strong areas along the quality of care dimension of the matrix. The category, while present all along the access to care dimension, does not increase in prevalence moving from medium to strong. The undocumented migrant category appears to increase in prevalence moving from weak to strong along the access to care dimension of the matrix and is present all along the quality of care dimension. Important to note, 
however, is that the category is not present in the area of the matrix that is strong in both access to care and quality of care.

\section{Target Population Major Category Matrix Summary}

Two target population categories have an apparent alignment with the access to care dimension and two categories seemed to relate to quality of care. The special population and migrant child categories appear to be more associated with the quality of care dimension as they are prevalent on or below the shaded diagonal in the area of matrix where quality of care is medium and strong. The newly arrived migrant and undocumented migrant categories seem to be more related to the access to care dimension as they appear on or above the diagonal in the area of the matrix that is medium and strong along the access to care dimension. The two categories also increase in prevalence along the access to care dimension. The documented migrant category appears throughout the matrix.

\section{Summary of Major Category Apparent Association with the Typology Matrix} Keeping in mind that relationships among the four major categories (e.g., objective, strategy, health services, and target population) are tendencies rather than absolutes, the following is a summary of apparent associations across the major categories as determined by each category's presentation in the typology matrix that was based upon the initial policy strategy major category that was mapped onto the typology matrix and presented in Figure 4.9 on page 57. 
In the initial policy strategy major category typology matrix presented in Figure 4.9 , the policy cases generally spread along a diagonal, moving from weak to medium to strong along both the access to care and quality of care dimensions. None of the policy cases were in the area of the matrix that is weak on quality of care and strong on access to care and vice versa, (i.e., strong in quality and weak in access). This finding suggests that the policy cases form a continuum from weak to strong along the two dimensions, access to care and quality of care.

An apparent association with either one or both the access to care and quality of care matrix dimensions is a defining component of some categories of the policy objective major category. While these tendencies are not absolutes, the assimilation category is the only policy objective category that is weak in both the access to care and quality of care dimensions of the matrix. The integration/social cohesion category has a tendency to align with the access to care dimension as it increases in prevalence as levels of access to care increase. The health system adapts to migrants category an apparent relationship with the quality of care dimension, as it increases in prevalence with more quality. The health equity category seems to have an equally strong relationship with both the access to care and quality of care dimensions and generally appears in the matrix with either the health system adapts to migrants category, the integration/social cohesion category, or both categories.

In the health services major category, we see the primary and secondary prevention categories all along the access to care and quality of care dimensions. 
Moreover, the primary and secondary categories do not appear to have a tendency to align more with access to care or quality of care. Rather, the categories move independently along access to care and quality of care areas of the matrix. The tertiary category, however, has an equally strong tendency to relate to both access and quality. We see the category in the area of the matrix with the highest levels of access to care and quality of care.

The target population major category varies throughout the matrix. The special populations and migrant child categories seem to be more associated with the quality of care dimension, while the newly arrived migrant and undocumented migrant categories have a tendency to be more aligned with access to care. The documented migrant category appears throughout the matrix and is not associated with either the access to care or quality of care dimension.

\section{Policy Strategy \& Health Services Major Category Subcategory Analysis Introduction}

Two of the four major categories' organizational structure include subcategories. The policy strategy major category has two categories, access to care and quality of care. The access to care category has five subcategories while the quality of care category has three subcategories. The health services major category's structure includes the primary, secondary, and tertiary prevention categories. The three categories have between one and six subcategories. Presentation of the policy strategy and health services major categories in the typology matrix is a rather general presentation at the category level. Due to the structure of the two major categories, 
more detail and information of apparent tendencies and patterns is available with examination at the subcategory level. This section maps the policy strategy and health services subcategories separately onto the typology matrix and examines apparent relationships with the matrix structure found above that connects strategies related to access and quality with policy objectives. As the policy strategy subcategories are already assigned to access or quality, the interest here is whether any of the subcategories better define stronger versus weaker access or quality, and thus health system adaptation versus integration/social cohesion objectives, but also whether any strategy subcategories are strongly related to strong access and quality or weak access and quality, and thus associated with health equity or assimilation objectives respectively. The health services subcategories are assessed from the same perspective.

\section{Policy Strategy Major Category Subcategories}

To get a better sense of the relationship between the policy strategy

subcategories and access to care and quality of care dimensions of the typology matrix, Figure 4.12 depicts the subcategories categorized in the access to care category isolated along the access to care dimension of the matrix. Figure 4.13 presents the subcategories in the quality of care category isolated along the quality of care dimension of the matrix. Table 4.21 is a key for the abbreviations and color coding used in Figure 4.12 and Table 4.22 presents a key for abbreviations used in Figure 4.13.

The number of subcategories associated with associated with a policy case (breadth) and the number of codes associated with a policy case (depth) in the access to 
care and quality of care categories are in parentheses under the country name of a case in Figures 4.12 and 4.13. The number on the left is a policy's breadth and the number on the right is its depth within the category.

Figure 4.12. Policy Strategy Major Category Subcategories in the Access to Care Category Mapping on the Access to Care Dimension.

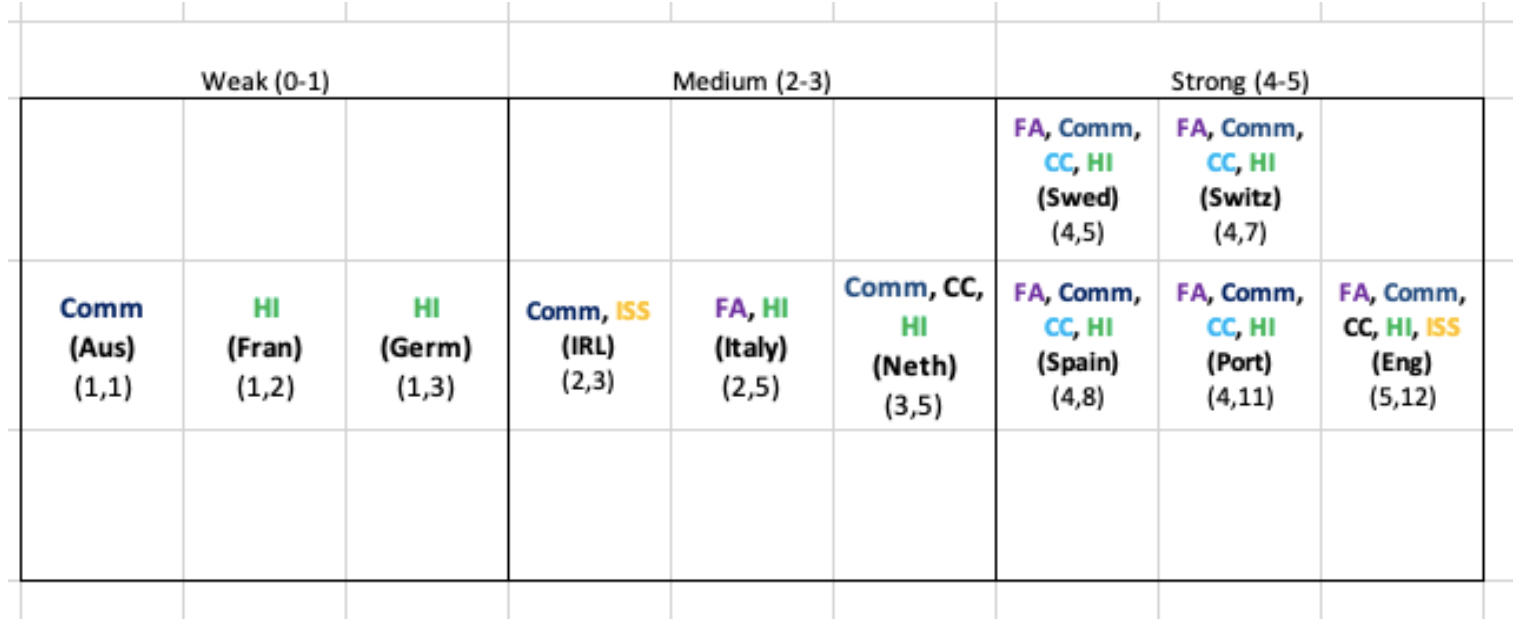

Table 4.21. Subcategories in the Access to Care Category Abbreviations.

\begin{tabular}{|l|c|}
\hline Policy Strategy Subcategories & Abbreviation \& Color \\
\hline Facilitate Access to Health Care Services & FA \\
\hline Communication & CC \\
\hline Care Coordination & HI \\
\hline Health Information & ISS \\
\hline Increase Supply of Services & \\
\hline
\end{tabular}


Figure 4.13. Quality of Care Policy Strategy Subcategories Along the Quality of Care Matrix Dimension.

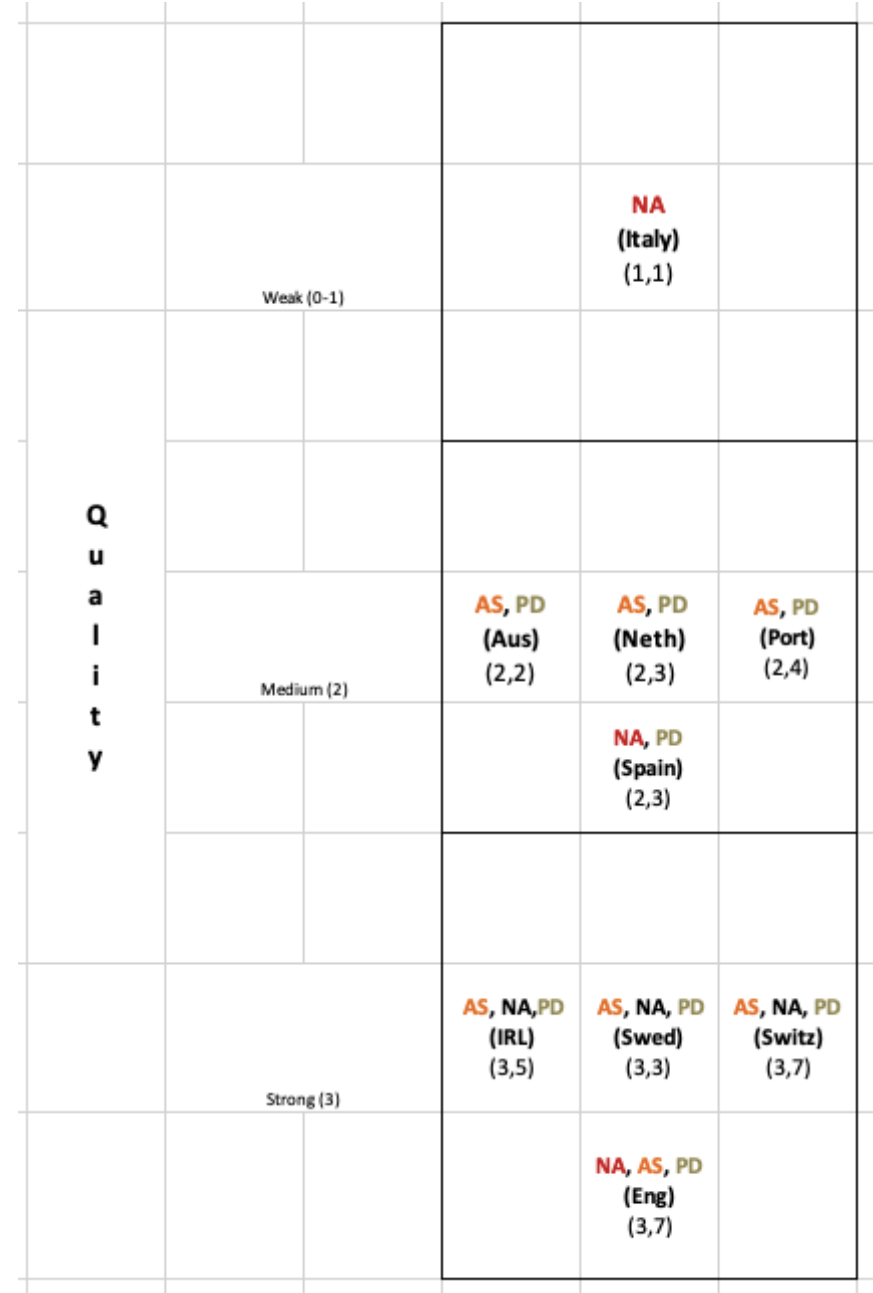

Table 4.22. Subcategories in the Quality of Care Category Abbreviations.

\begin{tabular}{|l|c|}
\hline Policy Strategy Subcategories & Abbreviation \\
\hline Needs Assessment & NA \\
\hline Adaptation of Services & AS \\
\hline $\begin{array}{l}\text { Health System Workforce Professional } \\
\text { Development }\end{array}$ & PD \\
\hline
\end{tabular}


Isolation of subcategories in the access to care and quality of care categories informed their movement along the matrix' two dimensions of access to care and quality of care. This analysis found that two subcategories seem to closely align with access to care. The facilitate access to health care services and care coordination subcategories appear in the medium and strong areas of the access to care dimension. They are most prevalent in the area of the matrix that is strong on access. The adaptation of services and health system workforce professional development subcategories appear to be related to the quality of care dimension. The adaptation of services subcategory appears in the area of the matrix that is medium in quality and increases in prevalence when quality is strong. The health system workforce professional development subcategory is prevalent in the medium and strong areas of the quality of care dimension. While the needs assessment subcategory is present all along the quality of care dimension, it appears to have an equally strong association with both access and quality as depicted in Figure 4.14 on page 185.

The typology matrix is presented once again with the policy strategy subcategories in Figure 4.14. The purpose of this presentation is to examine how the policy strategy subcategories interact with both access to care and quality of care and well as investigate apparent interrelationships between the subcategories and the policy objective categories. The breadth and depth of each policy case is not included in this figure as it is a compilation of both the access to care and quality of care categories in the policy strategy major category. 
Figure 4.14. Subcategories in the Policy Strategy Major Category Typology Matrix Presentation.

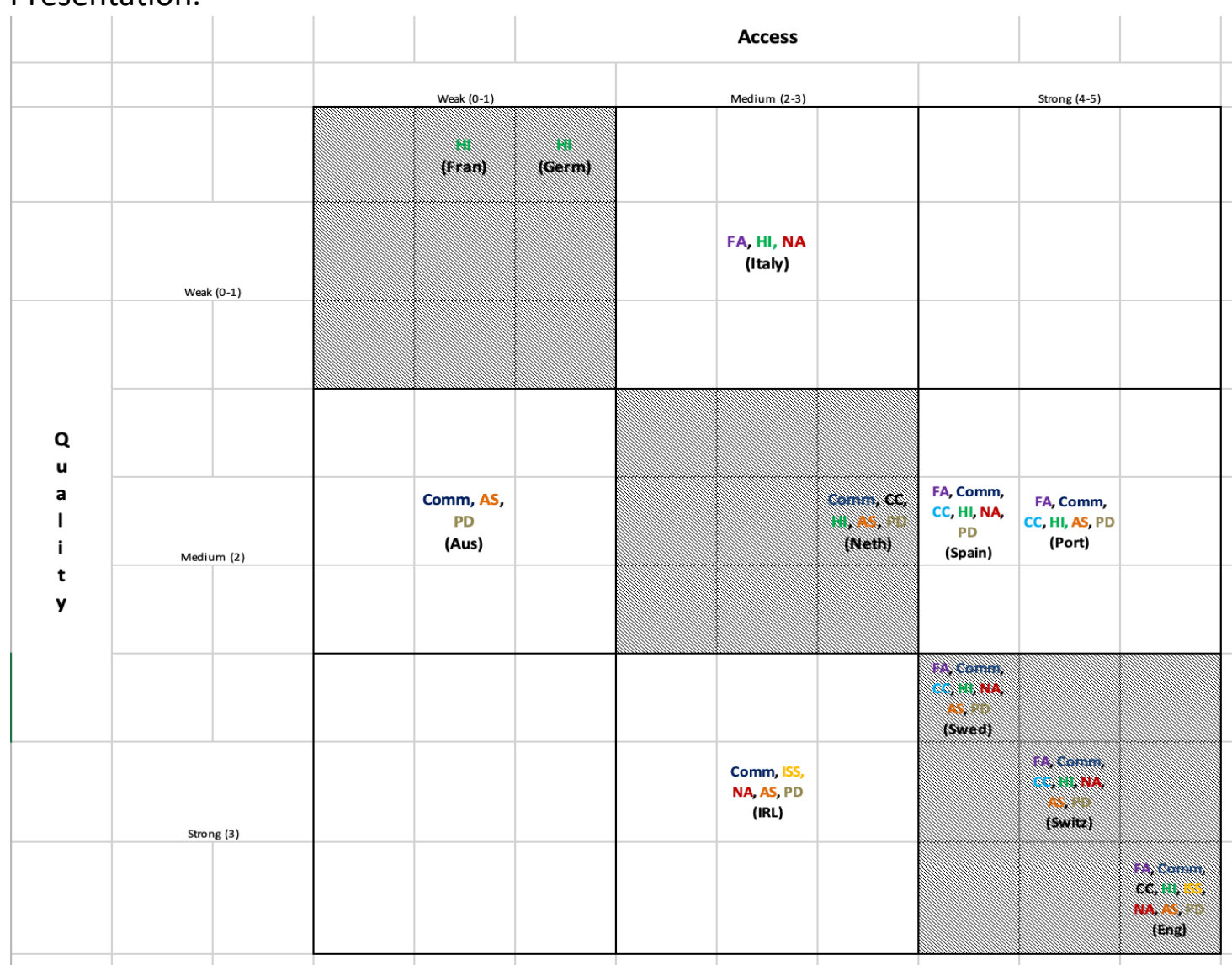

Table 4.23. Policy Strategy Subcategory Abbreviations.

\begin{tabular}{|l|l|}
\hline Subcategory & Abbreviation \\
\hline Facilitate Access to Health Care Services & FA \\
\hline Communication & Comm \\
\hline Care Coordination & CC \\
\hline Health Information & HI \\
\hline Increase Supply of Services & ISS \\
\hline Needs Assessment & NA \\
\hline Adaptation of Services & AS \\
\hline Health System Workforce Professional Development & PD \\
\hline
\end{tabular}

Some of the policy objective categories seem to have an apparent alignment with certain policy strategy subcategories as measured by prevalence in the same area 
of the typology matrix. For example, while the integration/social cohesion policy objective category seems to follow the same tendency as the majority of policy strategy subcategories in the access care category, it seems to have the strongest relationship with the facilitate access to health care services and care coordination subcategories. We see the integration/social cohesion policy objective category and the two subcategories on or above the shaded diagonal where the level of access is medium and strong. The health system adapts to migrants policy objective category appears to align with the adaptation of services and health system workforce professional development subcategories as all are present in the same area of the matrix that is strong on quality (i.e., below the shaded diagonal). The health equity policy objective category appears to be associated with the needs assessment subcategory. The subcategory is most prevalent in the area of the matrix with the strongest levels of both access to care and quality of care. This is the same area of the matrix where health equity is also the most prevalent. The assimilation policy objective category appears in the same area of the matrix as the health information policy strategy subcategory. Worth noting is that this is the only subcategory that is present in the same area of the matrix as the assimilation category. The health information subcategory, however, appears throughout the matrix and increases in prevalence with stronger levels of access and quality. As a result, an association between the objective category and policy strategy subcategory is rather weak. 
Interrelationships Among Health Policy Subcategories and Policy Objective Categories Certain policy strategy and policy objective categories align in that policy strategy subcategories that define low and high access to care and quality of care relate to policy objective categories. For example, the health system adapts to migrants category has an apparent alignment with the adaptation of services and health system workforce professional development subcategories as all three seem to have an apparent association with the quality of care dimension. The integration/social cohesion category appears to be related to the facilitate access to health care services and care coordination subcategories as all seem to align with the access to care dimension of the typology matrix. The health equity policy objective category, which has, has an apparent association with the needs assessment policy strategy, as both are prevalent in the area of the matrix with the highest levels of both access and quality. Conversely, the assimilation policy objective category, which has a tendency to be weak in access and quality, appears in the same area of the matrix with one subcategory, health information. However, as previously stated, health information does not distinguish the assimilation policy objective category as it appears throughout the matrix. The important takeaway is that the assimilation policy objective category appears with only one policy strategy subcategory.

\section{Typology Matrix Framework Summary of Policy Strategy Subcategories} The number of policy strategy subcategories increase along both the access to care and quality of care dimensions. The highest concentration of subcategories is in the area of the matrix that is strong in both access and quality. 
Subcategories categorized in the access to care category generally have an apparent alignment with the access to care dimension of the matrix. The alignment with access to care is particularly strong with the facilitate access to health care services and care coordination subcategories, as these subcategories are most prevalent in the area of the matrix that is strong along the access to care dimension.

We see a similar pattern with the adaptation of services and health system workforce professional development policy strategy subcategories and the quality of care dimension. The two subcategories appear on or below that shaded diagonal in the area of the matrix that is medium and strong along the quality of care dimension. The needs assessment policy strategy subcategory appears to be equally aligned with the strongest levels of access to care and quality of care.

\section{Health Services Major Category Subcategories}

The primary, secondary, and tertiary prevention categories placement in the typology matrix was presented in Figure 4.10 and page 159 . This presentation showed general tendencies among the three categories, but did not offer much detail regarding patterns, tendencies, and relationships with the access to care and quality of care dimensions. This is due to the number of subcategories in the primary (i.e., four), and secondary prevention (i.e., six) categories. Examination of the categories individually reveals more information pertaining to apparent patterns and relationship among subcategories and the matrix's two dimensions. Figure 4.15 depicts the primary prevention category mapped onto the typology matrix. The secondary prevention 
category's mapping onto the matrix is presented in Figure 4.16 . Tables 4.24 and 4.25 are a key for abbreviations used in the two figures. The parentheses below each country name are a count of the number of subcategories associated with a policy case (breadth) and the number of codes associated with a policy case (depth) in the health services primary prevention category (Figure 4.15) and secondary prevention category (Figure 4.16). The number on the left is a policy's breadth and the number on the right is its depth within the category.

The tertiary prevention category has a single subcategory, disease treatment. As there is only one subcategory, presentation of the category mapped onto the typology matrix is redundant as this information was presented in Figure 4.10 on page 164. For these reasons, presentation of a typology matrix with the tertiary prevention category is redundant and is not included.

Figure 4.15. Primary Prevention Category Typology Matrix Presentation.

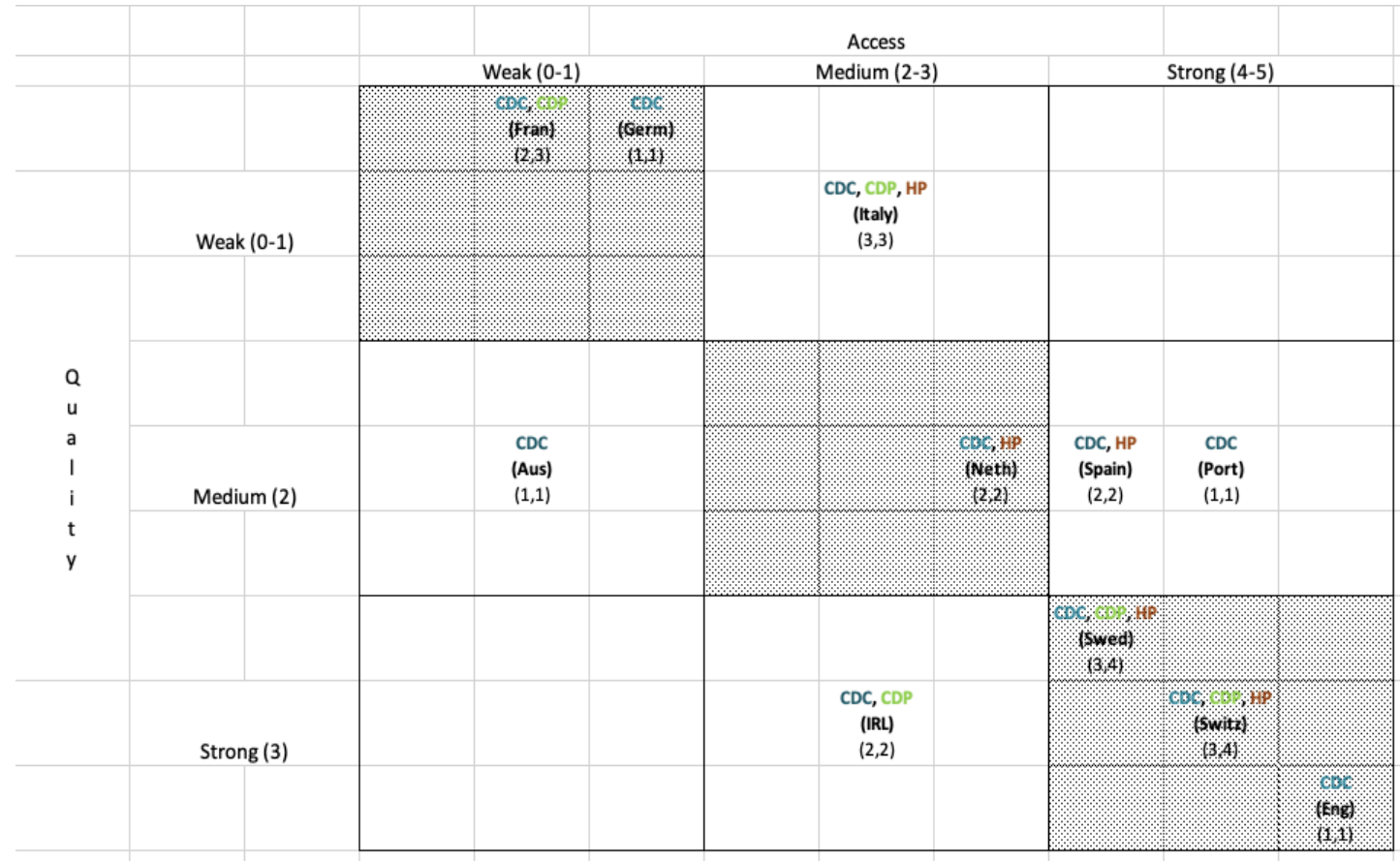


Table 4.24. Primary Prevention Category Abbreviations.

\begin{tabular}{|l|c|}
\hline \multicolumn{1}{|c|}{ Subcategory } & Abbreviation \\
\hline Communicable Disease Control & CDC \\
\hline Health Promotion & HP \\
\hline Communicable Disease Prevention & CDP \\
\hline
\end{tabular}

The communicable disease control subcategory does not vary at all in the matrix as all eleven cases are associated with codes in the subcategory. The health promotion subcategory has an apparent alignment with the access to care dimension of the matrix. We see the subcategory on or above the shaded diagonal in the area of the matrix that is associated with access to care. Health promotion is most prevalent in the area of the typology matrix where the access to care is strong. The communicable disease prevention subcategory appears on, above, and below that shaded diagonal on the matrix. The subcategory seems to have a slightly weaker relationship with the access to care dimension than quality of care as it is slightly more prevalent in the area of the matrix that is strong on quality.

\section{Secondary Prevention Category Matrix Presentation}

Figure 4.16 is a mapping of subcategories in the secondary prevention category on the typology matrix. Table 4.25 is a key for abbreviations used in Figure 4.16. 
Figure 4.16. Subcategories within the Health Services Secondary Prevention Category Matrix Presentation.

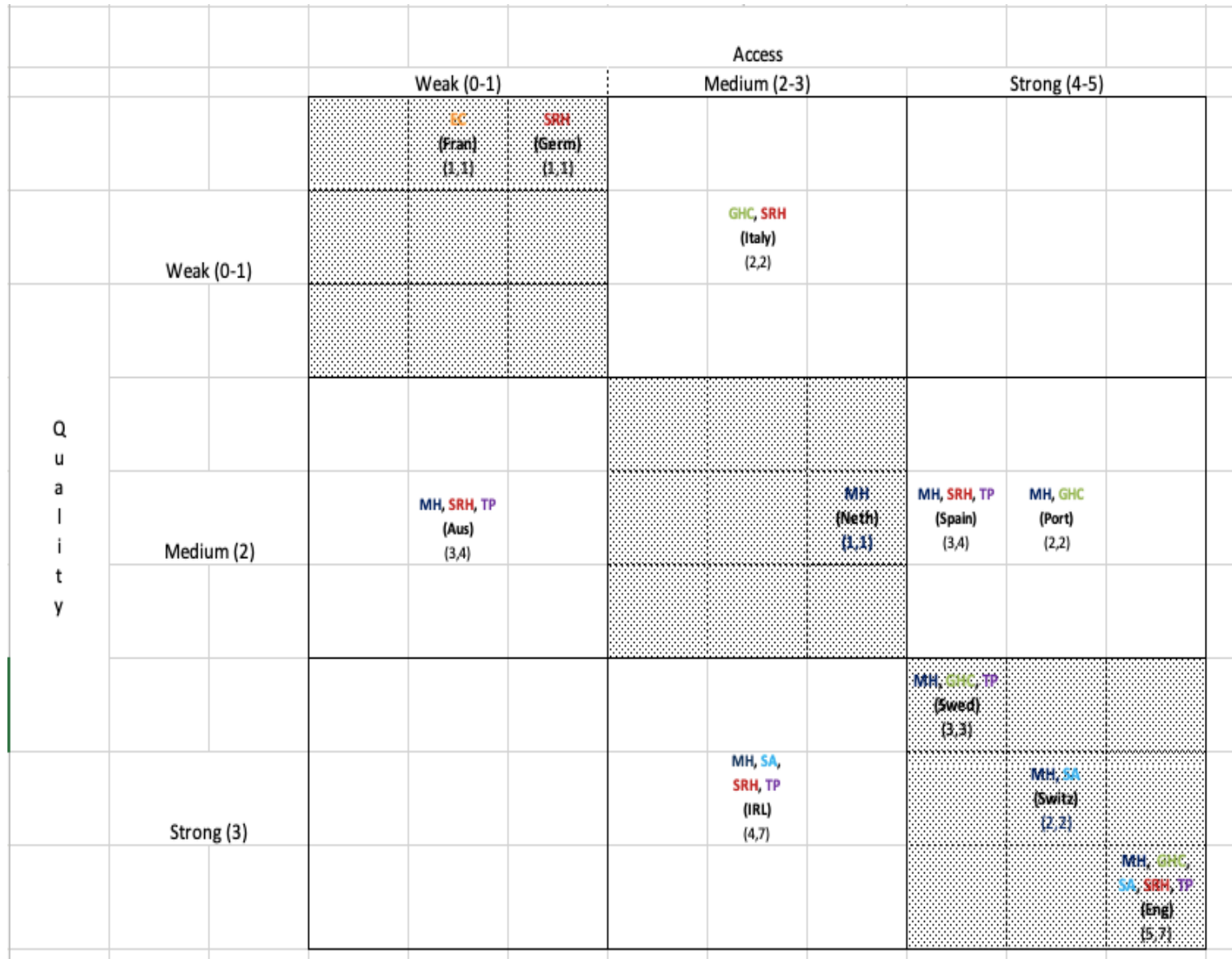

Table 4.25. Secondary Prevention Category Abbreviations.

\begin{tabular}{|l|c|}
\hline Subcategory & Abbreviation \& Color \\
\hline Mental Health & MH \\
\hline Substance Abuse & SA \\
\hline General Health Care & GHC \\
\hline Health Care for Target Populations & TP \\
\hline Sexual \& Reproductive Health & SRH \\
\hline Emergency Care & EC \\
\hline
\end{tabular}


The emergency care subcategory appears once in the matrix in the area that is weak in both the access to care and quality of care dimensions. General health care appears on or above the shaded diagonal and seems to relate more to the access to care dimension than the quality of care dimension. The subcategory increases in prevalence with higher levels of access. The subcategories mental health and substance abuse appear to have a stronger relationship with the quality of care dimension than the access to care dimension of the matrix. Mental health, while present all along the quality of care dimension, is more prevalent in the medium and strong areas of the quality of care dimensions. Substance abuse appears on or below the shaded diagonal on the matrix in the area that is medium and strong along the quality of care dimension. The tendency for these two subcategories to align with quality of care suggests that behavioral health may be more associated with quality of care than access to care. The health care for target populations subcategory generally appears on the matrix on or below the shaded diagonal and is most prevalent in the area of the matrix that has the strongest levels of access to care and quality of care.

\section{Health Services Subcategories \& Policy Objective Category Interrelationships}

Some health services subcategories and policy objective categories seem to relate. For example, the assimilation policy objective category seems to align with the emergency care only health services subcategory. Again, alignment was determined by category and subcategory prevalence in the same area of the typology matrix. The health system adapts to migrant category, in the policy objective major category, and 
the health services subcategories mental health and substance abuse also appear to be aligned as all three are most prevalent in the area of the matrix that is strong along the quality of care dimension. The policy objective category integration/social cohesion appears to have an apparent relationship with the health promotion subcategory, categorized in the health services primary prevention category, as well as the general health care subcategory in the secondary prevention category. The health equity policy objective category seems to relate to the health services for target population subcategory, in the secondary prevention category. The category and subcategory are prevalent in the area of the matrix with the strongest levels of the access to care and quality of care dimensions in the matrix. Lastly, the tertiary prevention category in the health services major category appears to be associated with health equity. Tertiary prevention is only present in the area of the matrix that is strong along both the access to care and quality of care dimensions. This is the same area of the matrix where the health equity policy objective category is most prevalent.

\section{Primary and Secondary Category Subcategory Matrix Summary Subcategories grouped in the primary and secondary prevention categories} appear all along the access to care and quality of care dimensions of the typology matrix. The number of subcategories in both categories vary throughout the matrix. Some subcategories appear to have a stronger relationship with either the access to care or quality of care dimension. For example, the health promotion subcategory (in the primary prevention category) and general health care (in the secondary prevention 
category) seem to relate with the access to care dimension based upon prevalence in the typology matrix. The mental health and substance abuse subcategories in the secondary prevention category seem to be associated with the quality of care dimension of the matrix.

Some subcategories in the secondary and tertiary prevention categories seem to be equally related to both the access to care and quality of care dimensions. Health care for target populations tends to increase in prevalence along both the quality of care and access to care dimensions. The subcategory seems to be associated with the strongest levels of access and quality. We see a similar trend with the disease treatment subcategory in the tertiary prevention category. Disease treatment appears twice in an area of the matrix where both the access to care and quality of care dimensions are strong. The emergency care subcategory, in the secondary prevention category, also appears to be equally associated with the both dimensions. The emergency care subcategory seems to have a weak apparent association with both the access to care and quality of care dimensions of the typology matrix.

Layering categories in the policy objective major category over subcategories in the health services major category informed whether or not apparent associations between the two were present. The tertiary prevention health services category and health care for target populations subcategory (in the secondary prevention category) are both prevalent in the same area of the matrix as the health equity policy objective category. Additionally, there seems to be an alignment between the assimilation policy 
objective category and the emergency care subcategory (in the secondary prevention health services category) as both have an apparent weak association with both the access to care and quality of care dimensions of the matrix. The health promotion subcategory (in the primary prevention category) and general health care subcategory (in the secondary prevention category) have an apparent alignment with the access to care dimension that mirrors that of the integration/social cohesion policy objective category as they all are most prevalent along the access to care dimension of the matrix. The health system adapts to migrants policy objective category seems to have an apparent alignment with the substance abuse and mental health subcategories in the secondary prevention category. All are most prevalent along the quality of care dimension of the matrix.

As we saw with the presentation of categories in the policy objective major category that formed a diagonal in the typology matrix, with the assimilation and health equity categories at opposite ends, a similar pattern appears among the subcategories in the primary, secondary, and tertiary prevention categories of the health services major category. The emergency care subcategory is at one end of the diagonal as it appears to have a weak association with both the access to care and quality of care dimensions. This is the same area of the matrix where the assimilation category in the policy objective major category appears. At the other end of the diagonal, we see the health care for target populations subcategory (in the secondary prevention category) and the disease treatment subcategory (in the tertiary prevention category). Both 
subcategories appear to be related with the strongest levels of both the access to care and quality of care. These subcategories are present in the same position in the matrix and on the diagonal as the health equity policy objective category.

\section{Theme Identification}

The purpose of phases one and two was to determine if there was a defining structure across the eleven policy cases that could lead to a theme-based typology. That structure was identified by mapping the four major categories onto a typology matrix developed by Collier et al. (2012) and examining interrelationships between the four major categories and the matrix's two dimensions, access to care and quality of care. Investigation of interrelationships between the major categories also informed the identification of emergent themes. The analysis found that, while access to care and quality of care showed a strong structure, their interrelationship is best summarized by the categories in the policy objective major category. The assimilation and health equity categories form opposite ends of a diagonal. Integration/social cohesion and health system adapts to migrant populations categories move independently along the access and quality dimensions. As integration/social cohesion and health system adapts to migrants categories combine, we move toward health equity. As a result, the policy objective major categories best define the categorical variables, (i.e., the "squares"), in the typology matrix and areas along an associated migrant health policy continuum.

The two-phase analytic process resulted in the emergence of four distinct themes that include assimilation, integration, health system adaptation, and health 
equity. These themes emerged as a result of identifying apparent relationships across and within the major categories of data that include policy objective, policy strategy, health services, and target population. The titles of the theme intentionally reference the names of categories in the policy objective major category.

\section{Theme \#1 - Assimilation}

The assimilation theme is weak on both access to care and quality of care. The assimilation theme has four codes that align around the concept of a migrant assimilating into the host nation society. Protection of the host nation's population from communicable diseases transmitted from the migrant population is associated with this theme.

The assimilation theme is related to one policy strategy subcategory, health information. However, health information is present throughout the typology matrix. What distinguishes the assimilation theme is not so much its association with the health information subcategory. Rather, what is notable is the narrow breadth of policy strategy subcategories (one total) that have an apparent association with the theme.

A single health service subcategory in the secondary prevention category, emergency care only, is associated with the assimilation theme. The emergency care only subcategory has a weak association with both the access to care and quality of care dimensions and is not present anywhere else in the matrix.

The assimilation theme defined through its weak apparent association with the access to care and quality of care dimensions as well as the narrow breadth of policy 
strategies and health services that have an apparent association with the theme. The assimilation theme signals that migrants are not considered a special, medically vulnerable population in need of support from the health system.

\section{Theme \#2 - Integration}

The integration theme has a stronger apparent association with the access to care dimension and generally weaker association with the quality of care dimension. The theme appears to increase in prevalence along the access to care dimension and is most prevalent in the area of the matrix that is strong along the access to care dimension.

The policy strategy subcategories facilitate access to health care services and care coordination seem to be associated with the integration theme. The subcategories are prevalent in the same area of the matrix, above the shaded diagonal where the access to care dimension is stronger than the quality of care dimension. These policy strategy subcategories align with the integration theme in that they acknowledge migrants are a diverse and heterogeneous population and foster a feeling of social inclusion through activities that facilitate access to health care services for a population that is at risk of being socially and medically isolated.

Two health services are associated with the integration theme and include health promotion and general health care. Health promotion (in the primary prevention category) consists of both health promotion and disease prevention. General health care (a subcategory in the secondary prevention category) includes primary care which 
covers care for the entire family as well as dental care. These health services foster social inclusion by caring for the whole family and focusing on health promotion and disease prevention, (e.g. the healthier a person is, the more able they are to participate in society).

Two target population categories, newly arrived migrant and undocumented migrant, seem to be related to the access to care dimension as both appear to increase in prevalence with higher levels of access. Because the integration theme has a tendency to increase with higher levels of access, there is an apparent relationship with these target population categories.

The integration theme is distinct from the other three themes based on its association with access to care. We see the theme's orientation toward fostering access to health care services for heterogeneous migrant populations articulated in the policy objectives, policy strategies, health services, and target population that all have an apparent association with the integration theme through their respective associations with the access to care dimension of the typology matrix.

\section{Theme \#3 - Health System Adaptation}

The health system adaptation theme appears to have a stronger association with the quality of care dimension of the matrix and generally weaker association with the access to care dimension. The health system adaptation theme, health system workforce professional development, and adaptation of services policy strategy subcategories appear to be related based upon prevalence in the same area of the 
typology matrix, (i.e., on or below the shaded diagonal on the matrix). The two subcategories includes codes that are foundational aspects of the health system adapting to meet the needs of a diverse population. They are cultural competency training for a health system's workforce and adapting clinical practice to meet the health seeking and receiving needs of a medically vulnerable population.

In the health services major category, the health system adaptation theme has an apparent alignment with two subcategories in the secondary prevention category. The mental health and substance abuse subcategories are most prevalent in the area of the matrix that is strong along the quality of care dimension. The health system adaptation policy objective category is also prevalent in this area of the matrix. These health service subcategories are likely an acknowledgement that migrant populations have unique health profiles that have likely been shaped by experiences in their country of origin, the process of migration, and resettlement processes.

The health system adaptation theme is distinguished from the other three themes through its focus on health system level interventions to address or augment to quality of health care delivered to migrant populations. This is accomplished through adapting clinical practice to meet the needs of ethnically and culturally diverse migrant populations.

\section{Theme \#4 - Health Equity}

Health equity is distinguished by its association with access to care and quality of care coming together at the strongest levels. The health equity theme does not happen 
on its own. Rather, health equity is a function of stronger levels of access to care and quality of care in conjunction with the integration theme and/or health system adaptation theme. Health equity's orientation toward migrant health is apparent in its emphasis on: 1) equal opportunities for migrants; 2) equality between migrant and host nation populations; and 3) reducing health inequities that exist between migrant and host nation populations.

The health equity theme has an apparent association with the needs assessment policy strategy subcategory. The subcategory is most prevalent in the area of the matrix where the access to care and quality of care dimensions are the strongest. Alignment of this subcategory with the health equity theme supports its orientation to equal health care opportunities for migrant through the use of research and learning to identify and respond effectively to the health care needs of heterogeneous migrant populations.

In the health services major category, we see alignment between the health equity theme and the health care for target populations subcategory (in the secondary prevention category). The tertiary prevention category is also aligned with health equity as the category is only present in the area of the matrix with the strongest levels of the access to care and quality of care dimensions.

Health equity is distinguished from the other three themes through its association with access to care and quality of care coming together at strongest levels in conjunction with it association with the integration theme, health system adaptation theme, or both themes. 


\section{Migrant Health Policy Orientation Toward Migrant Health Typology Matrix Presentation}

The process of mapping the major categories of data onto the typology matrix framework and exploring their tendencies and apparent relationships supported placement of the four themes in the typology matrix framework. Each theme is a summary of the tendencies of apparent relationships between the major categories, (i.e., policy objective, policy strategy, health service, and target population), that have been explored in this chapter. Each theme's position in the typology matrix is supported by its apparent relationships with the policy objective, policy strategy, health services, and target population major categories. The title of the typology matrix, (i.e., the concept that is measured by the typology), is "Migrant Health Policy Orientation Toward Migrant Health". The typology matrix is characterized by categorization of the four themes' orientation toward protecting and promoting the health of migrant populations along the matrix's two dimensions, access to care and quality of care.

\section{Theme Positioning in the Typology Matrix as Categorical Variables}

The themes are the categorical variables in the matrix typology. Per Collier et al.

(2012) the categorical variable for each cell communicates a substantive meaningful label that corresponds with its position in the matrix in relation to the access to care (i.e., the row variable) and quality of care (i.e., column variable) and is mutually exclusive. 
The assimilation theme is positioned in the upper left quadrant of the typology matrix as it has an apparent weak relationship with both the access to care and quality of care dimensions. The relationship is reinforced with the theme's apparent association with few subcategories in the policy strategy and health services major categories. Assimilation is distinguished from the other three themes by its weak relationship with access and quality and narrow breadth of association with categories in the policy strategy major category and health services in the primary and secondary categories in the health services major category.

The integration theme is positioned in the upper right quadrant of the typology matrix. Its position is supported by the theme's apparent stronger association with the access to care dimension and slightly weaker association with the quality of care dimension. The theme's association with policy strategy subcategories in the access to care category supports its position in the typology matrix.

The health system adaptation theme is positioned in the lower left quadrant of the typology matrix. The theme's position in the matrix was determined based on its apparent stronger association with the quality of care dimension and slightly weaker association with the access to care dimension as well as its apparent relationship with the health system adaptation oriented health services and policy strategies.

The health equity theme appears in with matrix with the integration, health system adaptation, or together with both themes, plus stronger levels of access to care and quality of care. As a result, the health equity theme is positioned in the lower right 
quadrant of the typology matrix that is strong in both the access to care and quality of care dimensions.

\section{Typology Matrix Presentation}

The Migrant Health Policy Orientation Toward Migrant Health Typology matrix is

presented in Figure 4.18. The typology matrix includes the theme positioned as

categorical variables in the matrix that are: assimilation, integration, health system adaptation, and health equity. Also depicted in Figure 4.18 are the themes apparent alignment with the policy objective, health services, and target population major categories. Table 4.26 is a key for abbreviations presented in Figures 4.17 and 4.18.

Figure 4.17. Migrant Health Policy Orientation Pertaining to Migrant Health Typology Matrix.

\section{Access to Care}

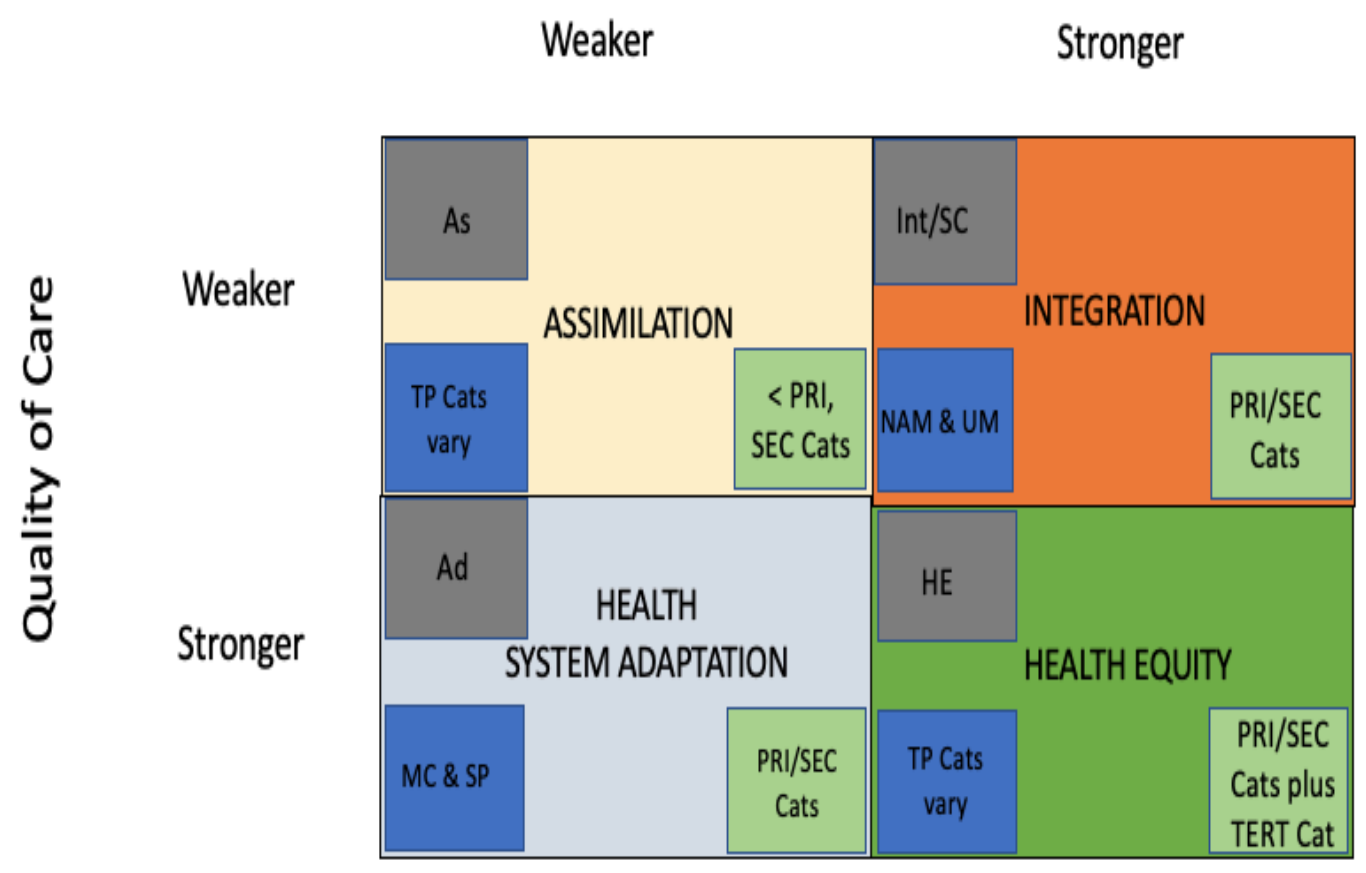


Figure 4.18 presents the four theme's alignment with subcategories in the policy strategy and health services major categories.

Figure 4.18. Theme Alignment with Subcategories in the Policy Strategy and Health Services Major Categories.

Access to Care

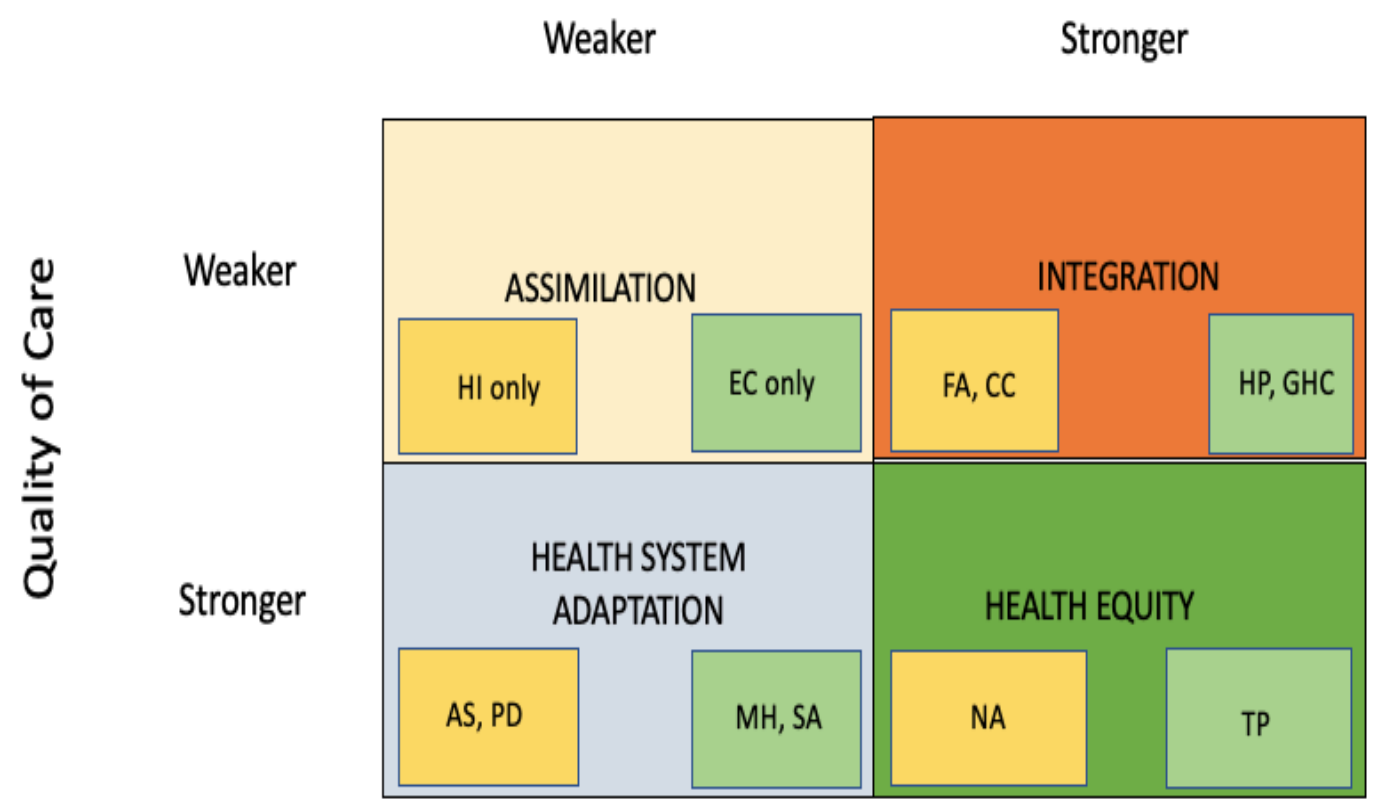


Table 4.26. Abbreviation Key for Figure 4.18 and 4.19.

\begin{tabular}{|c|c|c|c|}
\hline $\begin{array}{l}\text { Policy Objective } \\
\text { Category }\end{array}$ & $\begin{array}{l}\text { Target Population } \\
\text { Major Category }\end{array}$ & $\begin{array}{l}\text { Policy Strategy Major } \\
\text { Category }\end{array}$ & $\begin{array}{l}\text { Health Services Major } \\
\text { Category }\end{array}$ \\
\hline As - Assimilation & MC - Migrant Child & CC-Care Coordination & $\begin{array}{l}\text { PRI - Primary } \\
\text { Prevention Category }\end{array}$ \\
\hline $\begin{array}{l}\text { Int/SC - Integration and } \\
\text { Social Cohesions }\end{array}$ & $\begin{array}{l}\text { NAM - Newly Arrived } \\
\text { Migrant }\end{array}$ & $\begin{array}{l}\text { Comm - } \\
\text { Communication }\end{array}$ & $\begin{array}{l}\text { CDC-Communicable } \\
\text { Disease Control }\end{array}$ \\
\hline $\begin{array}{l}\text { Ad - Health System } \\
\text { Adapts to Migrant } \\
\quad . . .\end{array}$ & $\begin{array}{l}\text { SP - Special } \\
\text { Populations }\end{array}$ & $\begin{array}{l}\text { FA - Facilitate Access to } \\
\text { Health Care Services }\end{array}$ & $\begin{array}{l}\text { CDP - Communicable } \\
\text { Disease Prevention }\end{array}$ \\
\hline \multirow[t]{10}{*}{ HE - Health Equity } & $\begin{array}{l}\text { UM - Undocumented } \\
\text { Migrant }\end{array}$ & $\mathrm{HI}$ - Health Information & $\begin{array}{l}\text { HP - Health } \\
\text { Promotion }\end{array}$ \\
\hline & $\begin{array}{l}\text { DM-Documented } \\
\text { Migrant }\end{array}$ & $\begin{array}{l}\text { ISS - Increase Supply of } \\
\text { Services }\end{array}$ & $\begin{array}{l}\text { SEC - Secondary } \\
\text { Prevention Category }\end{array}$ \\
\hline & & $\begin{array}{l}\text { NA - Needs } \\
\text { Assessment }\end{array}$ & $\mathrm{MH}-$ Mental Health \\
\hline & & $\begin{array}{l}\text { AS - Adaptation of } \\
\text { Services }\end{array}$ & $\begin{array}{l}\text { GHC-General Health } \\
\text { Care }\end{array}$ \\
\hline & & & $\begin{array}{l}\text { TP - Health Care for } \\
\text { Target Populations }\end{array}$ \\
\hline & & & $\begin{array}{l}\text { SRH - Sexual \& } \\
\text { Reproductive Health }\end{array}$ \\
\hline & & & EC-Emergency Care \\
\hline & & & SA - Substance Abuse \\
\hline & & & $\begin{array}{l}\text { Tert - Tertiary } \\
\text { Prevention Category }\end{array}$ \\
\hline & & & $\begin{array}{l}\text { DT - Disease } \\
\text { Treatment }\end{array}$ \\
\hline
\end{tabular}

\section{Chapter Conclusion}

This chapter presented an analytic process that took part in two phases. Phase one involved identifying salient units of text from the eleven policy documents, the 
inductive and reflective process of assigning descriptive codes to units of text, identification of groups of codes, the organization of codes based on thematic alignment into major categories, and then the development of an organizing structure for each major category. The four major categories that emerged from this process include policy objective, policy strategy, health services, and target population.

The second phase involved application typological analysis to the content analysis that was completed in phase one. Organized by categorization rather than a hierarchal arrangement, scholars create typologies in order to form concepts, refine measurement, explore dimensionality, and organize claims (Given, 2008; Collier et al., 2012). Given (2008) states, "Typological analysis is a strategy for descriptive qualitative (or quantitative) data analysis whose goal is the development of a set of related but distinct categories within a phenomenon that discriminate across the phenomenon" ( $p$. 2).

Application of typological analysis was used to identify themes. Following a test of the typology matrix framework with the policy strategy major category, the three other major categories were mapped onto the matrix in order to identify apparent relationships, tendencies, and patterns across and within the four major categories that emerged from the first phase of analysis. This process resulted in the identification of four themes and their placement in a matrix typology with two dimensions, access to care and quality of care, that increase from weak to strong. The themes that emerged 
from phase two of the research process include assimilation, integration, health system adaption, and health equity.

Assimilation has a weak relationship with access and quality and is located in the upper left quadrant of the typology matrix. The theme position in the matrix is a reflection of it tendency to align with relatively few subcategories in the policy strategy and health services major categories.

Integration is located in the upper right quadrant of the typology matrix. The theme has a stronger tendency to align with the access to care dimension more than the quality of care dimension. Integration is distinguished by its apparent association with the facilitate access to health care services and care coordination policy strategy subcategories as well as the general health care and health promotion subcategories in the health care services major category.

Health system adaptation is located in the lower left quadrant of the typology matrix. The theme has a stronger association with the quality of care dimension than the access to care dimension. Health system adaptation is distinguished by its apparent association with the adaptation of services and health system workforce professional development policy strategy subcategories as well as the mental health and substance abuse health services subcategories. The theme's position in the matrix, in conjunction with its alignment with mental health and substance abuse, suggest an alignment between behavior health care and quality of care. 
Health equity is located in the lower right quadrant of the typology matrix, an area that is strong along both the access to care and quality of care dimensions. The theme is distinguished by its tendency to align with the needs assessment policy strategy subcategory as well as the health care for target populations health services subcategory. This apparent association can be interpreted as prioritizing the delivery quality health care services to specific populations, such as undocumented migrants, and applying knowledge gained through assessing the health care needs of heterogeneous migrant populations.

While no discernable association between any of the themes and target population major categories was established, target population category tendencies pertaining to access to care and quality of care are worth noting. The special population and migrant child categories appear to be more associated with the quality of care dimension as they are prevalent in the medium and strong areas of the matrix. Conversely, the newly arrived migrant and undocumented migrant categories seem to be more related to the access to care, as they increase in prevalence along the dimension. For these reasons, the special population and migrant child categories are positioned within the health system adaptation quadrant of the typology matrix. The newly arrived migrant and undocumented migrant categories are located in the integration quadrant of the matrix. 
The typology matrixes presented in Figures 4.18 and 4.19 are the basis for a more nuanced continuum that will be presented and thoroughly explored in chapter five. 


\section{Chapter V-Discussion and Conclusion}

\section{Chapter Organization}

Chapter five is a discussion of key findings and conclusions derived from the results of the study. Because there are two distinct phases of this research, the discussion pertaining to the study's context within the scope of existing migrant health policy comparative analysis research is addressed in relation to content analysis and typological analysis separately. The results of this research are reflected upon in relation to existing migrant health comparative policy analysis research. Assumptions and limitations of the study are then considered. The chapter concludes with a summary of research implications of this study for migrant health policy comparative analysis research, migrant health policy process research, and migrant health outcomes research.

\section{Discussion Introduction}

This study is a comparative policy analysis of eleven migrant health policies. It is among a handful of studies that examines eleven policy cases adopted in Europe between 1998 and 2007. The discussion of key findings is organized according to the study's two-phased analytic process, content analysis followed by typological analysis. Phase one resulted in the identification of four major categories of policy content (i.e., policy objective, policy strategy, health services, and target population) and the identification of general similarities and differences across the group of policies. The major categories were mapped onto the typology matrix framework in phase two. 
Documentation of tendencies and relationships with the major categories and the typology matrix's two dimensions were an outcome of typological analysis. The results of phase one and two was the emergence of four themes that are a "type" of orientation toward the health of migrant populations.

\section{Synthesis of Content Analysis of the Policy Cases}

Harold Laswell's seminal definition of politics and policy, "Who gets what, when, and how?" was applied as an organizing frame for the data analyzed in phase one (Laswell, 1936). Laswell's frame informed how data was grouped at the highest level of organization. These groupings were termed "major categories". In all, four major categories emerged from content analysis of the policy documents. Each major category has a unique organizational structure of thematically aligned data. In this study Laswell's "who" is the target population designated in a policy document; "what" is the policy objectives which are the stated goals the policy intends to achieve; and "how" are the policy strategies and health services specified in a policy that articulate a plan to achieve the "what". "When" was not explored as this information was not readily apparent in the policy documents analyzed in this study. Laswell's frame was utilized to identify and categorize structural elements of the policy documents, creating a comprehensive organizational scheme for the data analyzed. This distinctive organizing frame was used to derive meaningful comparisons and understanding of variation across the policy cases based solely on content analysis of the language of a policy document. Figure 5.1 
depicts the study's application of Laswell's frame as an organizing structure for that data analyzed, coded, and grouped in phase one.

Figure 5.1. Application of Laswell's frame to data organization.

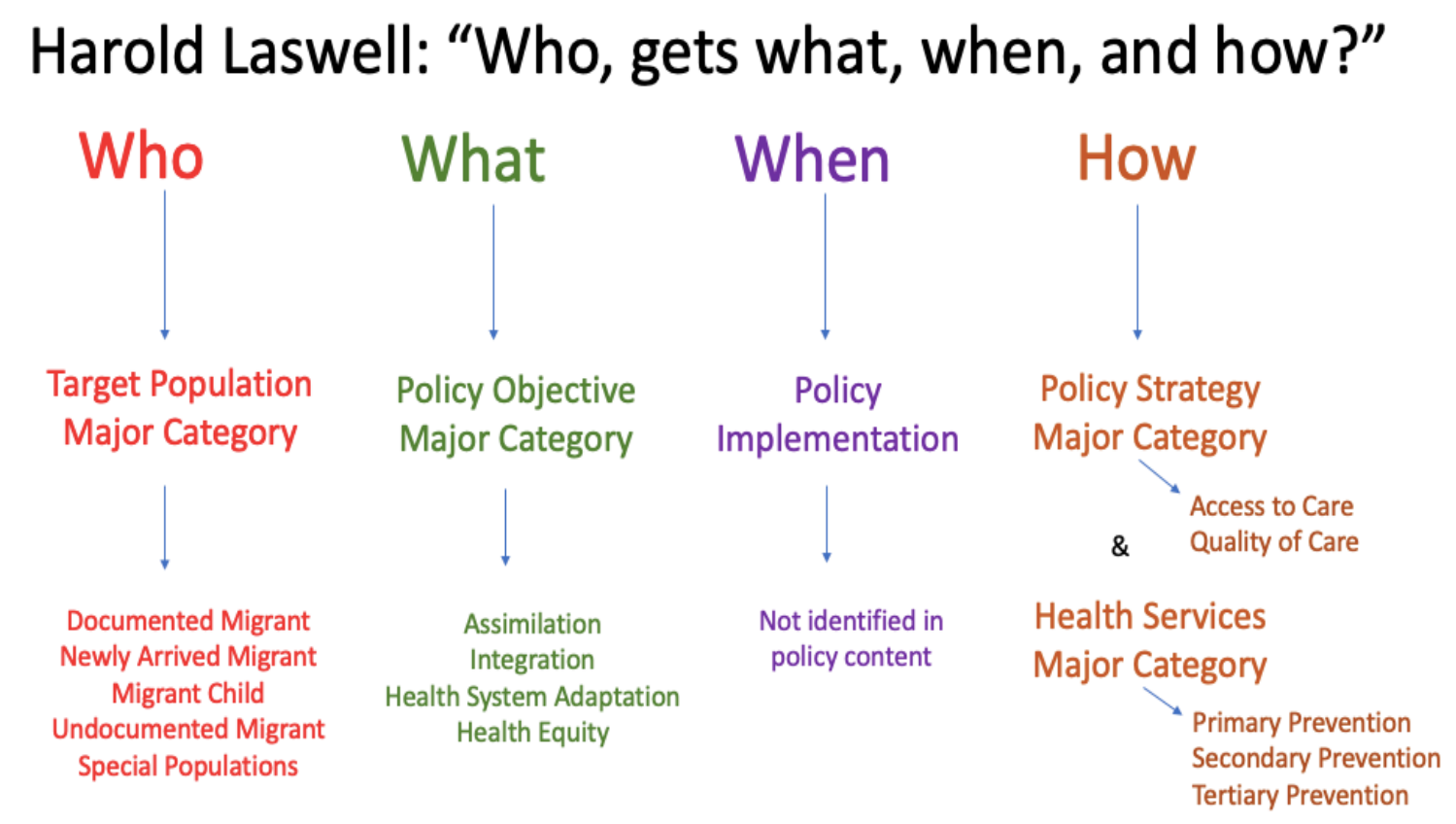

Key Findings from Phase One: Content Analysis

Organization of data into and within major categories enabled comparisons

across the eleven policy cases. In each of the major categories, areas of convergence and divergence were identified. Convergence is defined as content areas where the majority of policy cases ( i.e. six or more) are associated with a category or subcategory. Significant convergence is defined as ten or more cases associated with a specific content area. Divergence is defined as a minority of the policy cases (i.e., five or less) 
associated with a category or subcategory. Significant divergence is defined as less than two cases associated with a specific content area.

In the policy objective major category, we see areas of convergence in three of the four categories: health equity, health system adapts to migrants, and the integration and social cohesion category. The assimilation category, however, is a policy content area where we see significant divergence. A single policy is associated with this category. A thematic trait of the assimilation category is migrants adapt into the host nation's culture and society. The fact that one of the eleven policy cases is associated with the assimilation category indicates that the explicit expectation of migrants to fully assimilate into the host nation society is not a widely held perspective among the cases in this analysis.

All eight subcategories in the policy strategy major category are all content areas that are common across the eleven policy cases. The fact that the eight subcategories are areas of content convergence across the policy group signals that the cases generally have the same strategies for improving the quality of service delivery to migrant populations and augmenting health care access.

Policy case association with categories in the health services major category varies significantly. All eleven policy cases are associated with the communicable disease control subcategory in the primary prevention category. Within the secondary prevention category, the mental health and sexual and reproductive health subcategories are associated with the majority of cases. The target populations, general 
health care, and substance abuse categories, however, are associated with a minority of the policies. The emergency care subcategory is a notable area of significant divergence as a single policy case is associated with the subcategory. The tertiary prevention category is another area of significant divergence with its association with two cases. The fact that the majority of policy cases are associated with mental health care is likely an acknowledgement that this is a necessary health services stemming from the very real possibility that migrants may have experienced trauma during the pre-flight, flight, or resettlement phases of migration. Association with cases among the other health services in the secondary prevention category signals that policy cases have different priorities. Areas of significant divergence in the health services major category represent opposing ends of the health care service spectrum. Tertiary care is at one end of the spectrum and emergency care is at the opposite end. Tertiary care aims to reduce the impact of an established disease through the reduction of disease-related complications (Shi and Singh, 2008). Emergency care is the immediate diagnosis or medical treatment delivered an individual who health is in serious jeopardy. The fact that two or less cases are associated with emergency care and tertiary care suggests that the majority of policy cases fall between these two extreme spectrums of health care service delivery.

The target population major category has one content area of significant convergence and three areas of divergence. All eleven cases are associated with the documented migrant category. The remaining four categories (i.e., newly arrived, special population, undocumented migrant, and migrant child) are associated with a 
minority of the policy cases. The documented migrant category includes a set of codes that share one common trait, the legal right to live and work in the host nation. The formal rights attributed to documented migrant who have obtained permission from the state to live and work in the country are likely a recognition among all of the policies that this specific migrant population is deserving of benefits allocated in a migrant health policy. Association with the other target population categories indicates that there is not a clear agreement among the cases on how narrow or broadly to define migrant populations with regard to the state's responsibility for health.

\section{Section Summary}

Significant convergence was identified in two major categories, health services and target population. In the health services major category, all of the policy cases were associated with the communicable disease control subcategory. This was also the case with the documented migrant category in the target population major category. Significant convergence in these two content areas could be interpreted as foundational aspects or necessary elements of a migrant health policy. The literature offers evidence that the process of migration is a driver of communicable disease transmission in western and northern European nations (Wörmann and Krämer, 2011). Migrants coming from countries with a high burden of communicable disease can be vectors of transmission to the host nation's population. Communicable disease control as a necessary migrant health policy element is likely a population health response among nations receiving migrants from countries where communicable disease transmission is 
highly endemic. The fact that all eleven policies allocate policy benefits to documented migrants could be interpreted as nations acknowledging migrants who have gone through processes to obtain the legal right to live and work in the country as deserving of said benefits. In this regard, documented migrants could be considered as an example population for other migrant populations whose legal status is either yet to be determined (i.e., asylum seekers and refugees) or absent (i.e., undocumented).

Content areas associated with a majority of cases (i.e., all policy strategy subcategories and mental health) indicates generally agreed upon content element. The eight policy strategy subcategories are all likely pathways to achieve a policy case's stated objectives. The provision of mental health care may be interpreted as an acknowledgement that migrants have distinctive health needs that may be shaped by the process of migration.

Divergent content areas are found in the assimilation policy objective category and opposing ends of the health care services spectrum (i.e., emergency and tertiary care). The take away is that a minority of policy cases are associated with extreme policy content areas such as placing the onus on migrants to assimilation into the host nation's health system or providing limited (i.e., emergency care) and generous (i.e., tertiary care) health services. The majority of cases offer migrant populations health care services between these extreme ends of the health care continuum.

Identifying areas of convergence to divergence across the four major categories was the first step to understand variation among the policy cases included in this study. 
Variation in policy association with content areas signals policy may vary by "type". The idea that there might be policy "types" motivates further exploration of policy variation using typological analysis to fully explore policy variation by identifying patterns, tendencies, and relationships within and across the major categories.

\section{Existing Migrant Health Policy Research Comparisons}

An objective of this study was to identify "how" the policy cases are similar and different based on their content. How this group of policy cases are similar and different has been explored in extant research published in peer-reviewed journals and grey literature. Published migrant health policy research has generally examined a subset of the eleven policy cases. The majority of existing comparative migrant health policy analysis research is based upon a set of a priori domains deemed important by the researcher. The literature is unclear as to how and why researchers selected domains.

In her 2009 research, Mladovsky proposed a framework to compare and contrast these four policies. The framework is organized into five categories that are data collection, population groups targeted, health issues targeted, part of the health system targeted (i.e., supply-side versus demand-side), and implementation (Mladovsky, 2009). By creating an analytic framework with which to compare and contrast migrant health policies Mladovsky's research offers policy makers examples of other countries experiences implementing a migrant health policy.

A study by Mladovsky, P., Rechel, B., McKee, M. published in 2012 analyzed all eleven migrant health policy cases that are a part of this study. Data collected and 
synthesized came from policy makers and country-level reports on the health care system and migrant populations entitlement to care in order to identify main policy elements of the eleven cases (Mladovsky et al., 2012). Their framework was organized by population group targeted, health issues addressed, and whether the policy targeted patients (demand) or providers (supply), but excluded implementation (Mladovsky et al., 2012). The authors offer general conclusions about the possible strengths and limitations of the 11 policies' approach to migrant health. For example, they note that policies focusing on either new or established migrants is a limitation and that policies should equally focus on both migrant populations (Mladovsky, 2012). The researchers note that the policies include a mix of health care initiatives that target either patients or providers and that a few nations are notable for their focus on increasing health literacy among migrants (Mladovsky et al., 2012, pg. 8). The researchers found significant variation across the eleven policies in terms of population group targeted, health services addressed, and whether the policies were oriented toward health system demand or supply. They also found some disconnect between health services identified in a policy and the health needs of migrant populations served by that policy (Mladovsky et al, 2012).

This study aligns with Mladovsky's 2009 and 2012 work in that there are three areas of data categorization at the highest level of organization that are also found in Mladovsky's 2009 and 2012 work (i.e., population, health services, and health system supply-side versus demand-side). The access to care and quality of care categories 
within the policy strategy major category identified in this study are comparable to health system supply (i.e., quality) versus demand (i.e., access). Supply-side initiatives target providers and include interventions such as training for providers, while demandside health system interventions are aimed at modifying the health care seeking needs among migrant populations (Mladovsky et al., 2012). Providing health information, health education, cultural mediation, translation, and interpretation for migrant populations are examples of demand-side health system interventions. Demand-side interventions are similar to policy strategy subcategories in the access to care category. We see these health system interventions in the care coordination, communication, facilitate access to health care services, and health information subcategories in the access to care category. Supply-side health system interventions are present in the health system workforce professional development subcategory that is in the quality of care category. This subcategory includes cultural competency training for providers which a specific intervention noted in Mladovsky et al.'s (2012) research.

This study differs from Mladovsky's research in a couple of ways. Her analytic framework was a priori and not derived directly from policy case content as is the case with this study. This study's content analysis of the eleven policy cases was systematic and transparent, categorizing all relevant units of text from policy documents. While Laswell's seminal definition of policy and politics informed how data was organized at the highest structural level, this study's process of identifying and categorizing relevant units of text was inductive, not a priori. The organizational structure of the data from 
the eleven cases is derived from their content and is one of the results of this research. Mladovsky's a priori conceptual framework did not categorize all aspects of a policy such as objectives and strategies. Rather, the researcher selected certain policy elements to analyze such as population or health services addressed. As a result, we do not have a sense of the complete structure of policies analyzed in their research. Policy objectives and policy strategies were identified in all eleven cases and were determined to be important aspects of policy content. Mladovsky also did not focus on common and uncommon content areas in the migrant health policies. This is an important component of this research as common and uncommon policy content areas were identified in order to fully explore and understand variation across the eleven policies. The fact that variation in content areas was found across the policies motivates the need to explore if there are policy "types".

Vasquez et al. (2011) analyzed the content of three of the policy cases that are a part of this analysis, (i.e., England, Italy, and Spain). Their analysis identified and categorized policy objectives, strategies, and health services. The 2011 study did not identify nor categorize migrant populations identified in the three policies. Many of the policy objectives identified by Vasquez et al. (2011) were also identified in this study. The two studies identified improvement of the health status of migrant populations as the same broad objective across the set of cases (i.e., three policy cases in the Vasquez et al. 2011 study and this study's eleven policy cases). At the policy case level, this research aligns with the Vasquez et al. (2011) study's identification of several policy 
objectives associated with England, Italy, and Spain such as the reduction of inequalities in health, promotion of health equity, improvement of the health status among migrant populations, the right to health care, and fostering cultural competency in the health system through provider training (Vasquez et al., 2011). This study differs from Vasquez et al.'s research in that the aforementioned objectives were grouped within categories based upon thematic alignment. The Vasquez study listed policy objectives but did not categorize them. Vasquez et al.'s (2011) research confirms this study's identification of policy objectives as an important content area as well as the recognition of specific objectives as relevant units of text.

Vasquez et al. (2011) identified and categorized policy strategies as "types of actions aimed at improving access or improving immigrant population health" (Vasquez. Et al., 2011, pg. 74-75). This study aligns with Vasquez et al.'s 2011 research in that the eight policy strategy subcategories were categorized in one of two categories that include access to care or quality of care. Categorization of policy strategies in a similar manner by the two studies mutually affirms that policy strategies are an important policy content element to consider. Moreover, this study confirms Vasquez et al.'s (2011) classification of policy strategies in the two categories, as access to care or quality of care were found to be key elements in developing a policy typology.

This study differs from Vasquez et al.'s research in eleven policy cases are included in this research. The result of a larger sample was the identification of more policy strategy examples particularly in the access to care category. Vasquez et al.'s 
(2011) access to care domain spans three areas that include improving information (i.e., "improving the provision of information"), improving communication (i.e., "improve the interaction between the immigrant patient and the health professional") and increasing the offer of services (i.e., "improving the allocation of physical and human health resources and at speeding up administrative procedures") (pg. 74). In addition to the health information, communication, and increasing the supply of services strategies included in Vasquez et al.'s scope of access to care, this study identified two additional strategies that are facilitate access to health care services and care coordination.

Three strategies constitute actions for improving quality of care in the Vasquez et al. (2011) study. They include service adaptation (i.e., "introducing organizational changes and to the information systems in order to adapt to the immigrant population"), professional training (i.e., "training of professionals in cultural diversity") and identifying health needs (i.e., "to generate knowledge in order to respond to and monitor health needs of the immigrant population") (pg. 74). This study adopted a definition of quality of care developed by the Institute of Medicine in 2018, "the degree to which health care services for individuals and populations increase the likelihood of desired health outcomes and are consistent with current professional knowledge". While the three policy strategy subcategories in the quality of care category in this study align with the Vasquez et al. (2011) study, they are more expansive. The health system workforce professional development subcategory includes cultural competence and cultural diversity training, but also includes occupational safety and workplace health, 
migrant populations health profile training, and training for providers on social determinants of health specific to migrant populations. The needs assessment subcategory also expands upon the scope of the Vasquez et al. (2011) study with the inclusion of monitoring the health of migrant populations, improving understanding of migrant health needs, and increasing awareness of migrant health disparities in addition to research and evaluation of migrant health outcomes. The scope of the adaptation of services subcategory in this study is also broader than the adaptation of services strategy in Vasquez et al.'s (2011) research adding culturally competent service delivery and health system workforce diversity as additional specific service adaptation strategies.

Health services were grouped as a type of action aimed at health promotion, health prevention, and health care in the Vasquez et al. 2011 study. The researchers identified approximately five types of health services that include communicable diseases, mother and child health, prevalent diseases, mental health and drug abuse, and health education and promotion (Vasquez. et al., 2011). All health services were grouped in a single category, "types of actions aimed at specific health problems" (Vasquez. et al., 2011, pg. 73). Several health services were identified by the Vasquez study and this research. The two studies differ in the number of health services identified and the organizational structure of health service coded data.

While both this study and Vasquez et al.'s (2011) research applied the same analytic method, descriptive content analysis, they varied in the number of cases 
analyzed and organizational structure of the data. The Vasquez et al.'s (2011) noted but did not categorize policy objectives. Health services were grouped as a type of action aimed at health promotion, health prevention, and health care. The researchers also positioned policy strategies as "types of actions aimed at improving access or improving immigrant population health" (Vasquez. et al., 2011, pg. 74-75). The data scheme developed in this study is more expansive. Policy objectives were categorized into four categories. Eight policy strategies subcategories were identified, compared to the six in the Vasquez et al. (2011) study. Ten health service subcategories were grouped three were categorized in three categories that include primary, secondary, and tertiary prevention. Health services identified in the Vasquez et al. study identified five types of health services that were categorized together as actions aimed at specific health problems. This study's inclusion of eleven policy cases is likely the reason for an expanded data scheme. The result is a comprehensive organization and presentation of the content of the policy cases.

\section{Section Summary}

Some aspects of the organizational structure of data in this study were confirmed in existing comparative policy analysis literature on all or a subset of the eleven policy cases. At the highest level of organization (i.e., policy objective, policy strategy, health services, and target population major categories), this study aligns with Mladovsky (2009), Mladovsky et al. (2012) framework that was categorized by population, health services addressed, and supply-side/demand-side and Vasquez et al.'s (2011) content analysis that was organized by policy objectives, health issues 
addressed, and categorization of policy strategies as an action oriented towards access or quality. For example, the use of access to care and quality of care as an organizing frame is evident in Vasquez et al. (2011) (i.e., access and quality), Mladovsky's (2009), and Mladovsky et al. (2012) research (i.e., health system supply/demand). Mladovsky et al. (2012) and Mladovsky (2009) health system supply-side domain is similar to access to care in that an adequate supply of health care services must be available for people to access them. The quality of health care service delivery influences demand for services. Synergy with extant literature suggests that access and quality are important policy content areas.

Laswell's "Who gets what, when, and how" was applied as a frame to identify all relevant segments of policy content and guide the broad organizational structure of data into major categories (Laswell, 1936). Data was organized without a preconceived vision or value judgement of the importance of certain policy content areas. This is one area where this study is different from extant research on the policy cases. The thorough coding scheme emerged from policy documents associated with the eleven cases. This process led to a more in-depth understanding of variation across the policy group. Existing literature does not provide a clear direction as to how analytic decisions were made to include or exclude areas of policy content to be analyzed, nor does it provide a picture of the extent of variation in policy content. This study contributes to extant migrant health policy literature with a comprehensive organizational structure of the content of the eleven policy cases derived solely from policy documents associated 
with the cases and void of a priori assumptions of content area priorities. As a result, this research blends Mladovsky and Vasquez et al.'s research as the major categories are effectively covered by both of these researchers but are not exclusive to either. This study also provides an understanding of the extent and nature of variation across the eleven migrant health policies.

\section{Synthesis of Policy Typology Analysis}

The purpose of the study's second phase of analysis was to determine if there was a defining structure across the eleven policy cases that could lead to a theme-based typology derived from the content analysis that was completed in phase one. That structure was identified by creating a typology matrix relating the two categories, access and quality, within the policy strategy major category and then mapping the remaining three major categories individually in a sequential process onto the initial access/quality based typology matrix. This allowed for examination and identification of interrelationships both between and within policy objective, policy strategy, health services, and target population major categories and the typology's two dimensions that are access to care and quality of care. The result was the emergence of four themes that are a "type" of orientation toward the health of migrant populations. They are assimilation, integration, health system adaptation, and health equity. Figure 5.2 below reflects the summary typology matrix. 
Figure 5.2. Migrant Health Policy Orientation Pertaining to Migrant Health Typology Matrix.

\section{Access to Care}

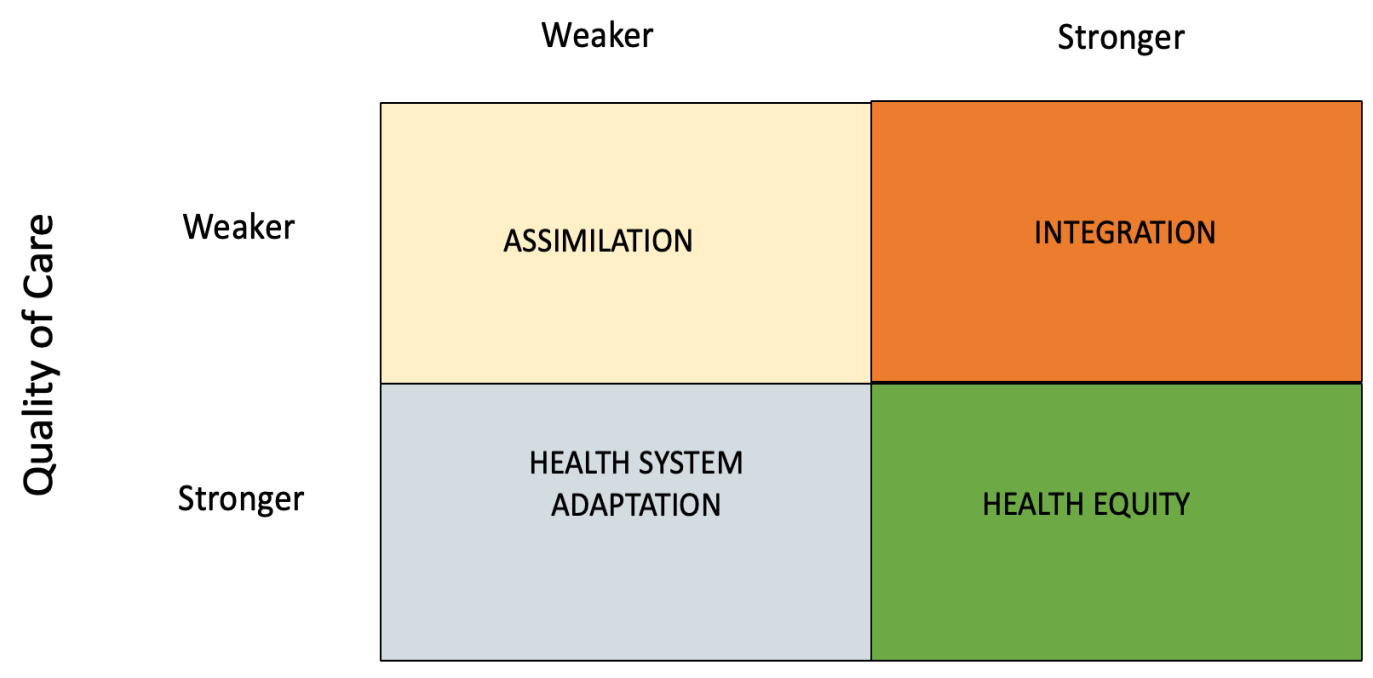

These themes emerged from apparent relationships between the policy

objective and policy strategies major categories. The assimilation theme has a weak association with access and quality, while the health equity theme has a strong association with the two dimensions coming together at higher levels. The integration theme is related to a stronger emphasis on access to care and a weaker emphasis on quality of care, while the health system adaptation theme has a stronger association with quality of care than access to care.

Theme titles intentionally reference the policy objective category headings. While the policy objective categories and themes share the same titles, they do not share the same meaning. Policy objective category names are a synthesis of a group of thematically aligned codes. Theme titles are a summary of apparent relationships 
between the major categories that were sequentially mapped onto the typology matrix and its two dimensions, access to care and quality of care. For example, the health equity policy objective category heading is different from the health equity theme in that the theme is a conceptually distinct concept with dimensionality, (i.e., access to care and quality of care coming together at the highest levels). Dimensionality and associations among the major categories are not a part of the health equity policy objective category heading as it only reflects stated objectives in the policy.

Each of the themes has a unique relationship with access to care and quality of care that is determined by stronger or weaker levels of association. The themes are conceptually distinct concepts in part because of these relationships. A theme's association with access and quality informed its placement in the typology matrix. Important to note, however, is that a theme's position in the typology matrix is a conceptual distinction as it does not rest on an exactly measured criteria. In other words, there is not an established definition of higher or lower levels of access to care and quality of care.

\section{Major Category Interrelationships with Themes}

As previously stated, a relationship was identified between the policy objective and policy strategy major categories that led to the four themes. While the health services and target population major categories informed dimensionality of the themes, they do not necessarily define them. However, associations between the themes and the health services and target population major categories are worth noting as these 
areas of alignment provide important contextual information about the meaning of a theme regarding its orientation toward migrant health.

\section{Health Services Major Category}

Associations between the health services major category and the themes

provided important information about the meaning of the themes in terms of the types

of health services that are prioritized. Figure 5.3 is a summary of the theme's association with the primary, secondary, and tertiary prevention categories. Table 5.1 lists abbreviations used in Figure 5.3.

Figure 5.3. Migrant Health Policy Orientation Pertaining to Migrant Health Typology Matrix. Theme Association with the Primary, Secondary, and Tertiary Prevention Categories.

\section{Access to Care}

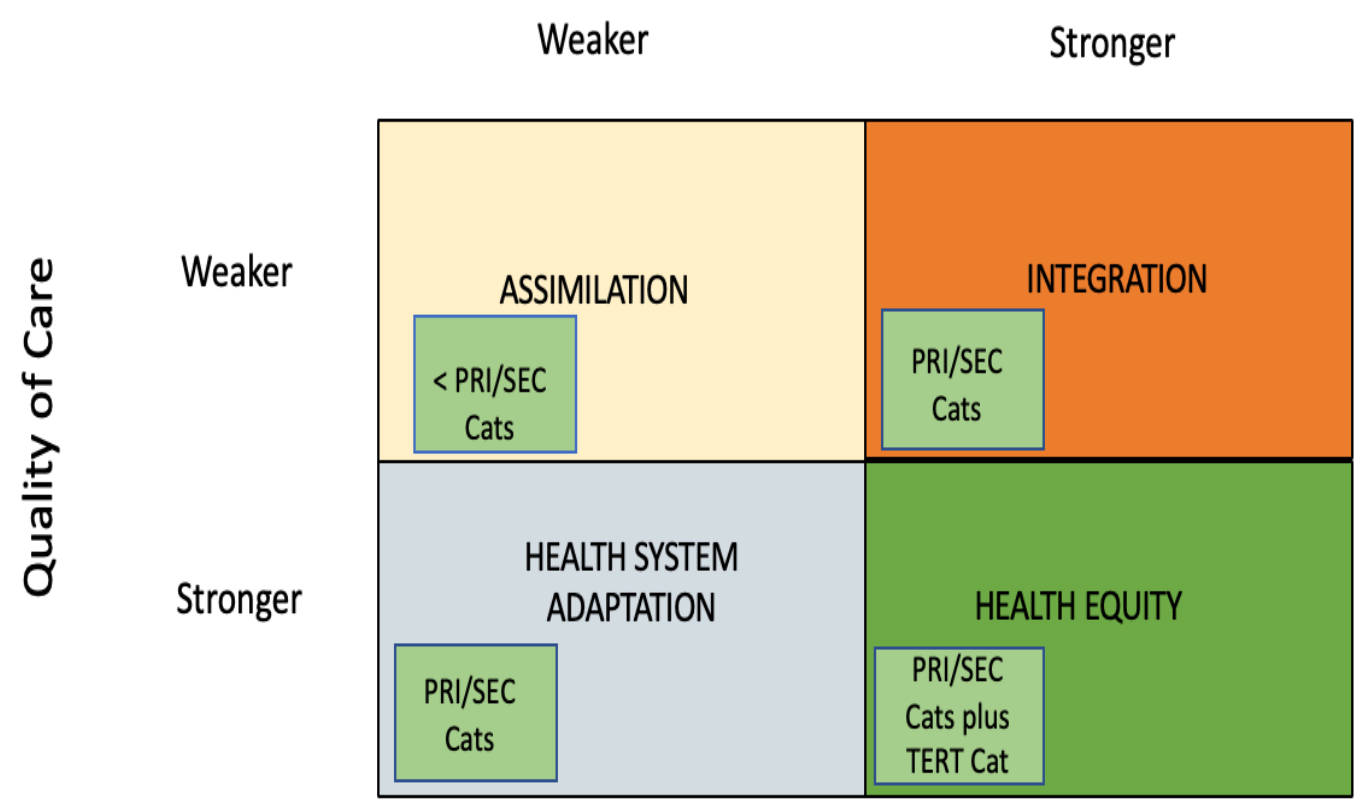


Table 5.1. Abbreviations Key for Figure 5.3.

\begin{tabular}{|l|}
\hline Health Services Categories \\
\hline PRI-Primary Prevention \\
\hline SEC- Secondary Prevention \\
\hline TERT - Tertiary Prevention \\
\hline
\end{tabular}

The primary and secondary prevention categories have a relationship with access to care and quality of care at varying levels. The categories generally increase in prevalence with higher levels of access and quality. The assimilation theme is associated with fewer subcategories in the primary and secondary prevention categories compared to the other three themes. Within the primary prevention category, the association theme is linked to the communicable disease control and prevention of communicable disease transmission subcategories. The integration and health system adaptation themes are associated with several health services in the primary and secondary prevention categories. The health system adaptation theme is related to the primary and secondary prevention categories. The primary, secondary, and tertiary prevention categories are all related to the health equity theme. We only see the tertiary prevention category where access and quality are at their strongest levels. The take away from this alignment is that the health equity theme is about the full continuum of care, from primary through tertiary prevention.

\section{Target Population Major Category Interrelationships with Themes}

An association between the target population major category and the themes is not as distinct as we have seen with the other major categories. Overall, there appears 
to be more randomness and less intention regarding a relationship between the target population categories and a theme. The assimilation and health equity themes do not have a clear association with any of the target population categories. The integration and health system adaptation themes have an association with certain target population categories. These associations inform the meaning of the integration and health system adaptation themes and help distinguish their "type" of orientation toward migrant health. Figure 5.4 below reflects the typology matrix with interrelationships between the themes and target population categories. Table 5.2 is a list of abbreviations used in Figure 5.4 .

Figure 5.4. Migrant Health Policy Orientation Pertaining to Migrant Health Typology Matrix Theme Association with Target Population Categories.

\section{Access to Care}

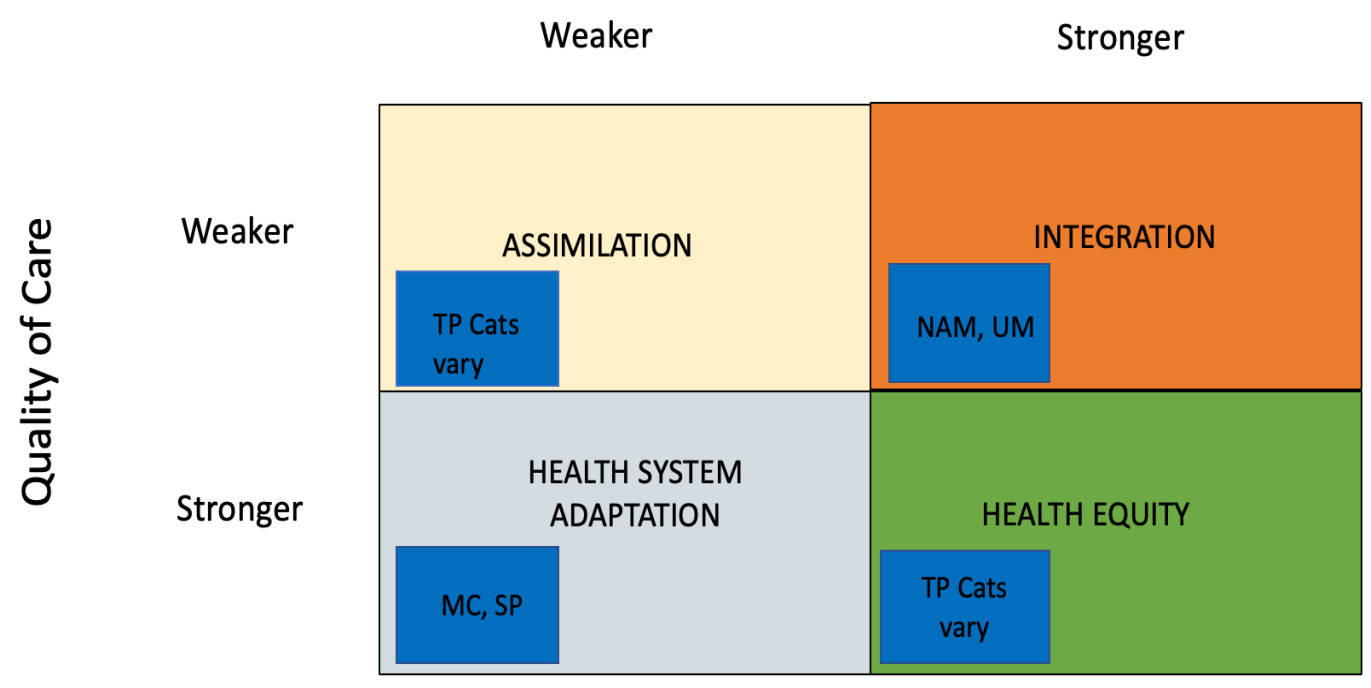


Table 5.2. Abbreviations Key for Figure 5.4.

\begin{tabular}{|l|}
\hline Target Population Categories \\
\hline TP- Target Population \\
\hline MC- Migrant Child \\
\hline NAM - Newly Arrived Migrant \\
\hline SP- Special Populations \\
\hline UM- Undocumented Migrant \\
\hline
\end{tabular}

The newly arrived migrant and undocumented migrant target population categories are all associated with the integration theme as they are have a stronger association with access to care than quality of care. This association adds context to the integration theme alignment with as facilitating access to care encompasses multiple migrant population. The migrant child and special populations target population categories share an association with health system adaptation theme. These target populations have a stronger association with quality of care than access to care. Alignment between the health system adaptation theme and the two target population categories indicates that health system level changes are inclusive of meeting the health care seeking and receiving needs of diverse migrant populations. In this context diverse migrant populations extends to age and immigration circumstances.

\section{Policy Strategy Subcategory Interrelationships with Themes}

Each theme is a summary, in part, of the tendencies of apparent relationships with certain policy strategy subcategories. These apparent relationships convey the meaning of a theme and its orientation toward migrant health. The typology matrix 
presented in Figure 5.5 describes apparent relationships between the themes and the policy strategy subcategories. Table 5.3 is a key for abbreviations in Figure 5.5.

Figure 5.5. Migrant Health Policy Orientation Pertaining to Migrant Health Typology Matrix Theme and Policy Strategy Subcategory Apparent Relationships.

\section{Access to Care}

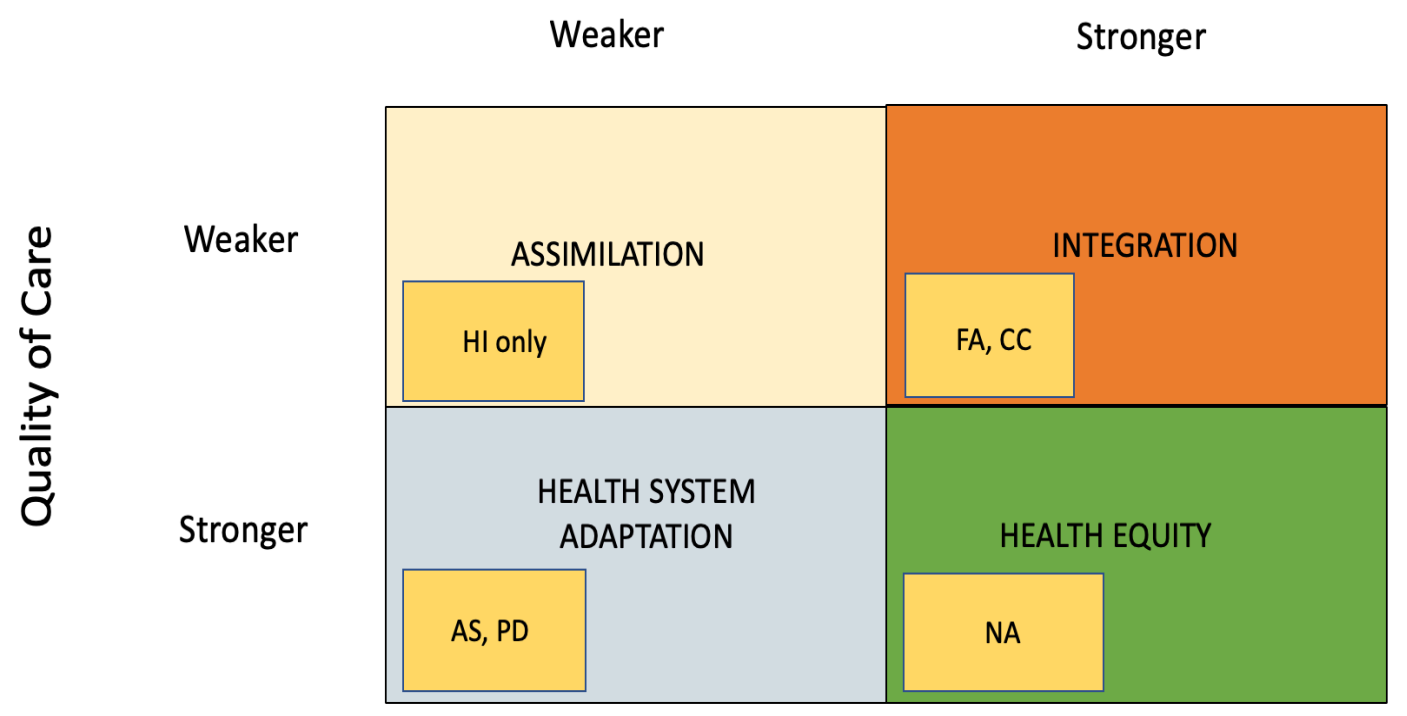

Table 5.3. Abbreviation Key for Figure 5.5.

\begin{tabular}{|l|}
\hline \multicolumn{1}{|c|}{ Policy Strategy Major Category } \\
\hline AS - Adaptation of Services \\
\hline CC - Care Coordination \\
\hline FA - Facilitate Access to Health Care Services \\
\hline HI - Health Information \\
\hline NA - Needs Assessment \\
\hline PD - Health System Workforce Professional Development \\
\hline
\end{tabular}


The assimilation theme is associated with one policy strategy subcategory, health information. However, health information is present throughout the typology matrix. What distinguishes the assimilation theme is not so much its association with the health information subcategory. Rather, what is notable is the narrow breadth of one policy strategy subcategory associated with the theme.

The integration theme appears to be related to the facilitate access to health care services and care coordination subcategories as all more prevalent where access to care is stronger than quality of care. This alignment indicates that the integration theme has a focus on fostering access to health care services for a population that is at risk of encountering barriers to health care service delivery. This focus is operationalized through strategies that are intended to reduce or eliminate obstacles to service delivery The health system adaptation theme has an apparent alignment with two policy strategy subcategories, adaptation of services and health system workforce professional development. The policy strategy subcategories are more prevalent with stronger levels quality of care than access to care. This interrelationship signals that the health system adaptation theme is about changes at the health system level in the manner that health care is delivered to migrant populations. For example, health system adaptation is physical changes to the health system such as signage and places to worship that reflect the cultural and spiritual beliefs of multiple populations. Adaptation of the health system includes training of health care professionals in providing culturally competent care that meets the health care service delivery needs of an ethnically diverse 
population. We see this emphasis in the health system workforce professional development subcategory that includes the codes cultural competence/cultural diversity training for the health system's workforce.

The health equity theme is particularly associated with the needs assessment policy strategy subcategory as both are associated with the highest levels of access to care and quality of care. The needs assessment subcategory includes a set of codes that pertain to monitoring and understanding the health profiles, health needs, and health disparities among migrant populations. This alignment indicates that the health equity theme is in part about investigating and understanding the health care needs of migrant populations.

\section{Health Services Subcategory Interrelationships with Themes}

The health services major category has three categories (i.e., primary, secondary, and tertiary prevention), each with between one (tertiary) and six (secondary) subcategories. Valuable insights into the orientation and meaning of a theme can be gained by exploring these apparent associations. The typology matrix in Figure 5.6 below is a summary of interrelationships between the themes and subcategories in the primary and secondary categories within the health services major category. Table 5.4 lists abbreviations used in Figure 5.6. 
Figure 5.6. Migrant Health Policy Orientation Pertaining to Migrant Health Typology Matrix. Theme Association with Health Services Subcategories.

\section{Access to Care}

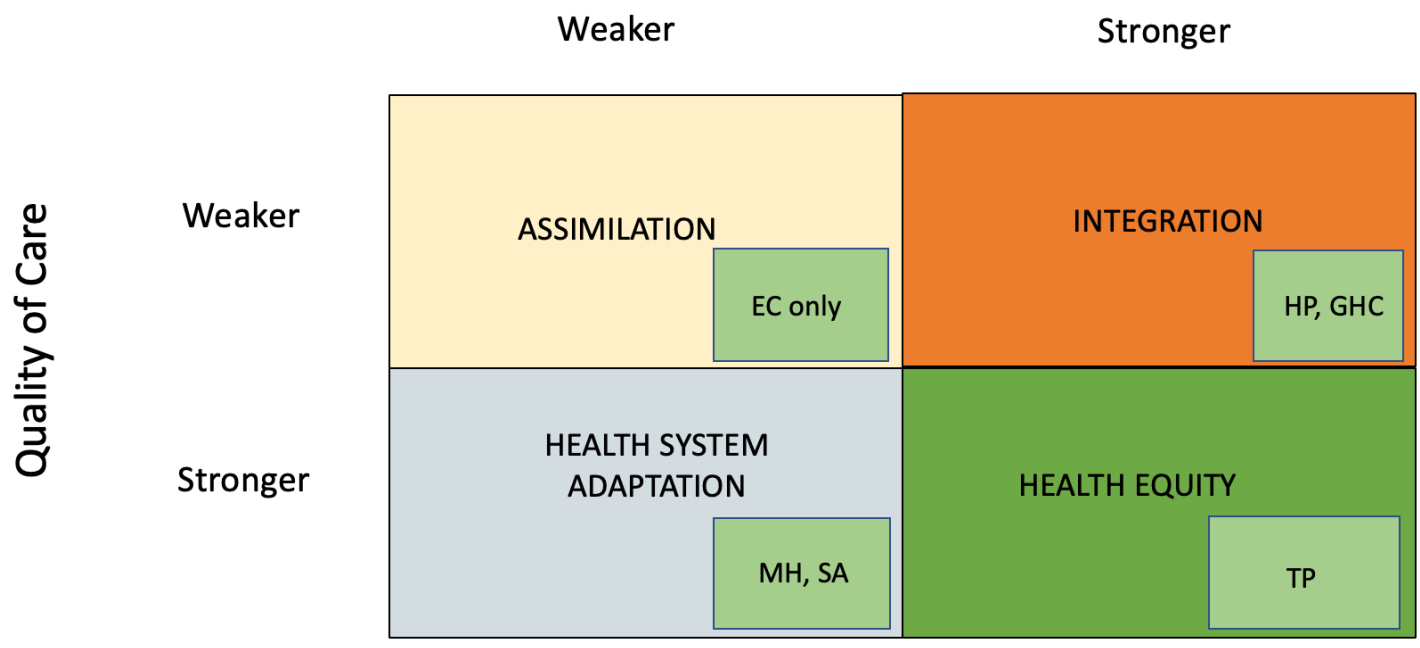

Table 5.4. Abbreviation key for Figure 5.6.

\begin{tabular}{|l|}
\hline \multicolumn{1}{|c|}{ Health Services Major Category } \\
\hline \multicolumn{1}{|c|}{ Primary Category } \\
\hline HP - Health Promotion \\
\hline EC - Emergency Care \\
\hline GHC- General Health Care \\
\hline SA- Substance Abuse \\
\hline TP - Health Care for Target Populations \\
\hline
\end{tabular}

We see alignment of certain health services with specific themes. The emergency care health services subcategory in the secondary prevention category is associated with the assimilation theme and is not present elsewhere in the typology matrix. The 
emergency care subcategory limits health service delivery for migrants to medical conditions that require immediate emergency medical care. The integration theme has an apparent association with the health promotion subcategory in the primary prevention category and the general health care subcategory in the secondary prevention category. The theme and the subcategories move together along the access to care dimension, increasing in prevalence as levels of access increase. The mental health and substance abuse subcategories, in the secondary prevention category, have an apparent association with the health system adaptation theme. These health services recognize the unique behavioral health care needs among migrant populations. Delivery of these health care services place the onus on the health system to meet the mental and behavioral health needs of migrant populations which may include trauma experienced in any of the phases of immigration. The tertiary prevention health services category and health care for target populations subcategory, in the secondary prevention category, however, are associated with the health equity theme.

\section{Theme Description Summary}

The themes emerged primarily from interrelationships between the policy objective and policy strategy major categories. Their meaning is derived from these interrelationships and tendencies to align with access to care or quality of care or both dimensions. Apparent associations with the health services and target population major categories offer context and dimensionality that flesh out what the four themes are about and how they are conceptually different from one another. Below are summary 
descriptions of the themes derived from the combination of objectives, strategies, target populations and health services identified in the typological analysis.

\section{Assimilation Theme}

The assimilation theme has a weak association with access and quality. It is associated with one policy strategy subcategory, one health services subcategory, and three target population categories. The assimilation theme's narrow breadth of association with categories and subcategories is revealing insight about its meaning and "type" of orientation toward migrant health. The assimilation theme prioritizes communicable disease control and emergency care. The theme was not associated with a particular migrant population and thus is not defines by any of the target population categories that include documented migrant, newly arrived migrant, and undocumented migrant. One can infer that newly arrived migrant and undocumented migrant populations are perceived to pose the greatest threat to communicable disease transmission. Association with a single policy strategy subcategory, health information, indicates that the theme does not consider migrants as a special population requiring enhanced levels of support to access the health care system.

The assimilation theme's association with the policy strategy, health services, and target population categories and subcategories aligns with a synthesis of codes in the assimilation category in the policy objective major category. Characterized primarily by two ideas, priorities of the assimilation theme are: 1) protection of the host nation population from communicable diseases introduced and transmitted by migrant 
populations; and 2) the assumption that migrants will assimilate into the host nation society. The assimilation theme does consider enhanced levels of support in accessing or receiving quality health service delivery necessary.

\section{Integration Theme}

With a stronger association with access to care than quality of care, the integration theme fosters mutual respect between migrant populations and host nation populations by removing barriers to accessing health care services. This focus on alleviating barriers to accessing the health system is evident in the theme's association with the facilitate access to health care services and care coordination policy strategy subcategories. In addition, alignment with health promotion and general health care services which include primary care indicates that the integration theme is about getting migrants into the health system and general health services and valuing migrants through health services aimed at keeping migrant populations healthy and active members of society. The integration theme association with the newly arrived migrant and undocumented migrant target population categories signals its emphasis on working toward social inclusion social inclusion through fostering access to health care service delivery for migrant populations who are vulnerable to social exclusion and less likely to find a way to into the health system to receive health care services. Newly arrived migrants are recent arrivals to a host nation and may be lacking social support. Undocumented migrants are exceptionally vulnerable due to their lack of legal residency and are at greater risk of not seeking health care when needed for fear of deportation. 
The meaning of the integration theme derived from its association with the policy strategy, health services, and target population categories and subcategories and apparent relationship with access to care can be seen in a synthesis of codes in the integration and social cohesion category in the policy objective major category. Based on a synthesis of codes in the integration/social cohesion category, five premises depict the integration theme's access to care orientation: 1) acknowledging migrants are a diverse and heterogeneous population; 2) fostering a feeling of social inclusion and belonging through activities that facilitate access to health care services for a population that is at risk of being socially isolated; 3) mutual respect for diversity; 4) valuing migrants; and 5) enhancing access to health care services.

\section{Health System Adaptation Theme}

The health system adaptation theme has a stronger affiliation with quality of care than access to care. As evidence through the adaptation of services and health system workforce professional development policy strategy subcategories, the health system adaptation theme is about meeting the health care service delivery needs of an ethnically diverse population through health system level changes. Characterized by creating change at the health system level to meet the diverse health seeking and receiving needs of migrant population, the health system adaptation theme places the onus on the health system to meet the health care seeking and receiving needs of diverse migrant populations, rather than requiring them to adapt to the health system. For example, the theme's association with mental health and substance abuse health 
services can be seen as a health system level response to challenges a migrant may encounter during resettlement in a host nation and/or trauma that may have occurred during the pre-flight, flight, and resettlement immigration phases (Rechel et al., 2012).

The migrant child and special populations target population categories are associated with health system adaptation theme. The health system adaptation theme's alignment with the migrant child and special populations target population categories signals that the theme is about meeting the health care needs of diverse and vulnerable populations that may need specialized health services. This association also communicates that the health system adaptation theme's interpretation of diverse and vulnerable populations is inclusive of age and circumstances that instigated migration such as natural disaster, conflict, or fear of persecution.

The meaning of health system adaptation theme that was derived from the major categories is evident in a synopsis of codes in the health system adaptation policy objective category. Key ideas consist of: 1) an acknowledgement that migrant populations have unique health profiles that have likely been shaped by experiences in their country of origin, the process of migration, and resettlement processes; 2) adapting clinical practice to meet the needs of ethnically and culturally diverse migrant populations; 3 ) awareness and attention to migrant's experience of receiving health care services; and 4) focus on the quality of care delivered to migrant populations. 


\section{Health Equity Theme}

The health equity theme is characterized by its association with access to care and quality of care coming together at higher levels. The theme does not happen on its own. Rather, it is a function of higher levels of access to care and quality of care in conjunction with either the integration theme, the health system adaptation theme, or both themes. In addition to being associated with all of the policy strategy subcategories, the health equity theme is particularly aligned with the needs assessment policy strategy subcategory. The theme prioritizes investigating health profiles among migrant populations as a pathway to mitigating health disparities. Association with the primary, secondary, and tertiary prevention category communicates that the theme is about providing migrants with health promotion, more health services, as well as the care and treatment of disease. Moreover, alignment across the three health services categories communicates that health equity is about comprehensive service delivery because all people should have the opportunity to pursue good health on an equal basis.

The meaning of the health equity theme is echoed in a summary of codes in the health equity policy objective category. A synthesis of the codes are organized into three key areas that include: 1 ) equal opportunities for migrants; 2) equality between migrant and host nation populations; and 3) reducing health inequities that exist between migrant and host nation populations. These areas of emphasis are a synthesis of codes in the health equity category in the policy objective major category. 


\section{Policy Typology Analysis Section Summary}

Four conceptually distinct themes emerged as a result of typological analysis of the major categories that were the project of phase one. The themes emerged from a relationship between the policy objective and policy strategy major categories.

Alignment between a theme and aspects of the health services and target populations categories add important context to a theme's meaning which is a "type" of orientation toward migrant health, but do not necessarily define them.

The assimilation theme does not consider migrants in need of enhanced levels of support to access health care services. As such, this onus is on migrants to assimilate into the health system. With the integration theme, we see a focus on facilitating access to the health system through a series of strategies aimed at mitigating barriers encountered by migrants. Fostering access to health care service delivery is embedded in the integration theme's broader goal of encouraging social inclusion of migrant populations. The health system adaptation theme is defined by its focus on quality of care achieved through health system level changes aimed at meeting the health care seeking and receiving needs of a heterogenous population. We see this emphasis articulated through the provision of specialized health services such as mental health care and substance abuse. Higher levels of access and quality coming together, along with the presence of the integration theme, health system adaptation, or both themes are distinguishing factors of the health equity theme. The health equity theme is about mitigating inequities in health experience by migrant populations through an array of strategies and health services that span health promotion to disease treatment. 


\section{Migrant Health Policy Case Theme Alignment}

The eleven policy cases were mapped onto the migrant health policy typology conceptual framework to test how they fit within the framework developed in this research. Policy characteristics suggest that some policy cases fit with conceptual themes that are different from their stated objectives given their content. We also see policy cases with multiple stated objectives that are associated with one of the themes.

Content analysis completed in phase one informed a case's association to a theme and its overall orientation toward migrant health. Policy case association with the number of policy strategy subcategories categorized in the access to care and quality of care categories guided its placement in the migrant health policy typology matrix. Cases lined with a minority of the policy strategy subcategories (i.e., less than one access to care and quality of care policy strategy subcategories) were placed within the assimilation cell in the typology matrix. A case associated with the majority of subcategories in both the access to care and quality of care categories (i.e., three or four or more subcategories access to care and three subcategories in the quality of care category) placed it within the health equity cell in the matrix to reflect that case's stronger association with access and quality. Cases linked with more policy strategy subcategories in the access to care category than subcategories in the quality of care category are positioned in the integration cell in the matrix (i.e., more than three access to care subcategories and less than two subcategories in the quality of care category). Policy cases linked to more subcategories in the quality of care category than access to care category (i.e., more than two policy strategy subcategories categorized in the 
quality of care category and less than two subcategories in the access to care category) were placed in the matrix's health system adaptation cell. A case's position in the typology matrix reflects its association with access to care and quality of care and the other themes. For example, a policy case that is associated with the majority of subcategories in the quality of care category and a medium number of subcategories in the access to care category are positioned in the area of the health system adaptation cell that is close to the border of the health equity cell. Investigation of policy case and theme alignment revealed that the policy cases appear to form a continuum ranging from a weak/weak association with access and quality to strong/strong relationship with access to care and quality of care given that cases with large divergences in quality or access (i.e., strong access and weak quality or weak quality and strong access) are not apparent in the policy set. A summary of the policy case continuum is shown in Figure

\section{7.}

Figure 5.7. Policy Case Positioning on the Migrant Health Policy Orientation Toward Migrant Health Policy Typology Matrix.

Access to Care

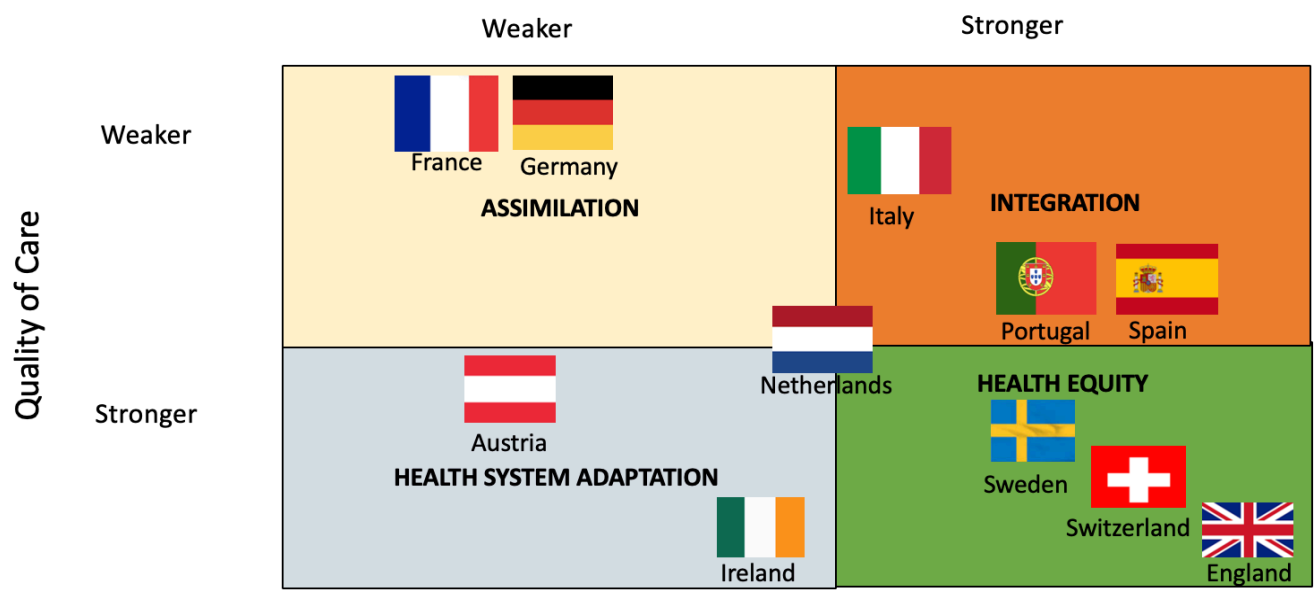




\section{Assimilation Theme: France and Germany}

France aligns with the assimilation theme. The case has a weak association with

access and quality, a narrow breadth of policy strategies, and relatively few health services. France's policy is associated with two objectives in the policy objective major category assimilation. They are assimilation of migrants into host nation's national identity and protection of the health of the host nation population. This is particularly evident in the health services associated with France that include communicable disease control, communicable disease prevention, and emergency care. Three target populations are associated with the case and include documented migrant, newly arrived migrant, and undocumented migrant. Identification of these health services and the three migrant populations demonstrate France's priority of protecting the health of the host nation population from communicable diseases that could be introduced and transmitted by migrant populations. Additionally, with limited interest on facilitating access, the case places the onus on migrant populations to adapt to the nation's health system as evidence by the absence of system levels supports and services.

Germany's policy states that it adopts a two-way approach to integration, placing onus on both migrants and the host nation population to achieve meaningful integration of migrants into German society. According to the policy, "successful integration requires mutual respect, openness to others and a desire to work together to share our common future" (German Federal Government, p. 2). Germany's policy has objectives that are linked with the health system adaptation and integration themes. However, the objectives associated with the case are not an articulation of either theme 
as there is a disconnect between its objectives and other relevant content areas.

Germany is associated with one policy strategy subcategory, health information, in the access to care category. Additionally, the case has a fairly narrow breadth in the health services primary and secondary prevention categories. Specifically, the case is associated with the communicable disease control subcategory in the primary prevention category and sexual and reproductive health subcategory in the secondary prevention category. A single target population category, documented migrant, is related to the policy case.

The policy objectives associated with Germany may be aspirational or symbolic political statements as they are disconnected from the policy strategies, health services, and target populations articulated in the case. The narrow breadth and depth of the policy strategies, health services, and target populations associated with the case are more consistent with the assimilation theme.

\section{Integration Theme: Italy, Portugal, and Spain}

Portugal and Spain have a stronger association with access to care than quality

of care. This tendency mirrors that of the integration theme. Both cases are identified as strong on access as they are linked to four of five policy strategy subcategories in the access to care category, while they are identified as medium on quality of care as they are linked to two of the three strategies in the quality of care category. Integration and health equity policy objectives linked to Spain. Portugal is connected with objectives in the integration, health equity, and health system adaptation categories. While Portugal 
and Spain span policy objectives in multiple categories their position in the integration cell is supported by a higher level of association with access to care than quality of care. Both cases are associated with four policy strategy subcategories in the access to care category, compared to two in the quality of care category. The cases are connected with the primary and secondary health services categories and have the most depth in the secondary prevention category. Portugal is associated with two subcategories in the secondary prevention category compared to one in the primary prevention category. Spain is linked to four subcategories in the secondary prevention category compared to two in the primary prevention category. Within the secondary prevention category, the cases are connected with five subcategories that include the health care for target populations, mental health, emergency care, general health care, and sexual and reproductive health. Target populations associated with the cases span four categories that are documented migrant, special populations, newly arrived migrant, and undocumented migrant.

Policy cases in this group approach integration as a two-way process involving mutual adaptation by the host nation and immigrant population. Dominant themes of the Portugal and Spain cases are mutual respect between migrant and host nation populations, acknowledgement of the value of migrants in host nations, empowering migrants, and recognizing the value of cultural diversity. In some cases, integration is viewed as a pathway to social peace. The value of integration for these policy cases is evident in the inclusion of the word "integration" in the titles of their migrant health 
policies, (i.e., Portugal's Plan for the Integration of Immigrants, 2007-2009 and Spain's Strategic Plan for Citizenship and Integration Strategic Plan - 2007-2010).

Italy is in the integration theme group due to the fact that it has a medium association with access to care and a weak association with quality of care. While the case is associated with objectives in the health equity category, it does not meet the theme's higher level of association with access and quality. Italy is affiliated with two policy strategy subcategories in the access to care category and one subcategory in the quality of care category. The narrow breadth of the policy strategies associated with Italy do not meet the health equity theme's access and quality level as a defining characteristic of the health equity theme is its association with access to care and quality of care coming together at the highest levels. The two policy objectives associated with Italy appear to be aspirational or symbolic political statements as they are disconnected from the policy strategies. The case's association with higher levels of access than quality is the reason for its position in the integration theme.

\section{Health System Adaptation Theme: Austria and Ireland}

Austria and Ireland have a stronger association with quality of care than access

to care. Austria has a medium association with quality of care and a weak relationship with access to care. Ireland has a strong association with quality and medium association with access. The two cases are linked with policy objectives that place the responsibility on the health system to adapt and respond to the health care seeking and receiving needs of a pluralistic and heterogeneous society. Health services associated 
with the cases are categorized in the primary and secondary prevention categories in the health services major category. Austria and Ireland have the greatest breadth in the secondary prevention category and are connected with the mental health care, health care for target populations, sexual and reproductive health, and substance abuse subcategories. Austria is associated with three target population categories and Ireland is associated with all five categories. Ireland's association with all five target population categories could be seen as an example of an inclusive health system adapting to meet the health care seeking and receiving needs of all migrant population groups.

The cases share the trait that health system level transformation is necessary to provide inclusive and intercultural health care delivery that meets the health care seeking and receiving needs of a pluralistic and heterogeneous society. Dominant themes across the cases include promoting inclusive care of migrants through increasing the intercultural competence of the health system, improving migrant health seeking and user experience, and health service delivery adaptation. Cases in this group do not place the responsibility of adapting to the health system on migrant populations.

\section{Health Equity Theme: England, Sweden, \& Switzerland}

Health equity's orientation is evident in the cases from England, Sweden, and

Switzerland. All are associated with policy objectives that include eliminating inequalities in health, promoting the inclusive care of migrants, orienting the health system toward a pluralistic society, eliminating discrimination, and racial equality. The three cases have an equally strong association with policy strategy subcategories in the 
access to care and quality of care categories. England is associated with five subcategories in the access to care category and three subcategories in the quality of care category. Sweden and Switzerland are both associated with four subcategories in the access to care category and three subcategories in the quality of care category. The cases also have breadth and depth of health services in the primary and prevention categories. Sweden and Switzerland have the most breadth and depth in the primary category, while England has more representation in the secondary prevention category. Worth noting is England's association with the tertiary prevention category in addition to the primary and secondary prevention categories. Sweden is linked to four target population categories, Sweden is associated with two, and England is only connected to the documented migrant. While we might expect equity to be broadly applied with these three cases in terms of being associated with the most target population categories, there appears to be more randomness and less intention regarding a relationship between the target population categories and this theme. A key takeaway is that policy cases select specific migrant populations to receive the objectives, strategies, and health services articulated in the policy.

Dominant themes associated with these three cases include equal opportunities for migrants, a holistic understanding of public health that considers quality of life, and the improvement of the health of the entire population. Health equity is driven through several strategies designed to increase both access to care and the quality of health care service delivery to migrant populations. England is positioned at the very extreme end 
of the continuum that has the highest levels of access and quality. The policy's placement reflects its breadth and depth of objective categories, policy strategy subcategories, and health services categories. Sweden and Switzerland are positioned to the left of England. Their position on the continuum represents slightly fewer policy strategy subcategories in the access to care category compared to England.

\section{The Netherlands}

The Netherlands is an interesting case. Within the conceptual framework, the case crosses the borders of multiple themes. While the Netherlands is associated with two policy objectives in the health system adaptation policy objective major category, it is associated with policy strategies that align with the integration, health system adaptation, and, to some degree, the health equity themes. The Netherlands is associated with three policy strategy subcategories in the access to care category that include health information, care coordination, and communication. All three subcategories increase in prevalence with higher levels of access. Health information and care coordination are associated with the integration theme and communication is most prevalent in the area of the typology matrix where we find the health equity theme. The Netherlands is also associated with two subcategories in the quality of care category that include adaptation of services and professional development. Both of these subcategories are linked to the health system adaptation theme. In regard to health services, the Netherlands has more depth and breadth of health services categorized in the primary prevention category than the secondary prevention category. 
The case is associated with health promotion which has an alignment with access to care and the integration theme. It also has a connection with the mental health subcategory in the secondary prevention category. Mental health is a health service linked to the health system adaptation theme. Lastly, the Netherlands is associated with two target population categories, documented migrant and migrant child. As all eleven cases are linked to the document migration target population, the Netherlands alignment with this target population does not inform case alignment with the themes. What is notable, however, is that migrant child and the health system adaptation theme are associated.

The Netherlands is associated with policy objectives, policy strategies, health services, and target populations that are aligned with the integration, health system adaptation, and health equity theme. It does not clearly fit within the themes. Rather, the Netherlands is on the path from health system adaptation to health equity as it incorporates elements of the integration theme.

\section{Migrant Health Policy Case Theme Alignment Section Summary}

The purpose of this exercise was to broadly assess how policies fit with the theme-based typology conceptual model. While the themes are conceptually distinct, policy association with the themes is not as straight forward. Some cases align perfectly with a theme, while others show a disconnect between the stated policy objectives and policy strategies. France and England represent the meaning of a theme in its entirety. Other cases, however, have somewhat of a weaker association with a theme in that 
they align with some but not all aspects of a theme. Some cases (e.g., Germany and Italy) have inconsistencies between the policy objectives and policy strategies. Germany has policy objectives associated with the integration and health system adaptation themes. However, it has a weak association with both access and quality based on the number of policy strategy subcategories related to the policy. Italy has two policy objectives in health equity objective category. However, the case has a medium association with access to care and a weak association with quality of care based on the number of policy strategies connected to it. As a result, Italy has somewhat of a weak association with the health equity theme. Other cases cross theme boundaries. These cases align with aspects of more than one theme. This is the situation with the Netherlands. The Netherlands has a slightly stronger affiliation with the access to care subcategory than the quality of care subcategory and crosses the boundaries of the health system adaptation, integration, and health equity themes.

None of the policy cases are weak in access/strong in quality or strong in access/weak in quality. In other words, cases do not anchor the integration and health system adaptation themes like we see with the assimilation theme (i.e., France) and health equity theme (i.e., England). Rather, the cases appear to form a continuum increasing in levels of access and quality from weak to strong with some divergence in the relative strength of access versus quality. The continuum is anchored by five policy cases at its extreme ends. France and Germany occupy the end that is weak in both access and quality. Sweden, Switzerland, and England are at the opposite end that is 
strong in access and quality. The remaining seven cases link the end points continuum with varying levels of access and quality that increase from weak to strong. The Netherlands is in the middle of the continuum.

\section{Extant Migrant Health Policy Comparative Analysis Research}

Only one other scholar has developed a conceptual typology framework related

to migrant health policy. Milena Chimienti (2007) created a typology of seven cases included in this analysis based "upon the logic of the health system" (p. 83). Policy cases included in her analysis include Austria, France, Germany, the Netherlands, Sweden, Switzerland, and the United Kingdom. Her typology classifies policies by health system organizational structure and societal values. Health system organizational structure was either a universalistic oriented approach with tax-based financing and open access to health services or a categorical-type system where access to the health system is guaranteed by an individual's possession of health insurance (Chimenti, 2007). Chimenti posited that societal values are either based on communitarian or republican approach to diversity and are embedded within a health system's organizational structure (Chimenti, 2007). Communitarian/difference-sensitive social values are sensitive to difference, while republican/difference-blind values do not recognize differences or diversity. Chimienti theorized that categorizing migrant health policies first according to health system financing structures and then by the health systems values (i.e., sensitivity or lack of sensitivity toward migrant populations) explained variation across the policy cases included in her analysis (Chimienti, 2007). She posited that, while 
further distinctions could be made within these two primary categorizations, "policy answers regarding migration and health are related to the logic of the health system" (Chimienti, 2007, p. 83). Originally referenced in chapter two, Chimenti's typology matrix is presented once again in Figure 5.8. The migrant health policy typology matrix framework depicting policy case association with themes (Figure 5.7) is presented again to provide a visual reference of comparison.

Figure 5.8. Health Structure and Value System of Differences Typology Matrix.

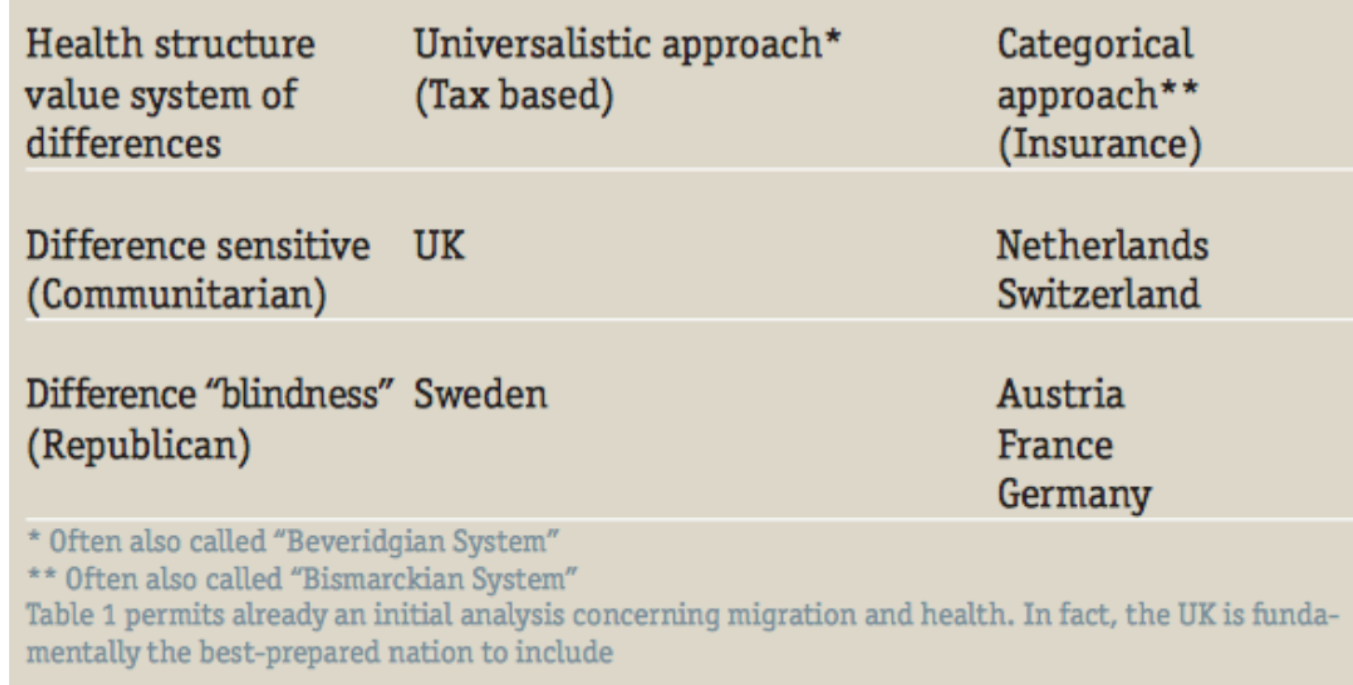

Source: Chimienti, M. (2007). Migration and Health: National Policies Compared. 
Figure 5.7. Migrant Health Policy Orientation Pertaining to Migrant Health Typology Matrix Framework.

\section{Access to Care}

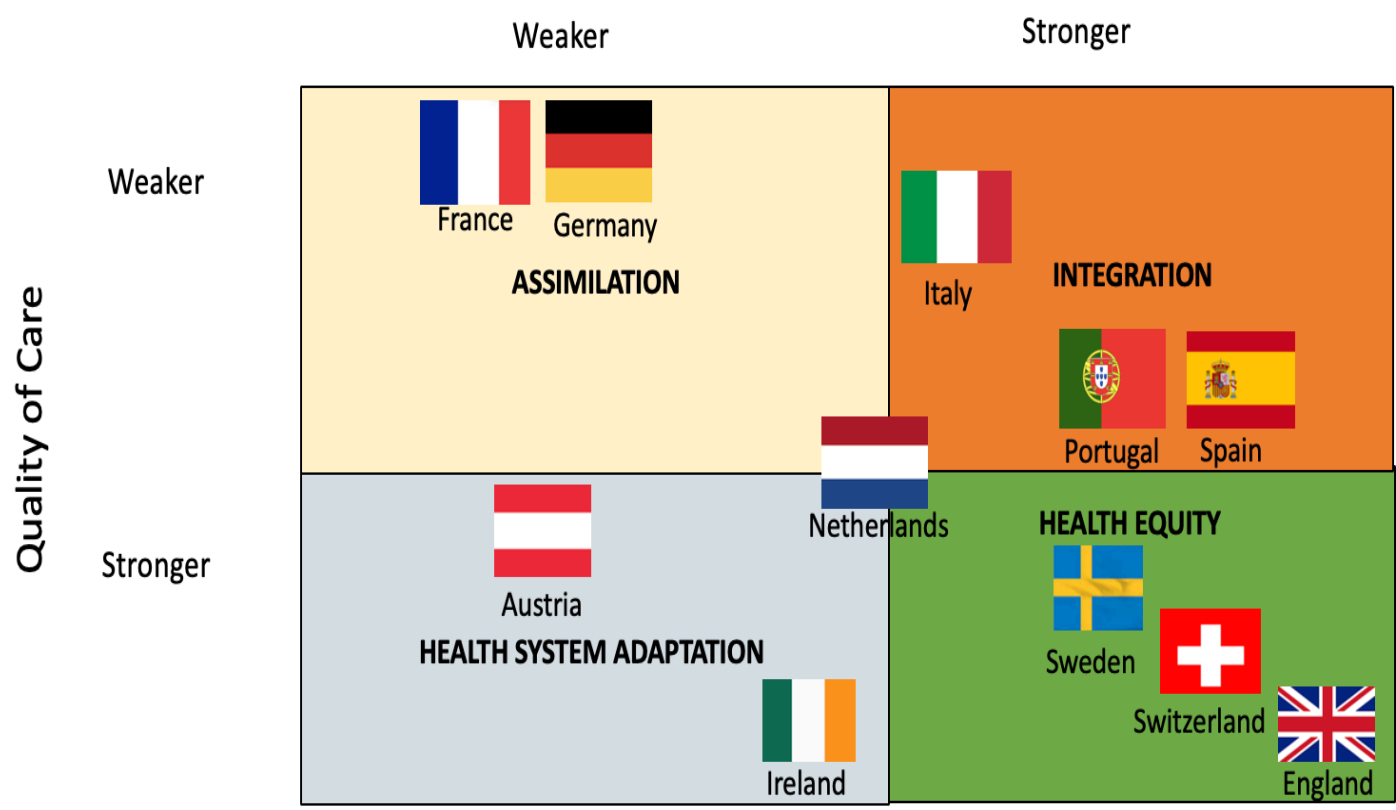

Chimenti's health system structure/values-based typology is meaningful to this study as there is alignment in how policies are grouped. Both studies developed typologies that position France, Germany in one corner and England in the opposite corner. Policy positioning in the theme-based typology that emerged from this study generally confirms Chimenti's health system organizational structure and societal values typology is aligned with policy content. With the exception of Italy, policy cases positioned in the weak to medium access and quality range of the continuum (i.e., France, Germany, Austria and the Netherlands) have categorical/insurance based health systems. These cases, with the exception of the Netherlands, are difference-blind and 
have a weaker association with access and quality. Two cases, France and Germany, align with the assimilation theme. Five cases that include England, Ireland, Portugal, Spain, and Sweden have a Beveridge/single payer tax-based health system financing model. These cases are positioned between the medium to strong access and quality area of the continuum. With the exception of Sweden, policies that are difference-blind in Chimenti's study (i.e., Austria, France and Germany) tend to have a weaker association with access and quality in this study than the policy cases that are difference sensitive (i.e., England, the Netherlands, and Switzerland). Additionally, we see some clear distinctions between health system organizational structure and the themes. We are less likely to see the health equity theme associated with policies that have a Bismarck/insurance-based health system financing organizational structure. Policies with a Beveridge/single payer health systems financing model have a greater tendency to be associated with the health equity theme. This finding signifies that certain comparative aspects of Chimenti's typology and the migrant health policy typology developed in this study validate one another generally. For example, there is a relationship between low access/quality and difference-blind and high access/quality and difference-sensitive. Additionally, this study's migrant health policy typology affirms Chimenti's argument that health system organizational structure and societal values are important in that they relate to policy content pertaining to migrant health.

While this study and Chimenti's research have some mutually validating aspects, this research applied a different analytic approach to identifying and examining 
variation across the eleven policies. Chimenti's typology applied elements external to the policies (i.e., health system organizational structure and societal values) as the building blocks of her matrix typology framework. This research looked internally to the policy cases. The theme-based typology matrix framework that is a product of this study emerged from the policy cases that are the data analyzed. The structure that emerged from the data (i.e., coding scheme) in phase one was mapped onto a typology matrix and resulted in themes that are a "type" of orientation toward migrant health. Exploring variance from an external versus an internal perspective is a subtle, yet important distinction between this research and Chimenti's comparative analysis of seven policy cases that are included in this research. This distinction supports connecting the content based typology that is a result of this research to policy making processes associated with the cases included in this study. Policy making processes include both political and social influences that are better reflected in Chimenti's health system structure/valuesbased typology constructed. While the content of a policy indicates something about policy "type" in terms of orientation toward the health of migrant populations, it also reflects political influences and social values.

Vasquez et al.'s (2011) content analysis of three of the policy cases included in this analysis, (i.e., England, Italy, and Spain) was discussed earlier in this chapter. The researchers categorized strategies into one of two fields of action, actions directed toward facilitating access to services or actions directed towards improving the quality of care (Vasquez. Et al., 2011). This study intentionally referenced these two actions and 
applied them as dimensions of the typology framework, access to care and quality of care. This research validates Vasquez et al.'s (2011) identification of policy objectives and policy strategies as significant policy content elements in regard to understanding a policy's "type". It also extends Vasquez et al.'s (2011) application access to care and quality of care by disaggregating these constructs by higher and lower levels in order to impose dimensionality onto the theme-based typology and continuum. Ranging from weak to strong, access to care and quality of care provide context and dimensionality to the policy cases, theme-based typology, and continuum.

\section{Section Summary}

The typology matrix framework developed by Chimenti (2007) provides some validation of the migrant health policy typology matrix framework developed in this study. In addition to similar categorization of three policy cases (i.e., France, Germany, and England) in opposing areas of the two typologies, there is an apparent connection between policy content and socio-political conditions that influence policy making processes. Austria, France, and Germany have Bismarck/insurance-based health systems. In this study, these cases have a weaker association with access to care and quality of care. With the exception of Sweden, England and Switzerland are associated with higher levels of access and quality and have Beveridge/single payer/social health insurance model. This research supports Chimenti's perspective that health system organizational structure and societal values are important factors in comparative analysis of migrant health policies. This confirmatory aspect between Chimenti's 
research and this study is meaningful as the two typologies validate some aspects of one another.

\section{Migrant Health Policy Case Continuum}

The study explored alignment between the individual policy cases and the themes in order to understand how well individual cases represented the themes. While the four themes that emerged are conceptually distinct, the cases seem to populate the themes as a continuum from assimilation (i.e., weak/weak in access and quality) to health equity (i.e., strong/strong in access and quality) rather than being evenly distributed across all four themes. The assimilation and health equity themes have clear "anchor" policies that clearly represent all aspects of a theme. None of the policy cases are low in access/high in quality or high in access/low in quality, meaning that the policies are distributed equally in terms of anchoring representations in the integration and health system adaptation themes. The end points continuum are linked by cases with varying levels of access and quality that increase from weak to strong, moving through the integration and health system adaptation themes toward health equity.

Cases at the extreme ends of the continuum, (i.e., France and England) represent the meaning of a theme in its entirety. These cases have policy objectives and strategies that are in complete alignment. Some of the seven cases that link the extreme ends of the continuum do not fully align with a theme as there is misalignment between the objectives and policy strategies. With these cases, Germany and Italy to be specific, the number or scope of policy strategies associated with a case are misaligned with the 
case's stated objectives in that they do not meet the access or quality threshold associated with a particular theme. Other cases cross the boundaries of a theme in that the content that aligns with more than one theme. The Netherlands is associated with policy objectives, policy strategies, health services, and target populations that are aligned with the integration, health system adaptation, and health equity theme. It does not clearly fit within any theme. Rather, the Netherlands is on the path from health system adaptation to health equity as it incorporates elements of the integration theme.

For these reasons, the Netherlands appears in the middle of the continuum, crossing boundaries of the health system adaptation, integration, and health equity themes.

The continuum is anchored by the assimilation and health equity themes. Policy cases move through the integration and health system adaptation themes from assimilation to the health equity themes. In other words, in order to move from the assimilation theme to the health equity theme, policy cases incorporate objectives and policy strategies associated with either the integration theme, health systems adaptation theme, or both themes along with higher levels of access and quality. In this regard, health equity does not happen on its own. Rather, the health equity theme is a product of policy case association with higher levels of access and quality along with a relationship with the integration theme, health system adaptation theme, or both themes. Figure 5.9 is a visual representation of the policy case continuum. The themes represent zone on the continuum which bounded by access to care and quality of care. 
Levels of access and quality increase as you move to the right and decrease as you move to the left.

Figure 5.9. Policy Case Continuum.

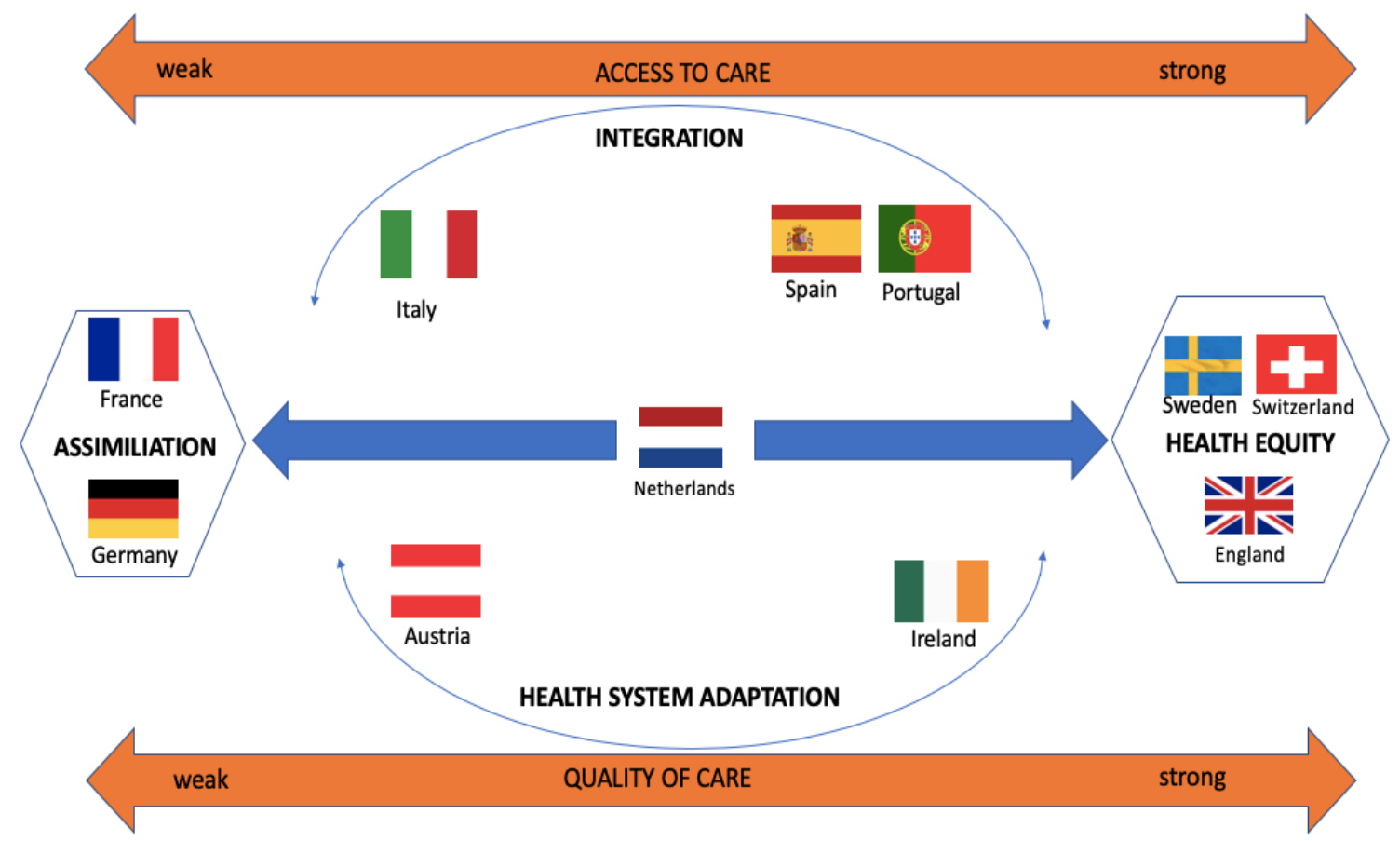

\section{Conclusion}

Content analysis of the policy cases that occurred in phase one resulted in an organizing structure for the data. Harold Laswell's seminal definition of policy, "Who get what, when, and how" informed how data was grouped at the highest level of organization (Laswell, 1936). The result was the emergence of an organizational structure of the data that included four major categories that are policy objective, policy strategy, health services, and target population. 
The identification of areas of commonality and distinction across the eleven policy cases is one of the contributions of this research extant comparative policy analysis research. The structure of the data enabled investigation of areas of similarities and differences. The result is a deeper understanding of policy content elements that range from very common to common to very uncommon. For example, documented migrant and communicable disease control are content policy elements that are associated with all eleven cases, indicating that these two policy components are a generally agreed aspect of a migrant health policy, at least within this policy case set. Conversely, policy objectives that place the onus on migrant populations to assimilate into the host nation society and the treatment of diseases such as cancer are aspects of a migrant health policy associated with a minority (i.e., two or less) of the policy cases. Policy content that is common among the majority of policy cases (i.e., association with six or more cases) include policy objectives associated with integration and social cohesions health system adapts to migrants, and health equity categories and all eight policy strategy subcategories in the policy strategy major category. The fact that the majority of cases are associated with three of the four policy objective categories and all eight policy strategy subcategories communicates that most of the cases included in this research have a general orientation toward meeting the health care needs of migrant populations and that numerous policy strategies are needed to achieve a policy's objectives. We also see an acknowledgement of mental health needs among migrant populations that may have been shaped by the pre-flight, flight, or resettlement phases 
of migration. Mental health is a health service that is associated with eight and six cases respectively. The data structure revealed that a minority of policies are associated with four of the five target population categories (i.e., newly arrived migrant, special populations, undocumented, and migrant child). This finding communicates that legal status of immigration is inherently important in a migrant health policy and that a minority of policies extend benefits to migrant populations whose legal status is either under review (i.e., special populations), less certain (i.e., migrant child), or non-existent (i.e., undocumented migrant). Broadly, understanding very common, common, and very uncommon policy content elements can inform future migrant health policy making processes as well as policy process research on these eleven cases. Research in this area will illuminate why certain policy content elements are very common, common, or very uncommon in a policy case.

Access to care and quality of care were identified as important components in the organization of policy strategy subcategories. These categories are comparable to health system supply and demand which Mladovsky et al. (2012) used to explore and identify variation across the migrant health policies. Supply-side initiatives target providers and include interventions such as training for providers, while demand-side health system interventions are aimed at modifying the health care seeking needs among migrant populations (Mladovsky et al., 2012). Synergy between Mladovsky's health system supply and demand and access to care and quality of care demonstrate that these are important dimensions of the migrant health policy cases. 
Mapping the policy strategy major category followed by the policy objective major category onto the typology matrix framework developed by Collier et al. (2012) revealed that, through subcategories grouped within the access to care and quality of care categories, a relationship between two major categories, policy objective and policy strategy. The alignment of these two major categories resulted in the emergence of four themes that are a conceptually distinct "type" of policy orientation toward migrant health. The themes defined by this relationship are assimilation, integration, health system adaptation, and health equity. Each theme has a unique relationship with access to care and quality of care that is determined by stronger or weaker levels of association. The assimilation theme has a weak association with access and quality, while the health equity theme has a strong association with the two dimensions coming together at higher levels. The integration theme is related to access to care, while the health system adaptation theme has a stronger association with quality of care than access to care.

An important result of this research is that, while the four themes that emerged are conceptually distinct, the cases seem to populate the themes as a continuum from assimilation (i.e., weak/weak in access and quality) to health equity (i.e., strong/strong in access and quality) rather than being evenly distributed across all four themes. The assimilation and health equity themes have clear "anchor" policies that clearly represent all aspects of these themes. The remaining policy cases link the end points continuum with varying levels of access and quality that increase from weak to strong, 
moving through the integration and health system adaptation themes toward health equity.

The difference between the conceptually distinct themes and fluidity of the policy case continuum is an area in need of more exploration. Understanding if the themes or policy case continuum are more representative is an important area of inquiry. Connecting policy case positioning on the continuum and relative association to a theme to migrant health outcomes associated with that case could inform the applicability of the themes and/or policy case continuum in terms of which one is more representative of depicting policy "type" of orientation toward migrant health.

This research fits within and extends the field of comparative analysis on this group of eleven policies in several ways. The structure of the data in this research connects organizational elements of research by Vasquez et al. (2011), Mladovsky (2009), and Mladovsky et al. (2012). In their study that was published in 2011, Vasquez et al. identified policy objectives and categorized policy strategies and health services in their content analysis of three policies. Mladovsky identified population, health services, and health system supply-side or demand-side as domains from which to explore variation among the migrant health policy cases. Evidence of aspects of the organizational structure of the data in existing research confirms the importance of the coding scheme at the highest and second highest levels of organization. This coding scheme is a starting point from which to examine content variation across the policy cases. Moreover, this research is a bridge between the organizational data structure 
that we find in Mladovsky (2009 and 2012)and Vasquez et al.'s (2011) work as it brings this structure together in one place.

In addition to identifying important policy content areas from which to explore variation across the policy cases, this study contributes to the existing migrant health policy comparative policy analysis literature with a transparent, comprehensive organizational structure of the content of the eleven policy cases that was derived solely from policy documents associated with the cases and void of a priori assumptions of content area priorities. Existing literature pertaining to the policy cases does not provide a clear direction as to how analytic decisions were made, such as how Mladovsky (2009) determined the organizing structure of her framework or the process Vasquez et al. (2011) used to identify access and quality as organizing elements in their content analysis of three policy cases in this study. While Laswell's "Who gets what, when, and how" was applied as a frame to identify all relevant segments of policy content and guide the broad organizational structure of data into major categories, data was organized into a structure without a preconceived vision or value judgement of the importance of certain policy content areas (Laswell, 1936).

An important component of this study is its confirmatory relationship with Milena Chimenti's (2007) migrant health policy typology. Chimenti's typology has two structural elements, health system organizational structure and societal values, (i.e., difference-blind and difference-sensitive). Policy cases with a weak or medium association access and quality area (i.e., Austria, France, and Germany) are located in 
the assimilation and weaker access area of the integration area) of the of the continuum developed in this study. These policy cases have a Bismarck/insurance-based health system organizational structure and are difference-blind the health needs of migrants. With the exception of one case, Switzerland, policy cases in the area of the continuum with higher levels of access and quality tend to have a Beveridge/single-payer health system that is difference-sensitive to migrant health. The result is that there appears to be a correlation between a policy case's health system organizational structure and its association with levels of access to care and quality of care. The fact that the policy continuum fits with Chimenti's typology suggests important deep connections between a policy and a nation's socio-politics that influence policy-making processes.

This study contributes to existing migrant health comparative policy analysis literature with its comprehensive organizational structure of the content of the eleven policy cases and theme-based typology depicting a "type" of orientation toward migrant health. The theme-based typology and migrant health policy continuum go beyond description and classification of the policy cases by offering a higher level of understanding of variation across the themes and cases. These are new frameworks from which to compare concepts, explore dimensionality, and identify hierarchical relationships at macro and micro levels. The macro level occurs across and within the emergent themes. The micro level is the policy case. 


\section{Assumptions and Limitations}

\section{Assumptions}

This study is mainly exploratory, with some confirmatory aspects. The process of determining content that aligns with Laswell's organizing frame is confirmatory, while the process of identifying policy content that is outside of the framework is exploratory. As described in chapter four, content analysis of the policies resulted in the identification of four major categories of data that are policy objective, policy strategy, health service, and target population. A structure emerged for each of the major categories that organized codes into categories or subcategories. The process of identifying and coding salient units of text, grouping codes into major categories, and then creating a structure of coded data in each major category is exploratory and confirmatory. Aspects of the categorization of data was confirmed in existing comparative migrant health policy literature. The structural organization of data by objective, health services, target population, and strategies that are actions to facilitate access to care and address quality of care was also confirmatory. Extant comparative analysis literature on the eleven policy cases published by Mladovsky (2009), Mladovsky et al. (2012), and Vasquez et al. (2011) confirmed analytic choices that were made during content analysis of the policies that occurred in phase one.

This study is the first to apply typological analysis to all eleven migrant health policies adopted in Europe between 1998 and 2005. To that end, the exploratory orientation of the study was not so much as in identifying salient units of text from policy content that did not align fit into the major categories, but rather in mapping the 
major categories onto the typology matrix. The process of investigating and identifying patterns, tendencies, and relationships within and across the major categories and their apparent relationships with access to care and quality of care was also exploratory. The result was the emergence of four themes that are a "type" of orientation to migrant health.

Another assumption was that the researcher used a valid and reliable system to maintain objectively throughout the research process. In order to support this assumption, the researcher was transparent throughout the research process. The researcher's intention of transparency is depicted through inclusion of coded units of text and the coding scheme for the major categories, and the mapping of major categories onto the typology matrix that was thoroughly documented in chapters three, four, and five of this dissertation. Furthermore, the researcher regularly collaborate with scholars external to the data collection and analysis process in order to ensure transparency, objectivity, and that sound empirical methods were applied in this study.

\section{A final}

assumption of this research is the eleven policy cases could be organized into a migrant health policy typology using typological analysis. This assumption was confirmed once the two-phased analytic process concluded. Emergence of four themes and migrant health policy continuum discussed earlier in this chapter are organizational frameworks that group the policy cases by orientation toward migrant health. 


\section{Limitations}

The study has several limitations. The first, and perhaps most important, is the source of the data analyzed in the study. The eleven policy cases are the data analyzed in the study. No other documents were referenced to provide context to the policy documents analyzed. Other comparative policy analysis research on a sub-set of the group of the eleven policy cases referenced other data sources such as census data, health surveys, living standards surveys, and health care utilization data (Mladovsky et al., 2012). Because this study was focused on identifying similarities and differences across the policy cases in order to develop a migrant health policy typology and continuum depicting migrant health policy orientation toward migrant health, the eleven policy documents were deemed sufficient and additional data sources were not collected or analyzed.

As the policy documents were the only source of data analyzed in the study, variation across the policy cases in terms of content and specificity is a limitation. Some policies are a broad articulation of goals pertaining to the health of migrant populations. Other policies are specific and detailed in regard to how the health of migrant populations will be addressed, by whom, and in what ways. This level of variation across the policy cases meant that there were more policy content pieces identified from content analysis of policies that were specific and less data identified from policies that were general articulations of policy objectives.

Another limitation is the reliance on one researcher to collect and analyzed the data. To that end, the threat of confirmatory bias was present throughout the analytic 
process. In order to mitigate the threat of confirmatory bias, the researcher invited scholars external to the analytic process to review policy content coding and classification of data into a coding scheme. Furthermore, when applicable, the researcher referenced published literature on a subset of the 11 migrant health policies as an external point of reference to check coding of relevant policy content areas.

As previously noted, the study did not exclude policies that were either not written in English, the primary language of the researcher. This limitation was not significant as funding was secured to translate policy documents written in a foreign language to the researcher into English. In the end, only one of the eleven policy documents was not readily available in English. The study followed a translation protocol outlined in chapter three to authenticate the integrity of translated policy documents.

\section{Implications for Policy and Practice Implications for Policy Makers and Advocates}

International attention to migrant health has been growing and it is likely that

more countries will respond to addressing the health of increasingly diverse populations with a migrant health policy (Mladovsky et al., 2012). Policy makers and migrant health policy advocates engaged in a migrant health policy processes can reference this study and gain an understanding of structural content elements of a policy that are necessary to orient a policy toward a specific theme that emerged as a result of this research. The themes and their respective orientations toward access to care and quality of care offer migrant health policy makers and policy advocates a reference for a "type" of policy 
orientation toward migrant health. This is particularly relevant for migrant health policy advocates who are in favor of a specific "type" of policy orientation. For example, this study informs policy makers and policy advocates of the necessary policy content structural aspects of a policy with a health equity orientation.

An important finding from this study is the need for alignment between a policy's objectives and strategies. When these two structural elements are incongruent, the policy will likely not achieve its goals as the mechanism to do so is missing. This is a particularly important finding because policies are a response to a problem. The problem will not be addressed with a policy where the objectives and strategies are misaligned. Policy makers and migrant health policy advocates can reference this study for examples of policy objective and strategies alignment (i.e., France and England) and misalignment (i.e., Germany and Italy).

The study also has the potential to inform policy refinement processes among the eleven policy cases. Congruence and incongruence across the major categories, specifically policy objective and policy strategies, was documented for all cases included in this study. A nation with a policy case included in this study could realize that the migrant health policy is not what was intended. For example, Germany may refine its policy by augmenting the scope of policy strategies so that it aligns better with the policy strategy characteristics associated with either the health system adaptation and/or integration themes. Furthermore, a nation could learn from this research that its policy is oriented toward a theme that was not intended. In this example, policy makers 
can reference this research for necessary elements to reposition a policy to align with the assimilation, integration, health system adaptation, or health equity themes. As such, this study can inform policy refinement processes with its categorization of policy content into four major categories as well as the theme-based typology depicting policy orientation toward migrant health that emerged from this analysis.

Policy process research among the cases included in this research can tell us how these policy cases came about in different policy-making environments. Future research in this area could explain variation in policy content, policy case positioning on the continuum, as well as a case's association with one or more of the themes that emerged from this research. Moreover, questions that arose in this research could be addressed, such as why theme association with the target population category appears to have more variation and less intention or why certain health services are prioritized and others are not.

Implications for Future Research Implications for Future Comparative Policy Analysis Research Comparative policy analysis has gained traction in the last two decades as a method to study policy cases in different countries that address the same public problem or concern in order to generate rich insights on characteristics of public policy (Geva-May, Hoffman, Muhleisen, 2017; Cyr and deLeon, 1975). The study's two-phased analytic process is relevant to any field of comparative policy analysis research that seeks to categorize a set of policies that broadly share the same objective or goal, including future comparative analysis on all or a subset of the eleven policy cases. The 
research offers future comparative policy analysis research an analytic process that is transparent and can be replicated. Application of Laswell's "Who gets what, when, and how" is a relevant frame to organize policy content and identify variation across policies that have the same broad objective (Laswell, 1936). Given the higher level of meaning derived from a theme-based policy typology depicting orientation toward migrant health, future research can reference the analytic methods used this study to explain variation among a group of policies that are focused on the same broad problem.

\section{Implications for Future Migrant Health Policy Process Research}

Findings of this study evoke a number of questions and areas for future policy process research. This study identified and explained variation across eleven policy cases based upon their content. Investigating policy processes characteristics would tell us "why" this group of eleven policy cases are similar and different. Potential future policy process research questions include:

1. What are the characteristics of policy processes that led to the eleven migrant health policies?

Policy process research would explain "why" the policy cases vary and provide valuable context to this study that explored "how" the eleven cases are similar and different. Investigation of the policy process through application of the Multiple Streams Approach will inform how the problem was defined, public opinion regarding migrant health among politicians, interest groups, and stakeholders, the public agenda versus private agenda regarding migrant health, the influence of a focusing event if there was one, and whose idea "won" as represented in the policy document. How and why the 
policy processes differed across the eleven cases is an important topic for future research as it will offer context to this study as well as forthcoming migrant health policy processes.

2. How do policy process characteristics align with the policy content and resulting policy groups or classifications?

Another area for future research is mapping findings from this study to policy process research examining dominant migrant and migrant health narratives and the social constructions of migrant populations among nations with a policy case analyzed in this research. This area of research presents an opportunity to examine whether or not the social constructions of migrants aligns with the four themes that are a product of this research and in what ways.

3. How does a policy case's position on the policy case continuum align with migrant health outcomes?

Future research could investigate if there is a correlation between a policy case's position on the continuum (i.e., association with access and quality and proximity to a theme) and relevant migrant health outcomes. For example, England is associated with the health equity theme which has the highest levels of access and quality. Future research could examine access indicators such as the number of migrants receiving services and quality of care indicators such as health system utilization among migrant populations residing in England. 
4. How does a case's association with a theme and position on the policy case continuum align with relevant population level migrant health outcomes?

Future research in this area would reference a policy case's association with a theme and position on the continuum in order to determine specific migrant health outcomes to measure. The area of research would test the relevance and applicability of the theme or themes and policy case's position on the continuum in order to test of the theme of continuum is more representative of depicting policy "type" of orientation toward migrant health.

5. How does policy implementation research among the eleven policy cases inform the results of this study?

Future research could explore the connection between the results of this study and policy implementation research. Research in this area would explore how the policy cases were implemented. Results from implementation research could inform and provide context to the results from phases one and two of this study. Implementation research also has the potential to frame migrant health outcomes research.

\section{Implications for Future Migrant Health Policy Evaluation \& Health Outcomes Research} Numerous scholars note that the field of migrant health policy comparative analysis research is in its infancy and further research is needed, specifically in the area of migrant health policy evaluation and mapping migrant health outcomes to a migrant health policy (Mladovsky, 2009; Mladovsky et al., 2012; Rechel et al, 2011). This study is a timely and necessary first step to address these deficiencies. The organizational 
structure of the data (i.e., the coding schema) developed in this study can be used to evaluate one or more of the policy cases and determine successes and areas where improvement is needed. The structure of the four major categories (i.e., policy objective, policy strategies, health services, and target population) are areas of measurement and monitoring for individual policy cases. Among policy cases included in this research, findings from this study offer migrant health policy evaluation research context with which to position findings, more thoroughly understand policy performance, identify best practices, and recognize areas for policy refinement.

As previously noted, an area of inquiry currently underrepresented in the literature is connecting migrant health outcomes to a specific migrant health policy. Future research exploring connections and understanding between migrant health policy content and health outcomes among migrant populations is both timely and necessary given the number of people migrating annually worldwide. Research in this area would inform what the policy cases are aiming to accomplish and provide measurement for how well they are doing it.

The study creates a frame for which to examine migrant health outcomes among nations that have adopted a migrant health policy. Results from this study can assist health outcomes researchers develop hypotheses based upon one of the eleven cases' orientation toward migrant health based on a case's association with a theme and position on the policy continuum. For instance, we would expect better treatment outcomes among migrant patients who reside in nation states with a migrant health 
policy orientated toward quality delivery of services through health system adaptation. Higher quality of health service delivery through health system adaptation may lead to better care plan adherence among migrant patients. One result may be reduction in either the number or severity of Type II Diabetes cases among migrant populations. Another area of research is investigating if there is reduction is substance abuse among migrants residing in countries that have a health system adaptation policy. One hypothesis is that countries with health system adaptation oriented policies would have a lower incidence of substance abuse among migrants. Substance abuse treatment and mental health are two health services that are associated with the health system adaptation theme. Policy cases oriented toward integration could track the number of migrant patients accessing the health system pre- and post policy adoption. A higher volume of migrants patients going through the health system is a reasonable hypothesis of integration theme oriented policy cases.

Another area of future research is understanding the applicability of this study. For example, this research can be used as a basis for migrant health policy process and migrant health outcomes research. Application of this research in either of these contexts would serve to validate its applicability.

\section{Chapter Conclusion}

The comprehensive content analysis of the eleven policies is the result of a thorough coding scheme that emerged from policy documents. No a priori assumptions guided the identification and categorization of the data. The coding scheme that 
emerged was mapped onto the typology framework, leading to the emergence of four themes that are conceptually distinct "types" of policy orientation toward migrant health. The four themes include assimilation, integration, health system adaptation, and health equity. Policy cases were compared with the themes and associated with varying levels of access to care and quality of care. The cases form a continuum from weak to strong in access and quality. None of the cases are outliers, meaning that none are weak quality/strong access or vice versa. Cases positioned at the continuum's extreme ends fully represent the meaning of a theme, while cases linking the end points are more likely to have a disconnect between policy objectives and strategies and represent aspects of a theme or cross theme boundaries.

Existing research confirms aspects of this study's analytic process and its results. Categorization of data at the highest level of organization into the policy objective, policy strategy, health services, and target population major categories is evident in existing migrant health policy comparative analysis literature that applied a similar organizational structure to the data. Alignment between the policy case continuum that is an important result of this study and Chimenti's health system structure and value system of differences typology matrix (2007) signals a correlation between a policy case's health system organizational structure and its association with levels of access to care and quality of care. This is a valuable and unexpected outcome of this research.

The products of phases one and two of this study include a comprehensive and transparent coding scheme of the data, a theme/based migrant health policy typology 
matrix, four themes that are conceptually distinct "types" of orientation toward migrant health, and a migrant health policy case continuum depicting policy case association with a theme, access to care, and quality of care. These products contribute to the field of migrant health policy comparative analysis as they are tools to inform future policy making processes and guide forthcoming migrant health policy and migrant health outcomes research. 


\section{References}

Agudelo-Suárez, A., Ronda-Pérez, E., and Benavides, F. (2011). Occupational health. In: Rechel, B., Mladovsky, P, Deville, W., Rijks, B., Petrova-Benedict, R., and McKee, M. (Eds.) Migration and health in the European Union. (pp. 155-168). Maidenhead: Open University Press.

Aronsson, G. and Gustafson, K. (2005). Sickness presenteeism: prevalence, attendancepressure factors, and an outline of a model for research. Journal for Occupational and Environmental Medicine, 47(9), 958-66.

Baker, CA., Thomas, W., Stauffer, WM., et al. (2009). Serial testing of refugees for latent tuberculosis using the QuantiFERON-gold-in-tube: effects of an antecedent tuberculin skin test. American Journal Tropical Medicine Hygiene, 80: 628-633.

Balch, A. and Geddes, A. (2011). Opportunity from Crisis? Organisational Responses to Human Trafficking in the UK. The British Journal of Politics and International Relations, 13: 26-41. Doi: 10.1111/j.1467-856X.2010.00437.x.

Barniol, J., Niemann, S., Louis, VR., et al. (2009). Transmission dynamics of pulmonary tuberculosis between autochthonous and immigrant sub-populations. BMC Infectious Diseases, 9: 197.

te Beek, LA., van der Werf, MJ., Richter, C., Borgdorff, MW. (2006) Extrapulmonary tuberculosis by nationality, The Netherlands, 1993-2001. Emerging Infectious Diseases Journal, 12: 1375-1382.

Bhuga, D. and Jones, P. (2001). Migration and mental illness. Advances in Psychiatric Treatment, 7, 216-33.

Bollini, P. and Siem, H. (1995). No real progress toward equity: Health of migrants and ethnic minorities on the eve of the year 2000. Social Science Medicine, 41(6): 819-828.

Borde, 2008. Migrants, access to health care. Encyclopedia Public Health. Berlin. Springer

Borgdorff, MW., van den Hof, S., Kremer, K., et al. (2010). Progress towards tuberculosis elimination: secular trend, immigration and transmission. European Respiratory Journal, 36: 339-347.

Borrás, S. and Radaelli, C. (2011). The Politics of governance architecture: creation, change and effects of the EU Lisbon Strategy. Journal of European Public Policy, 18(4): 463-484. 
Boswell, C., Geddes, A., Scholten, P. (2011). The Role of Narratives in Migration PolicyMaking: A Research Framework. British Journal of Politics and International Relations, 13: 1-11

Buja, A., Gini, R., Visca, M., Damiani, G., Federico, B., Francesconi, P. . . Project, V. (2013). Prevalence of chronic diseases by immigrant status and disparities in chronic disease management in immigrants: a population-based cohort study, Valore Project. BMC Public Health, 13(504): 1-7. doi: 10.186/1471-2458-13-504

Cairney, P. and Heikkila, T. (2014). A Comparison of Theories of the Policy Process. In P.A. Sabatier \& C.M. Weible (Eds.), Theories of the Policy Process ( $3^{\text {rd }}$ ed., p. 363390). Boulder, CO: Westview Press.

Carling, J. and Hernández-Carreto, M. (2011). Protecting Europe and Protecting Migrants? Strategies for Managing Unauthorised Migration from Africa. The British Journal of Politics and International Relations, 13: 42-58.

Carneiro, I.G., Ortega, A., Borg, V., and Hogh, A. (2010). Health and sickness absence in Denmark: A study of elderly-care immigrant workers. Journal of Immigrant and Minority Health, 12(1), 43-52.

Cattacin, S., Chimienti, M., in collaboration with Cuadra, C.-B. (2006). Difference Sensitivity in the Field of Migration and Health: National Policies Compared. Geneva: Research Report of the Department of Sociology of the University of Geneva.

Cattacin, S., Chimienti, M., Bjorngren, \& and Quadra, C. (2006). Difference sensitivity in the field of migration and health. National policies compared. Geneva: Research Report of the Department of Sociology of the University of Geneva.

Centers for Disease Control. (2017). Health Equity: Cultural Competency Training for Healthcare Providers. Retrieved from: www.cdc.gov. Accessed on 27 April 2017.

Chimienti, M. (2007). Migration and Health: National Policies Compared. In Fernandes, A. and Miguel, J.-P. (Eds.) Health and Migration in the European Union: Better Health for All in an Inclusive Society. (pp. 83-90). Portugal: Instituto Nacional de Saúde Doutor Ricardo Jorge.

Cobb, R., Ross, J-k., Ross, M-H. (1976). Agenda Building as a Comparative Political Process. The American Political Science Review, 70(1): 126-138. 
Collier, D., LaPorte, J., and Seawright, J. (2008). Typologies: Forming Concepts and Creating Categorical Variables. In Box-Steffensmeier, J., Brady, H., and Collier, D. (Eds.), Oxford Handbook of Political Methodology. Oxford: Oxford University Press.

Collier, D., LaPorte, J., Seawright, J. (2012). Putting Typologies to Work: Concept Formation, Measurement, and Analytic Rigor. Political Research Quarterly, 65(1): 217-232.

Compston, H. and Per Kongshoi Madsen. (2001). Conceptual Innovation and Public Policy: Unemployment and Paid Leave Schemes in Denmark. Journal of European Social Policy, 11(2): 117-32.

Cuadra, C. (2011) Right of access to health care for undocumented migrants in the EU: a comparative study of national policies. European Journal of Public Health, 22(2), 267-271.

Curtale, F., Perrelli, F., Mantovani, J., Ciofi degli Atti, M., Filia, A., Nicoletti, L., Magurano, F., Borgia, P., and Di Lallo, D. (2010). Description of two measles outbreaks in the Lazio Region, Italy (2006-2007). Importance of pockets of low caccine coverage in sustaining the infection. BMC Infectious Diseases, 10: 62.

Cyr, A. and deLeon, P., 1975, Comparative policy analysis. Policy Sciences, 6(4), pp. 375-384. doi:10.1007/ BF00142380

Dahl, R. (1971). Polyarchy: Participation and Opposition. New Haven, CT: Yale University Press.

Directorate-General for Communication European Commission. (2014). How the European Union Works: Brussels, European Union.

Doyle, Y., McKee, M., Rechel, B., Grundy, E. (2009). Meeting the challenge of population ageing. British Medical Journal, 339, 892-4.

Dudley, G., and Richardson, J. (1999). Competing Advocacy Coalitions and the Process of 'Frame Reflection': A Longitudinal Analysis of EU Steel Policy. Journal of European Public Policy, 6(2): 225-48.

Espelt et al, 2008. Socioeconomic inequalities in diabetes mellitus across Europe at the beginning of the $21^{\text {st }}$ century. Daibetologia, 5(11), 1971-9. 
Ethridge, M. (Ed.). (2002). The Political Research Experience: Readings and Analysis. (3 ${ }^{\text {rd }}$ ed.). New York, NY: M.E. Sharpe.

Euro Stat. 2017. Migration and Population Statistics. Retrieved from: http://ec.europa.eu/eurostat/statistics explained/index.php/Migration_and_migrant_population_statistics. Accessed on 28 Feb 2017.

EuroHIV. (2007). HIV/AIDS Surveillance in Europe. End-year report 2006, No. 75. SaintMaurice: Institute de Veille Sanitaire.

European Commission. (1958). The Single European Act. (1958/Article 152). Brussels: European Union.

European Quality Standard for Translation Service Providers. (2006). European quality standard EN-15038:2006. Retrieved from: http://qualitystandard.bs.en15038.com. Accessed on 5 November 2017.

European Union. (2010). Consolidated versions of the Treaty of the European Union and the Treaty on the Functioning of the European Union Charter of Fundamental Rights of the European Union, (OJ C 83, 30.32010). Brussels: European Union.

European Union. (2000). Charter of Fundamental Rights of the European Union, (2000/C 364/01). Brussels: European Union.

Fortier, J.-P., (2010). Migrant-Sensitive Health Services. Geneva: World Health Organization.

German Federal Government. (2007). National Integration Plan: The Driver of Integration Policy. Retrieved from: https://www.bundesregierung.de/Content/EN/StatischeSeiten/Schwerpunkte/In tegration/kasten1-der-nationale-integrationsplan.html. Accessed on 17 August 2017.

Gerring, J. (2007). Case Study Research: Principles and Practices. New York, NY: Cambridge University Press.

Gissler, M., Alexander, S., Macfarlane, A., et al. (2009). Stillbirths and infant deaths among migrants in industrialized countries. Acta Obstetrica et Gynecologica Scandinavica, 88(2), 134-48.

Glaser, B.G., and Strauss, A.L. (1970). Discovery of substantive theory. In W. Filstead (Ed., Qualitative methodology (pp. 288-297). Chicago: Rand McNally. 
Green, J. and Thorogood, N. (2014). Qualitative Research Method for Health Research. Thousand Oaks, CA: Sage Publications Ltd.

Gupta, K. (2012). Comparative Public Policy: Using the Comparative Method to Advance our Understanding of the Policy Process. The Policy Studies Journal, 40(S1), 1126.

Gushulak, B., Pace, P., \& Weekers, J. (2010). Migration and health of migrants. In Koller, T. (Ed.) Poverty and Social Exclusion in the WHO European Region: Health systems respond. Copenhagen: WHO Regional Office for Europe: 257-81.

Hämäläinen, R.-M., Koivusalo, M., and Ollila, E. (2004). EU Policies and Health, Themes from Finland, Helsinki, Finland: STAKES, p. 6.

Health \& Consumer Directorate General. 2004. The State of Mental Health in Europe. Luxemburg: European Commission.

Health Service Executive. (2008). National Intercultural Health Strategy, 2007-2012. Nurse, D., \& O’Flynn, A. (Eds.) (2008 (Publication No. 978-1-906218-00-41). Dublin, Ireland.

Healy, J. and McKee, M. (2004). Accessing health care: responding to diversity. Oxford: Oxford University Press.

Healthcare Access and Quality Index based on mortality from causes amenable to personal health care in 195 countries and territories, 1990-2015: A novel analysis from the Global Burden of Disease Study 2015. (2017). The Lancet, 390(10091), 231-266.

Hoffman, J., Tsouros, A., Kristiansen, M., Mygind, A., and Krasnik, A. (2009). Migrant Health in the Urban Context, WHO. In Fernandes, A. and Miguel, J.-P. (Eds.) Health and Migration in the European Union: Better Health for All in an Inclusive Society. Portugal: Instituto Nacional de Saúde Doutor Ricardo Jorge.

Howarth, D. (2000). Discourse. Philadelphia, PA: Open University Press.

Hsieh, HF \& Shannon, SE. (2005). Three Approaches to Qualitative Content Analysis. Qualitative Health Research. 15(9): 1277-1288.

lacobuţă, A. (2012). Patients' Evaluation of Access and Quality of Healthcare in EU Countries. A Comparative Analysis. Procedia - Social and Behavioral Sciences, 62, 896-900. 
Ingleby, D., Chimenti, M., Hatziprokopiou, P., Ormond, D., \& De Freitas, C. (2005). The role of health in integration. In: Fonseca, M.L. and Malheiros, J. (Eds.) Social Integration and Mobility: Education, Housing and Health. Lisbon: Centro de Estudos Geograficos: 101-37.

International Organization for Migration. (2007). Migration and the Right to Health: A Review of European Community Law and Council of Europe Instruments. Geneva, Switzerland: Mierzewski, P. \& Perruchoud, R.

International Organization for Migration. (2011). World Migration Report for 2011. Geneva, Switzerland.

International Organization for Migration. (2007). Migration and the Right to Health: A Review of European Community Law and Council of Europe Instruments. Geneva, Switzerland: Mierzewski, P. \& Perruchoud, R.

Krippendorff, K. (2004). Content Analysis: An Introduction to Its Methodology. (2 ${ }^{\text {nd }}$ ed.). Thousand Oaks, CA: Sage Publications, Inc.

Lama, T. (2017). "Villain" vs. "Victim": A News Headline Analysis and Literature review of Canadian News Print Media in Representing Refugees and Framing Canadian Perceptions of Refugees. (Unpublished Masters' Thesis). McMaster University, Ontario.

Lasswell, H. (1936). Who Gets What, When, and How? New York: McGraw-Hill.

Laubrntahl, B. (2008). Two steps forward, one step back. Recent trends in German migration policy. CeSPI Country Paper. Retrieved from: http://www.cespi.it/sites/default/files/documenti/country mig-germania.pdf. Accessed on 14 September 2017.

Learning and Skills Council. (2006). Employer Perceptions of Migrant Workers Research Report. London: England. Publication reference number: LSC-P-NAT-060574

Long T., Johnson, M. (2000). Rigour, reliability and validity in qualitative research. Clinical Effectiveness in Nursing, 4:30-7.

Lowi, T. (1972). Four Systems of Policy, Politics, and Choice. Public Administration Review, 32(4): 298-310.

Mazur, A. (2001). State Feminism, Women's Movements, and Job Training: Making Democracies Work in the Global Economy. New York: Rutledge. 
McBeth, M., Jones, M. and Shanahan, E. (2014). The Narrative Policy Framework. In P.A. Sabatier \& C.M. Weible (Eds.), Theories of the Policy Process ( $3^{\text {rd }}$ ed., p. 225-266). Boulder, CO: Westview Press.

McGaghie, W.-C, Bordage, G., and Shea, J. (2001). Problem Statement, Conceptual Framework, and Research Question. Journal of the Association of American Medical Colleges, 76(9): 923-924.

McKay, L., Macintyre, S., and Ellaway, A. (2003). Migration and Health: A Review of the International Literature. Glasgow: MRC.

Malmusi, D., Borrell, C., Benach, J. (2010). Migration-related health inequalities: Showing the complex interactions between gender, social class and place of origin. Social Science and Medicine, 71: 1610-1619.

Markuzzi, A., Schlipköter, U., Weitkunat, R., and Meyer, G. (1997). Measles, mumps and rubella vaccination status of school beginners in Munich. Sozial und Präventivmedizin, 42(3): 133-143.

Miles, M. and Huberman, A.M. (1994). Qualitative Data Analysis. (2 ${ }^{\text {nd }}$ ed., p. 173). Thousand Oaks: CA: Sage Publications.

Mladovsky, P. (2007). Migration and health in EU health Systems. Euro Observer, 9(4), 1-2.

Mladovsky, P. (2009). A framework for analyzing migrant health policies in Europe. Health Policy (Amsterdam, Netherlands), 93(1), 55-63. doi:10.1016/j.healthpol.2009.05.015

Mladovsky, P. (2011). Migrant health policies in Europe. In: Rechel, B., Mladovsky, P, Deville, W., Rijks, B., Petrova-Benedict, R., and McKee, M. (Eds.) Migration and health in the European Union. (pp. 55-66). Maidenhead: Open University Press.

Mladovsky, P., Rechel, B., Ingleby, D., \& McKee, M. (2012). Good practices in migrant health: The European Experience. Clinical Medicine, 12(3), 248-52. doi:10.1016/j.healthpol.2012.01.007

Mladovsky, P., Rechel, B., Ingleby, D., and McKee, M. (2012). Responding to diversity: An exploratory study of migrant policies in Europe. Health Policy, 105, 1-9.

Nagy, R. (2011). Migrants and healthcare within the European Union. International Review of Social Research, 1(1): 61-72. 
National Health Service Education for Scotland. (n.d.). Public Health, Health Protection. Retrieved from: http://www.nes.scot.nhs.uk/education-and-training/by-themeinitiative/public-health/health-protection.aspx. Accessed on 14 March 2016.

Nielsen S, Krasnik A, Rosano A. (2009). Registry data for cross-country comparisons of migrants' healthcare utilization in the EU: a survey study of availability and content. BMC Health Services Research; 9(210).

Nurse, D., \& O'Flynn, A. (Eds.) (2008). National Intercultural Health Strategy, 2007-2012. (Publication No. 978-1-906218-00-41). Dublin, Ireland.

Pace, P. (2011). Migration and the Right to Health: A Review of European Community Law and Council of Europe Instruments. Geneva: International Organization of Migration.

Pace, P. and Gushulak, B. (2010). Policy and legal frameworks affecting migrants' health. In: Lopez-Acuna, D., Mosca, D., Pace, P, Fortier, J.-P, Rijks, B., Weekers, J. (Eds.) Health of Migrants- The Way Forward. (pp. 43-60). France: World Health Organization.

Pace, P. (2011). Migration and the Right to Health: A Review of European Community Law and Council of Europe Instruments. Geneva: International Organization of Migration.

Pace, P. (2011). The right to health of migrants in Europe. In: Rechel, B., Mladovsky, P, Deville, W., Rijks, B., Petrova-Benedict, R., McKee, M. (Eds.) Migration and health in the European Union. (pp. 55-66). Maidenhead: Open University Press.

Padilla, B. and Miguel, J.-P. (2009). Health and Migration in the European Union: Building a Shared Vision for Action. In Fernandes, A. and Miguel, J.-P. (Eds.) Health and Migration in the European Union: Better Health for All in an Inclusive Society. (pp. ). Portugal: Instituto Nacional de Saúde Doutor Ricardo Jorge.

Peiro, M.-J. and Benedict, R. (2009). Migration Health: Better Health for All in Europe. Brussels: International Organization of Migration.

Peiro, M.-J. and Benedict, R. (2010). Migrant Health Policy: the Portuguese and Spanish EU presidencies. Eurohealth, 16(1), 1-4.

Pezzoli, M.C., El Hamad, I., Scarcella, C., et al. (2009) HIV infection among illegal migrants, Italy, 2004-2007. Emerging Infectious Diseases, 15(11): 1802-1804. 
Rechel, B., Mladovsky, P., Devillé, W, Rijks, B., Petrova-Benedict, R., and McKee, M. (2011). Introduction. In: Rechel, B., Mladovsky, P, Devillé, W., Rijks, B., PetrovaBenedict, R., and McKee, M. (Eds.) Migration and health in the European Union. (pp. 3-13). Maidenhead: Open University Press.

Rechel, B., Mladovsky, P., and Devillé, W. (2012). Monitoring migrant health in Europe: A narrative review of data collection practices. Health Policy, 105(1), 10-16.

Rechel, B., Mladovsky, P., Ingleby, D., Mackenbach, and McKee, M. (2013). Migration and health in an increasingly diverse Europe. The Lancet, 381, 1,235-45.

Richards, L. and Morse, J.M. (2007). Readme first for the user's guide to qualitative methods ( $2^{\text {nd }}$ ed.). Thousand Oaks, CA: Sage.

Rowlands et al. (2015). Building on research evidence to change health literacy policy and practice in England. Journal of Communication in Healthcare, 8(1), 22-31.

Saldana, J. (2013). The Coding Manual for Qualitative Researchers. Los Angeles: CA: Sage.

Salt, J. (2007). Europe's migration streams: implications and policy concerns. Zeitschrift für Bevölkerungswissenschaft: Demographie.-Wiesbaden: VS, Verl. für Sozialwiss, 32(3/4), 469-503.

Sandelowski, M. (1993). Rigor or rigor mortis: the problem of rigor in qualitative research revisited. Advances in Nursing Science, 16:1-8.

Smith, K. (2002). Typologies, Taxonomies, and the Benefits of Policy Classification. Policy Studies Journal, 30(3): 379-395.

Substance Abuse and Mental Health Services Administration. Center for the Application of Prevention Technologies. Applying the Strategic Prevention FrameworkCultural Competence. www.samhsa.gov / Institute for Healthcare Improvement www.ihih.org. Accessed on 1 April 2017.

Uniken Venema, H.P., Garretsen, H.F.L., and Van Der Maas, P.J. (1995). Health of Migrants and Migrant Health Policy, The Netherlands as an Example. Social Science Medicine, 41(6), 809-818.

United Nations High Commissioner for Refugees. (2014). Asylum-Seekers. Retrieved from: www.unhcr.org/pages/49c3646c137.html. 
United Nations, Department of Economic and Social Affairs, Population Division. (2016). International Migration Report 2015 Highlights. (ST/ESA/SER.A/375).

United Nations. (1948). Universal Declaration of Human Rights. New York: United Nations.

United Nations. (1990.) International Convention on the Protection of the Rights of All Migrant Workers and Members of Their Families. New York: United Nations.

United Nations. (1966). International Covenant on Economic, Social and Cultural Rights. New York: United Nations.

United Nations Department of Economic and Social Affairs. (1998). Recommendations on Statistics of International Migration, Revision 1. New York: Statistics Division, UN DESA (Statistical Papers, Series M, No. 58, Rev. 1).

Vázquez, M.-L, Terraza-Núñez, R., Vargas, I., Rodriquez, D., and Lizana, T. (2011). Health policies for migrant populations in three European countries: England, Italy and Spain. Health Policy, 101, 70-78.

Walt, G., Shiffman, J., Schneider, H., Murray, SF., Bruga, R., Gilson, L. (2008). Doing health policy analysis: methodological and conceptual reflections and challenges. Health Policy Planning:23(5): 307-17.

Woetzel, J., Madgavkar, A., Rifai, K., Mattern, F., Bughin, J., Manyika, J., Elmasry, T., di Lodovico, A., Hasyagar, A. (2016). People on the Move: Global Migration's Impact and Opportunity. McKinsey Global Institute. Retrieved from: https://www.mckinsey.com/ /media/McKinsey/Featured\%20Insights/Employm ent\%20and\%20Growth/Global\%20migrations\%20impact\%20and\%20opportunity /MGI-People-on-the-Move-Executive-summary-December-2016.ashx. Accessed on 20 May 2019.

The World Bank. (2017). MBDs announce new coordination platform to accelerate support for economic migration and forced displacement. Retrieved from: www.worldbank.org. Accessed on 18 October 2017.

World Health Assembly. (2008). Health of Migrants. Geneva: World Health Assembly.

World Health Organization. (1978). Declaration of Alma Ata. International Conference on Primary Healthcare, Alma-Ata, USSR Retrieved from: www.who.int/publications/almaata_declaration_en.pdf. 
World Health Organization. (1946). WHO Constitution. Geneva: World Health Organization. Article 12, International Covenant on Economic, Social and Cultural Rights (ICESCR), 1966, U.N.G.A. Res. 2200 A (XXI), 993 U.N.T.S. 3.

World Health Organization Regional Office for Europe. (2010). How health systems can address health inequities linked to migration and ethnicity. Copenhagen: WHO Regional Office for Europe.

World Health Organization. (2016). Accountability for Women and Children's Health. Retrieved from: www.who.int/woman_child_accountability/progress information/recommendation2. Accessed on 14 March 2016.

World Health Organization. (2016). Health Topics, Health Promotion. Retrieved from: http://www.who.int/topics/health_promotion/en/. Accessed on 14 March 20.

Wörman, T. and Krämer, A. (2011). Communicable Disease. In: Rechel, B., Mladovsky, P, Devillé, W., Rijks, B., Petrova-Benedict, R., and McKee, M. (Eds.) Migration and health in the European Union. (pp. 121-138). Maidenhead: Open University Press.

Yin, R.K. (1989). Case study research: design and methods. London: Sage

Publications, Inc.

Yin, R.K. (2009). Case study research: Design and methods. Los Angeles, CA: Sage Publications.

Zimmerman, C., Kiss, L. and Hossain, M. (2011). Migration and Health: A Framework for $21^{\text {st }}$ Century Policy-Making. PLoS Medicine, 8(5): 1-7. 
Post Office Box 751 503-725-2227 tel

\section{觜 Portland State}

Portland, Oregon 97207-0751 503-725-8170 fax

Research Integrity (Research \& Strategic Partnerships) I

RB (Human Subjects Research Review Committee)

hsrrc@pdx.edu

Date: December 20, 2017

To: Neal Wallace / Jessica Currier, School of Community Health

From: Lindsey Wilkinson, IRB Chair

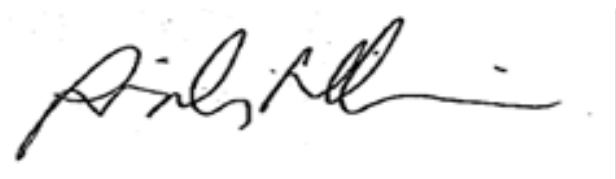

Re: IRB review determination for your protocol \# 174457, entitled: "Migrant Health Policies in the European Union: A Comparative Policy Analysis."

\section{Notice of IRB Review and Determination - Initial Review Exempt Review Category 4; as per Title 45 CFR Part 46}

In accordance with your request, the PSU Research Integrity office, on behalf of the IRB (Human Subjects Research Review Committee), has reviewed and approved your protocol for compliance with PSU policies and DHHS regulations covering the protection of human subjects. Research Integrity has determined your protocol qualifies for exempt review and is satisfied that your provisions for protecting the rights and welfare of all subjects participating in the research are adequate. Please note the following requirements:

Approval: You are approved to conduct this research study after receipt of this approval letter, and the research must be conducted according to the plans and protocol submitted (approved copy enclosed).

Consent: Consent is waived as the project involves analysis of publicly available data.

Changes to Protocol: Any changes in the proposed study, whether to procedures, survey instruments, consent forms or cover letters, must be outlined and submitted to Research Integrity immediately. The proposed changes cannot be implemented before they have been reviewed and approved by Research Integrity.

Adverse Reactions and/or Unanticipated Problems: If any adverse reactions or unanticipated problems occur as a result of this study, you are required to notify Research Integrity office within 5 days of the event. If the issue is serious, approval may be withdrawn pending an investigation by the IRB. 
Completion of Study: Please notify Research Integrity as soon as your research has been completed. Study records, including protocols and signed consent forms for each participant, must be kept by the investigator in a secure location for three years following completion of the study (or per any requirements specified by the project's funding agency).

If you have questions or concerns, please contact the Research Integrity office in Research \& Strategic Partnerships at hsrrc@pdx.edu or call 503-725-2227. 